\title{
Soot Emissions from Turbulent Diffusion Flames Burning Simple Alkane Fuels
}

\author{
By \\ Pervez M. Canteenwalla

\begin{abstract}
A thesis submitted to
The Faculty of Graduate Studies and Research

in partial fulfilment of

the degree requirements of

Master of Applied Science in Aerospace Engineering
\end{abstract} \\ Ottawa-Carleton Institute for \\ Mechanical and Aerospace Engineering \\ Department of Mechanical and Aerospace Engineering \\ Carleton University \\ Ottawa, Ontario, Canada \\ September 2007 \\ Copyright $(C$ \\ 2007 - Pervez M. Canteenwalla
}




$\begin{array}{ll}\begin{array}{l}\text { Library and } \\ \text { Archives Canada }\end{array} & \begin{array}{l}\text { Bibliothèque et } \\ \text { Archives Canada }\end{array} \\ \begin{array}{l}\text { Published Heritage } \\ \text { Branch }\end{array} & \begin{array}{l}\text { Direction du } \\ \text { Patrimoine de l'édition }\end{array} \\ \begin{array}{l}\text { 395 Wellington Street } \\ \text { Ottawa ON K1A ON4 }\end{array} & \begin{array}{l}\text { 395, rue Wellington } \\ \text { Ottawa ON K1A ON4 } \\ \text { Canada }\end{array}\end{array}$

Your file Votre référence

ISBN: 978-0-494-33641-0

Our file Notre référence

ISBN: 978-0-494-33641-0

NOTICE:

The author has granted a nonexclusive license allowing Library and Archives Canada to reproduce, publish, archive, preserve, conserve, communicate to the public by telecommunication or on the Internet, loan, distribute and sell theses worldwide, for commercial or noncommercial purposes, in microform, paper, electronic and/or any other formats.

The author retains copyright ownership and moral rights in this thesis. Neither the thesis nor substantial extracts from it may be printed or otherwise reproduced without the author's permission.
AVIS:

L'auteur a accordé une licence non exclusive permettant à la Bibliothèque et Archives Canada de reproduire, publier, archiver, sauvegarder, conserver, transmettre au public par télécommunication ou par l'Internet, prêter, distribuer et vendre des thèses partout dans le monde, à des fins commerciales ou autres, sur support microforme, papier, électronique et/ou autres formats.

L'auteur conserve la propriété du droit d'auteur et des droits moraux qui protège cette thèse. $\mathrm{Ni}$ la thèse ni des extraits substantiels de celle-ci ne doivent être imprimés ou autrement reproduits sans son autorisation.
In compliance with the Canadian

Privacy Act some supporting forms may have been removed from this thesis.

While these forms may be included in the document page count, their removal does not represent any loss of content from the thesis.
Conformément à la loi canadienne sur la protection de la vie privée, quelques formulaires secondaires ont été enlevés de cette thèse.

Bien que ces formulaires aient inclus dans la pagination, il n'y aura aucun contenu manquant.

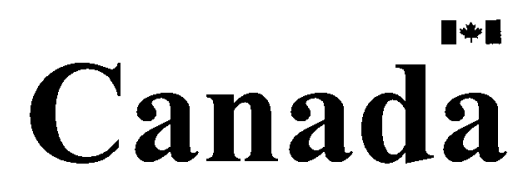




\section{Abstract}

Detailed experiments were conducted to examine the effects of changing flow conditions on the soot emissions from buoyant turbulent diffusion flames burning simple alkane fuels. A turbulent diffusion burner and sampling system were designed and constructed to allow a wide range of conditions to be tested. With a laser induced incandescence (LII) instrument, parametric measurements of soot yield were performed spanning a range of flow rates, fuel mixtures and burner diameters. Preliminary results showed that soot yield measurements could be strongly influenced by the sampling conditions. A correction protocol was developed to minimize these errors so the results could be properly analyzed. The main results show that soot emissions can not be scaled using simple global parameters such as fuel velocity, burner diameter, and flame length. These results were confirmed through direct comparison and analysis with data in the published literature. Measurements of soot yield from mixed fuels showed similar results to the literature in which laminar diffusion flames were used to demonstrate a synergistic effect in soot formation for methane/ethane mixtures but not for methane/propane mixtures. For the entire range of experiments performed, soot yield was found to be less than 0.005 $\mathrm{kg}$ per $\mathrm{kg}$ of fuel burned and less than $0.002 \mathrm{~kg}$ per $\mathrm{kg}$ fuel for fuels containing at least $70 \%$ methane. 


\section{Acknowledgements}

This thesis would not have been possible without the incredible support of my supervisor, Dr. Matt Johnson. Through the good and the bad (which happened all too much!) you always stuck by me. I could not have asked for a better supervisor and you truly made this Master's a great experience for me. Thanks Dr. Johnson!

I would also like to thank the National Research Council of Canada for their use of facilities and the staff (Greg Smallwood, Faz Baksh, Bob Sawchuk, Dan Clavel, and Dave Snelling) who have helped me along the way. I would like to especially thank Kevin Thomson, my NRC "supervisor", for his guidance throughout this project and Reg Smith for teaching me how to "turn a wrench before building a bridge".

And finally, thank you to my family and Alison who support all my endeavours in life. 


\section{Table of Contents}

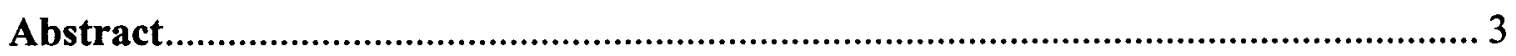

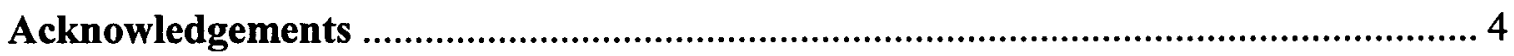

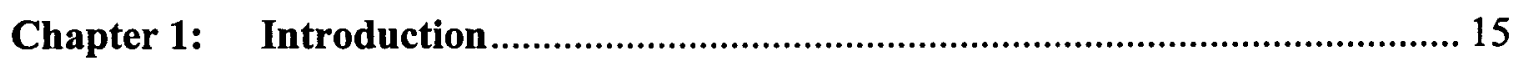

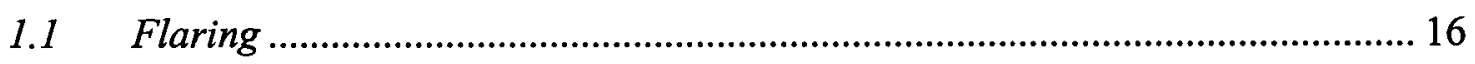

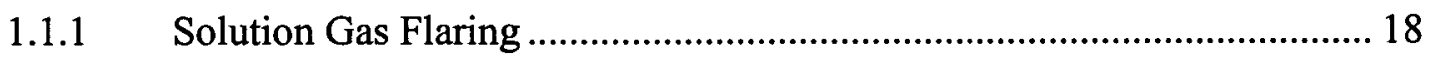

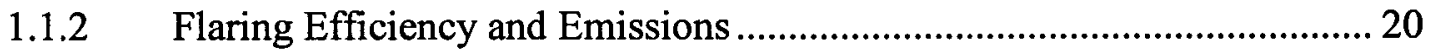

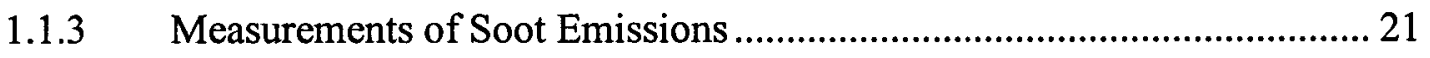

1.1.4 Characteristics of Diffusion Flames................................................... 23

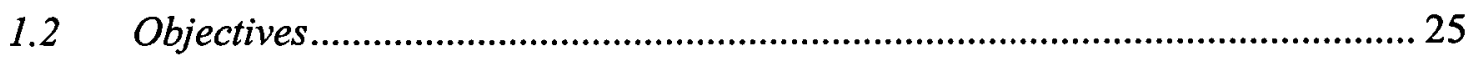

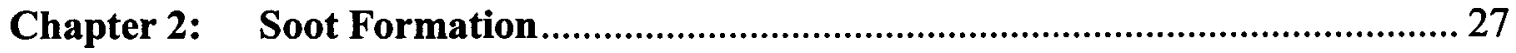

2.1 Soot Emissions from Turbulent Diffusion Flames ........................................ 28

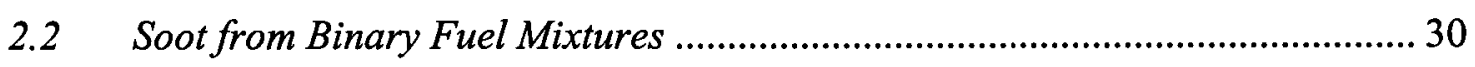

2.3 Scaling Parameters for Soot from Turbulent Diffusion Flames ....................... 31

Chapter 3: Experimental Methodology ............................................................... 37

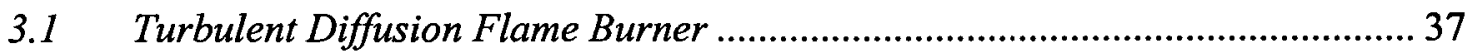

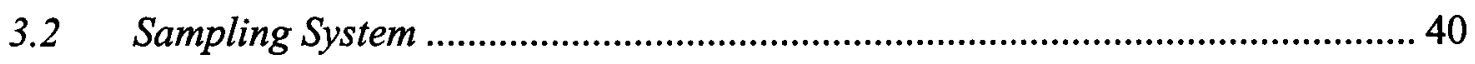

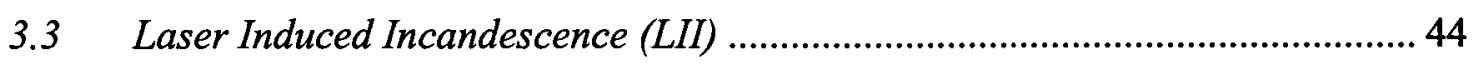

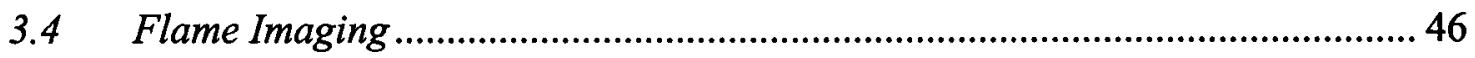

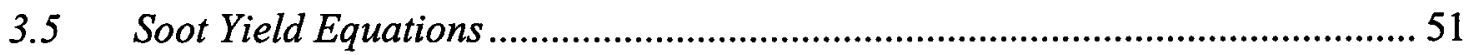

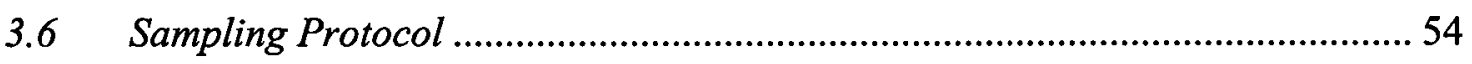

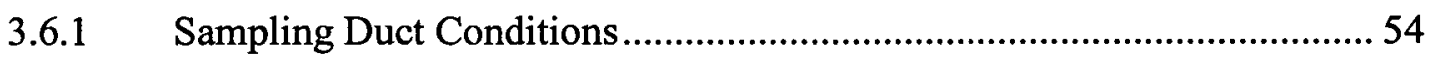

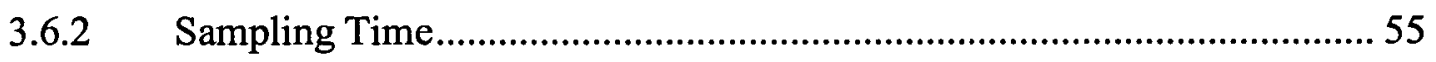

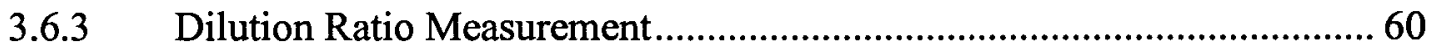

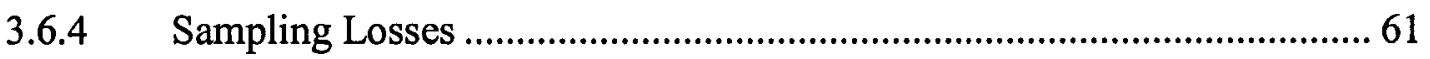

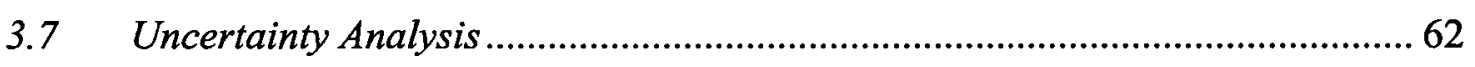

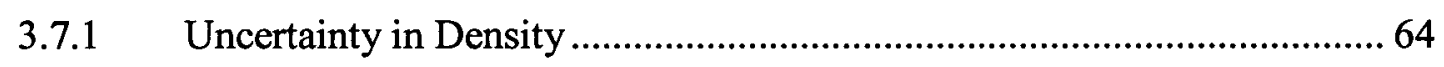

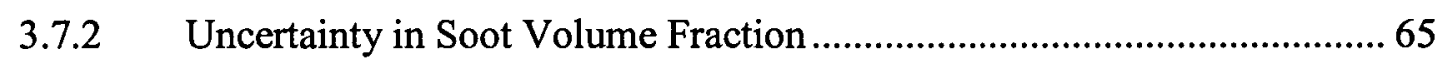

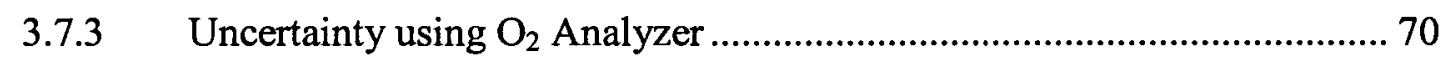

3.7.4 Uncertainty using Averaging Pitot-Static Tube ............................... 72 
3.7.5 Overall Soot Yield Uncertainty ......................................................... 75

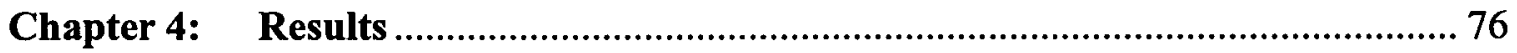

4.1 Soot Yield and Flame Length Results ............................................................. 76

4.1.1 Methane Turbulent Diffusion Flames................................................... 76

4.1.2 Ethane Turbulent Diffusion Flames................................................... 78

4.1.3 Propane Turbulent Diffusion Flames...................................................... 80

4.2 Comparison of Results with Published Literature ............................................ 82

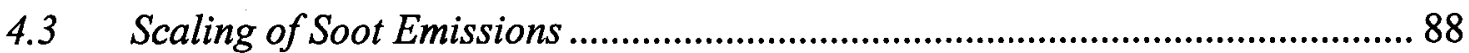

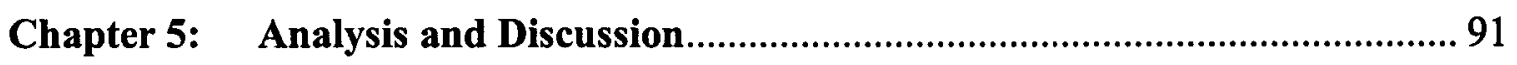

5.1 Effects of Dilution Ratio and Exhaust Flow Rate .......................................... 91

5.1.1 Flow Rate Measurement Bias .............................................................. 94

5.1.2 Duct Flow Rate Correction .................................................................. 99

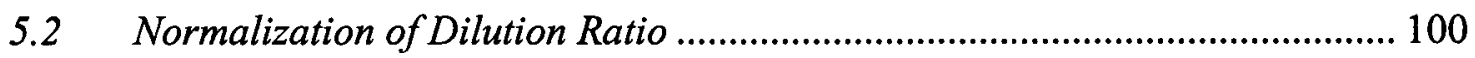

5.3 A Revised Look at Simple Scaling Relations for Soot Emissions from Pure

Fuels 106

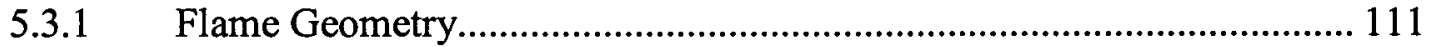

5.4 Physical Modeling of Soot Formation in Turbulent Flames ......................... 114

5.4.1 Residence Time......................................................................... 114

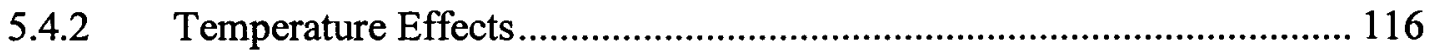

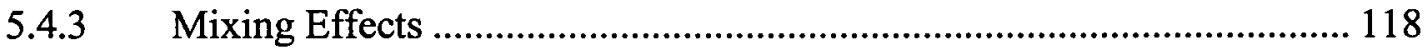

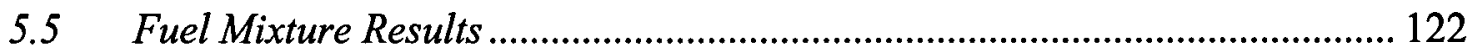

5.5.1 Methane / Propane Mixtures ................................................................ 123

5.5.2 Methane / Ethane Mixtures ............................................................. 125

5.5.3 Methane/Ethane/Propane Mixtures.................................................... 126

Chapter 6: Conclusion and Future Work ........................................................ 131

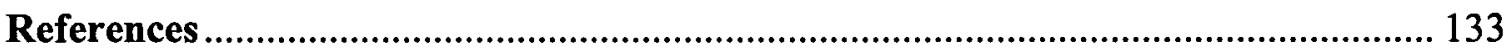

Appendix A: Characterizing Burner Turbulence............................................ 138

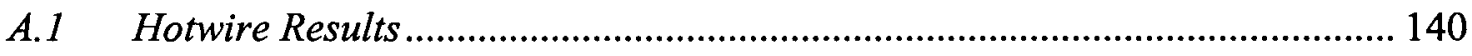

Appendix B: $\quad$ Scanning Mobility Particle Sizer (SMPS) .................................... 143

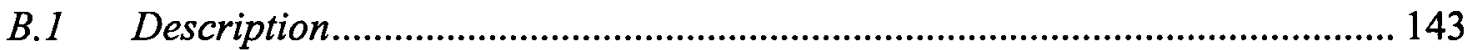

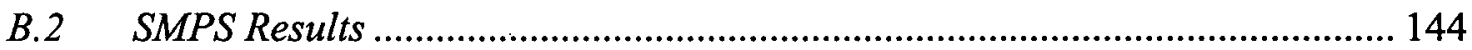


Appendix C: Sampling Loss Calculations ...................................................... 148

C.1 Inlet Efficiency of Sampling Probe ............................................................. 148

C.2 Transport Efficiency through Sampling Duct and Sample Lines.................... 151

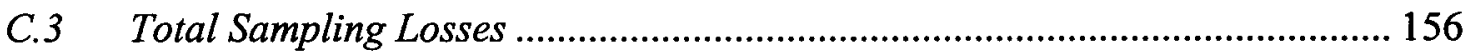

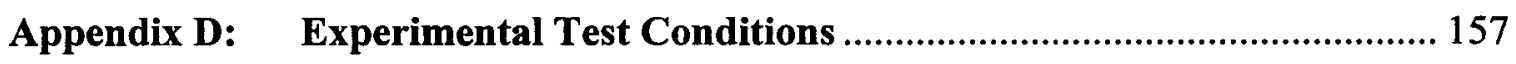




\section{List of Figures}

Figure 1.1: Analysis of solution gas at individual oil well sites in Alberta [8] 19

Figure 2.1: Soot aggregates from propane turbulent diffusion flame using $25.4 \mathrm{~mm}$ burner exit diameter at fuel flow rate of a) $3.2 \mathrm{e}-5 \mathrm{~kg} / \mathrm{s}$ and b) $6.4 \mathrm{e}-5 \mathrm{~kg} / \mathrm{s}$ 28

Figure 2.2: Example of synergistic effect on soot concentration in binary fuel mixtures 31

Figure 2.3: Scaling soot generation efficiency with residence time [36] 34

Figure 2.4: Characteristic residence time compared with measured residence time using Sivathanu data [36]

Figure 2.5: Comparison of Froude number and measured residence time from Sivathanu data [36] 36

Figure 3.1: Schematic of lab-scale flare 38

Figure 3.2: Radially traversed hotwire measurements for $38.1 \mathrm{~mm}$ burner exit diameter with turbulence grid using air ..... 39

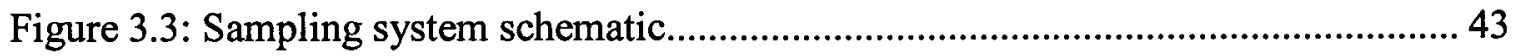

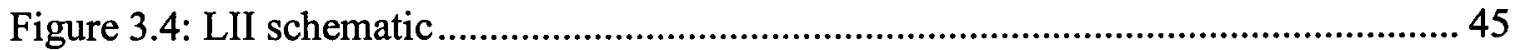

Figure 3.5: Repeatability test for flame length using different number of frames 48

Figure 3.6: Four sequential frames from video of methane flame at flow rate of $2.8 \mathrm{e}-4$ $\mathrm{kg} / \mathrm{s}$ 50

Figure 3.7: a) flame image from single video frame b) binarized flame image c) $10 \%$ contour flame image over 1 minute sample. 50

Figure 3.8: Mean flame image ( 0 indicates a $0 \%$ probability of finding flame in the pixel and 1 indicates a $100 \%$ probability).

Figure 3.9: Soot concentration across diameter of duct for propane at flow rate of 1.6e-4 $\mathrm{kg} / \mathrm{s}$ 55

Figure 3.10: Typical soot volume fraction data for propane burning at $1.6 \mathrm{e}-4 \mathrm{~kg} / \mathrm{s}$ with $25.4 \mathrm{~mm}$ burner.

Figure 3.11: Temperatures of ambient room temperature $\left(T_{\text {ambient }}\right)$, inside the sampling duct $\left(T_{\text {duct }}\right)$, inside the aluminum enclosure $\left(T_{\text {cage }}\right), 25 \mathrm{~mm}$ below the burner exit ( $\left.T_{\text {burner25 }}\right), 13 \mathrm{~mm}$ below the burner exit $\left(T_{\text {burner13 }}\right)$. 
Figure 3.12: Typical soot volume fraction data for a test with $38.1 \mathrm{~mm}$ burner using methane fuel at $2.8 \mathrm{e}-4 \mathrm{~kg} / \mathrm{s}$

Figure 3.13: Anomalies in soot volume fraction data for ethane fuel burning at $1.5 \mathrm{e}-4$

$\mathrm{kg} / \mathrm{s}$ with $12.7 \mathrm{~mm}$ burner.....

Figure 3.14: Soot volume fraction data after applying Chauvenet's criterion for ethane

fuel burning at $1.5 \mathrm{e}-4 \mathrm{~kg} / \mathrm{s}$ with $12.7 \mathrm{~mm}$ burner

Figure 3.15: Effect of $D R$ on the duct volumetric flow rate uncertainty using the averaging pitot-static tube and $\mathrm{O}_{2}$ Analyzer

Figure 3.16: Effect of dilution ratio on duct volume flow rate uncertainty using an $\mathrm{O}_{2}$

Analyzer.

Figure 3.17: Effect of dilution ratio measurement on soot yield uncertainty using a averaging pitot-static tube. 74

Figure 4.1: Soot yield from turbulent diffusion flames burning methane 77

Figure 4.2: Visible flame lengths of methane turbulent diffusion flames at range of flow rates and burner exit diameters 77

Figure 4.3: Soot yield from turbulent diffusion flames burning ethane 79

Figure 4.4: Visible flame lengths of ethane diffusion flames for a range of flow rates and burner exit diameters. 79

Figure 4.5: Soot yield from propane turbulent diffusion flames 81

Figure 4.6: Visible flame lengths of propane diffusion flames for a range of flow rates and burner exit diameters

Figure 4.7: Comparison of experimental results with Becker and Liang [27] and

Sivathanu and Faeth [26] for (a) propane, (b) methane, and (c) ethane 83

Figure 4.8: Soot generation efficiency data from Sivathanu [36] plotted on linear axes . 87

Figure 4.9: Soot yield as a function of Froude number for the different fuels and burner exit diameters

Figure 5.1: Effect of varied dilution ratio on measured soot yield of a) propane and b) methane flames at different fuel flow rates.

Figure 5.2: Effect of exhaust gas temperature on measured soot yield for a) propane and

b) methane flames at different fuel flow rates .93 
Figure 5.3: a) Vertical and b) horizontal velocity profiles obtained with a traversing pitotstatic tube in the sampling duct (flame burning ethane fuel at $1.1 \mathrm{e}-4 \mathrm{~kg} / \mathrm{s}$ ) 95

Figure 5.4: a) Vertical and b) horizontal temperature profiles obtained with a thermocouple in the sampling duct (flame burning ethane fuel at $1.1 \mathrm{e}-4 \mathrm{~kg} / \mathrm{s}$ ) 97

Figure 5.5: Comparison of duct volumetric flow rate measurement using an averaging pitot-static tube and a traversing pitot-static tube 98

Figure 5.6: Ratio of averaging pitot tube and traversing pitot tube duct flow rate measurements as a function of exhaust gas temperature.

Figure 5.7: Effect of dilution ratio on soot yield using a traversing pitot-static tube for the exhaust gas flow rate measurements (ethane fuel using $38.1 \mathrm{~mm}$ burner at two different fuel mass flow rates) 101

Figure 5.8: Summary of dilution ratio effect on soot yield for methane, ethane, and propane at different fuel flow rates

Figure 5.9: Dilution ratio and exhaust gas temperature for all soot emission tests performed

Figure 5.10: Soot yield as a function of dilution ratio in the range $20<D R<50$ for methane, ethane, and propane

Figure 5.11: Estimate of the soot yield uncertainty introduced from dilution ratio correction factor

Figure 5.12: Soot yield as a function of characteristic residence time compared with Sivathanu and Faeth [26] and Becker and Liang [27] for a) methane, b) ethane, and c) propane fuels 108

Figure 5.13: Soot yield as a function of Froude number for a) methane, b) ethane, and c) propane fuels

Figure 5.14: Normalized flame geometry parameters as a function of $\mathrm{Fr}$ for methane, ethane, and propane

Figure 5.15: Comparison of estimated residence times assuming a particle with and without acceleration (methane fuel).

Figure 5.16: Peak mean centerline temperature for propane turbulent diffusion flames [62] 
Figure 5.17: New scaling parameter for soot yield from a) methane, b) ethane, and c)

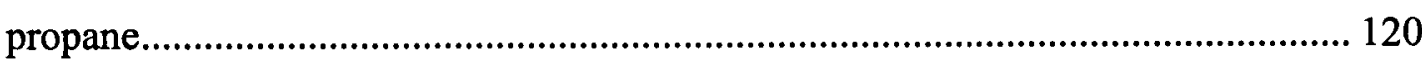

Figure 5.18: Soot generation efficiency from methane/propane fuel mixture................ 124

Figure 5.19: Soot generation efficiency from methane/ethane fuel mixture ................. 125

Figure 5.20: Soot generation efficiency of methane/ethane/propane fuel mixture running at a flow rate of 15 SLPM................................................................................. 127

Figure 5.21: Soot generation for all fuel mixture data at a flow rate of 15 SLPM with a) $25.4 \mathrm{~mm}$ burner and b) $50.8 \mathrm{~mm}$ burner. 128

Figure 5.22: Normalized soot generation efficiency for all fuel mixtures at 15 SLPM with a) $25.4 \mathrm{~mm}$ burner and b) $50.8 \mathrm{~mm}$ burner .................................................... 130

Figure A.1: Turbulence grid schematic 139

Figure A.2: Turbulence intensity profiles for the four burner diameters using the grids listed in Table A.2 at the largest $R e$ value

Figure B.1: DMA schematic [68] 144

Figure B.2: Particle size distribution results from SMPS for methane and propane flames with different burner diameters and fuel flow rates 145 


\section{List of Tables}

Table 3.1: Estimate uncertainties of soot yield parameters ............................................ 63

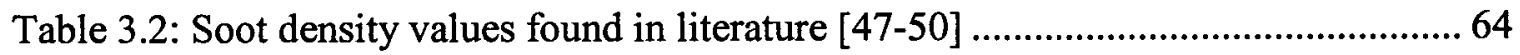

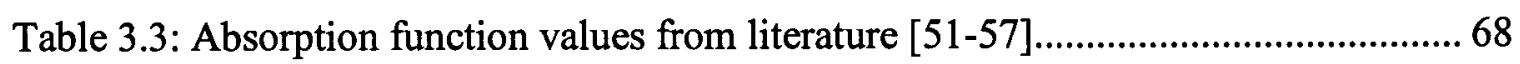

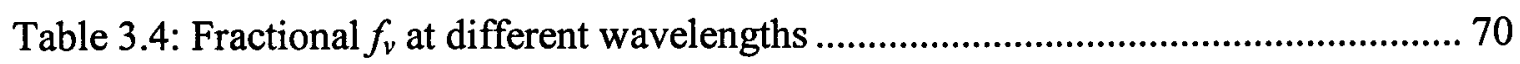

Table 3.5: Combustion product volume flow rate at different combustion efficiencies .. 71

Table 3.6: Molecular weight of exhaust gas at different dilution ratios ........................... 73

Table 3.7: Estimate uncertainties for $Q_{d u c t}$ using a pitot tube .......................................... 74

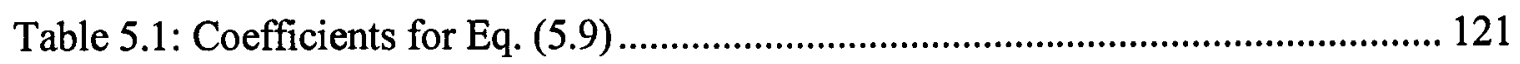

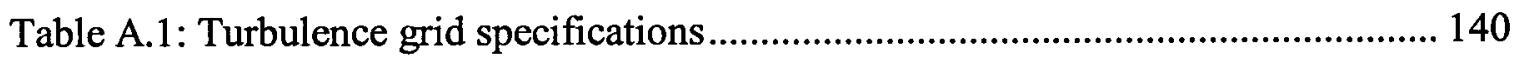

Table A.2: Turbulence intensity results from turbulence generating grid ..................... 142

Table D.1: Methane test conditions ....................................................................... 157

Table D.2: Ethane test condtions ........................................................................... 158

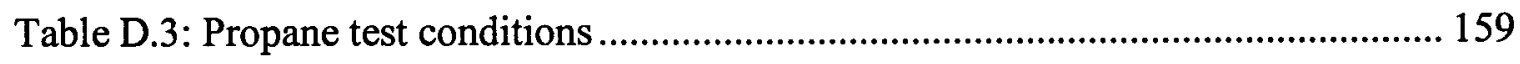




\section{Nomenclature}

\begin{tabular}{|c|c|}
\hline$A$ & area \\
\hline$d$ & diameter \\
\hline$d_{p}$ & particle diameter \\
\hline$D R$ & dilution ratio \\
\hline$E(m)$ & soot absoprtion function \\
\hline$F r$ & Froude number \\
\hline$F r_{s}$ & Stiochiometric Froude number \\
\hline$f_{v}$ & soot volume fraction \\
\hline$g$ & acceleration due to gravity \\
\hline$L$ & flame length \\
\hline$\dot{\boldsymbol{m}}_{\text {carbon }}$ & mass flow rate of fuel carbon \\
\hline$\dot{\boldsymbol{m}}_{\text {fuel }}$ & mass flow rate of fuel \\
\hline$\dot{m}_{o}$ & jet mass flux at burner exit \\
\hline$\dot{m}_{\text {soot }}$ & mass flow rate of soot \\
\hline$M W$ & molecular weight \\
\hline$\left[\mathrm{O}_{2}\right]$ & oxygen concentration \\
\hline$p_{o}$ & stagnation pressure \\
\hline$p_{s}$ & static pressure \\
\hline$Q$ & volumetric flow rate \\
\hline $\operatorname{Re}$ & Reynolds number \\
\hline$R i$ & Richardson Number \\
\hline$S$ & Stoichiometric air to fuel mass ratio \\
\hline$S G E$ & soot generation efficiency \\
\hline$S t k$ & Stokes number \\
\hline$T$ & temperature \\
\hline$u$ & velocity \\
\hline$u^{\prime} / \bar{u}$ & turbulence intensity \\
\hline$W_{l}$ & stiochiometric mixture fraction \\
\hline
\end{tabular}




$\begin{array}{ll}Y_{s} & \text { soot yield } \\ \eta_{\text {asp }} & \text { aspiration efficiency } \\ \eta_{c} & \text { combustion efficiency } \\ \eta_{\text {inlet }} & \text { sampling inlet efficiency } \\ \eta_{\text {sample }} & \text { total sampling efficiency } \\ \eta_{\text {transport }} & \text { sampling transport efficiency } \\ \eta_{\text {trans }} & \text { sampling transmission efficiency } \\ \lambda & \text { wavelength } \\ \mu & \text { gas viscosity } \\ \nu & \text { gas kinematic viscosity } \\ \rho_{\infty} & \text { ambient air density } \\ \rho_{\text {soot }} & \text { soot density } \\ \sigma & \text { blockage ratio } \\ \tau_{R} * & \text { characteristic residence time }\end{array}$




\section{Chapter 1: Introduction}

Soot formation from combustion of hydrocarbon fuels has received significant attention in the past two decades; however, it is still one of the least solved problems in combustion [1]. Although the individual mechanisms for soot formation have been studied, there is no universal theory or model able to predict soot from a wide range of conditions. Most experiments studying soot formation from diffusion flames involve either laminar diffusion flames or shock tubes, as the non-homogenous nature of turbulence creates difficulties in isolating the effects of the individual mechanisms on soot formation and oxidation [2]. The coupling of soot formation and a turbulent diffusion flame becomes a formidable problem, involving soot chemical kinetics, turbulence, and radiation interactions. However, many practical applications, such as diesel engines, furnaces, gas turbines, and flaring involve turbulent diffusion flames.

Part of the reason for the interest in soot formation is that fine soot particles (less than 2.5 $\mu \mathrm{m})$ have recently been linked to serious health effects such as cancer and heart disease in humans and animals [3]. Soot particles have also been linked to the formation of high altitude clouds which can affect the earth's climate [4]. In Canada, particulate matter (PM) emissions (i.e. soot) are considered to be a Criteria Air Contaminant (CAC) and are tracked by Environment Canada through the National Pollutant Release Inventory (NPRI) [5]. It is therefore important to gain an understanding of soot formation in order to reduce emissions. 


\subsection{Flaring}

One potentially important source of soot emissions is gas flaring, an approach used extensively in the oil and gas industry to burn unwanted flammable gas in an elevated turbulent diffusion flame in the open atmosphere. Although the emissions released through the oxidation of the gas are generally preferred over simply venting the gas to the atmosphere, flaring can create other pollution problems such as the formation of soot. The World Bank estimates that worldwide, more than 150 billion cubic meters of gas are flared annually [6]. The majority of flaring in Canada is from Alberta, which flared 0.887 billion cubic meters of gas in 2006 [7]. Though the majority of flared gas is methane [8], which is known to have a low sooting propensity [9], the prevalence of flaring globally leads to a significant cumulative soot emission. To date little attention has been focused on this problem despite federal requirements for industry to quantify and report PM emissions through the NPRI.

There are three main types of flaring in the oil and gas industry: emergency flaring, process flaring, and production flaring [8, 10]. Emergency flaring typically occurs at large facilities such as refineries when large volumes of gas may have to be safely disposed of in a few seconds due to an emergency situation such as a valve rupture, fire, or compressor failure. The gas flow rate during emergency flaring can be on the order of

$10^{5} \mathrm{~kg} / \mathrm{h}$ which can result in exit velocities that approach sonic speed. Process flaring can also take place at large facilities but typically at much lower flow rates than emergency flaring. When gas leaks past safety valves it is usually sent to a process flare to be 
burned. The flow rates during process flaring can be much greater during startup or shutdown or during a blowout procedure. Production flaring is a broad heading given to the flaring of gas that is not deemed economical to process. The flares continuously burn gas at relatively low flow rates. Solution gas, which is a by-product of extracting oil from a high pressure reservoir, is a primary contributor to continuous gas flaring in the industry [8]. In Alberta, solution gas flaring contributed to $43 \%$ (0.382 billion cubic meters) of the total gas flared in 2006 [7]. In that same year, an additional 0.307 billion cubic meters of solution gas were vented directly to atmosphere.

The exit of the flare, known as the "flare tip" is generally where the design of flares differs. There is a wide variety of flare tip designs which are used in the oil and gas industry. Brzustowski [10] gives a good overview of the technology used in different flare tips. A utility flare tip is essentially a pipe which may have a pilot flame at the tip to prevent flameout. The centre-steam tip is similar to a utility flare tip but has a nozzle in the centre of the flare which injects steam into the fuel. The steam is used as a smoke suppressant. A steam-ring tip has nozzles placed in a ring slightly above the flare tip. The steam is used to entrain air in the flame which lowers the amount of steam required for smoke suppression. There are many more designs which involve some variation of air or steam injection. To use air or steam injection there must be a supply of compressed air or steam available on-site, which may not be the case in production flaring where the flare is in a remote location. 
In Canada, almost all solution gas flaring occurs at smaller installations that do not use complex flare-tips. The focus of this study is on turbulent diffusion flames relevant to solution gas flaring. Thus, simple utility flare tips were used without a pilot flame as a pilot can obscure the combustion efficiency [11].

\subsubsection{Solution Gas Flaring}

The term "solution gas" is used to describe dissolved gases that come out-of-solution when conventional and heavy oil is brought from high reservoir pressure to atmospheric pressure at the surface. As shown in Figure 1.1 [8], some of the main components of the gas are methane ( $\mathrm{C} 1$ hydrocarbon), ethane $(\mathrm{C} 2)$, and propane $(\mathrm{C} 3)$. There are also inert gases such as carbon dioxide $\left(\mathrm{CO}_{2}\right)$ and nitrogen $\left(\mathrm{N}_{2}\right)$ which can reduce the energy density of the gas and have an affect on soot formation.

Solution gas can be processed into sales gas but occasionally it is uneconomical to do so and the gas is either flared or vented into the atmosphere. As mentioned above, flaring is preferable over venting the gas directly into the atmosphere. The global warming potential (GWP) of methane is 23 times greater (by mass) than that of $\mathrm{CO}_{2}$ which is the main product of hydrocarbon combustion [8]. On a volumetric basis, venting $1 \mathrm{~m}^{3}$ of methane has eight times the GWP as burning the same volume of methane. 


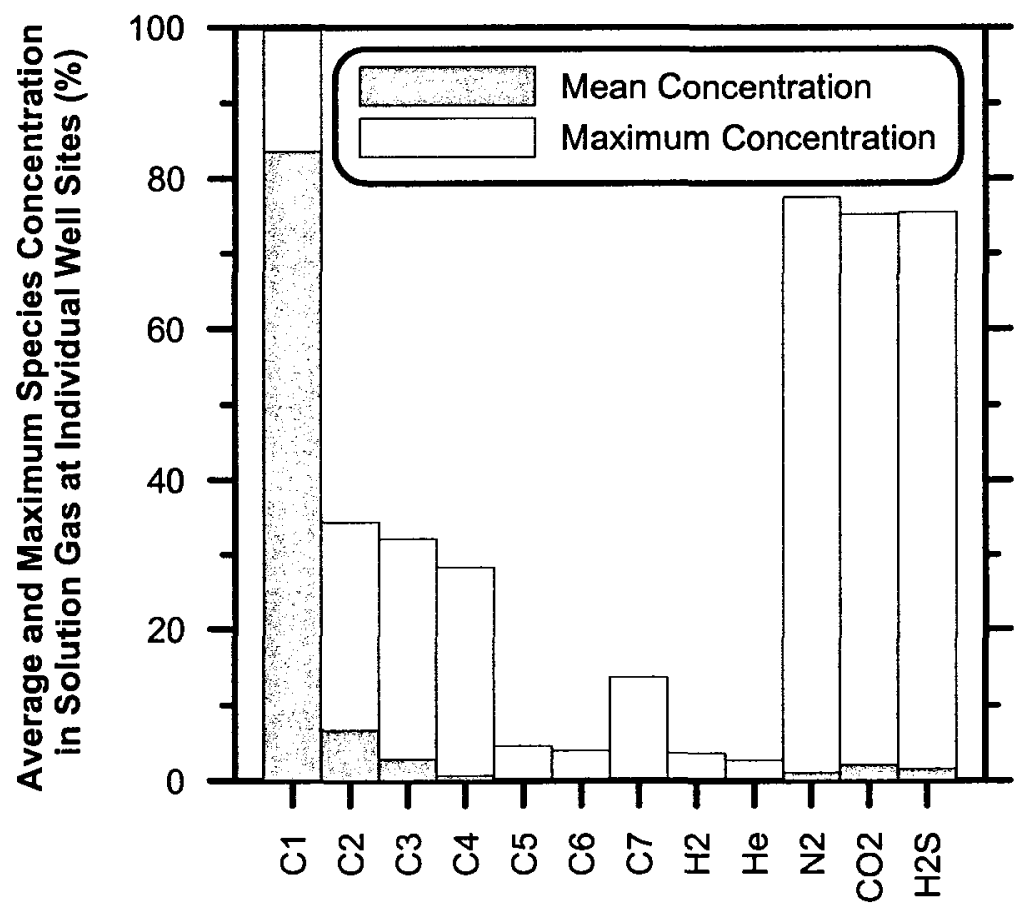

Figure 1.1: Analysis of solution gas at individual oil well sites in Alberta [8]

Although there is no "typical" solution gas flare, flare stack heights are on the order of 10 $\mathrm{m}$ and inner exit diameters generally range from $0.08 \mathrm{~m}$ to $0.20 \mathrm{~m}$ with wall thicknesses typical of standard pipe sizes. The Richardson number $\left(R i=g d / u^{2}\right.$, where $g$ is the gravitational constant, $u$ is the flare exit velocity and, $d$ is the flare exit diameter) for commercial flares can vary from 15 to $10^{4}$ according to Pohl et al. [11]. However, Johnson et al. [8] estimate for most solution gas flaring the exit gas velocities to be less than $6 \mathrm{~m} / \mathrm{s}$ for a "typical" flare, which would result in $R i>0.02$. There is a considerable discrepancy between the $R i$ ranges given by Johnson et al. [8] and Pohl et al. [11]; however, Pohl et al. [11] do not explicitly state where the range is calculated from, whereas Johnson et al. [8] use actual volume data from the oil and gas industry. The gas flow is characterized as fully-developed turbulent pipe flow due to the height of the flare 
stack and exit velocity of the gas. The air and fuel are not premixed, which results in a turbulent diffusion flame.

\subsubsection{Flaring Efficiency and Emissions}

There have been two extensive studies investigating the combustion efficiency of flaring $[11,12]$. The combustion (or flaring) efficiency is defined as the ability to convert fuel carbon into carbon dioxide. The main factors found to affect flaring efficiency are the fuel energy density, wind speed, fuel exit velocity, and flare tip diameter, with the energy density and wind speed having the greatest influence. The flaring efficiency decreases substantially when the energy density is decreased or the wind speed is increased. Pollutant emissions associated with flare inefficiency were determined to be a result of fuel stripping and had a composition very similar to that of the raw fuel plus some additional carbon monoxide $[13,14]$. Under low wind speeds and stable flame conditions, flare efficiency is quite high $(>98 \%)$ for methane, ethane, and propane flames $[11,12]$.

Although there has been substantial research effort spent investigating flaring efficiency, few have studied the soot emissions from flaring. Pohl et al. [11] conducted experiments with full-scale propane flares and found the soot emissions account for less than $0.5 \%$ of the unburned hydrocarbons emitted. Other studies $[12,15,16]$ have investigated the effect of crosswind on soot emissions and have shown that the mass of soot decreases with an increase in the mixing ratio which is a function of the wind speed $\left(U_{\infty}\right)$ and the fuel exit velocity $\left(U_{j}\right)$. 


$$
\dot{\boldsymbol{m}}_{\text {soot }}=\alpha\left(\boldsymbol{U}_{\infty} \boldsymbol{U}_{j}\right)^{\beta}
$$

where, $\alpha$ and $\beta$ are experimentally fit coefficients.

The decrease in soot emissions with an increase in wind speed is believed to be caused by an increase in the mixing rate of the turbulent diffusion flame [15].

The focus of this study is on soot emissions from turbulent diffusion flames in the absence of crosswind. In terms of flaring, soot emissions should thus be at a maximum under these conditions and emissions of species associated with poor carbon conversion and fuel-stripping should be at a minimum. Results are generally presented in terms of a soot yield $\left(Y_{s}\right)$ which is defined as a mass of soot $\left(\dot{\boldsymbol{m}}_{\text {soot }}\right)$ per mass of fuel burned $\left(\dot{\boldsymbol{m}}_{\text {fuel }}\right)$,

$$
Y_{s}=\frac{\dot{\boldsymbol{m}}_{\text {soot }}}{\dot{\boldsymbol{m}}_{\text {fuel }}}
$$

Other authors sometimes use a soot generation efficiency ( $S G E)$ which is defined as a mass of soot per mass of fuel carbon $\left(\dot{\boldsymbol{m}}_{\text {carbon }}\right)$ burned,

$$
S G E=\frac{\dot{m}_{\text {soot }}}{\dot{m}_{\text {carbon }}}
$$

\subsubsection{Measurements of Soot Emissions}

There are several techniques available for measuring the total mass of soot emissions, such as gravimetric sampling, line-of-sight attenuation (LOSA), and laser induced incandescence (LII). Gravimetric sampling is the technique recommend by the National Institute for Occupational Health and Safety (NIOSH) and involves collecting soot on a 
filter and weighing the total mass of soot [17]. Although the technique is straightforward in principle, relatively large quantities of soot are required to ensure accurate mass measurement. In addition, special sample handling protocols are generally necessary including conditioning the humidity of sample filters before and after sample collection, which can further complicate measurements. Preliminary tests with an available LII system indicate the highest achievable soot yield from a methane flame in the current experimental setup is approximately $1.0 \mathrm{e}-4 \mathrm{~kg}$ soot $/ \mathrm{kg}$ fuel $(0.1 \mathrm{ppb})$ at a fuel flow rate of $1.7 \mathrm{e}-4 \mathrm{~kg} / \mathrm{s}$. For a mass balance with a sensitivity of $0.001 \mathrm{mg}$, this would require the flame to burn for approximately $6 \mathrm{~s}$ to achieve an accuracy of $1.0 \%$. However, this is a simplification of the problem, since the filter would need to be the size of the sampling duct $(0.15 \mathrm{~m})$ and would weigh considerably more than the soot; therefore, a mass balance would need to have a very large measurement range. Also, it would be very difficult to find a filter which is capable of capturing particles ranging in size from $0.01-$ $1.0 \mu \mathrm{m}$.

In a standard implementation of the LOSA technique, a collimated light source passes through a soot plume and the amount of light transmitted through to the other side of the plume is measured. Assuming negligible losses due to scattering, the soot volume fraction $\left(f_{v}\right)$ is given by [18],

$$
f_{\nu}=\frac{-\ln (\tau) \lambda}{6 \pi L E(m)}
$$

where, $\tau$ is the transmissivity which equals the transmitted/incident laser intensity ratio 
$\lambda$ is the laser wavelength $(577 \mathrm{~nm})$

$L$ is the length the laser light travels through the attenuating medium $(0.15 \mathrm{~m})$

$E(m)$ is the soot absorption coefficient $(0.285)$

The sensitivity of LOSA is based on the highest transmissivity the system can discern. Snelling et al. [18] indicate that achieving a transmissivity greater than 0.999 is very difficult, especially with a laser based transmissivity measurement. Solving Eq. (1.4) with the above constants and $\tau=0.999$, it yields a minimum detectable soot volume fraction of $0.78 \mathrm{ppb}$, which is well above the volume fraction expected from methane.

LII is a laser-based technique in which a pulsed laser is used to rapidly heat soot particles and their incandescence is measured as they cool (Section 3.3). Preliminary tests showed that LII is capable of measuring the low soot concentrations produced by methane flames. LII has an estimated sensitivity of better than one part per trillion [19].

\subsubsection{Characteristics of Diffusion Flames}

A flame is referred to as a diffusion flame when the fuel and oxidizer are not premixed inside the burner. In a diffusion flame, the fuel and oxidizer come together at the reaction zone through molecular diffusion for a laminar flame or turbulent diffusion for a turbulent flame. 
Laminar and turbulent flames can be distinguished by the scaling parameter used for their flame lengths $(L)$. In the classic description from Hottel and Hawthorne [20] in 1949, for a laminar flame, the flame length is only dependent on the fuel exit velocity and is independent of the burner exit diameter. However, as the velocity continues to increase, Hottel and Hawthorne [20] showed the laminar flame transitioning to a fully developed turbulent flame corresponding to a slight decrease in flame length followed by an extended region of constant flame length. Delichatsios [21] updated this definition in 1993 and showed that before the flame length becomes constant there is another region of increasing flame length where the flame is considered to be a buoyancy-controlled turbulent flame. The Froude number $\left(F r=u /(g \cdot d)^{0.5}\right)$, which is the inverse square-root of the Richardson number as defined above, has been shown to have the following relationship to flame length for a buoyant turbulent diffusion flame [21],

$$
\frac{L}{d} \propto F r^{2 / 5}
$$

Delichatsios [21] shows that it is after this region where a buoyant turbulent diffusion flame transitions to a momentum-controlled flame, that the flame length becomes constant with increased flow. According to the Delichatsios [21], the flow regime of a flame is dictated by both the Reynolds number $(R e)$ and the stiochiometric Froude number $\left(F r_{s}\right)$. The fire Froude number is similar to basic Froude number defined above except that it also incorporates the stoichiometric air to fuel mass ratio $(S)$ so that $F_{\boldsymbol{s}}=\boldsymbol{F r} /(\boldsymbol{S}+1)^{3 / 2}$. The transition from a laminar flame to a buoyant turbulent flame occurs when $R e=288 \cdot \mathrm{Fr}_{s}^{2 / 5}$ [21]. For the range of stiochometric Froude numbers 
expected in these experiments, the transition from a laminar to a buoyant turbulent flame occurs at a Reynolds number range of approximately 25-50 for methane. The flame transitions to a momentum-controlled turbulent flame only when $R e>4000$ and $F r_{s}>$ 100. Both $F r_{s}$ and $R e$ for the experiments presented in this thesis (refer to Appendix D) are well within the range to be considered buoyant turbulent diffusion flames.

\subsection{Objectives}

Field measurements of soot emissions from flares are difficult to obtain for several reasons: the ambient conditions are constantly changing, the emissions can be rapidly dispersed in the atmosphere, leading to poor sampling, and there is large site-to-site variation of flares, so measurements at a single site are not representative of every flare. In light of these difficulties, it was decided to create a lab-scale turbulent diffusion burner to allow emission measurements in a controlled environment. The turbulent diffusion flame burner is able to operate under a wide range of conditions relevant to those found for solution gas flares. Although flaring can often occur in crosswind conditions, the maximum soot concentration occurs in still air and reduces with increasing wind speed (see Section 1.1.2) and therefore the experiments will be run at the "worse-case" condition in still air.

However, there are also challenges associated with simulating a flare under laboratory conditions. The dilution ratio, relative humidity, residence time, and temperature of the sample exhaust can all lead to a significant change in the soot emissions $[22,23]$. An efficient sampling protocol had to be developed to ensure that measured emissions at the 
sample location can be accurately related to actual emissions from the flame. Using this new approach and experimental setup, experiments were conducted to investigate effects of varying fuel composition, fuel flow rate, and flare diameter on soot emissions.

The research outlined in this thesis is the first step in developing experimentally based models to predict soot emissions from turbulent diffusion flares used in industry by using soot emission data from lab-scale flares. Such a model will help industry to meet its federally mandated reporting requirements while providing industry a framework for emissions reduction.

In summary, the main objectives of this research were:

1) To develop a laboratory scale flare facility using a turbulent diffusion flame burner to simulate full-scale turbulent flares burning in quiescent air

2) To develop a measurement protocol which can accurately measure the soot yield using LII

3) To use this facility to quantify soot yield during a wide range of conditions, including, various fuel compositions, fuel flow rates, and burner exit diameters

4) To develop a scaling parameter which is capable of predicting emissions for fullscale flares from the lab-scale turbulent diffusion burner 


\section{Chapter 2: $\quad$ Soot Formation}

Ideal hydrocarbon combustion leads to a production of only carbon dioxide, water, and heat. However, in most practical combustion devices ideal combustion does not occur and can lead to the production and emission of soot. Soot formation is an extremely complicated process which is still not fully understood $[1,2]$. A soot particle has no unique physical or chemical structure but it is considered to be a carbonaceous agglomerate containing several million carbon atoms [1].

Although the details of the formation mechanism are not understood, the generally accepted process contains four steps: formation of aromatic hydrocarbons, soot inception, soot growth and coagulation, and soot oxidation [1, 24]. During the pyrolysis of the hydrocarbon fuel, acetylene species are formed which can form aromatic rings. These rings grow by an acetylene addition mechanism and the larger rings then undergo coagulation to form the primary soot particles. The primary particles have been observed to be as small as $1.5 \mathrm{~nm}$ but are most often in the $10-50 \mathrm{~nm}$ range. The primary particles grow by picking up molecules from the gas phase and also coagulating together. The rate at which the primary particles form can largely determine the final soot concentration from a flame. The whole soot formation process can occur in less than $1 \mathrm{~ms}[2,24]$. Finally, soot oxidation is a complex process dependent on three main factors: the mixing rate, temperature, and species concentration [25]. The oxidation rate increases with the mixing rate and temperature but will cease if the temperature falls below $\sim 1300 \mathrm{~K}[25]$. 
Soot aggregates from a propane fueled turbulent diffusion flame viewed from a transmission electron microscope (TEM) can be seen in Figure 2.1. The figures show that primary particles have a roughly spherical shape and are agglomerated into aggregates of greatly varying size.

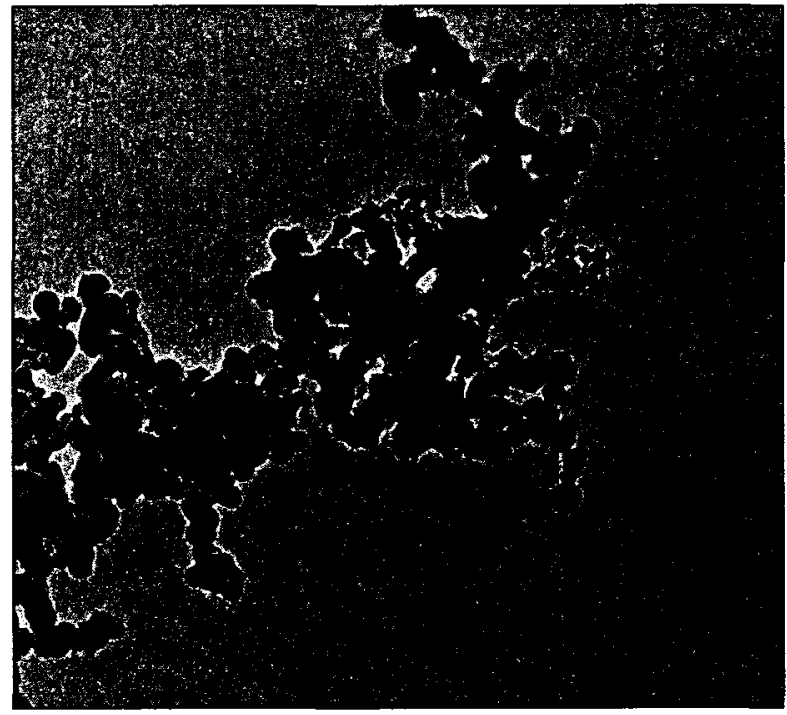

a) TEM image (1.4 $\mu \mathrm{m} \times 1.4 \mu \mathrm{m})$

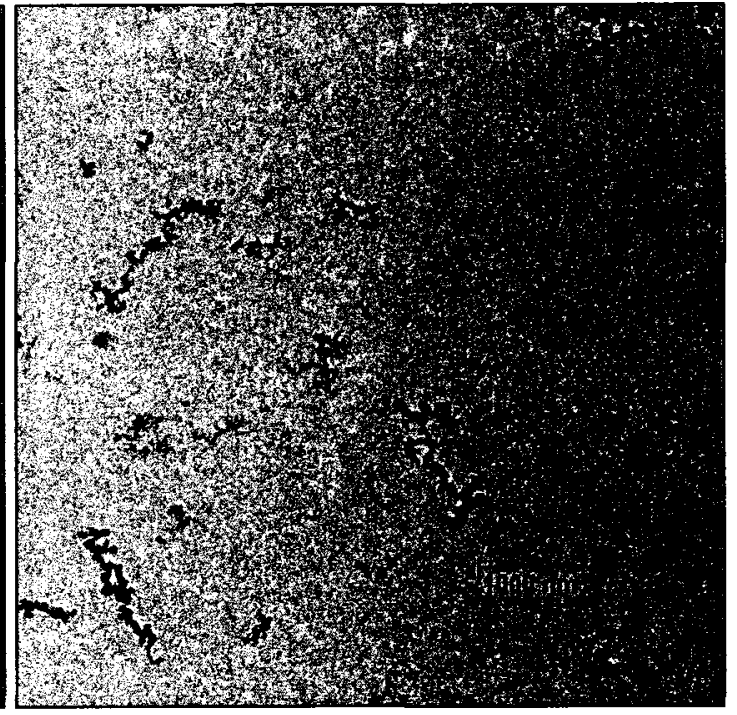

b) TEM image (6.9 $\mu \mathrm{m} \times 6.9 \mu \mathrm{m})$

Figure 2.1: Soot aggregates from propane turbulent diffusion flame using $25.4 \mathrm{~mm}$ burner exit diameter at fuel flow rate of a) $3.2 \mathrm{e}-5 \mathrm{~kg} / \mathrm{s}$ and b) $6.4 \mathrm{e}-5 \mathrm{~kg} / \mathrm{s}$

\subsection{Soot Emissions from Turbulent Diffusion Flames}

Measuring and predicting soot emissions from turbulent diffusion flames is a classic problem in combustion that has been considered by many investigators. However, the majority of these studies have considered alkene or alkyne based fuels or longer chain alkanes while very few studies have considered mixed fuels in detail. Sivathanu and Faeth [26] and Becker and Liang [27] both measured soot emissions in the overfire 
region of turbulent diffusion flames. Both $[26,27]$ conducted experiments using a range of burner exit diameters, fuel flow rates, and different fuels in an attempt to establish a scaling parameter for soot emissions. Kent and Bastin [25], Coppalle and Joyeux [28], and Nishida and Mukohara [29] made soot volume fraction measurements within the flame to gain an understanding of how parameters such as temperature and mixing will affect soot formation and oxidation. It should be clarified that soot formation and oxidation refer to the in-flame processes. Soot formation may occur in a flame but the soot could be completely oxidized, which would result in no soot being emitted postflame. Therefore, while a certain parameter may increase soot formation it does not necessarily indicate an increase in soot emitted from the flame.

Gülder [2], citing numerous sources, identifies several important parameters which affect soot formation in a diffusion flame for a given flow condition (i.e. same fuel flow rate and burner exit diameter). The important parameters are the fuel molecular structure, the flame temperature, the presence of diluents in the fuel, and the pressure. The flame temperature is an extremely important parameter since it affects the chemical kinetics in soot formation and soot oxidation. The soot formation rate increases with an increase in temperature $[25,30]$ for a diffusion flame. However, the soot oxidation also increases with temperature so there is a competing effect between the two mechanisms. Glassman [24] notes that the overall soot released from a diffusion flame decreases with an increase in temperature. The fuel molecular structure is also extremely important since the pyrolysis mechanism for a particular fuel can affect the amount of soot precursor species 
formed and therefore the overall amount of soot. The fuel structure also affects the flame temperature.

The smoke point is a measure often used to compare the sooting propensity of different fuels. Experiments are conducted with laminar flames where the fuel flow rate is increased until soot is emitted from the flame tip. The relative sooting propensities of different fuel structures in a diffusion flame are believed to be [31],

$$
\text { napthalenes }>\text { benzenes }>\text { alkynes }>\text { alkenes }>\text { alkanes }
$$

The addition of inert diluents can affect soot formation by not only diluting the fuel but also by altering the flame temperature $[25,30]$. Operating a diffusion flame at elevated pressure has been shown to increase the soot formation [32].

\subsection{Soot from Binary Fuel Mixtures}

Several authors $[33,34,35]$ have studied soot formation from binary fuel mixtures but have obtained conflicting results and given conflicting explanations for the results. The most recent study completed by Trottier et al. [33] used methane/ethane, methane/propane, and ethane/propane mixtures. The results from the methane/ethane mixture showed a synergistic effect whereby higher soot concentrations were observed than would be produced by either of the pure fuels (Figure 2.2). This effect was not seen 
in the methane/propane or ethane/propane mixtures, which both produced soot concentrations in proportion to the amount of the pure fuel in the mixture.

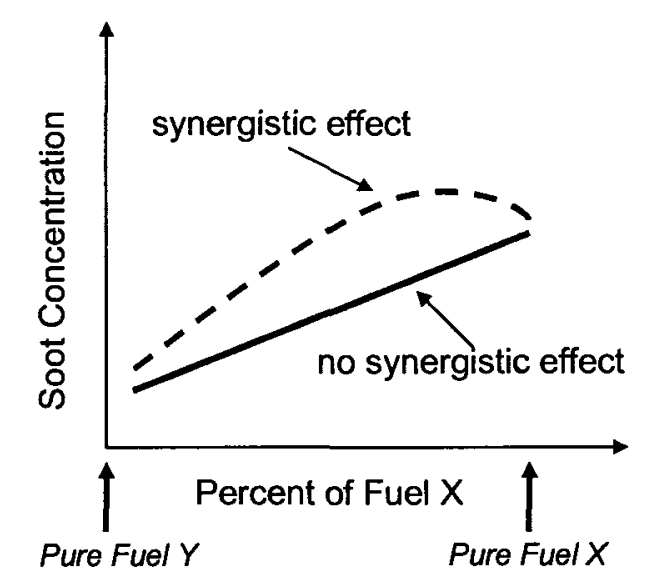

Figure 2.2: Example of synergistic effect on soot concentration in binary fuel mixtures

Trottier et al. [33] hypothesized that the synergistic effect is the result of an interaction between a methyl radical $\left(\mathrm{CH}_{3}\right)$ and ethylene $\left(\mathrm{C}_{2} \mathrm{H}_{4}\right)$ which form a vinyl radical $\left(\mathrm{C}_{2} \mathrm{H}_{3}\right)$ that leads to the acetylene based pathway of soot formation. The synergistic effect was observed in the methane/ethane mixture because of the large amounts of ethylene produced during pyrolysis of ethane.

\subsection{Scaling Parameters for Soot from Turbulent Diffusion Flames}

The important parameters with respect to flaring are the fuel molecular structure and the presence of diluents, which both affect the flame temperature as discussed above. The effects of pressure are insignificant for flaring since flares operate at atmospheric 
pressure. However, for a given fuel composition, the flow conditions are the only controlled parameters that dictate the soot emission rate.

In order to predict the soot yield (mass of soot per unit mass of fuel burned) produced by a full-scale industry flare from the lab-scale turbulent diffusion burner, a scaling parameter must be used. Becker and Liang [27] and Sivathanu and Faeth [26] have both presented parameters to scale the soot yield for buoyant turbulent diffusion flames. Becker and Liang [27] use a Richardson ratio $\left(R i_{L}\right)$ defined as,

$$
R i_{L}=\frac{\text { buoyancy of flame }}{\text { source momentum flux }}=\frac{\pi g \rho_{\infty} L^{3}}{4 \dot{G}_{0}}
$$

where, $g$ is the acceleration due to gravity

$\rho_{\infty}$ is the ambient air density

$L$ is the flame length

$\dot{G}_{0}$ is the jet momentum flux at the burner exit

Becker and Liang [27] also use a form of the first Damköhler ratio $\left(D a_{l}\right)$ but refer to it as a characteristic residence time $\left(\tau_{r}{ }^{*}\right)$ as shown below,

$$
D a_{1}=\frac{\text { homogeneous reaction rate }}{\text { convection }}=\frac{\rho_{\infty} W_{1} L^{3}}{\dot{m}_{0}}=\tau_{r} *
$$

where, $W_{l}$ is the mixture fraction in a stiochiometric mixture 
$\dot{m}_{0}$ is the jet mass flux at the burner exit

Becker and Liang [27] go on to show that there is a strong correlation between $\tau_{r}{ }^{*}$ and $R i_{L}$ and that either one can be used as the scaling parameter. Sivathanu and Faeth [26] found that the soot yield scaled with a measured residence time, which they define as the time from shutting off the fuel to the time that all luminosity of the flame disappears. Figure 2.3 shows a recreated figure from Sivathanu and Faeth [26] that scales soot generation efficiency (ratio of soot output to carbon input, similar to soot yield) with residence time. Sivathanu and Faeth [26] used a normalized residence time which is the measured residence time divided by the smoke point residence time. By using the normalized residence time, they sought to show that the soot generation efficiency reaches a plateau region at residence times that are approximately ten times the smoke point residence time. It should be noted that the lines shown in Figure 2.3 were reproduced from the original figure in Sivathanu and Faeth [26], who simply fitted the data with a hand-drawn line and did not perform a regression analysis.

The data shown in Figure 2.3 was obtained from Sivathanu [36] and used to calculate the characteristic residence time. Figure 2.4 shows a comparison between the measured residence time and the calculated characteristic residence time using Sivanthanu's [36] data. 


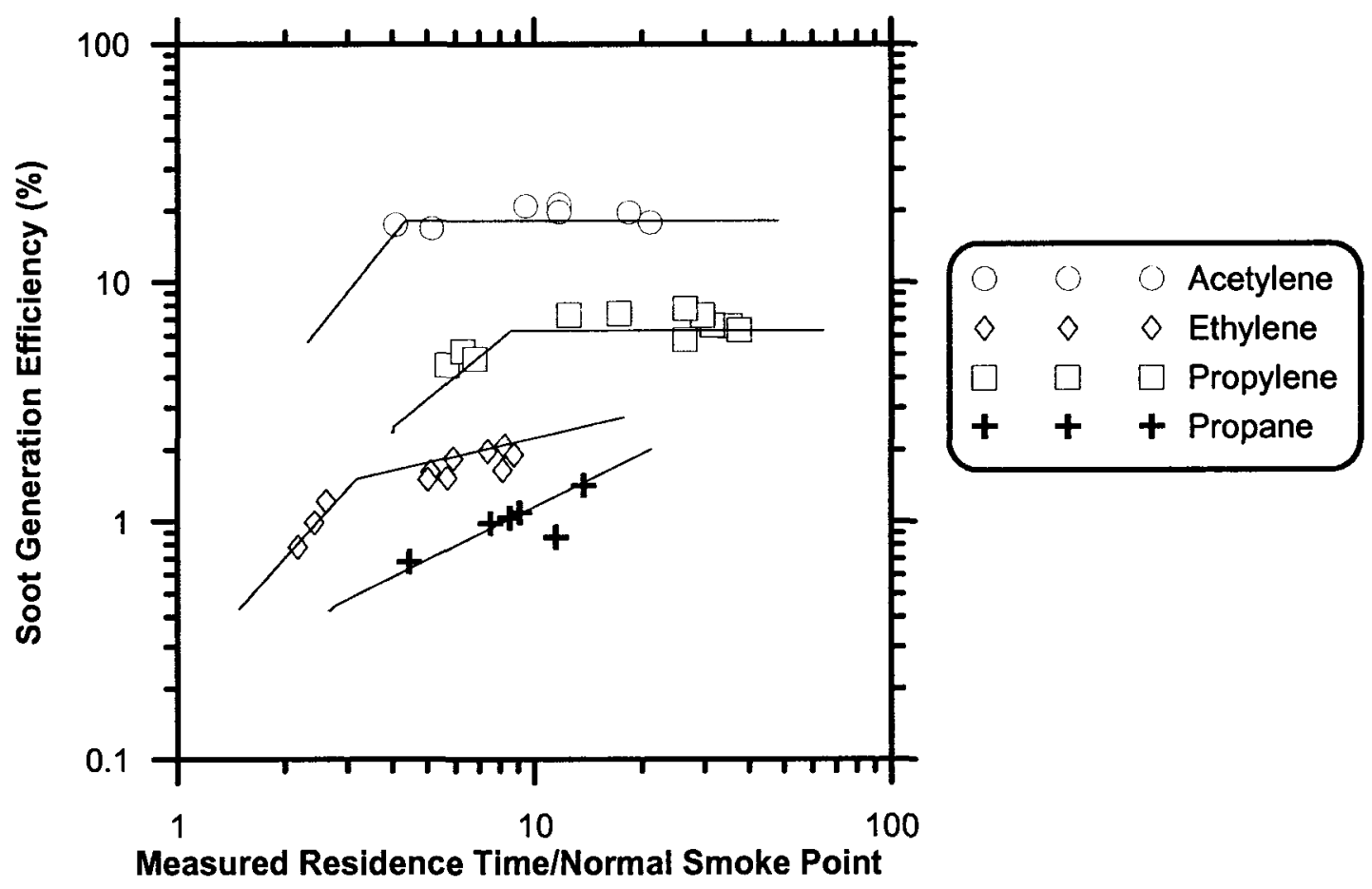

Figure 2.3: Scaling soot generation efficiency with residence time [36]

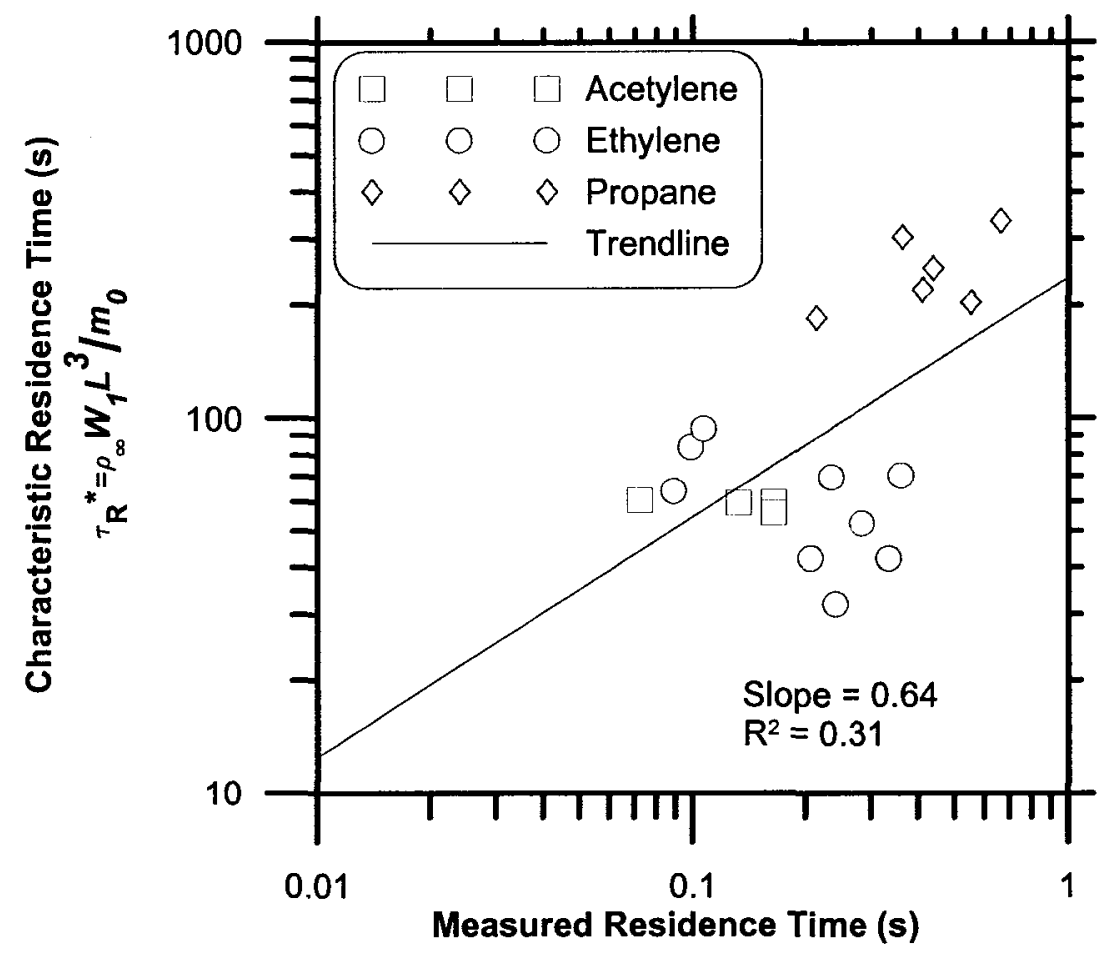

Figure 2.4: Characteristic residence time compared with measured residence time using Sivathanu data [36] 
Ignoring the difference of magnitude in Figure 2.4 it can be seen that the calculated residence time tends to under-predict the actual residence time and may not be an appropriate scaling parameter for all conditions. Sivathanu and Faeth [26] suggest that Becker and Liang's [27] characteristic residence time may not apply at long residence times as the scaling laws change when buoyant jet flame conditions are approached. Sivathanu and Faeth [26] observed a decrease in their measured residence time on their smallest diameter burner ( $5 \mathrm{~mm}$ burner) when fuel flow rates were increased.

From an industry perspective, it is not practical to measure residence time in the field. Therefore, the measured residence time must be related to other parameters which are known in the field, such as the flow rate and burner exit diameter. A useful parameter to accomplish this could be the Froude number, defined as,

$$
F r=\frac{\text { momentum }}{\text { buoyancy }}=\frac{u_{o}}{\sqrt{g \cdot d}}
$$

where, $u_{o}$ is the burner exit velocity

This is similar to the Richardson ratio given by Becker and Liang [27] but does not include the flame length. However, Delichatsios [21] gathered flame length data from numerous published sources and showed that the flame length scales with the Froude number and therefore could be a good measure of the Richardson ratio. The data from Sivathanu [36] was used to create Figure 2.5 which compares the Froude number and the measured residence time. 


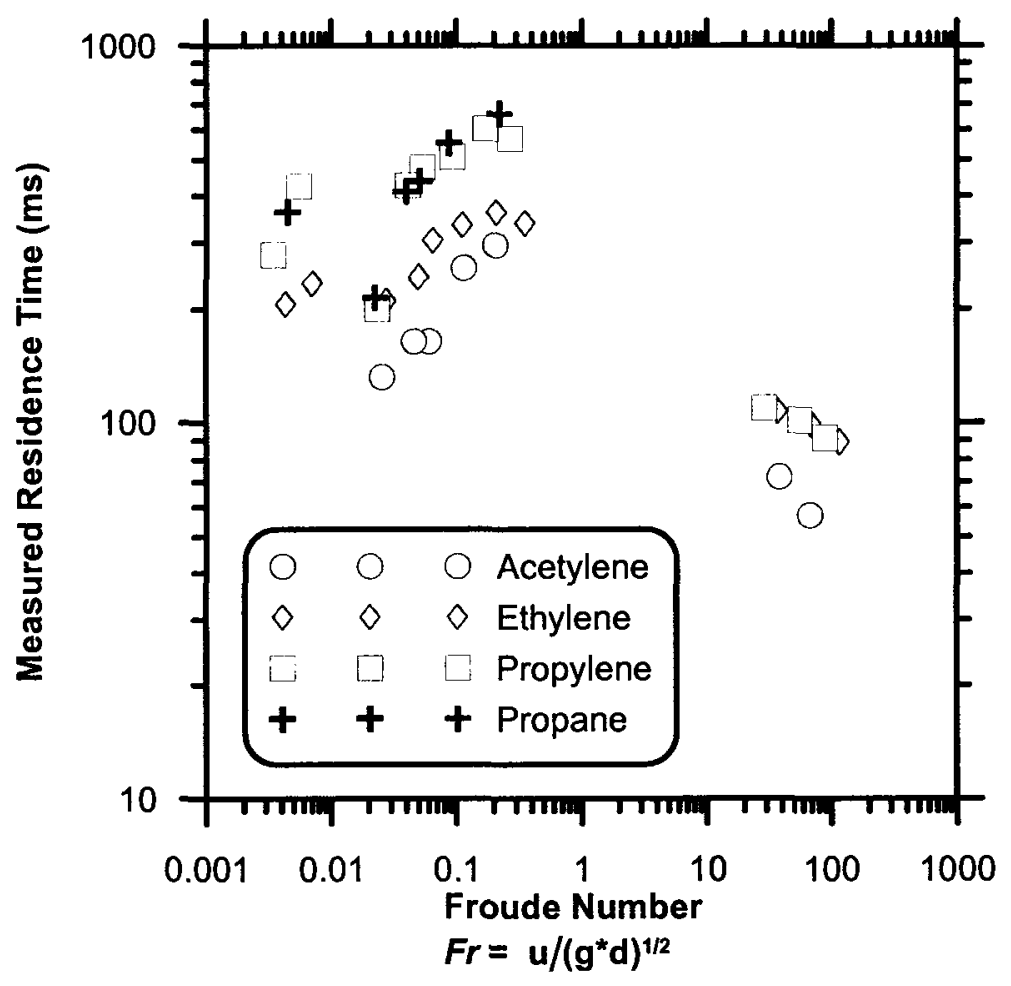

Figure 2.5: Comparison of Froude number and measured residence time from Sivathanu data [36]

\begin{abstract}
Although there is not enough data to draw any definite conclusions, it appears that the measured residence time increases with Froude number until a certain point at which the trend reverses and the measured residence time begins to decrease. This could be the effect mentioned above by Sivathanu and Faeth [26] where the residence time scaling laws change at large characteristic residence times (same as large Froude numbers). The scalability of these parameters will be further investigated in Section 5.3.
\end{abstract}




\section{Chapter 3: Experimental Methodology}

The main goal in the design of the experimental setup was to create a system that could operate under a wide range of controlled conditions and be used to generate flames relevant to those of solution gas flares in the field. The experimental facilities were located at the National Research Council of Canada (NRC) and manufactured for the purpose of these experiments with the assistance of their staff.

\subsection{Turbulent Diffusion Flame Burner}

The turbulent diffusion flame burner consists of five main components: the diffuser, settling chamber, converging nozzle, turbulence generating grids, and burner exit tube (Figure 3.1). The multi-component fuel mixture enters the diffuser, which is filled with 5 $\mathrm{mm}$ glass beads to break up the incoming fuel jet and to help uniformly distribute the flow. The flow then enters a settling chamber containing three equally spaced fine mesh screens followed by a converging nozzle, which creates a uniform top-hat velocity profile upstream of the turbulence generating grid. The turbulence generating grid is placed three to five diameters from the burner exit and is used to produce a turbulent velocity profile at the burner exit which is characteristic of the fully developed pipe turbulence expected in a full-size flare. 
Different nozzles and turbulence grids can be chosen to accommodate flare exit tubes up to $76.2 \mathrm{~mm}$ in diameter. Four flare tube sizes were manufactured for these experiments with inner diameters of $12.7 \mathrm{~mm}, 25.4 \mathrm{~mm}, 38.1 \mathrm{~mm}$, and $50.8 \mathrm{~mm}$. The ratio of the inner diameter to the outer diameter of the burner exit is 0.89 , which is representative of a standard ASTM $101.6 \mathrm{~mm}$ diameter pipe used in a "typical" flare tip as was discussed in Section 1.1.1. Figure 3.2 shows representative profiles of velocity and turbulence intensity measured at the exit of the $38.1 \mathrm{~mm}$ burner. The profiles mimic those of fully developed turbulent pipe flow, and turbulent intensities in the core flow for all burners are on the order of $3-6 \%$. Further details of the turbulence measurements to characterize the burners are shown in Appendix A.

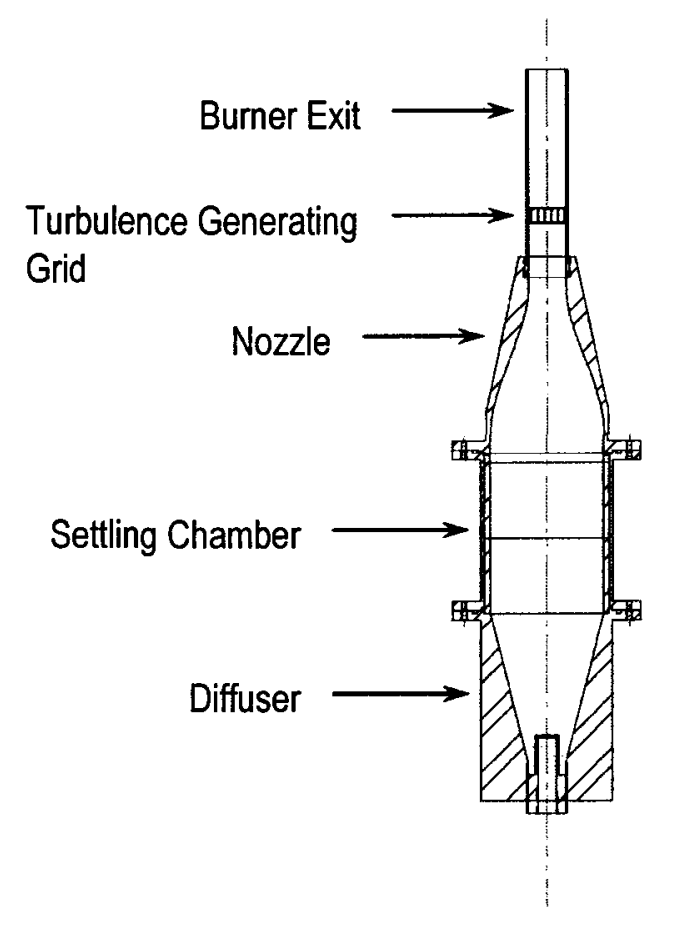

Figure 3.1: Schematic of lab-scale flare 
All fuels used were of commercially pure (99.0\%) grade. The fuel flow is controlled by Brooks 5851S thermal mass flow controllers which have a full scale accuracy of $1.0 \%$. The flow ranges for the meters are 0-60 SLPM for methane and 0-20 SLPM for ethane and propane. The flow controllers were calibrated with nitrogen at the factory; therefore, a new calibration was conducted with the fuel of interest using a bubble flow meter. The factory calibrations proved accurate for the rated gases, so these calibration factors have been used. After exiting the flow controllers, the fuel enters a $1 \mathrm{~m}$ long vertical tube filled with glass beads before entering the main fuel line to the burner. This tube ensured a uniform mixture when running multiple fuels. A test matrix of the tests conducted can be found in Appendix D.

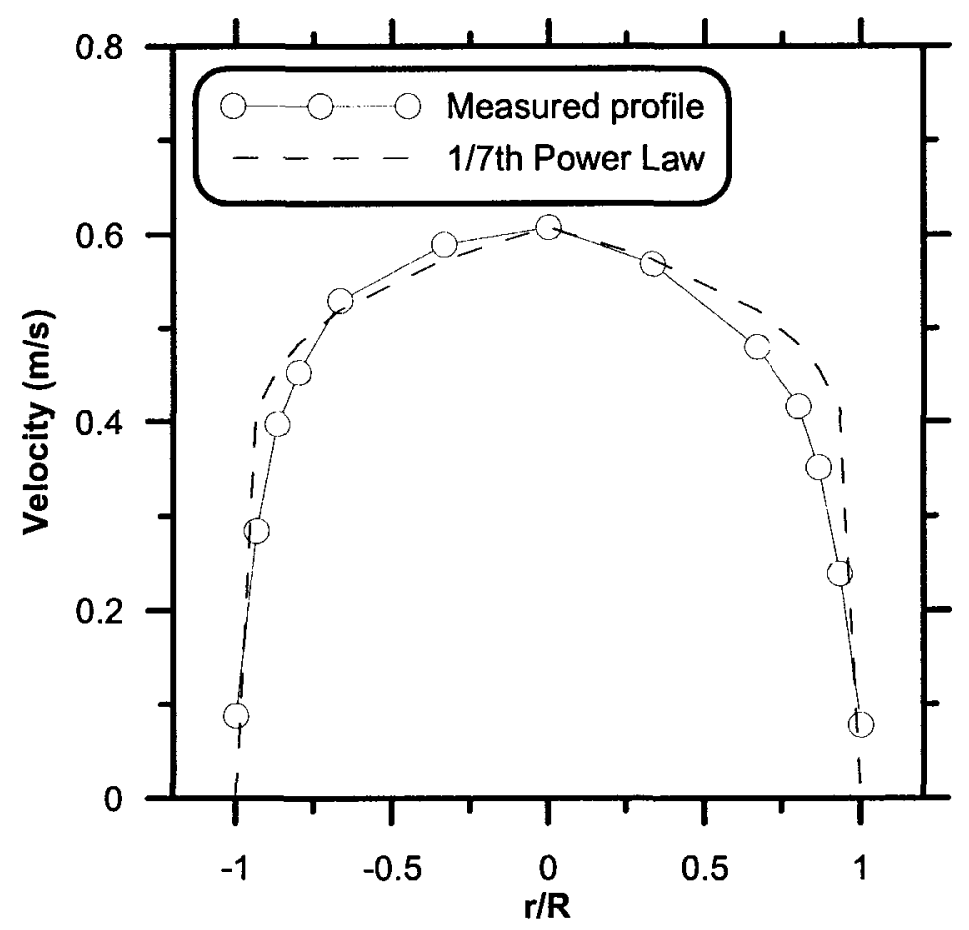

a) Velocity profile with air at flow rate of $8.0 \mathrm{e}-4 \mathrm{~kg} / \mathrm{s}$ and theoretical $1 / 7^{\text {th }}$ power law turbulent velocity profile

Figure 3.2: Radially traversed hotwire measurements for $38.1 \mathrm{~mm}$ burner exit diameter with turbulence grid using air 


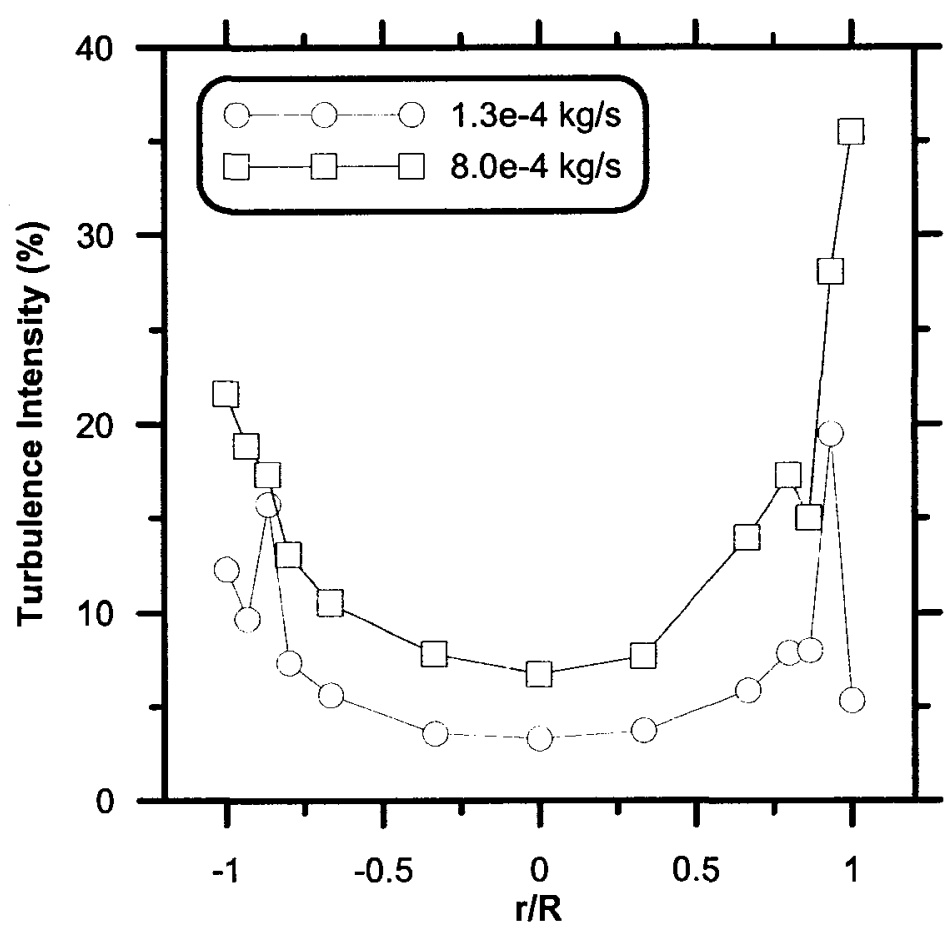

b) Turbulence intensity profile at two flow rates

Figure 3.2: Radially traversed hotwire measurements for $38.1 \mathrm{~mm}$ burner exit diameter with turbulence grid using air

\subsection{Sampling System}

The turbulent diffusion burner is situated inside an aluminum enclosure $(1.5 \times 1.5 \times 2.5 \mathrm{~m}$ high) as shown in Figure 3.3a,b. Inside the aluminum enclosure is a cylindrical wire mesh screen ( $1.0 \mathrm{~m}$ diameter, 690 wires per meter, $0.23 \mathrm{~mm}$ wire diameter), which is used to minimize disturbances to the flame. The exhaust is discharged into an insulated $152 \mathrm{~mm}$ diameter duct. The insulation reduces the temperature gradient between the duct wall and the exhaust flow, thereby avoiding particulate loss by thermophoresis (Appendix 
B), which is a phenomenon in which hot particles migrate towards cooler surfaces [37]. A $7.7 \mathrm{~mm}$ inner diameter probe samples at a single point within the duct approximately $4 \mathrm{~m}$ away from the flame. A fully mixed exhaust is required to ensure that a single point sample is representative of the entire duct. A variable iris damper was used to create a flow obstruction within the duct to promote mixing. A traverse of the duct with the sampling probe showed the exhaust was fully mixed under a wide range of operating conditions (Section 3.7.1). Deposition of soot in the sampling system is considered to be negligible as shown in Section 3.6.4.

Kittelson et al. [38] and Chang et al. [23] have shown that the sampling conditions can have an important effect on the soot particles. The dilution ratio, defined as the ratio of entrained room air to combustion product gases, and the dilution air temperature can both affect the nucleation rate and growth of ultrafine particles $(<100 \mathrm{~nm})$. Therefore, both of these variables need to be controlled in the experimental setup.

Chang et al. [23] performed tests from stationary combustion sources with natural gas fuel and suggested a dilution ratio of greater than 20 to achieve stable conditions. Kittelson et al. [38] conducted experiments with emissions from a diesel engine to measure changes in the particle number concentration and size distribution when the sampling conditions are varied. They showed that for particles in the nuclei mode $(3-30$ $\mathrm{nm}$ ) the nucleation and growth mechanism is greatly affected by small changes in the sampling conditions. The concentration of larger particles $(30-500 \mathrm{~nm})$ can also affect the nucleation and growth mechanisms, where a high concentration of large particles will 
suppress both mechanisms. However, they believe that nuclei particles account for less than $1 \%$ of the total mass of particulate emissions. Kittelson et al. [38] suggest having a dilution ratio greater than 200 to freeze coagulation for diesel soot emissions. Both authors $[23,38]$ also showed that the exhaust gas temperature can have an effect on the size distribution; however, the temperatures used in their experiment were considerably higher $(\sim 100-300 \mathrm{~K}$ higher) than those experienced in the present experiments.

Samples were drawn through a heated sample line and analyzed by a laser-induced incandescence (LII, Artium Technologies) system, which measures the soot volume fraction and effective primary particle size. A scanning mobility particle sizer (SMPS, DMA Model 3080, CPC Model 3025A, TSI) was also used to measure the number concentrations and electric mobility diameter of particles ranging from $15 \mathrm{~nm}$ to $673 \mathrm{~nm}$ during a 120 second scan time. SMPS measurements were conducted for a limited range of conditions only as outlined in Appendix C. The dilution ratio (Section 3.6) is controlled by a variable speed fan. As explained below in Section 3.6.3, the dilution ratio for an experiment could be determined using either an $\mathrm{O}_{2}$ Analyzer (Siemens, OXYMAT 6) or an averaging pitot-static probe (OMEGA, FPT-6160). 


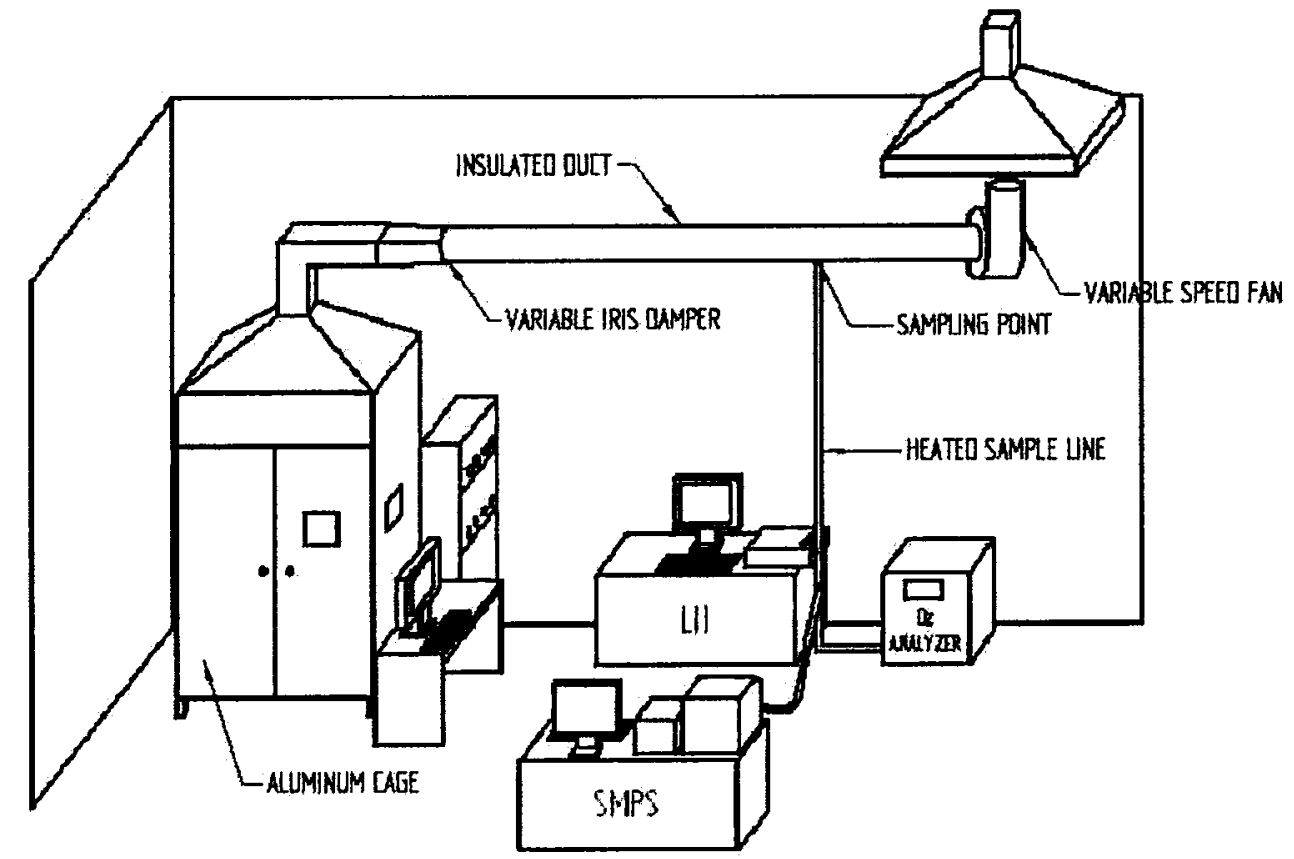

a) Schematic of overall experimental setup
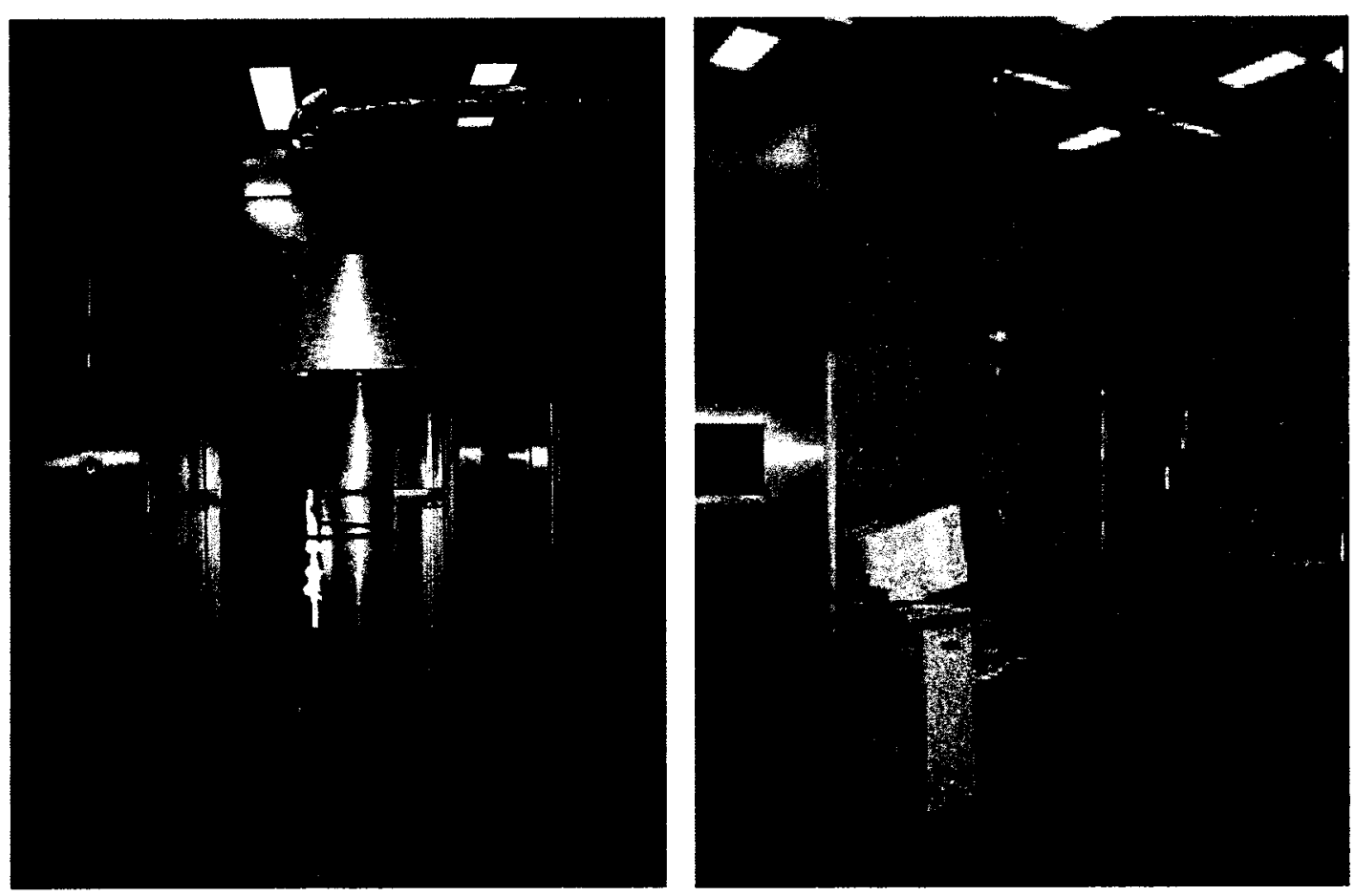

b) Pictures of the flame enclosure and sampling system

Figure 3.3: Sampling system schematic 


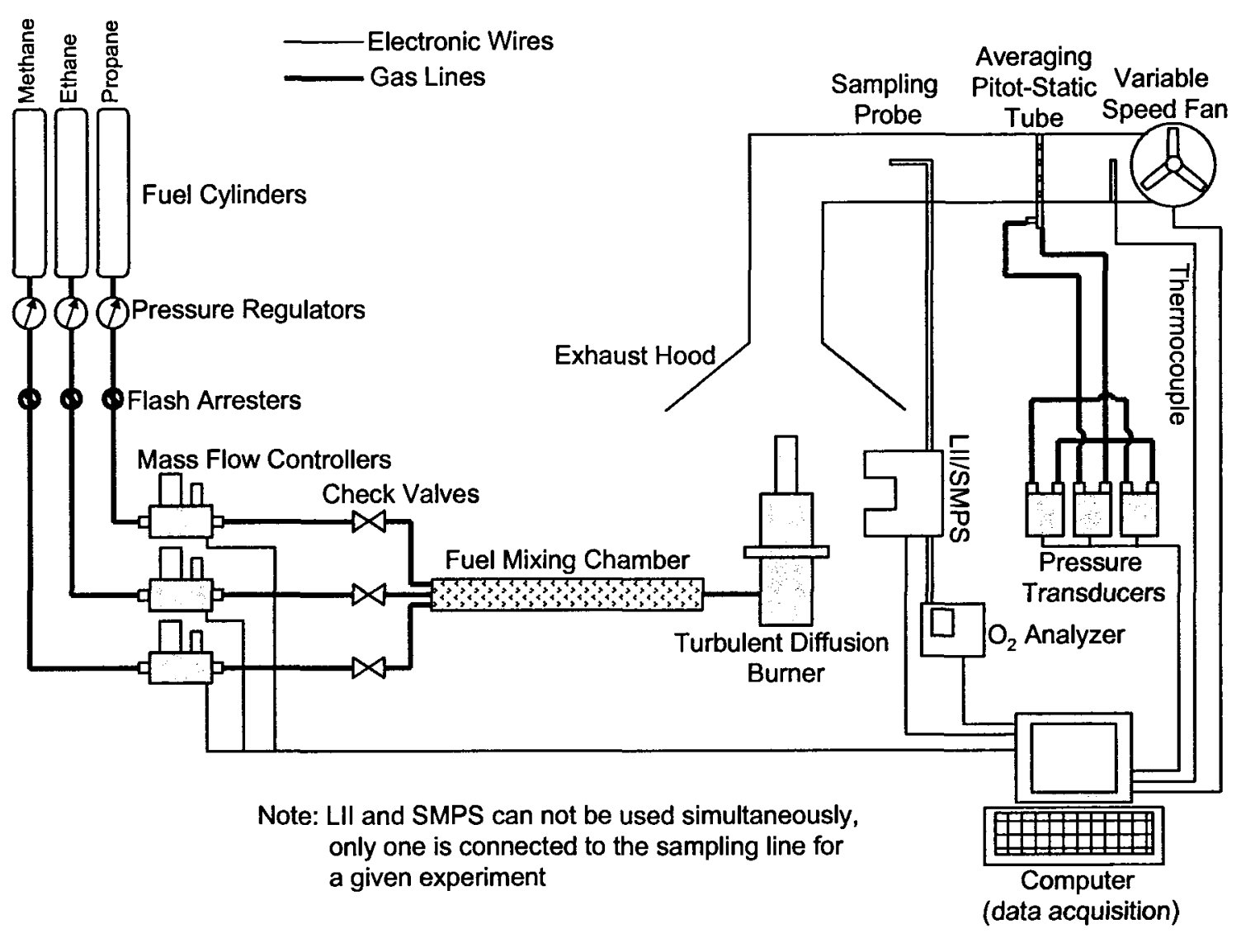

c) Detailed schematic of experimental setup

Figure 3.3: Sampling system schematic

\subsection{Laser Induced Incandescence (LII)}

LII works on the principle of measuring the incandescence of heated soot particles. A pulsed laser rapidly heats the soot in a gas path to near its sublimation temperature (4000$4500 \mathrm{~K})$. As the particles cool, their incandescence is measured and related to the soot volume fraction. A self-calibrating LII system is used in this experimental setup with the details described in Snelling et al. [39]. Briefly, soot incandescent emission is measured at two wavelengths by photomultiplier tubes equipped with narrowband interference filters $(400 \mathrm{~nm}, 780 \mathrm{~nm})$. From the measurement of incandescence at two wavelengths, 
the soot particle temperature and soot volume fraction are determined. The advantage of LII is that it is essentially a non-intrusive diagnostic that can make real-time measurements of soot at up to $20 \mathrm{~Hz}$ [19]. Figure 3.4 shows a schematic of the LII system used in this experimental setup.

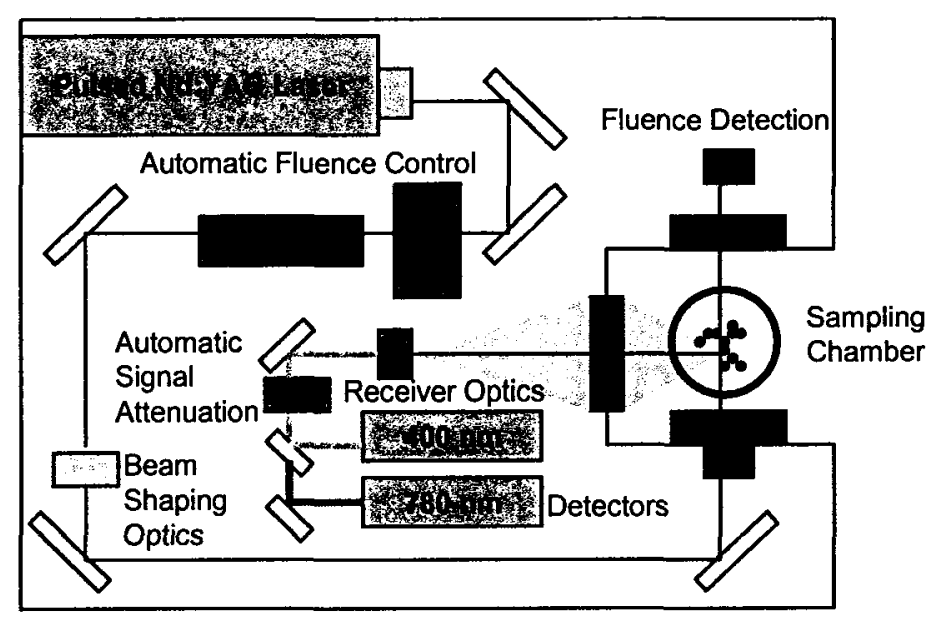

Figure 3.4: LII schematic

The soot volume fraction is expressed as [39],

$$
f_{v}=\frac{V_{E X P}}{\eta \omega_{b} G_{E X P} \frac{12 \pi c^{2} h}{\lambda_{c}^{6}} E\left(m_{\lambda_{c}}\left[\exp \left(\frac{h c}{k \lambda_{c} T_{p}}\right)-1\right]^{-1}\right.}
$$

where, $c$ is the speed of light

$h$ in the Plank constant

$k$ is the Boltzmann constant

$V_{E X P}$ is the experimental voltage signal 
$w_{b}$ is the laser sheet thickness

$\eta$ is the calibration factor

$G_{E X P}$ is the experimental detector gain

$E\left(m_{\lambda}\right)$ is the absorption function

$\lambda$ is the wavelength

$T_{p}$ is the particle temperature

The majority of the variables listed above are either known or measured via LII. Two variables of particular importance, especially for the uncertainty analysis, are $E(m)$ and $T_{p}$. The refractive index function $E(m)$, which quantifies the propensity of soot to absorb radiation is dependent on wavelength. There is some uncertainty in the literature regarding the correct magnitude and spectral variation as will be discussed in Section 3.7. The particle temperature is found by relating the ratio of the soot particle incandescence intensities at two wavelengths, $\lambda_{1}$ and $\lambda_{2}$, as shown in the expression below [39].

$$
T_{p}=-h c \frac{\lambda_{2}-\lambda_{1}}{\ln \left(\frac{V_{E X P 1} \cdot \eta_{2} \cdot G_{E X P 2} \cdot \lambda_{1}^{6} \cdot E\left(m_{2}\right)}{V_{E X P 2} \cdot \eta_{1} \cdot G_{E X P 1} \cdot \lambda_{2}^{6} \cdot E\left(m_{1}\right)}\right) \cdot k \lambda_{1} \lambda_{2}}
$$

As seen in Eq. (3.2), $T_{p}$ is dependent on the ratio of $E\left(m_{2}\right)$ to $E\left(m_{1}\right)$.

\subsection{Flame Imaging}

Numerous methods have been used to determine flame height for turbulent flames. Becker and Liang [40] visually observed the luminous flame height. Heskestad [41] 
believes this method can result in overestimating the flame height, as the human eye can not observe the pulsations of the flame. An example of the pulsations observed in our turbulent diffusion flame is shown in Figure 3.6. Sivathanu and Faeth [26] took 100 still photographs over a 5-10 s period and took the average luminous flame height. Kalghatgi $[42,43]$ has used two methods to determine the flame height. In one experiment [42], he took five random frames from a video record and averaged their heights. In the other [43], he took three still photographs with an exposure time of $1 / 30 \mathrm{~s}$ and averaged the flame height. Again, Heskestad [41] believes the pulsation period of the flame is faster than the exposure time, which can lead to aliasing. Kostiuk et al. [44] took 200 frames over a $150 \mathrm{~s}$ period from a video record and created a mean flame image. From the mean flame image, Kostiuk et al. [44] arbitrarily defined the flame length as the distance from the burner exit tip to the $10 \%$ contour line. The method of Kostiuk et al. [44] gives accurate measurements of flame length and since the equipment was readily available, a similar approach was adopted in the current research and is described in detail below.

Video records ( $720 \times 480$ pixels interlaced, $30 \mathrm{fps})$ of the flame were taken and converted to digital files on a computer. An estimate of the pulsation time is determined by looking at the individual frames. An appropriate sampling time is selected once the pulsation time is known so that aliasing can be prevented. After the sampling time is chosen, a study is done to determine how many frames are needed to give consistent results. Figure 3.5 shows how the calculated flame height changes with the number of frames used. The repeatability can be quite poor at a low number of frames as shown by the spread in the data points for a given number of frames. However, the flame height begins to converge 
at approximately 140 frames. Similar results were demonstrated for the flame width, perimeter, and area calculations. Therefore, a sample should have at least 140 frames in order to give an accurate result with a standard error less than $1.0 \%$.

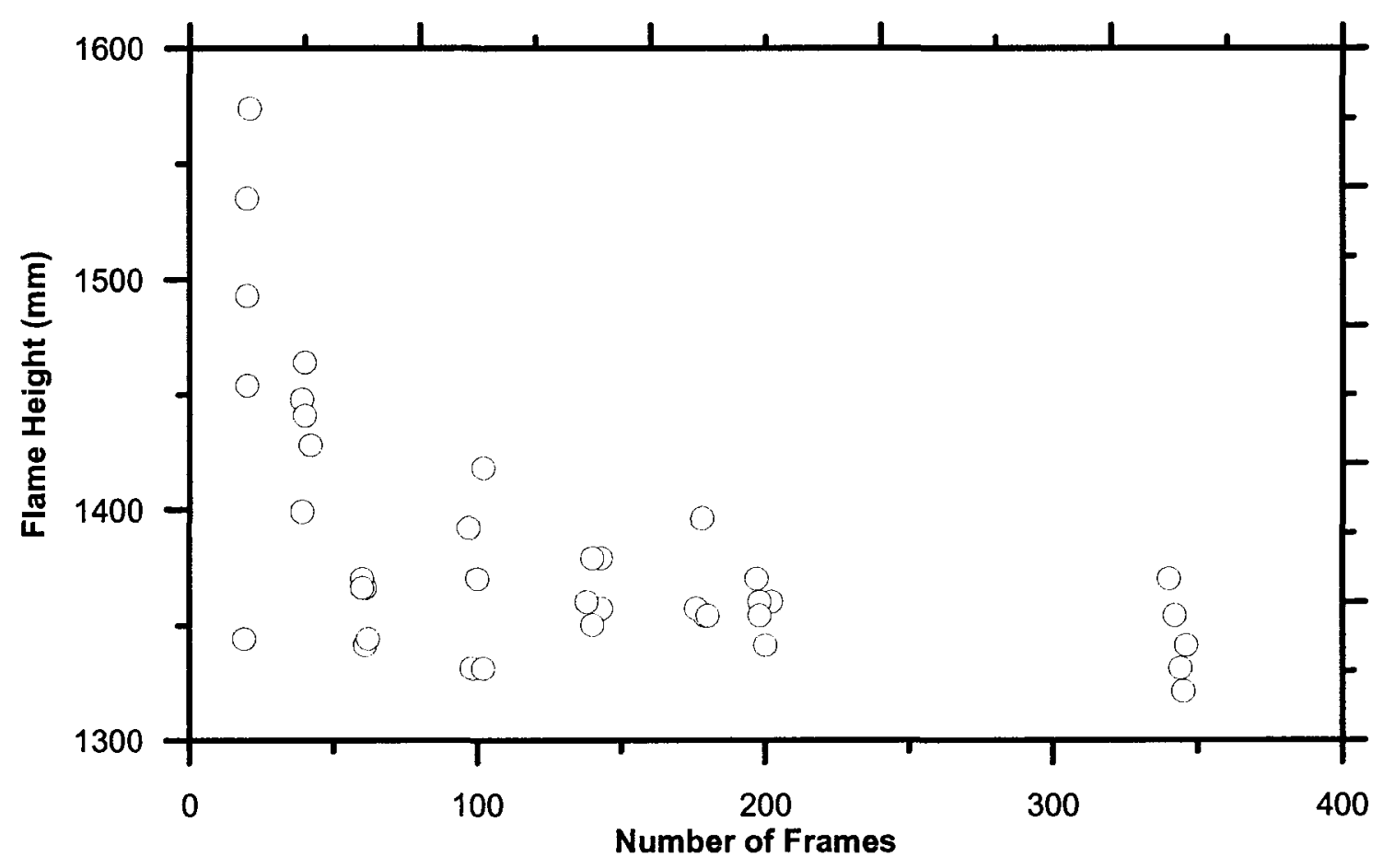

Figure 3.5: Repeatability test for flame length using different number of frames

A LabVIEW routine was written to determine the flame height, maximum flame width, flame perimeter, and flame area from the video clips. To create the mean flame image, the sampling time is used to establish a time "window" from which the LabVIEW program will randomly select an individual frame from the video clip to avoid aliasing. For example, if the sampling time is $0.3 \mathrm{~s}$, then the first time window is from 0 to $0.3 \mathrm{~s}$, the second is from 0.3 to $0.6 \mathrm{~s}$ and so forth until the end of the video clip is reached. The images are then converted to 8-bit grayscale images which have a pixel intensity range from $0-256$. A threshold ranging from 80 to 120 is applied to the individual images, 
which allows the flame to be separated from the background in each frame. If the pixel intensity is below this selected threshold value, it is assigned a value of zero, whereas if the pixel intensity is above the threshold value it is assigned a value of one. By assigning values of zero and one to the individual pixels, binary images (Figure 3.7b) are created which are then summed to create a mean flame image. The intensity of a pixel in the mean flame image represents the probability of finding flame in that pixel and can be shown as a contour plot (Figure 3.8). The LabVIEW routine was programmed to give the flame geometry at the desired contour line (Figure 3.7c). The maximum flame width is also measured from the contour image and the flame perimeter and area can be calculated using a Particle Analysis function found in the LabVIEW Vision software. The function is applied to the individual binarized images used to create the mean image and then averaged to give a flame perimeter and area. It should be noted that the black band which appears in the $\mathrm{t}=0.13 \mathrm{~s}$ and $0.20 \mathrm{~s}$ in Figure 3.6 was caused by an aluminium strip in the middle of the mesh screen surrounding the flame. An interpolation was used on the flame images to fill in the space where flame would be to minimize error in the flame perimeter and area calculations.

Another possible cause of error occurred when reading the digital AVI files into LabVIEW. It appeared that two sequential frames were being interlaced together. To correct for this problem, the even and odd fields were separated from each frame with the odd field being discarded. However, this resulted in the frame resolution being reduced to $720 \times 240$ pixels, which would yield incorrect results for flame width, perimeter, and area. A built-in LabVIEW bi-linear interpolation function was used to restore the image 
to a resolution of $720 \times 480$ pixels. Since a large number of frames were used for the flame geometry calculations, the effect of lowered resolution through only using the even field should be negligible on the overall results.
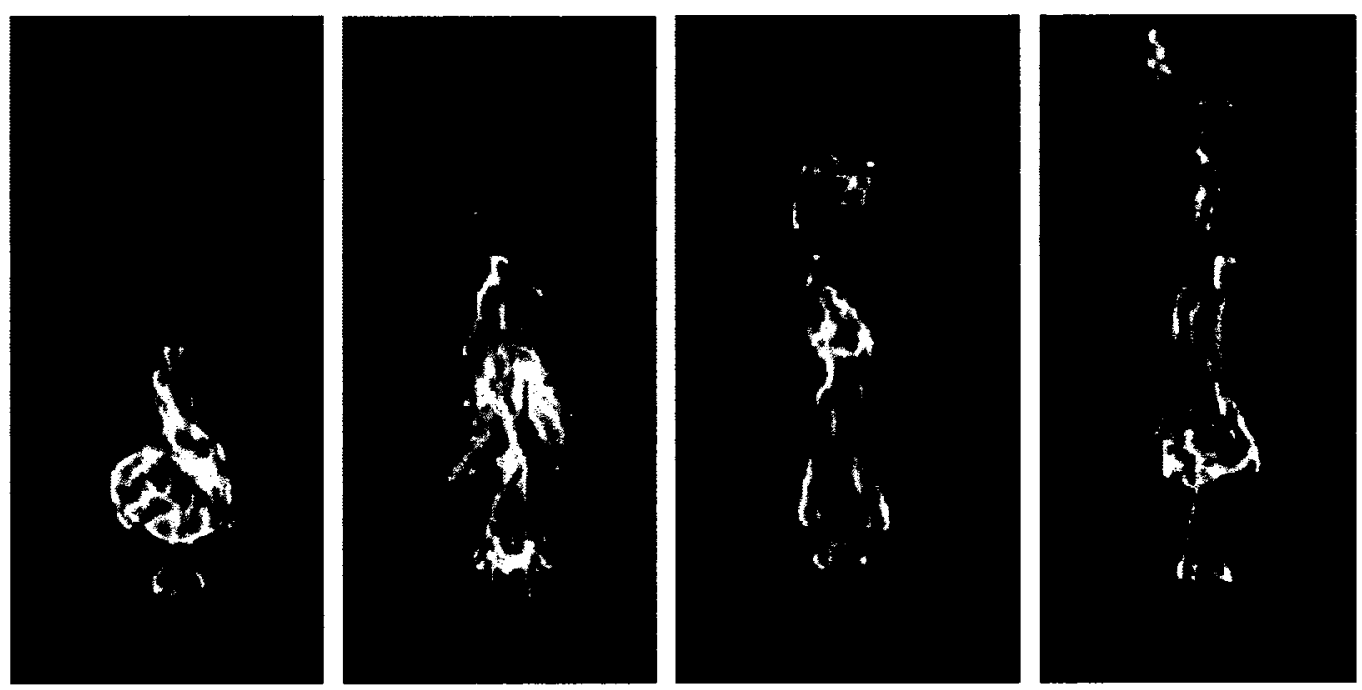

$\mathbf{t}=\mathbf{0 . 0} \mathrm{s}$

$\mathbf{t}=0.13 \mathrm{~s}$

$\mathbf{t}=\mathbf{0 . 2 0 s}$

Figure 3.6: Four sequential frames from video of methane flame at flow rate of $2.8 \mathrm{e}-4 \mathrm{~kg} / \mathrm{s}$

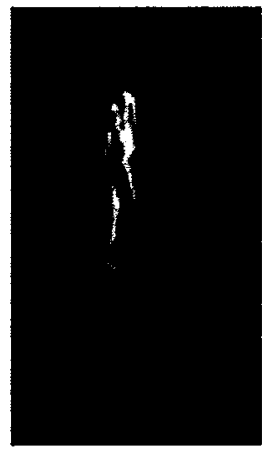

a)

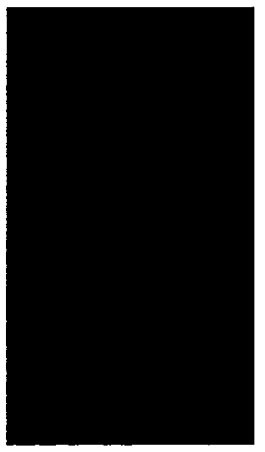

b)

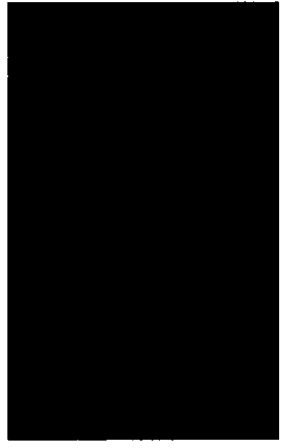

c)

Figure 3.7: a) flame image from single video frame b) binarized flame image c) $10 \%$ contour flame image over 1 minute sample 


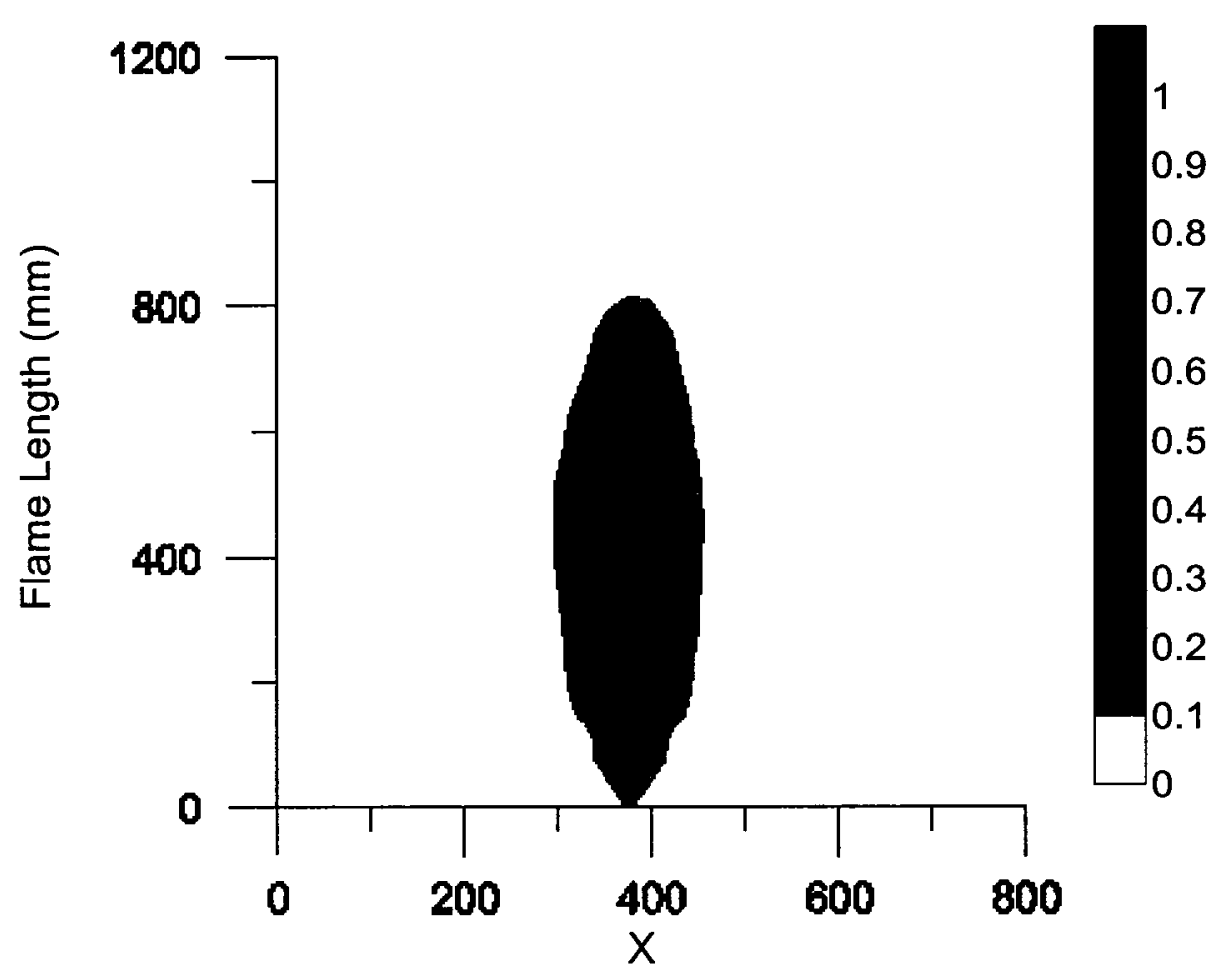

Figure 3.8: Mean flame image ( 0 indicates a $0 \%$ probability of finding flame in the pixel and 1 indicates a $100 \%$ probability)

\subsection{Soot Yield Equations}

Soot emissions are best quantified on a mass of soot per mass of fuel basis, known as soot yield $\left(Y_{s}\right)$, or soot generation efficiency $(S G E)$ which is the mass of soot per mass of carbon in the fuel and has been used by many authors [26, 27]. However, the LII gives a measurement of soot volume fraction $\left(f_{v}\right)$ which is a volume of soot per volume of sample air. The following equations outline the sampling protocol that was developed to determine $Y_{s}$ from measured LII data. 
The soot volume fraction, $f_{v}$, in a sample drawn from the exhaust duct and measured using LII is defined as, $f_{v}=\forall_{\text {soot }} / \forall_{\text {sample }}$, where $\forall_{\text {soot }}$ is the volume of soot within the optical sample volume, $\boldsymbol{H}_{\text {sample }}$. For iso-kinetic sampling from fully mixed conditions in the exhaust duct, this is equivalent to $f_{v}=Q_{\text {soot }} / Q_{\text {duct }}$, where $Q_{\text {soot }}$ and $Q_{\text {duct }}$ are the volume flow rates of soot and gases through the exhaust duct. Since the soot particles are demonstrated to be extremely small $(<1 \mu \mathrm{m})$, the requirement for iso-kinetic sampling is not at all critical as the particles will readily track the flow into the sample probe. More detailed estimates of the potential for sampling losses are described in Section 3.7.3 and Appendix C. Although the sample is drawn through a heated line, if the temperature at the LII measurement location differs from the temperature at the sample point in the duct, the change in gas volume of the sample must also be considered. Assuming ideal gas behaviour, the measured soot volume fraction is related to conditions in the duct via Eq. (3.3).

$$
f_{v, \text { duct }}=\frac{Q_{\text {soot }}}{Q_{\text {duct }}}=f_{v, \text { sample }}\left(\frac{T_{\text {sample }}}{T_{\text {duct }}}\right)
$$

If we assume that all of the measured soot originates from the flare, then if the volume flow rate in the duct can be determined, the mass emission rate of soot can be calculated as,

$$
\dot{m}_{\text {soot }}=\rho_{\text {soot }} \cdot f_{v, \text { duct }} \cdot Q_{\text {duct }}
$$


Combining Eq. (3.3) with Eq. (3.4), the soot yield is given as,

$$
Y_{s}=\frac{\dot{m}_{\text {soot }}}{\dot{m}_{\text {fiul }}}=\frac{\rho_{\text {soot }} \cdot f_{v, \text { sample }} \cdot Q_{\text {duct }} \cdot T_{\text {sample }}}{\dot{m}_{\text {fuil }} \cdot T_{\text {duct }}}
$$

The duct flow rate can be measured using a device such as an orifice plate or averaging pitot-static tube. However, the dilution ratio $(D R)$ of combustion products in the duct needs to be monitored as part of establishing a reliable soot sampling protocol $[23,38]$. Therefore, another approach to determining $Q_{d u c t}$ can be found by using the measured dilution ratio and calculated flow of combustion products $\left(Q_{\text {products }}\right)$ from the flare. By measuring oxygen concentrations in the exhaust duct and in the ambient room air, the dilution ratio can be determined as follows,

$$
D R=\frac{\left[\mathrm{O}_{2}\right]_{\text {duct }}}{\left[\mathrm{O}_{2}\right]_{\text {room air }}-\left[\mathrm{O}_{2}\right]_{\text {duct }}}-1=\frac{\boldsymbol{Q}_{\text {duct }}}{\boldsymbol{Q}_{\text {products }}}-1
$$

The ambient-temperature flow rate of combustion products is calculated by balancing the stoichiometric hydrocarbon combustion reaction equations assuming complete combustion. The potential uncertainty associated with assuming complete combustion is insignificant as shown below. The actual volume flow rate of mixed dilution air and combustion products through the exhaust duct is calculated as follows,

$$
Q_{\text {duct }}=\left[\left(Q_{\text {products }} \cdot D R\right)+Q_{\text {products }}\right] \frac{T_{\text {duct }}}{T_{\text {ambient }}}
$$


Combining Eq. (3.3) with Eqs. (3.4 and 3.7), the mass flow rate of soot from the flare is calculated as,

$$
\dot{m}_{\text {soot }}=\rho_{\text {soot }} \cdot f_{v, \text { sample }} \cdot Q_{\text {products }}(D R+1) \frac{T_{\text {sample }}}{T_{\text {ambient }}}
$$

which relates to the soot yield as,

$$
Y_{s}=\frac{\dot{m}_{\text {soot }}}{\dot{m}_{\text {fitel }}}=\frac{\rho_{\text {soot }} \cdot f_{v, \text { sample }} \cdot Q_{\text {products }} \cdot(D R+1) \cdot T_{\text {sample }}}{\dot{m}_{\text {fitel }} \cdot T_{\text {ambient }}}
$$

\subsection{Sampling Protocol}

\subsubsection{Sampling Duct Conditions}

Due to the large volume of data collection planned for these experiments, the decision was made to sample at a single point in the duct instead of traversing the duct and averaging the result for each test. A probe-rake was also deemed unacceptable as there is the potential for increased sample losses. However, sampling at a single point requires a fully mixed sample with a uniform soot concentration. Tests were conducted in which the probe was traversed vertically across the diameter of the duct at expected running conditions (i.e. fuel flow rate and dilution ratio) for methane and propane. Figure 3.9 shows the result for the propane test. The standard error between the soot volume 
fraction test values at the different probe heights is less than $1 \%$ for the propane test and $4 \%$ for the methane test. From these results, the soot in the duct was considered to be fully mixed.

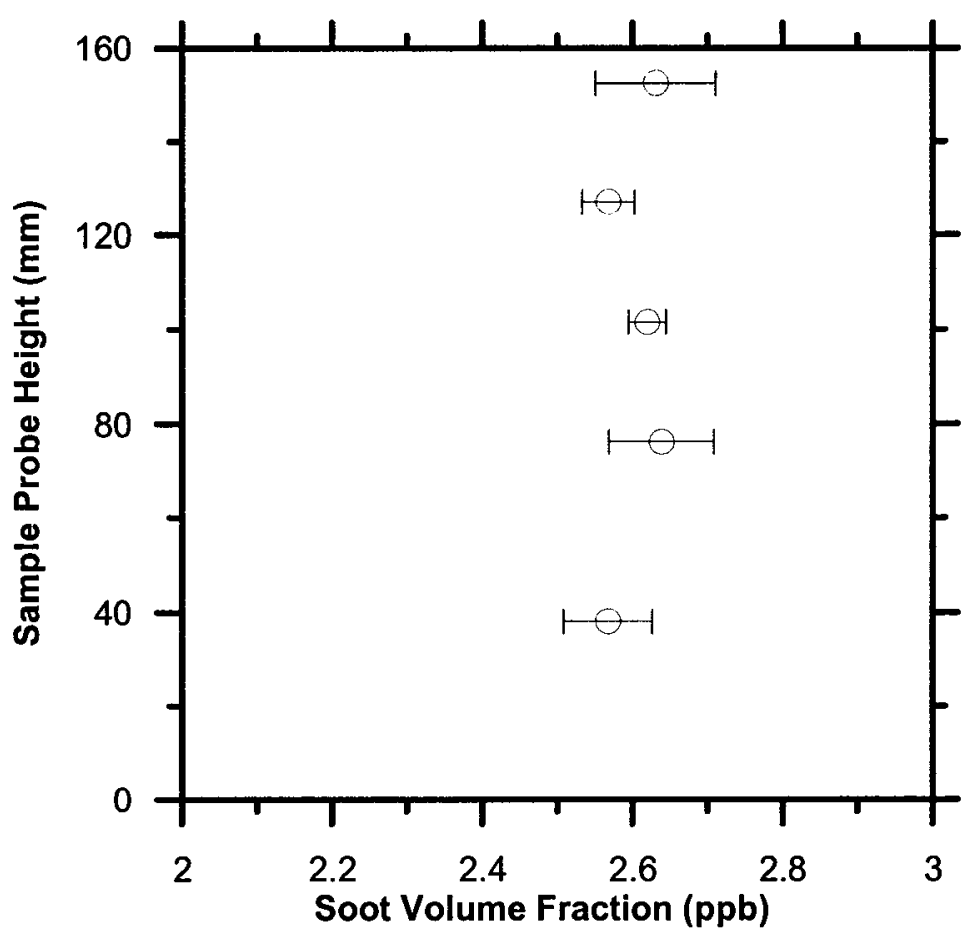

Figure 3.9: Soot concentration across diameter of duct for propane at flow rate of 1.6e-4 $\mathrm{kg} / \mathrm{s}$

\subsubsection{Sampling Time}

A repeatable trend in the data was found after running numerous tests for long time intervals. Figure 3.10 is a characteristic sample of data with several important features to note. The soot volume fraction has a sharp increase in the first two minutes following the lighting of the burner (i.e. time zero is the flame start time). This sharp rise is attributed 
to the heating of the burner exit as shown in Figure 3.11. After this period, $f_{v}$ begins to level-off.

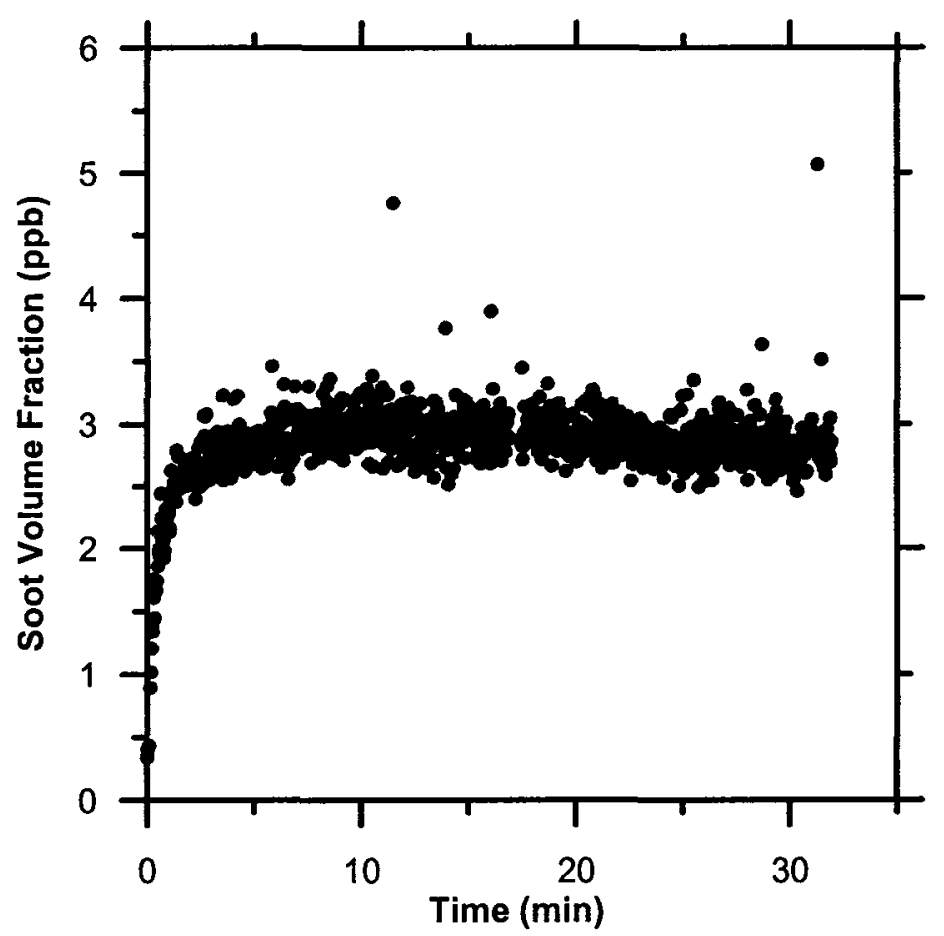

Figure 3.10: Typical soot volume fraction data for propane burning at $1.6 \mathrm{e}-4 \mathrm{~kg} / \mathrm{s}$ with 25.4 mm burner

A small sampling time is desirable due to the large number of test conditions that are required for this experiment. To ensure an adequate start time and sampling time are applied to all test conditions, proper definitions of these two variables are required.

The start time is defined as the time the slope of a line fit to the latest $30 \mathrm{~s}$ of data becomes negative. This ensures that the "warm-up" effects of start-up are no longer present. It also allows the test to start sooner than if a fixed start time is applied to all test 
conditions which would be conservatively selected due to the variability of the "warmup" period for different test conditions (Figure 3.12).

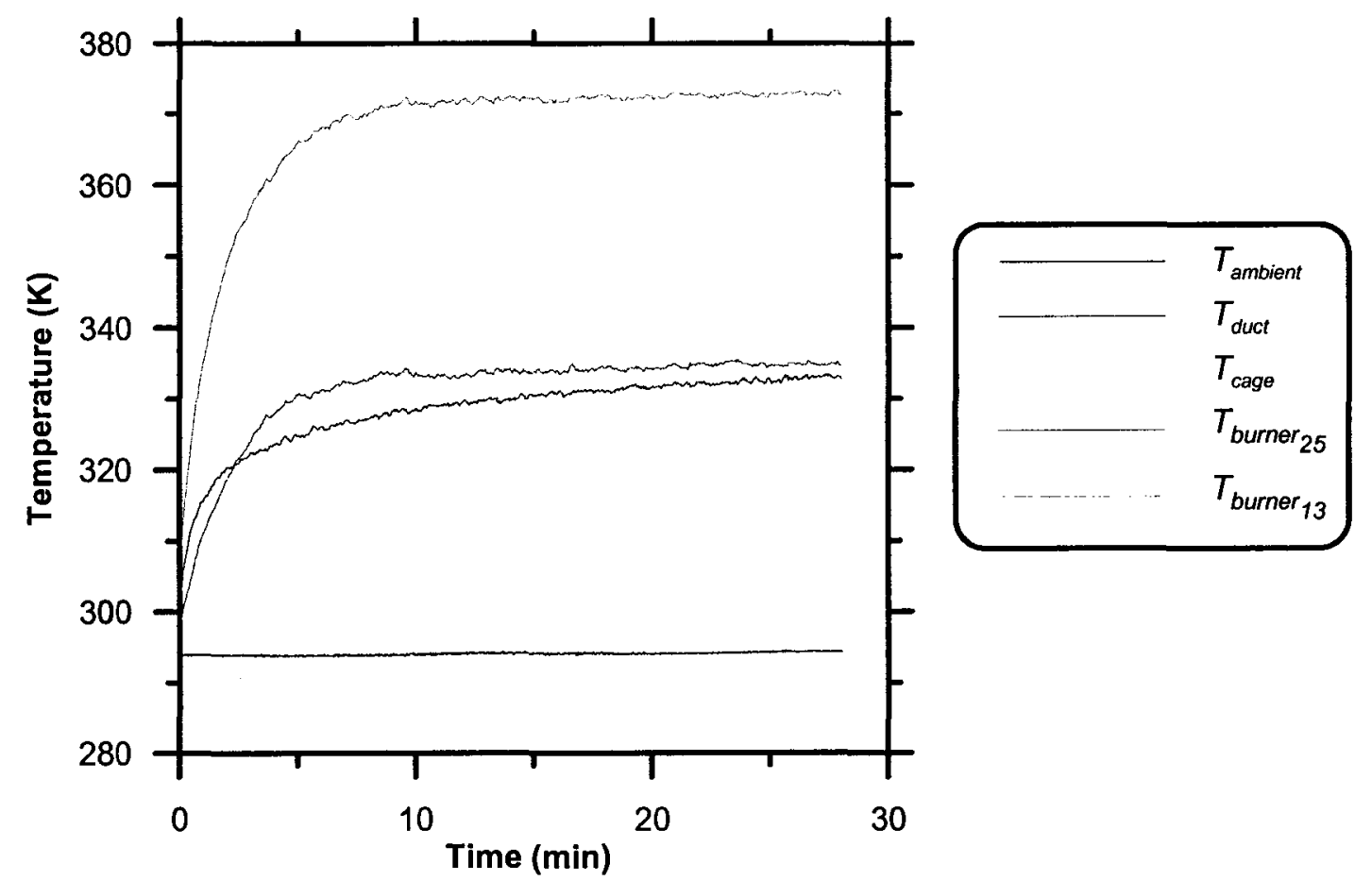

Figure 3.11: Temperatures of ambient room temperature $\left(T_{\text {ambient }}\right)$, inside the sampling duct $\left(T_{\text {duct }}\right)$, inside the aluminum enclosure $\left(T_{\text {cage }}\right), 25 \mathrm{~mm}$ below the burner exit $\left(T_{\text {burner } 25}\right), 13 \mathrm{~mm}$ below the burner exit $\left(T_{\text {burner13 }}\right)$

Since there is a band of scatter in the soot volume fraction data it is not possible to take a single value of $f_{\mathrm{v}}$ at any given time. Therefore, after the start time is reached the mean of all $f_{v}$ data is taken. The sampling continues until a $99 \%$ confidence interval $(C D)$ reaches $0.3 \%$ of the mean. Although choosing a $C I$ of $0.3 \%$ is somewhat arbitrary, it is found to give an adequate sampling time and the uncertainty produced by it when compared to the overall uncertainty is negligible (Section 3.7). The sampling time varied from approximately two minutes for a fuel with a strong signal, such as propane, to ten minutes for a fuel with a weaker signal, such as methane. 


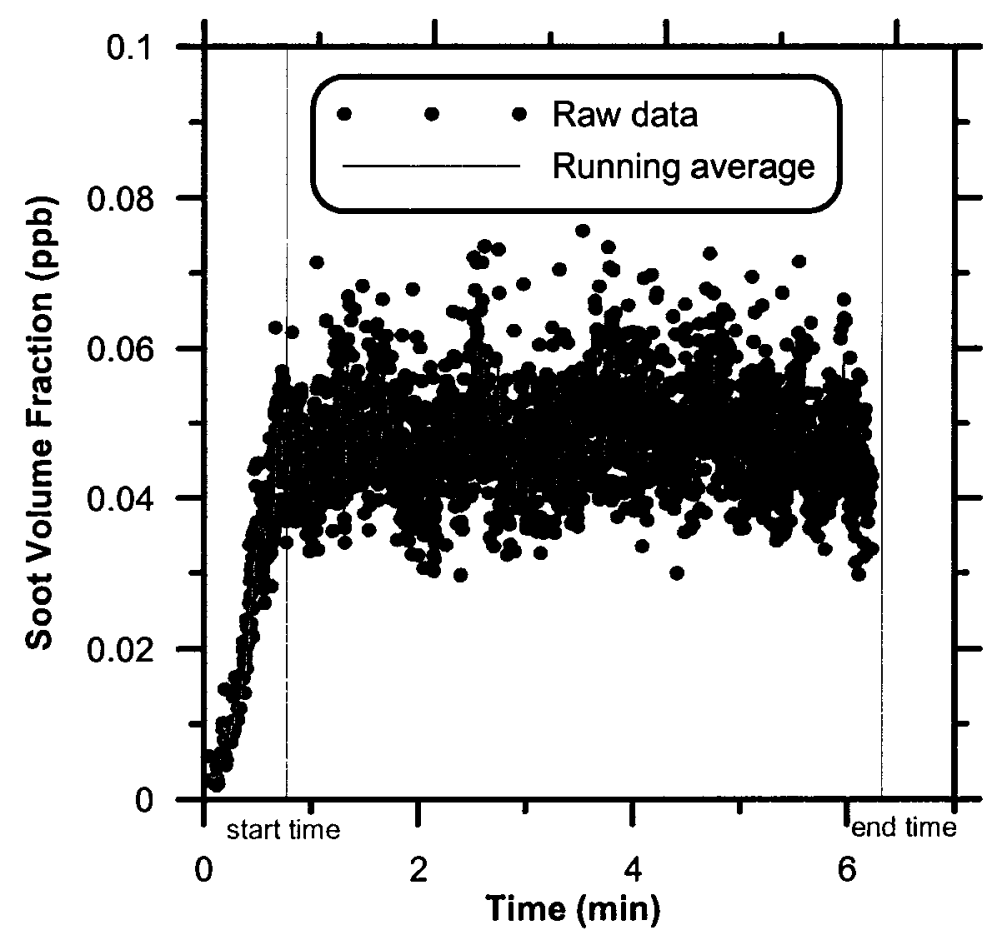

Figure 3.12: Typical soot volume fraction data for a test with $38.1 \mathrm{~mm}$ burner using methane fuel at $2.8 \mathrm{e}-4 \mathrm{~kg} / \mathrm{s}$

Occasionally it was found that anomalies (Figure 3.13) would occur in the $f_{v}$ data which caused the confidence interval to become quite large (>3.0\%) and resulted in erroneous data. These anomalies could be due to soot that was deposited on the sampling line walls being re-entrained in the sample flow. Also, the Artium LII software has a known bug which can sporadically calculate $f_{v}$ incorrectly and could be the source of these errors. It was decided to use Chauvenet's criterion to ensure these erroneous data points did not affect the data. The criterion is a statistical method which uses the normal distribution function to determine the probability of whether a given data point could have the value of the outlier data point in a data set of a particular size. Figure 3.14, shows the same data in Figure 3.13 after the Chauvenet criterion is applied to them. 


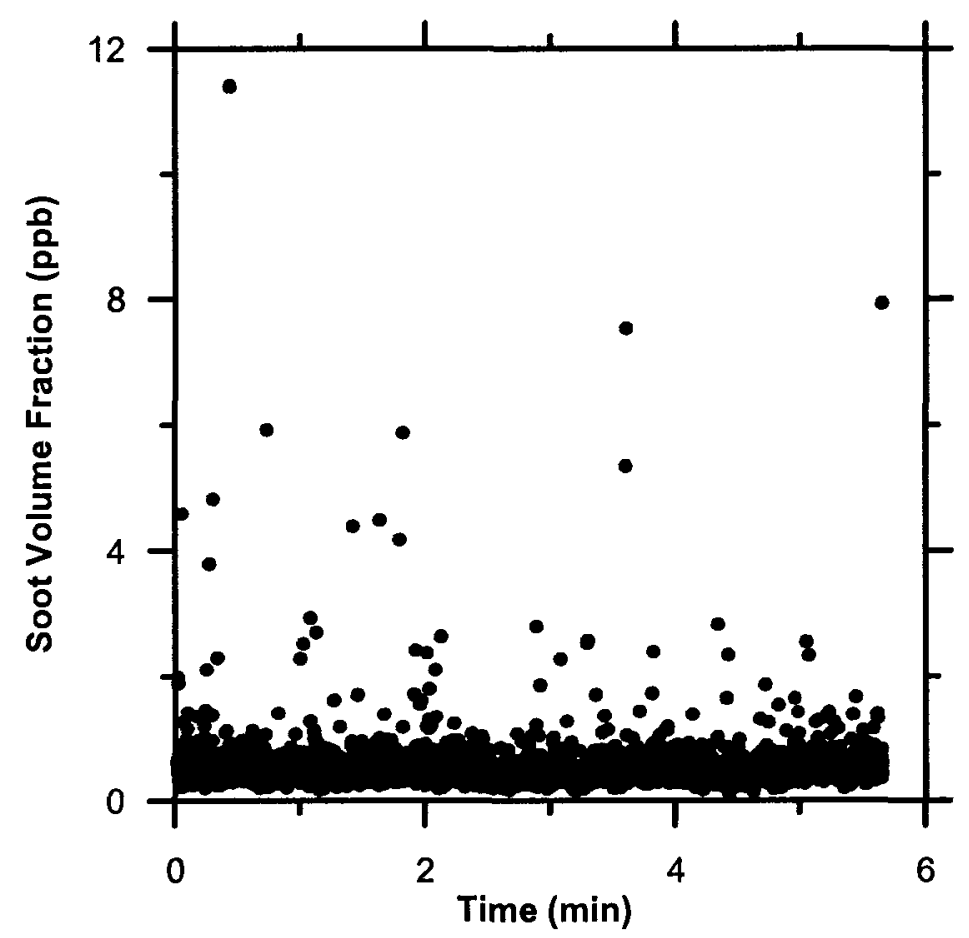

Figure 3.13: Anomalies in soot volume fraction data for ethane fuel burning at $1.5 \mathrm{e}-4 \mathrm{~kg} / \mathrm{s}$ with $12.7 \mathrm{~mm}$ burner

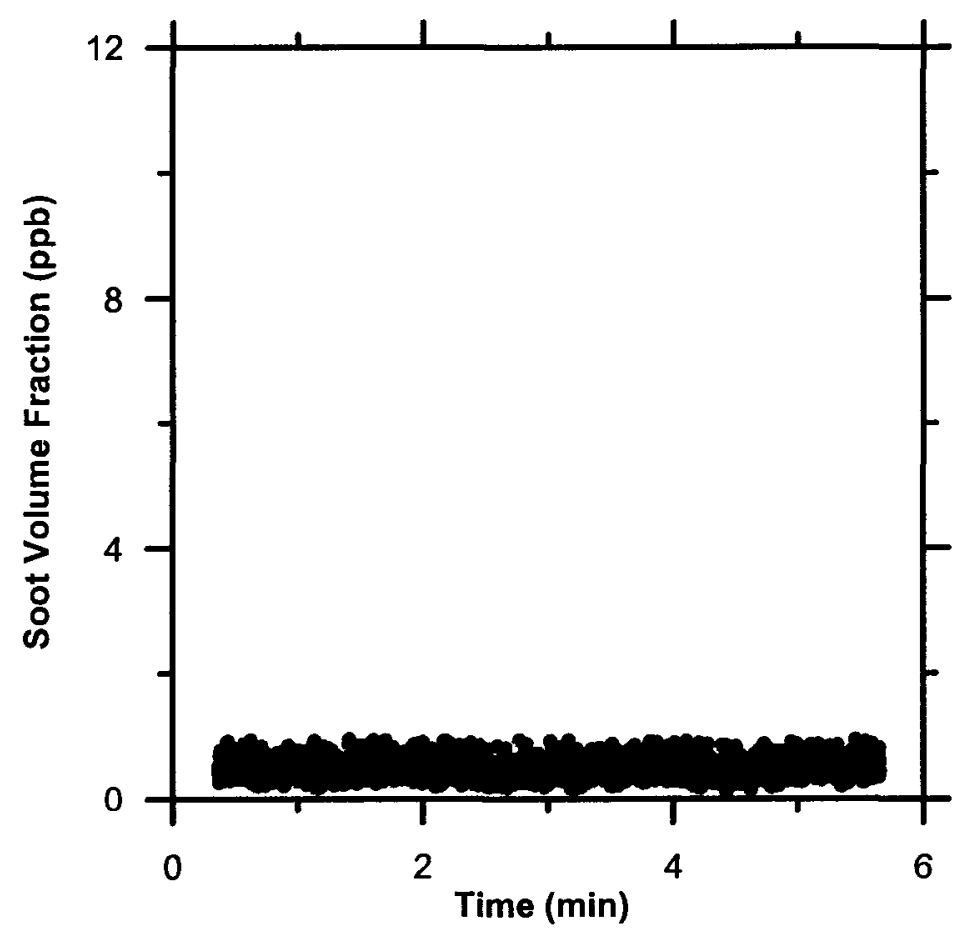

Figure 3.14: Soot volume fraction data after applying Chauvenet's criterion for ethane fuel burning at $1.5 \mathrm{e}-4 \mathrm{~kg} / \mathrm{s}$ with $12.7 \mathrm{~mm}$ burner 


\subsubsection{Dilution Ratio Measurement}

The dilution ratio $(D R)$ can be measured with either the $\mathrm{O}_{2}$ Analyzer or the averaging pitot-static tube. Figure 3.15 shows how the accuracy of the devices changes with $D R$. As $D R$ increases, the uncertainty in $Q_{d u c t}$ decreases with the pitot tube while it increases with the $\mathrm{O}_{2}$ Analyzer. Therefore, to minimize the uncertainty in $Q_{d u c t}$ and hence $Y_{s}$, the $\mathrm{O}_{2}$ Analyzer should only be used in cases where $D R$ is less than approximately 8 . Although Chang et al. [23] recommends $D R>20$, the low soot concentrations of methane may require running at a $D R<20$ to obtain a signal. Refer to Section 3.7 for further details on the uncertainty analysis.

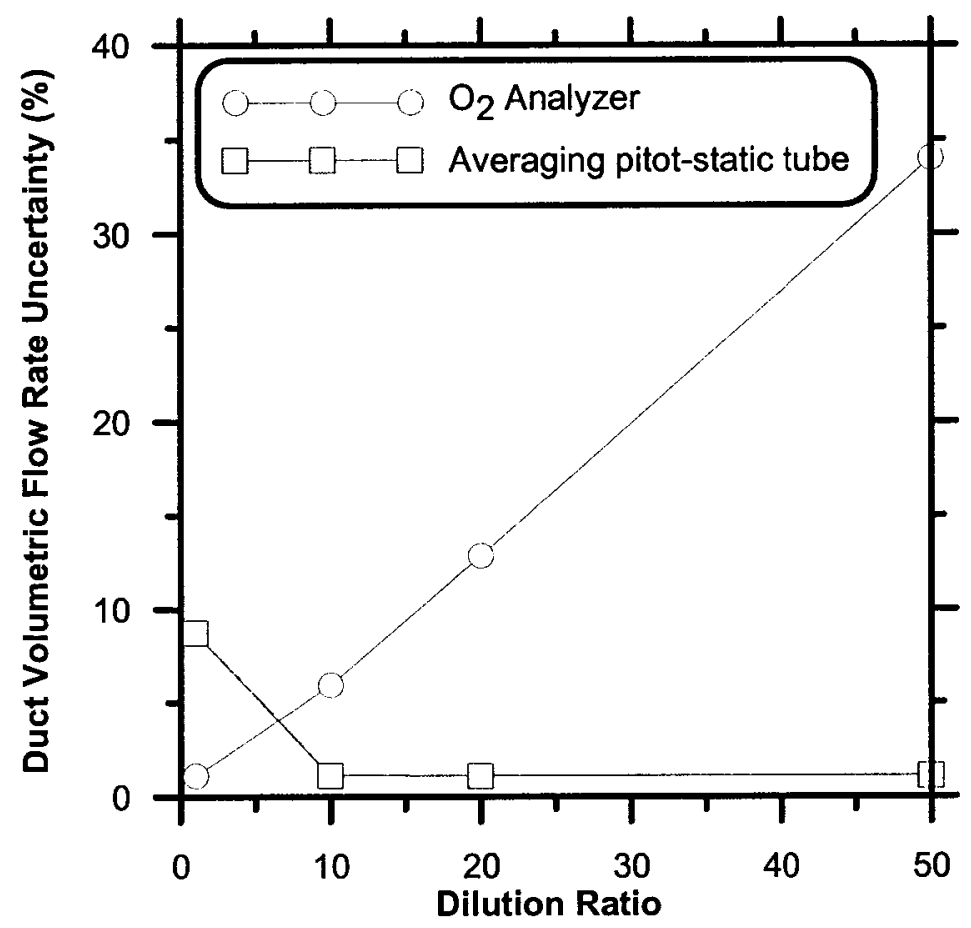

Figure 3.15: Effect of $D R$ on the duct volumetric flow rate uncertainty using the averaging pitot-static tube and $\mathrm{O}_{2}$ Analyzer 


\subsubsection{Sampling Losses}

Since the goal of this research is to measure total mass of soot emissions it is important to avoid soot particle deposition whenever possible. According to Brockmann [45], two main potential areas for sampling losses are when particles are entering the sampling probe which is known as the inlet efficiency $\left(\eta_{\text {inlet }}\right)$, and the transmission losses in transporting the particles from the source to the measuring equipment, known as the transport efficiency $\left(\eta_{\text {transport }}\right)$.

The inlet efficiency is related to the particle relaxation time, which is dependent on the particle diameter. As the particle relaxation time decreases (i.e. decreasing particle diameter), the inlet efficiency has been shown to converge to $100 \%$ [45]. Since the soot particles are demonstrated to be extremely small $(<1 \mu \mathrm{m})$, they will readily track the flow into the sample probe and therefore $\eta_{\text {inlet }} \approx 100 \%$.

The transport efficiency is affected by many modes of deposition, including gravitational settling, diffusional deposition, turbulent inertial deposition, inertial deposition at a bend, and thermophoretic deposition. From the correlations given in Brockmann [45] the losses from gravitational settling and diffusional deposition are considered to be negligible for the size of soot particles expected. To keep the transport efficiency high in a bend, it is recommended that the curvature ratio (ratio of bend radius to tube radius) be 4 or higher. This was done for both the sampling duct at the top of the sampling fume hood (Figure 3.3) and the sampling probe. As discussed above, thermophoretic deposition should be prevented due to the duct insulation and the heated sampling line. 
It should be noted that most of the correlations given in Brockmann [45] are based on empirical equations which were fitted to experimental data and may not be entirely accurate for the sampling system in these experiments. Therefore, the general equation for line losses proposed by Hurley [46] can be used as a check to determine if the estimates given by the calculations in Appendix $\mathrm{C}$ are reasonable.

$$
\eta_{\text {transport }}=\exp \left(-(1.05 e-4 \cdot U+2.27 e-4) \frac{L}{d \cdot U}\right)
$$

where, $L$ is the line length

$d$ is the sampling line diameter

$U$ is the gas flow velocity in the sampling line

From this equation, it is estimated that the sample efficiency could range from $98-99 \%$ depending on the gas velocity. This agrees with the correlations given in Appendix C which estimated a sample transport efficiency of $97 \%$, and therefore it should be expected that the sampling losses in the system are not greater than $3 \%$.

\subsection{Uncertainty Analysis}

From the equations developed in Section 3.1 the estimated uncertainty in soot yield can be calculated using Eq. (3.10) or (3.11) depending on which method for determining $Q_{\text {duct }}$ 
is used. Eq. (3.10) is for the direct measurement of $Q_{d u c t}$ whereas Eq. (3.11) uses the measured $D R$ to find $Q_{d u c t}$. Table 3.1 contains approximate values of the expected uncertainties for the various parameters. However, it should be noted that several of these parameters will vary depending on the particular test conditions and their uncertainties are calculated during experimentation. The derivations of the values in Table 3.1 are described in the sections below.

$\frac{\Delta Y_{s}}{Y_{s}}=\left[\left(\frac{\Delta \rho_{\text {soot }}}{\rho_{\text {soot }}}\right)^{2}+\left(\frac{\Delta f_{v}}{f_{v}}\right)^{2}+\left(\frac{\Delta Q_{\text {duct }}}{Q_{\text {duct }}}\right)^{2}+\left(\frac{\Delta T_{\text {sample }}}{T_{\text {sample }}}\right)^{2}+\left(\frac{\Delta T_{\text {duct }}}{T_{\text {duct }}}\right)^{2}+\left(\frac{\Delta \dot{m}_{\text {fuel }}}{\dot{m}_{\text {fuel }}}\right)^{2}\right]^{1 / 2}$

$\frac{\Delta Y_{s}}{Y_{s}}=\left[\left(\frac{\Delta \rho_{\text {soot }}}{\rho_{\text {soot }}}\right)^{2}+\left(\frac{\Delta f_{v}}{f_{v}}\right)^{2}+\left(\frac{\Delta Q_{\text {products }}}{Q_{\text {products }}}\right)^{2}+\left(\frac{\Delta D R}{D R+1}\right)^{2}+\left(\frac{\Delta T_{\text {sample }}}{T_{\text {sample }}}\right)^{2}+\left(\frac{\Delta T_{\text {ambient }}}{T_{\text {ambient }}}\right)^{2}+\left(\frac{\Delta \dot{m}_{\text {fiuel }}}{\dot{m}_{\text {fuel }}}\right)^{2}\right]^{1 / 2}$

Table 3.1: Estimate uncertainties of soot yield parameters

\begin{tabular}{cc}
\hline Parameter & Error \\
\hline$\rho_{\text {soot }}$ & $1.7 \%$ \\
$f_{v}$ & $6.4 \%$ \\
$Q_{\text {products }}$ & $1.0 \%$ \\
{$\left[O_{2}\right]_{\text {sample }}$} & $1.0 \%$ \\
{$\left[O_{2}\right]_{\text {room air }}$} & $1.0 \%$ \\
$T_{\text {sample }}$ & $0.7 \%$ \\
$T_{\text {ambient }}$ & $0.8 \%$ \\
$\dot{m}_{\text {fiel }}$ & $1 \%$ \\
\hline
\end{tabular}


The temperature uncertainty is calculated based on a thermocouple with an actual-reading accuracy of $\pm 2.2 \mathrm{~K}$. The mass flow rate uncertainty is from the mass flow controllers which have a full-scale accuracy of $1.0 \%$.

\subsubsection{Uncertainty in Density}

The density of soot has several different published values in the literature (Table 3.2). The average and standard error of these densities are $1.89 \pm 0.03 \mathrm{~kg} / \mathrm{m}^{3}$. This average excludes the value given by Newman and Steciak [47] as it is far removed from the other values and they used very different fuels to produce the soot, such as nylon, polystyrene, and coal.

Table 3.2: Soot density values found in literature [47-50]

\begin{tabular}{cll}
\hline $\begin{array}{c}\text { Soot Density } \\
\left(\mathbf{g} / \mathbf{c m}^{3}\right)\end{array}$ & \multicolumn{1}{c}{ Source } & \multicolumn{1}{c}{ Reference } \\
\hline 1.95 & Acetylene Black & Le Chatelier (1926)* \\
1.84 & Acetylene Black & Rossman and Smith (1943)* \\
1.84 & Carbon Black & Janzen (1980)* \\
2.05 & Acetylene Flame & Roessler and Faxvog (1980)* \\
1.95 & Propane Flame & Nishida and Mukohava (1983)* \\
1.9 & Acetylene Flame & Nelson (1989b)* \\
1.89 & Multiple Fuels & Wu et al. [50] \\
1.74 & Acetylene/Air Premixed & Choi and Jensen [49] \\
1.1 & Multiple Fuels & Newman and Steciak [47] \\
& * Values taken from data summary in Dobbins et al. [48]
\end{tabular}




\subsubsection{Uncertainty in Soot Volume Fraction}

The uncertainty in $f_{v}$ is mainly due to the uncertainty in the optical properties of soot. The absorption coefficient $(E(m))$ is the largest contributor to the uncertainty as there is no accepted value for it as yet. The uncertainty analysis in this section will show the relationship between the uncertainty in $E(m)$ and $f_{v}$.

As shown above, the soot volume fraction can be expressed as [7],

$$
f_{v}=\frac{V_{E X P}}{\eta \omega_{b} G_{E X P} \frac{12 \pi c^{2} h}{\lambda_{c}^{6}} E\left(m_{\lambda_{c}}\right)\left[\exp \left(\frac{h c}{k \lambda_{c} T_{p}}\right)-1\right]^{-1}}
$$

By using the Wien approximation, which approximates that $\exp \left[\mathrm{hc} /\left(\mathrm{k} \lambda_{c} T_{p}\right)\right]>>1$, grouping together the constant parameters and radiation parameters $\left(V_{E X P}, G_{E X P}, \eta\right)$, Eq. (3.12) becomes,

$$
f_{v}=\frac{c n s t \cdot R a d n_{2} \cdot \lambda_{2}^{6}}{E\left(m_{\lambda_{2}}\right)} \cdot \exp \left(\frac{h c}{k \lambda_{2} T_{p}}\right)
$$

where, cnst and Radn represent the constant and radiation parameters, respectively 
The uncertainty analysis can be carried through by choosing either $E\left(m_{l}\right)$ or $E\left(m_{2}\right)$ as the independent variable; therefore, $E\left(m_{2}\right)$ is arbitrarily chosen.

The particle temperature is given by [7],

$$
T_{p}=-h c \frac{\lambda_{2}-\lambda_{1}}{\ln \left(\frac{\operatorname{Radn_{1}} \cdot \lambda_{1}^{6} \cdot E\left(m_{2}\right)}{\operatorname{Radn_{2}} \cdot \lambda_{2}^{6} \cdot E\left(m_{1}\right)}\right) \cdot k \lambda_{1} \lambda_{2}}
$$

Substituting Eq. (3.14) into Eq. (3.13) and simplifying yields,

$$
f_{v}=c n s t \cdot \operatorname{Radn}_{2} \cdot \frac{\lambda_{2}^{6}}{E\left(m_{2}\right)}\left(\operatorname{Radn}_{1} \cdot \lambda_{1}^{6} \cdot \frac{E\left(m_{2}\right)}{\lambda_{2}^{6} \cdot E\left(m_{1}\right) \cdot \operatorname{Radn}_{2}}\right)^{\frac{-\lambda_{1}}{\lambda_{2}-\lambda_{1}}}
$$

The following equation can be used for the propagation of the uncertainty of $f_{v}$ with respect to $E\left(m_{1}\right)$ and $E\left(m_{2}\right)$ [8],

$$
\Delta \ln \left(f_{v}\right)=\left[\left(\frac{d \ln \left(f_{v}\right)}{d E\left(m_{2}\right)}\right)^{2} \cdot \Delta E\left(m_{2}\right)^{2}+\left(\frac{d \ln \left(f_{v}\right)}{d E\left(m_{1}\right)}\right)^{2} \cdot \Delta E\left(m_{1}\right)^{2}\right]^{\frac{1}{2}}
$$

where, $\Delta \ln \left(f_{v}\right)=\frac{\Delta f_{v}}{f_{v}}$

Taking the partial derivative of Eq. (3.15) with $E\left(m_{l}\right)$ and $E\left(m_{2}\right)$ gives, 


$$
\begin{aligned}
& \frac{d \ln \left(f_{v}\right)}{d E\left(m_{2}\right)}=\frac{-\lambda_{2}}{E\left(m_{2}\right) \cdot\left(\lambda_{2}-\lambda_{1}\right)} \\
& \frac{d \ln \left(f_{v}\right)}{d E\left(m_{1}\right)}=\frac{\lambda_{1}}{E\left(m_{1}\right) \cdot\left(\lambda_{2}-\lambda_{1}\right)}
\end{aligned}
$$

Eq. (3.17) and (3.18) can be substituted into Eq. (3.16),

$$
\Delta \ln \left(f_{v}\right)=\left[\left(\frac{-\lambda_{2}}{\left(\lambda_{2}-\lambda_{1}\right)}\right)^{2} \cdot\left(\frac{\Delta E\left(m_{2}\right)}{E\left(m_{2}\right)}\right)^{2}+\left(\frac{\lambda_{1}}{\left(\lambda_{2}-\lambda_{1}\right)}\right)^{2} \cdot\left(\frac{\Delta E\left(m_{1}\right)}{E\left(m_{1}\right)}\right)^{2}\right]^{\frac{1}{2}}
$$

The relative uncertainty in $E\left(m_{2}\right)$ can be found by carrying out a statistical analysis on the $E(m)$ values available in the literature (Table 3.3 ). The values for $E(m)$ in the literature are all given at different wavelengths; however, over the wavelength range of approximately $0.400-0.945 \mu \mathrm{m} E(m)$ can be considered to be independent of wavelength $[9,10]$. Therefore, the values in that range can be used to find a standard error for $E(m)$. Due to the small number of values available, the analysis will take all values with a wavelength less than $1 \mu \mathrm{m}$. The mean and standard error for $E(m)$ is $0.32 \pm$ 0.0090 which gives a relative uncertainty of $2.8 \%$. 
Table 3.3: Absorption function values from literature [51-57]

\begin{tabular}{|c|c|c|}
\hline Wavelength $(\boldsymbol{\mu m})$ & Absorption Function & Reference \\
\hline 0.351 & 0.2706 & Krishnan $[51,52,53]$ \\
\hline 0.405 & 0.3024 & Krishnan $[51,52,53]$ \\
\hline 0.436 & 0.2918 & Krishnan $[51,52,53]$ \\
\hline 0.458 & 0.3024 & Krishnan $[51,52,53]$ \\
\hline 0.488 & 0.2918 & Krishnan $[51,52,53]$ \\
\hline 0.514 & 0.2918 & Krishnan $[51,52,53]$ \\
\hline 0.546 & 0.3024 & Krishnan $[51,52,53]$ \\
\hline 0.577 & 0.2918 & Krishnan $[51,52,53]$ \\
\hline 0.6 & 0.2918 & Krishnan $[51,52,53]$ \\
\hline 0.633 & 0.2812 & Krishnan $[51,52,53]$ \\
\hline 0.8 & 0.24 & Krishnan $[51,52,53]$ \\
\hline 1.1 & 0.3 & Krishnan $[51,52,53]$ \\
\hline 1.55 & 0.34 & Krishnan $[51,52,53]$ \\
\hline 2.017 & 0.39 & Krishnan $[51,52,53]$ \\
\hline 3.98 & 0.42 & Krishnan $[51,52,53]$ \\
\hline 5.205 & 0.47 & Krishnan $[51,52,53]$ \\
\hline 0.351 & 0.33 & Koylu and Faeth [54] \\
\hline 0.4 & 0.32 & Koylu and Faeth [54] \\
\hline 0.425 & 0.32 & Koylu and Faeth [54] \\
\hline 0.45 & 0.31 & Koylu and Faeth [54] \\
\hline 0.48 & 0.31 & Koylu and Faeth [54] \\
\hline 0.514 & 0.3 & Koylu and Faeth [54] \\
\hline 0.633 & 0.31 & Koylu and Faeth [54] \\
\hline 0.8 & 0.36 & Koylu and Faeth [54] \\
\hline 1.1 & 0.43 & Koylu and Faeth [54] \\
\hline 1.7 & 0.41 & Koylu and Faeth [54] \\
\hline 2 & 0.52 & Koylu and Faeth [54] \\
\hline 3.98 & 0.73 & Koylu and Faeth [54] \\
\hline 5.205 & 0.7 & Koylu and Faeth [54] \\
\hline 0.488 & 0.2191 & Bruce et al. [55] \\
\hline 3.39 & 0.2843 & Bruce et al. [55] \\
\hline 10.6 & 0.8786 & Bruce et al. [55] \\
\hline 0.45 & 0.3686 & Schnaiter et al. [56] \\
\hline 0.55 & 0.3582 & Schnaiter et al. [56] \\
\hline 0.7 & 0.3592 & Schnaiter et al. [56] \\
\hline 0.45 & 0.3059 & Dobbins et al. [48] \\
\hline 0.63 & 0.373 & Dobbins et al. [48] \\
\hline 1 & 0.4223 & Dobbins et al. [48] \\
\hline 0.532 & 0.4 & Snelling et al. [57] \\
\hline 1.064 & 0.4 & Snelling et al. [57] \\
\hline 0.577 & 0.4 & Snelling et al. [57] \\
\hline 0.436 & 0.408 & Snelling et al. [57] \\
\hline 0.825 & 0.376 & Snelling et al. [57] \\
\hline
\end{tabular}


The Artium LII used in these experiments has laser wavelengths of $402.3 \mathrm{~nm}$ and 780.4 nm. Substituting the relative uncertainty for $E(m)$ and the laser wavelengths into Eq. (3.20) gives a $f_{v}$ uncertainty of $6.4 \%$. It should be noted that the same result is achieved if $E\left(m_{l}\right)$ is used as the original independent variable.

Another potential source of uncertainty in $f_{v}$ is due to the variation in the wavelengths, $\lambda_{I}$ and $\lambda_{2}$. Eqs. (3.13) and (3.14) use a single center wavelength for $\lambda_{1}$ and $\lambda_{2}$, whereas in reality the filters used to separate the LII signal into $\lambda_{1}$ and $\lambda_{2}$ can have a bandwidth of 40 nm. Thus, Snelling et al. [39] used the approximation of a center wavelength instead of integrating over the total filter bandwidth. They estimate the uncertainty from this approximation to be less than $1 \%$. A brief uncertainty analysis is shown here to confirm this result by comparing the $f_{v}$ at wavelengths of $402 \mathrm{~nm} \pm 40 \mathrm{~nm}$ and $780 \mathrm{~nm} \pm 40 \mathrm{~nm}$. Since the term Radn in Eq. (3.14) is unknown, a ratio of $f_{v}$ will be calculated so that the Radn term is not required.

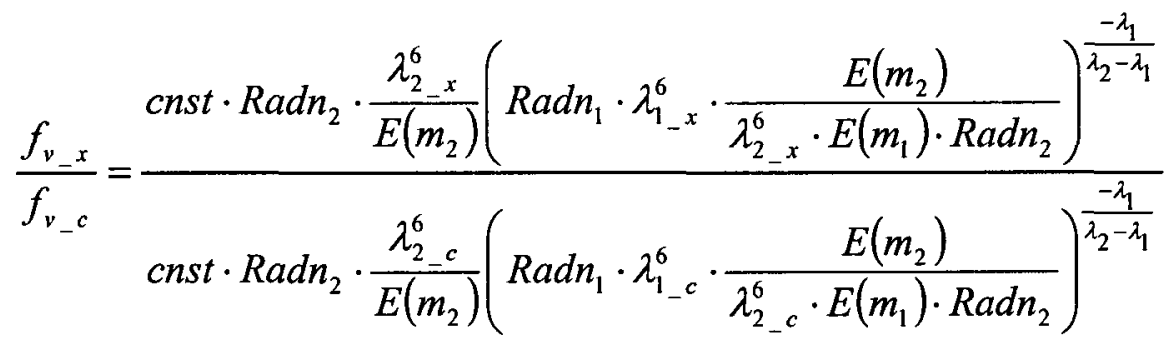

where, the subscript $c$ denotes the center line wavelength the subscript $x$ denotes the off-center line wavelength 
The exponent term $\left(-\lambda_{1} / \lambda_{2}-\lambda_{1}\right)$ will remain at the center line so the Radn term within the parentheses can be eliminated. By canceling terms in Eq. (3.21) it becomes,

$$
\frac{f_{v_{-} x}}{f_{v_{-} c}}=\frac{\lambda_{2_{-} x}^{6}\left(\frac{\lambda_{1_{-} x}^{6}}{\lambda_{2_{-} x}^{6}}\right)^{\frac{-\lambda_{1}}{\lambda_{2}-\lambda_{1}}}}{\lambda_{2_{-} c}^{6}\left(\frac{\lambda_{1_{-} c}^{6}}{\lambda_{2_{-} c}^{6}}\right)^{\frac{-\lambda_{1}}{\lambda_{2}-\lambda_{1}}}}
$$

Table 3.4 shows the results of the extreme cases where the wavelength is at $\pm 40 \mathrm{~nm}$. It can be seen that the change in $f_{v}$ is at most $1.7 \%$ and it is smaller when the wavelengths are closer to the center line values. This result agrees reasonably well with Snelling et al. [39] and therefore this uncertainty will be considered as having a negligible effect on the overall soot yield uncertainty.

Table 3.4: Fractional $f_{v}$ at different wavelengths

\begin{tabular}{ccc}
\hline$\lambda_{1}$ & $\lambda_{2}$ & fractional $\boldsymbol{f}_{\boldsymbol{v}}$ \\
\hline 362 & 740 & 1.017 \\
402 & 780 & 1.000 \\
442 & 820 & 1.013 \\
\hline
\end{tabular}

\subsubsection{Uncertainty using $\mathrm{O}_{2}$ Analyzer}

The uncertainty in calculating $Q_{\text {duct }}$ with the $\mathrm{O}_{2}$ Analyzer is given as, 


$$
\frac{\Delta Q_{\text {duct }}}{Q_{\text {duct }}}=\sqrt{\left(\frac{\Delta Q_{\text {products }}}{Q_{\text {products }}}\right)^{2}+\left(\frac{\Delta D R}{D R+1}\right)^{2}+\left(\frac{\Delta T_{\text {sample }}}{T_{\text {sample }}}\right)^{2}+\left(\frac{\Delta T_{\text {ambient }}}{T_{\text {ambient }}}\right)^{2}}
$$

$$
\text { where, } \Delta D R=D R \cdot(D R-1)\left[\left(\frac{\Delta\left[O_{2}\right]_{\text {room air }}}{\left[O_{2}\right]_{\text {room air }}}\right)^{2}+\left(\frac{\Delta\left[O_{2}\right]_{\text {sample }}}{\left[O_{2}\right]_{\text {sample }}}\right)^{2}\right]^{1 / 2}
$$

The uncertainty in the oxygen concentration as given by the analyzer manufacturer is $1.0 \%$ of the span. The uncertainty in $Q_{\text {products }}$ would result from an incorrect estimation of the combustion efficiency. It can be seen in Table 3.5 that the calculated $Q_{\text {products }}$ does not vary significantly at different combustion efficiencies. This calculation was carried out with methane fuel at a mass flow rate of $2.9 \mathrm{e}-4 \mathrm{~kg} / \mathrm{s}$ and with the product gases at a temperature of $353 \mathrm{~K}$. It also assumes that oxygen and fuel are the only additional products of incomplete combustion (Eq. (3.24)).

$C_{\alpha} H_{\beta}+x_{s}\left(O_{2}+3.76 N_{2}\right) \rightarrow \eta_{c}\left(\alpha C O_{2}+\frac{\beta}{2} H_{2} O\right)+3.76 x_{s} N_{2}+x_{s}\left(1-\eta_{c}\right) O_{2}+\left(1-\eta_{c}\right) C_{\alpha} H_{\beta}$

where, $x_{s}=\alpha+\frac{\beta}{4}$

Table 3.5: Combustion product volume flow rate at different combustion efficiencies

\begin{tabular}{cc}
\hline Combustion Efficiency & $\begin{array}{c}\text { Product Volume Flow } \\
\left(\mathbf{m}^{\mathbf{3}} / \mathbf{s}\right)\end{array}$ \\
\hline 0.90 & $8.73 \mathrm{e}-2$ \\
0.95 & $8.66 \mathrm{e}-2$ \\
1.00 & $8.60 \mathrm{e}-2$ \\
\hline
\end{tabular}


There is also an additional uncertainty arising from the measurement of the fuel mass flow rate, which is used in the calculation of $Q_{\text {products. }}$. This uncertainty is larger than the one resulting from assuming an incorrect combustion efficiency and therefore will be taken as the only contributor to the uncertainty in $Q_{\text {products }}$.

Figure 3.16 shows the uncertainty in $Q_{d u c t}$ is extremely sensitive to the $D R$.

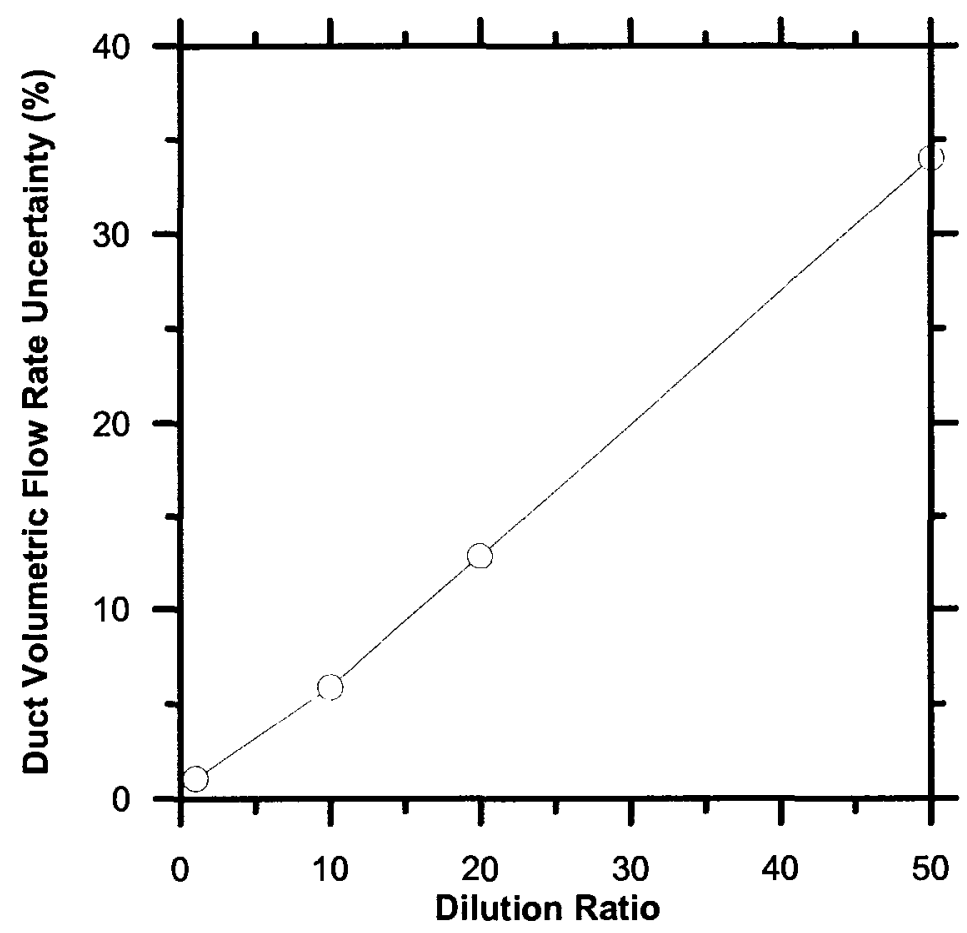

Figure 3.16: Effect of dilution ratio on duct volume flow rate uncertainty using an $\mathrm{O}_{2}$ Analyzer

\subsubsection{Uncertainty using Averaging Pitot-Static Tube}

The following shows an uncertainty analysis for $Q_{d u c t}$ using an averaging pitot-static tube. The duct flow rate can be calculated as, 


$$
Q_{\text {duct }}=A \sqrt{\frac{2\left(p_{o}-p_{s}\right)}{\rho_{\text {duct }}}}
$$

where, $A$ is the area of the duct,

$\left(p_{o}-p_{s}\right)$ is the pressure difference

$\rho_{\text {duct }}$ is the density of the mixed gases in the duct

The area uncertainty is taken to be $\pm 0.25 \mathrm{~mm}$ for a $152.40 \mathrm{~mm}$ duct. Determination of $\rho_{\text {duct }}$ requires knowledge of the gas composition and temperature which will vary with the $D R$ of combustion products and entrained room air. Table 3.6 contains the molecular weight $(M W)$ of the exhaust gases $(353 \mathrm{~K})$ calculated for methane fuel at $2.9 \mathrm{e}-4 \mathrm{~kg} / \mathrm{s}$ and assuming complete combustion. The $M W$ can vary by as much as $2.0 \%$ as $D R$ varies from 5 to 100 . However, the dilution ratio is expected to be above 20 for most experiments which would result in only a $0.5 \%$ difference from a $D R$ of 20 to 100 .

Table 3.6: Molecular weight of exhaust gas at different dilution ratios

\begin{tabular}{cc}
\hline Dilution Ratio & MW \\
\hline 0 & 26.729 \\
1 & 27.436 \\
5 & 28.244 \\
20 & 28.658 \\
100 & 28.809 \\
\hline
\end{tabular}

An uncertainty estimate for $Q_{d u c t}$ can be calculated with Eq. (3.26) where, the density of the exhaust gases is related to the temperature $(T)$, pressure $(p)$, and molecular weight through the ideal gas equation of state. Table 3.7 shows an estimate of the uncertainties 
expected during experimentation. The pressure uncertainty comes from a pressure transducer with a full-scale accuracy of $0.25 \%$.

$$
\frac{\Delta Q_{\text {duct }}}{Q_{\text {duct }}}=\sqrt{\left(\frac{\Delta A}{A}\right)^{2}+\frac{1}{4}\left(\frac{\Delta\left(p_{o}-p_{s}\right)}{\left(p_{o}-p_{s}\right)}\right)^{2}+\frac{1}{4}\left(\frac{\Delta p_{s}}{p_{s}}\right)^{2}+\frac{1}{4}\left(\frac{\Delta T}{T}\right)^{2}+\frac{1}{4}\left(\frac{\Delta M W}{M W}\right)^{2}}
$$

Table 3.7: Estimate uncertainties for $Q_{\text {duct }}$ using a pitot tube

\begin{tabular}{cc}
\hline Parameter & Uncertainty \\
\hline$A$ & $0.3 \%$ \\
$p_{o}-p_{s}$ & $0.6 \%$ \\
$p_{s}$ & $0.25 \%$ \\
$T$ & $0.7 \%$ \\
$M W$ & $2.0 \%$ \\
\hline
\end{tabular}

Figure 3.17 shows the effect of dilution ratio on uncertainty when using the averaging pitot-static tube to measure $Q_{d u c t}$.

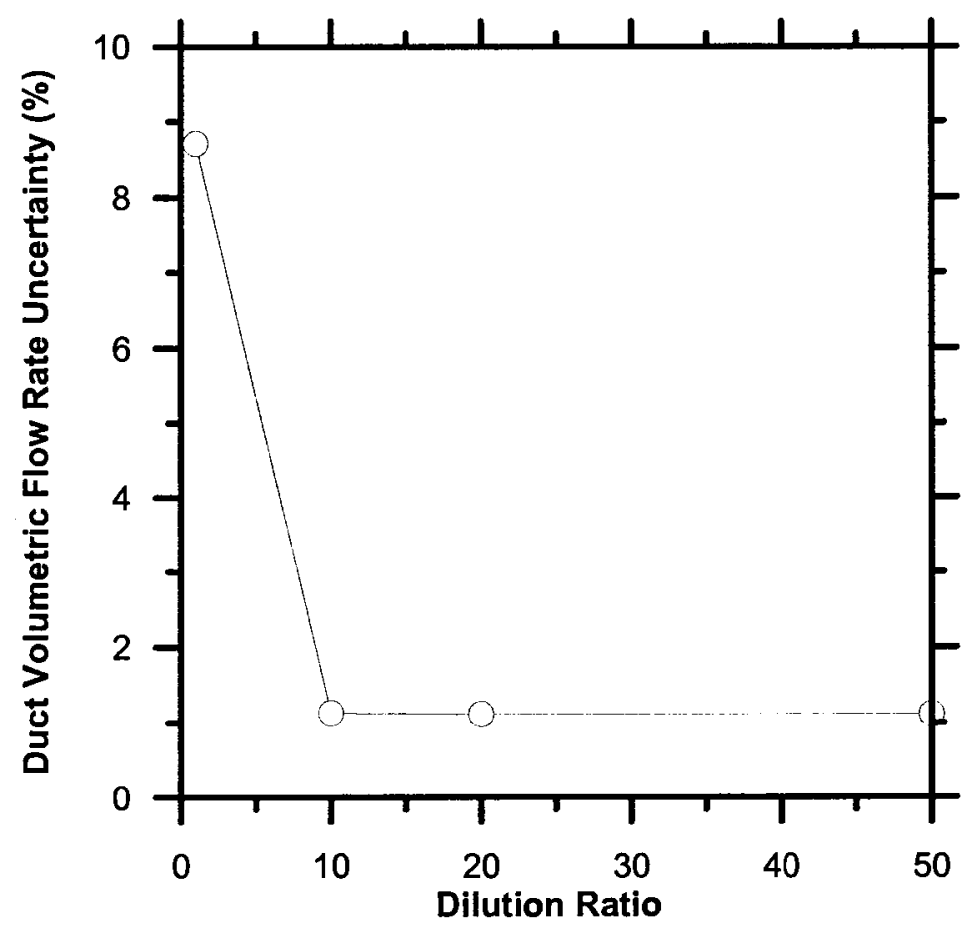

Figure 3.17: Effect of dilution ratio measurement on soot yield uncertainty using a averaging pitot-static tube 


\subsubsection{Overall Soot Yield Uncertainty}

From the above sections, it was shown that the major sources of uncertainty in these experiments are from the unknown properties of soot and the measurement of the duct flow rate. The total soot yield experimental uncertainty expected from these experiments should be no greater than approximately $6.8 \%$ when using the averaging pitot-static tube or $13.5 \%$ when using the $\mathrm{O}_{2}$ Analyzer. 


\section{Chapter 4: Results}

\subsection{Soot Yield and Flame Length Results}

\subsubsection{Methane Turbulent Diffusion Flames}

Soot yield from turbulent diffusion flames burning methane was measured for three different burner diameters and a range of mass flow rates as shown in Figure 4.1. Results could not be obtained burning methane with the $12.7 \mathrm{~mm}$ diameter burner since the soot volume fraction was below the detectable limits of the LII system. Figure 4.2 shows measured visible flame length data for the same range of conditions.

It is clear that the mass flow rate and burner exit diameter have an effect on the soot yield and flame length. The $25.4 \mathrm{~mm}$ burner has a substantially higher soot yield than the $38.1 \mathrm{~mm}$ and $50.8 \mathrm{~mm}$ burners at lower flow rates, but produces much lower soot yields as the flow rate is increased. The results are interesting in that the soot yield from the $25.4 \mathrm{~mm}$ burner appears to linearly decrease with an increase in mass flow rate while the two larger burners exhibit four separate regions of increasing and decreasing soot yield. The change in burner diameter and corresponding changes in velocity could be inducing a shift in flow regimes, especially since the larger two diameter burners track closely and differently from the $25.4 \mathrm{~mm}$ data. In all cases, the measured soot yield remained below $0.11 \mathrm{~g}$ of soot per $\mathrm{kg}$ of methane fuel. 


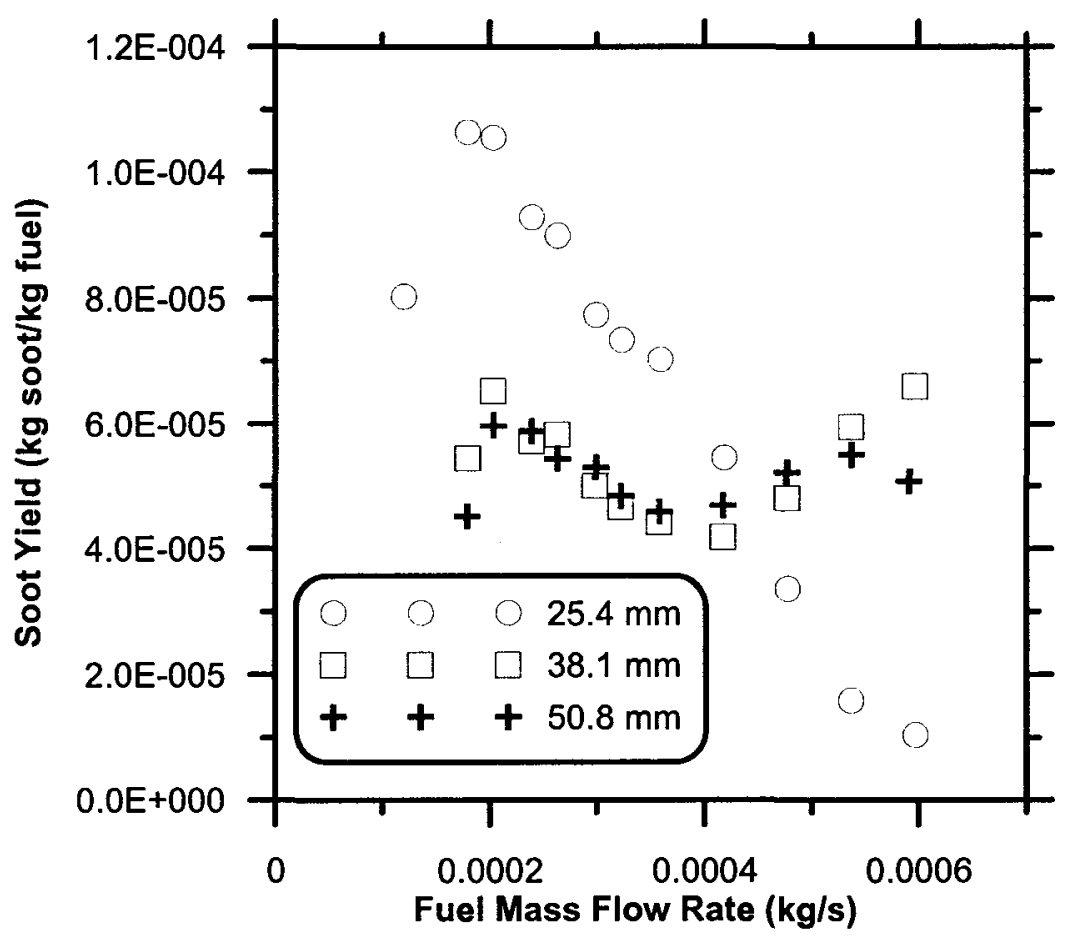

Figure 4.1: Soot yield from turbulent diffusion flames burning methane

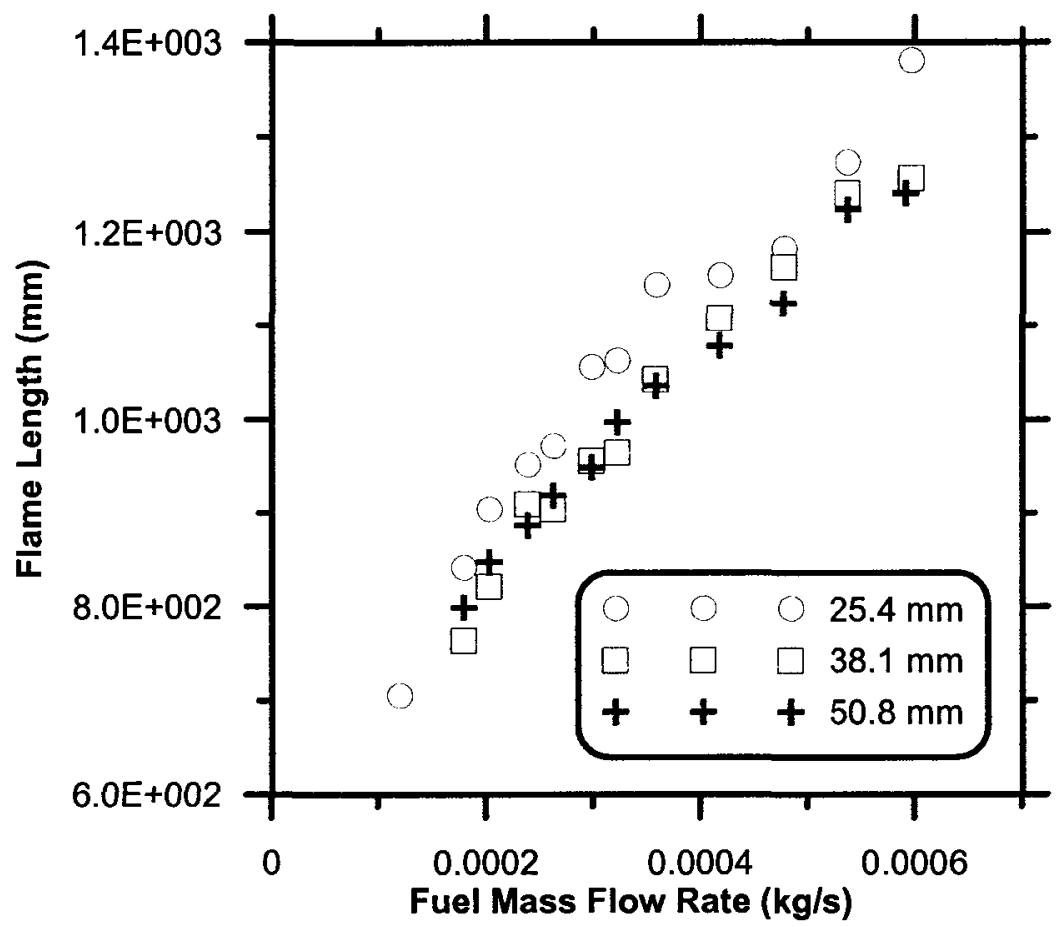

Figure 4.2: Visible flame lengths of methane turbulent diffusion flames at range of flow rates and burner exit diameters 
The trends in flame length were more consistent and showed a general monotonic increasing trend with increasing fuel flow. However, the flame lengths for the smallest burner $(25.4 \mathrm{~mm})$ increased more quickly than the 38.1 or $50.8 \mathrm{~mm}$ burners which followed the identical trend within experimental error. Again, each burner could be operating in a different flow regime which may be causing the differences in trends.

\subsubsection{Ethane Turbulent Diffusion Flames}

Soot yield measurements of turbulent diffusion flames burning ethane are shown in Figure 4.3. Four different burner exit diameters ranging from 12.7 to $50.8 \mathrm{~mm}$ were used for a range of fuel flow rates. There is considerable scatter in the data with the larger three burner diameters spanning a similar range of soot yield values and the smallest burner $(12.7 \mathrm{~mm})$ showing much less soot in proportion to the mass flow of fuel. There is arguably a common trend for the larger three burner diameters in which soot yield shows a local maxima at intermediate mass flow rates; however, the general dispersion of the data is of a similar magnitude. In comparison to methane flames, the soot yield is higher as expected, by nearly an order of magnitude. In all cases for ethane flames, however, the soot yield remained below $1 \mathrm{~g}$ of soot per $\mathrm{kg}$ of fuel consumed. 


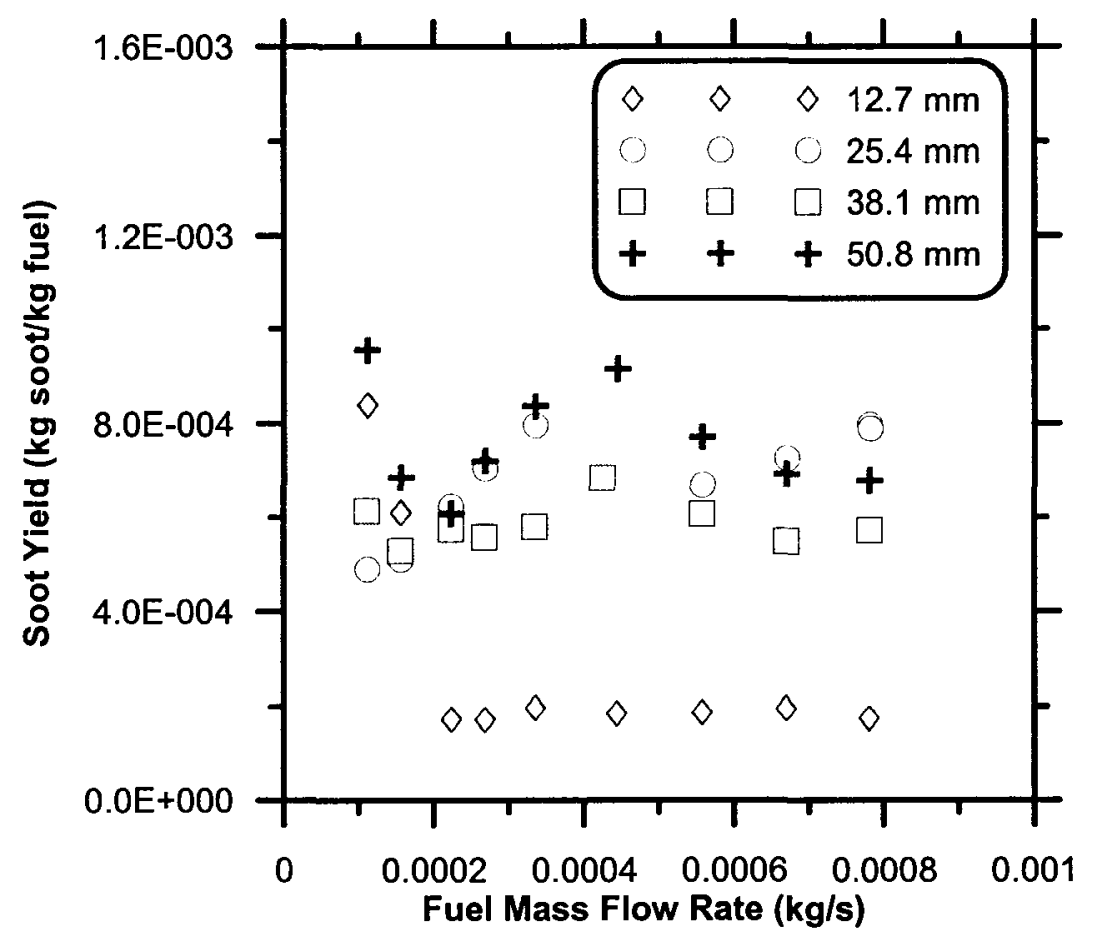

Figure 4.3: Soot yield from turbulent diffusion flames burning ethane

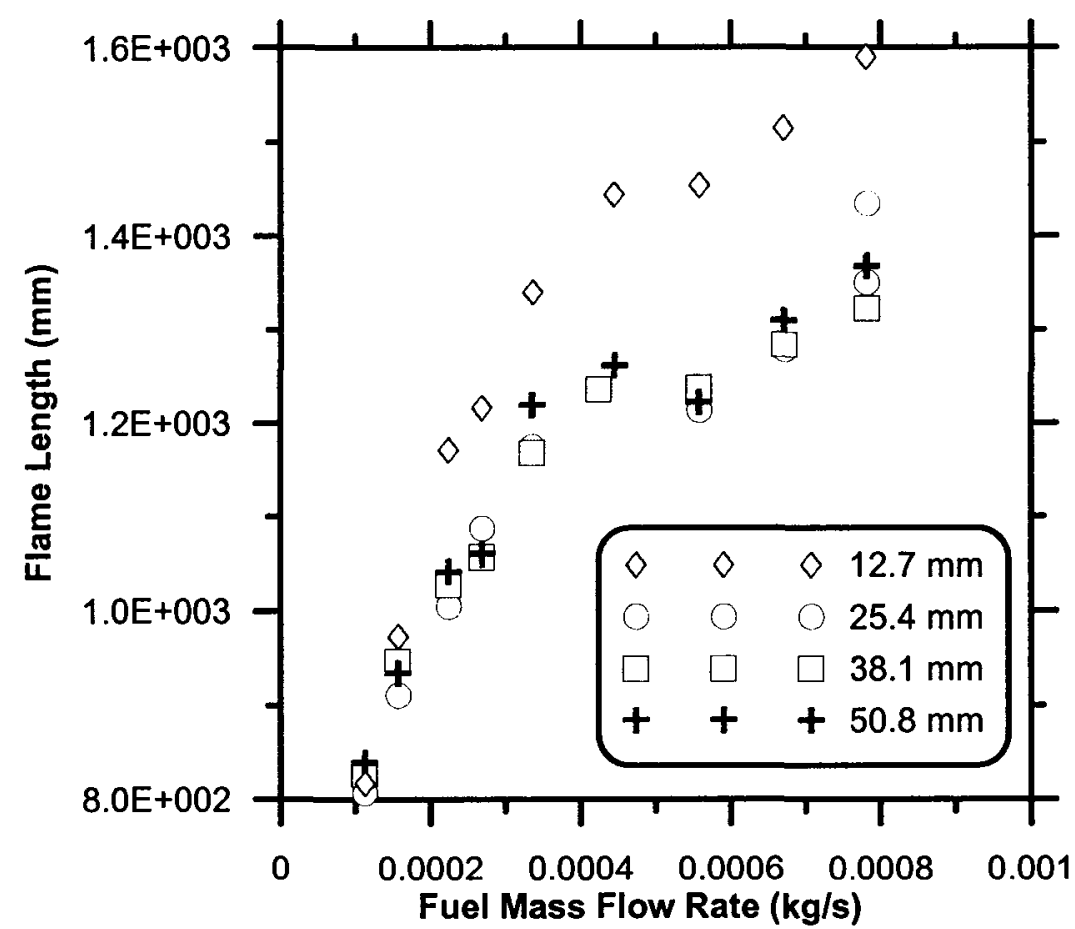

Figure 4.4: Visible flame lengths of ethane diffusion flames for a range of flow rates and burner exit diameters 
The ethane flame length data show similar trends to the methane data; however, there appears to be more of a logarithmic increase with fuel mass flow rate. The smallest diameter burner $(12.7 \mathrm{~mm})$ again appears to have flame length increase faster than the larger diameter burners.

\subsubsection{Propane Turbulent Diffusion Flames}

Soot yield data for propane fueled flames are shown in Figure 4.5 for all four burner diameters and a broad range of fuel flow rates. Corresponding visible flame length data are shown in Figure 4.6. Although the data are potentially confusing, on close inspection the $25.4 \mathrm{~mm}, 38.1 \mathrm{~mm}$, and $50.8 \mathrm{~mm}$ burner all show a similar "saw tooth" trend with increasing fuel flow rate, in which the soot yield initially decreases, then rises to a local maxima before decreasing again. As expected, of the three fuels, soot yield is largest for the propane flames but remains below $6 \mathrm{~g}$ per $\mathrm{kg}$ of fuel in all cases.

Similar to ethane, the propane flame lengths appear to increase with a logarithmic trend as fuel mass flow rate increases. Also, at lower flow rates, there is more agreement between the different burner diameters but then the flame length begins to diverge at higher flow rates. 


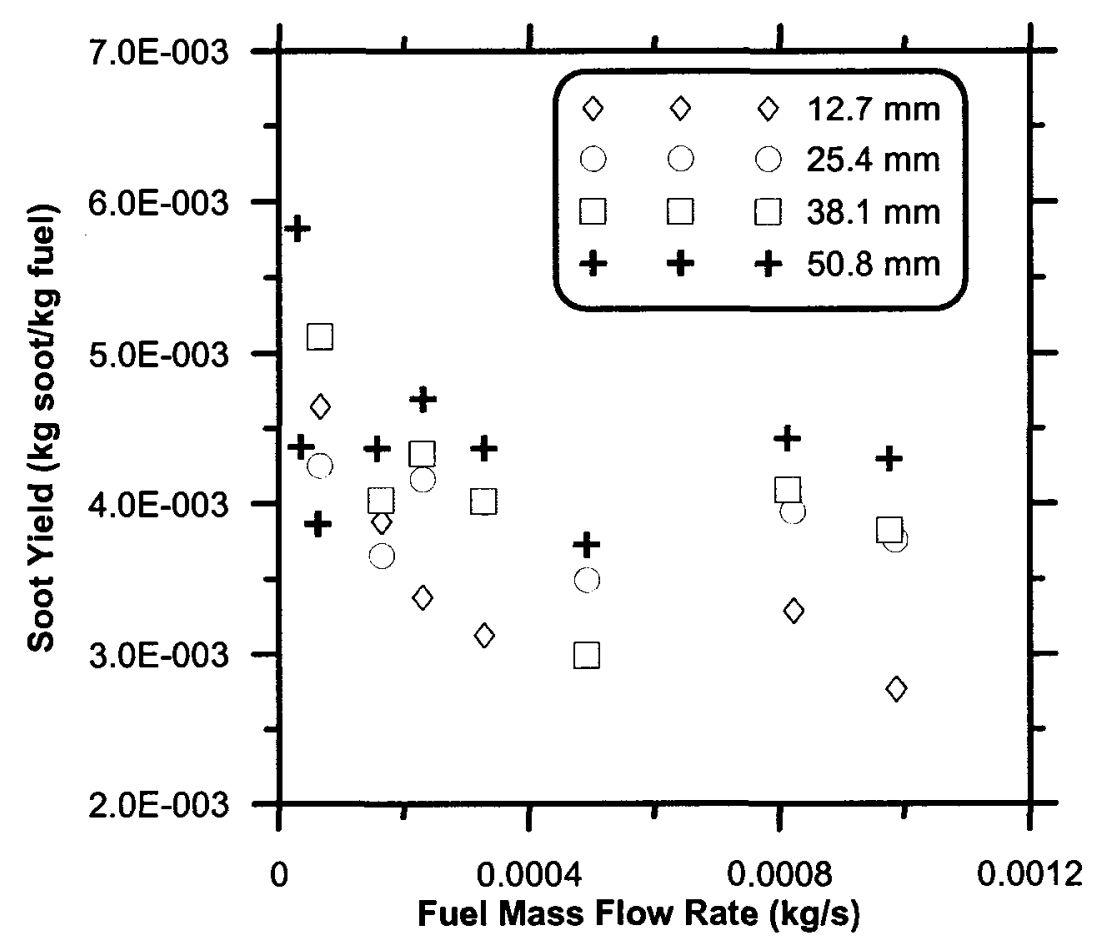

Figure 4.5: Soot yield from propane turbulent diffusion flames

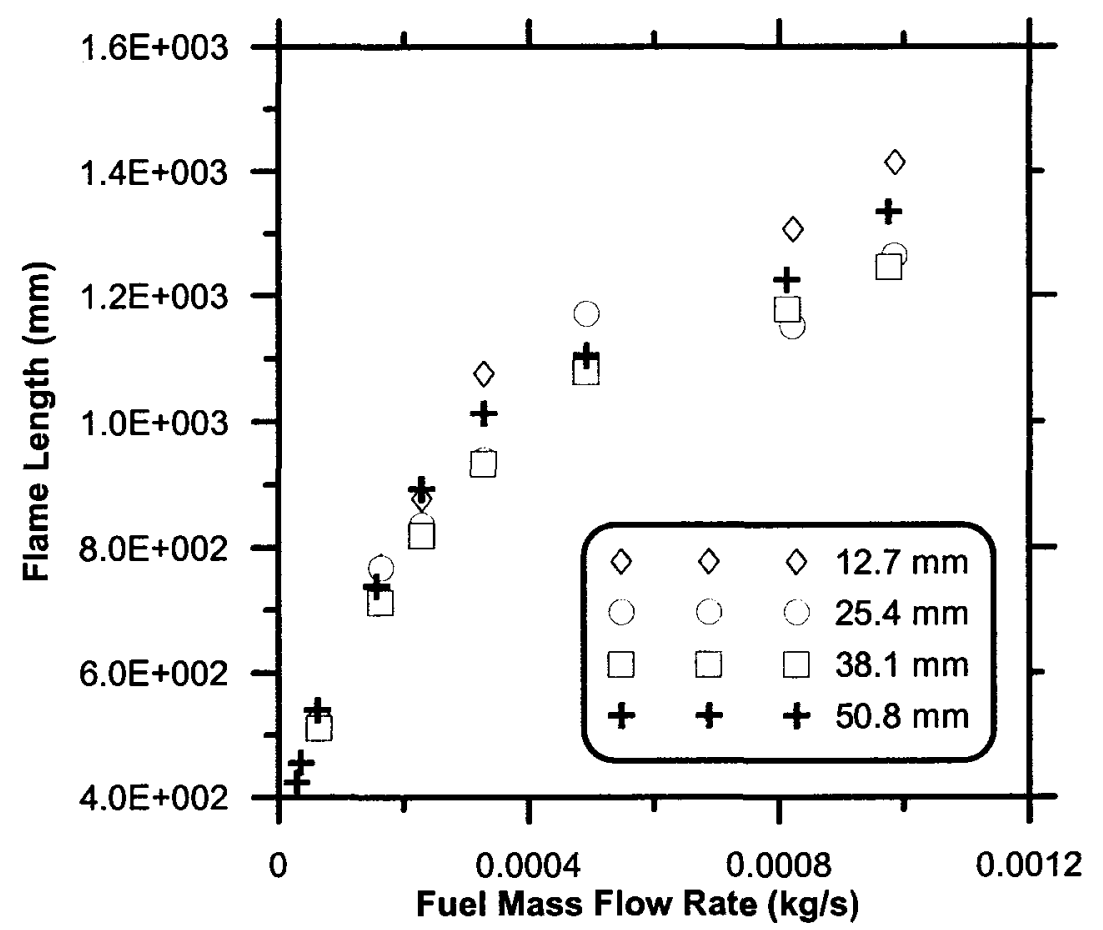

Figure 4.6: Visible flame lengths of propane diffusion flames for a range of flow rates and burner exit diameters 


\subsection{Comparison of Results with Published Literature}

The results for methane and propane were compared to the available data in the literature from Becker and Liang [27] and Sivathanu and Faeth [26]. The characteristic residence time established by Becker and Liang [27] and soot generation efficiency are used as the basis for comparison, since the raw data from Sivathanu [36] and our data can be reinterpreted in terms of these two parameters.

As outlined in Section 2.3, the characteristic residence time can be inferred from the flame length. However, a common definition of flame length is then critical for meaningful comparisons among data sets. As discussed in Section 3.5 (Flame Height), Becker and Liang [27] visually observed the flame length, which should yield to large estimations of length, comparable to the $10 \%$ contour. However, the flame lengths calculated using a $10 \%$ contour as described in Section 3.5 were larger than those measured by Sivathanu and Faeth [26] for identical sets of conditions. This difference illustrates an important discrepancy among the data sets of Becker and Liang [27] and Sivathanu and Faeth [26]. Nevertheless, to permit a fair comparison of the current data with that of Sivathanu and Faeth [26], an additional flame contour was chosen so that the experimentally determined flame lengths in the current data could match those of Sivathanu and Faeth [26] for an identical flow rate and burner diameter. Using available data for propane flames, a $70 \%$ contour produced flame lengths that matched those reported by Sivathanu and Faeth [26]. 
Figure 4.7a-c show the comparison of results for propane, methane, and ethane. The comparison for methane and ethane are only made with the results of Becker and Liang [27] since Sivathanu and Faeth [26] did not use methane or ethane as fuels. It should be noted that all three authors have used a different technique for measuring soot concentration. Becker and Liang [27] used gravimetric sampling whereas Sivathanu and Faeth [27] used a laser extinction method.

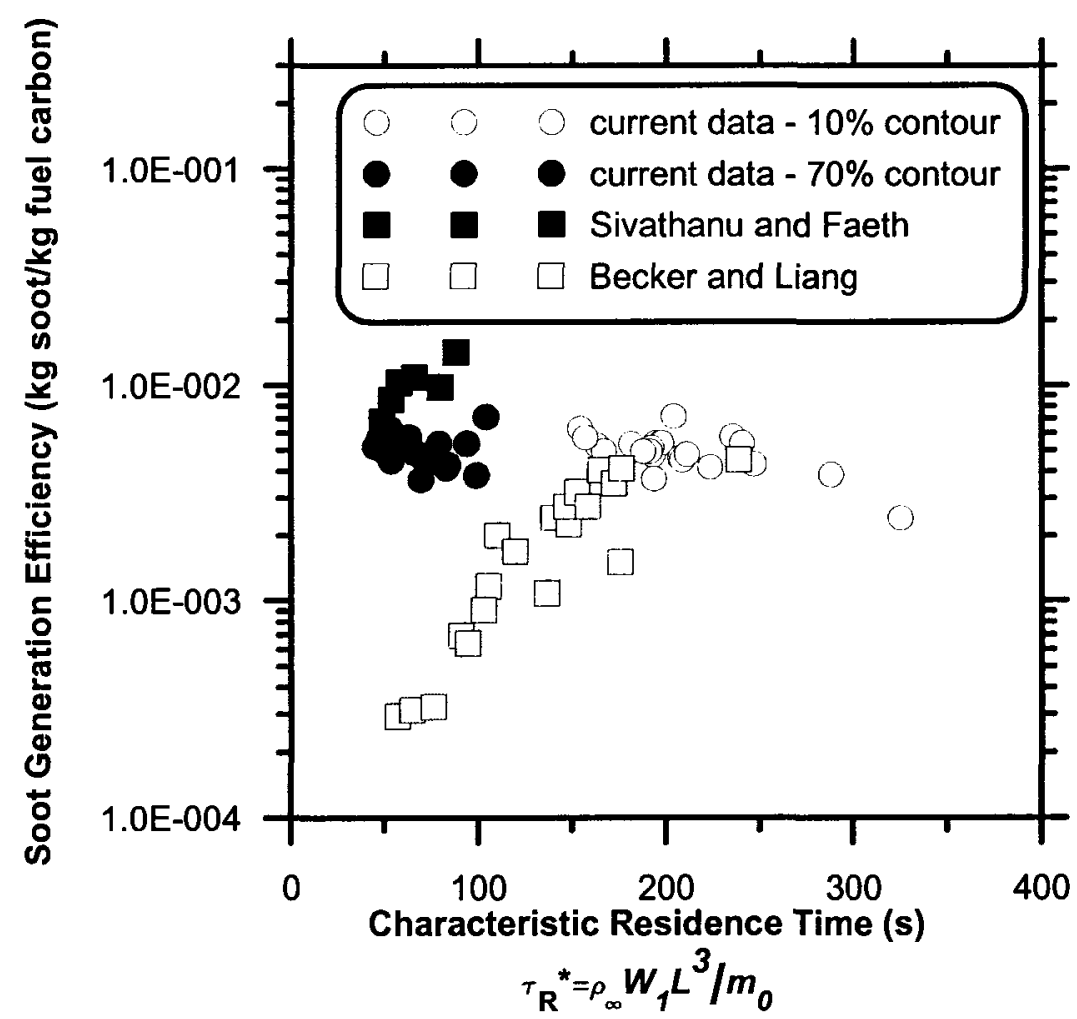

a) Propane

Figure 4.7: Comparison of experimental results with Becker and Liang [27] and Sivathanu and Faeth [26] for (a) propane, (b) methane, and (c) ethane 


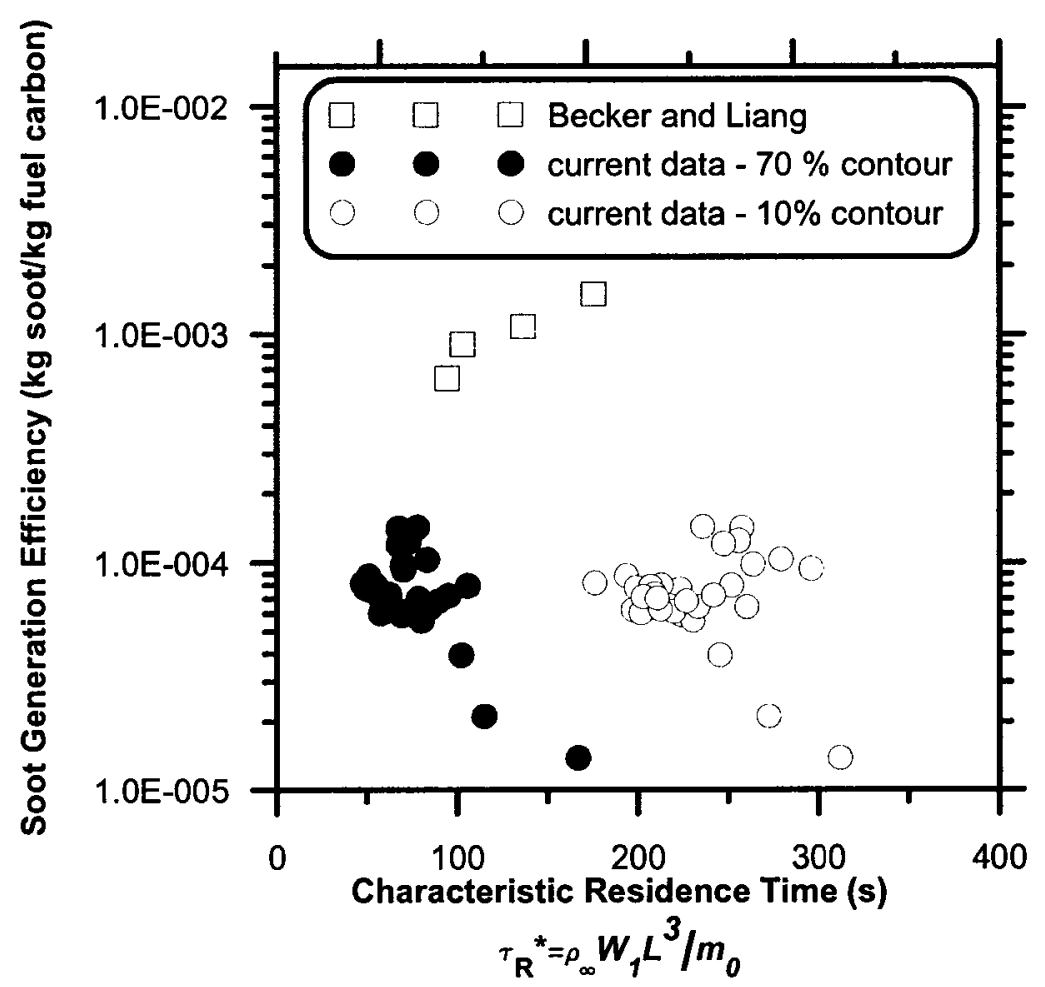

b) Methane

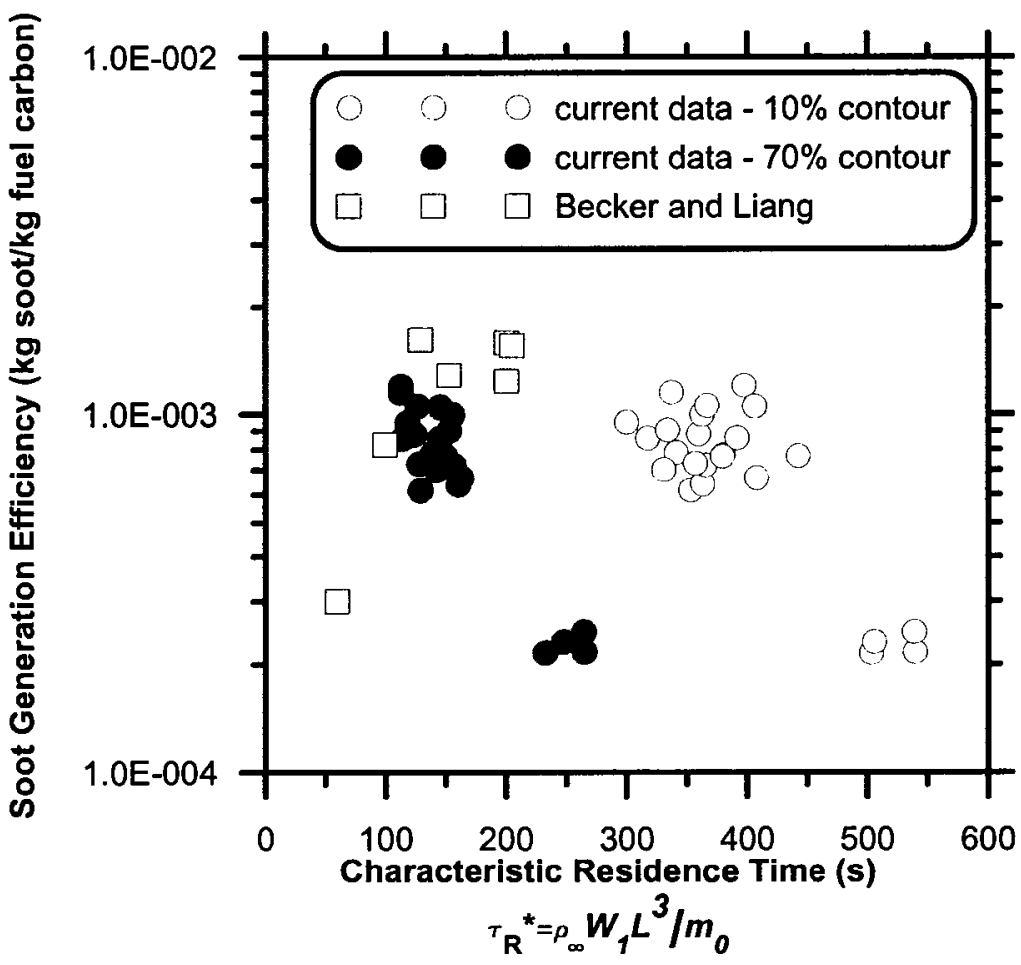

c) Ethane

Figure 4.7: Comparison of experimental results with Becker and Liang [27] and Sivathanu and Faeth [26] for (a) propane, (b) methane, and (c) ethane 
As shown in Figures 4.7a-c, the choice of contour used to calculate the flame length can greatly affect $\tau_{R} *$. For propane, several experiments were run to match the conditions (fuel flow rate and burner diameter) of Sivathanu and Faeth [26]. Thus, with the 70\% flame contour, which gives the same flame lengths as Sivathanu and Faeth [26], $\tau_{R}{ }^{*}$ should be identical. Despite matching $\tau_{R} *$ with Sivathanu and Faeth [26] for propane, the $S G E$ from the present experiments do not appear to agree with their data.

The $\tau_{R}{ }^{*}$ was expected to differ significantly from that of Becker and Liang [27] as their burner diameters were all less than $12 \mathrm{~mm}$ and their fuel exit velocities ranged from 8$127 \mathrm{~m} / \mathrm{s}$, whereas our velocities were mostly under $2 \mathrm{~m} / \mathrm{s}$. This could suggest that Becker and Liang [27] were operating in a much different flow regime than the present experiments. With the $10 \%$ contour flame lengths, the present data do tend to follow the trend of Becker and Liang [27] for propane, although the logarithmic scale tends to minimize the data spread.

There is considerably more separation in the methane and ethane data as shown in Figures 4.7b,c. Becker and Liang's [27] data appear to show upward trends with increasing $\tau_{R}$ * whereas the present data do not show any clear trends. Again, the flow conditions operated for these fuels by Becker and Liang [27] differed greatly from the present experiments.

From the above figures, it is apparent that $\tau_{R}{ }^{*}$ is not a suitable parameter for scaling of soot emissions. Although separately the data of Becker and Liang [27] and Sivathanu 
and Faeth [26] appear as though they may scale with $\tau_{R}^{*}$, their combined data sets for propane flames do not correlate as illustrated in Figure 4.7a. Since neither author has run experiments over a broad range of experimental conditions, there are not enough data points to establish a clear trend. Becker and Liang [27] did take numerous measurements from propane flames; however, this data was taken at conditions where $R i<0.0016$, which is considerably less than what is expected in industrial flaring (Section 1.1.1).

The other scaling parameter discussed in Section 2.3 (Scaling) was from Sivathanu and Faeth [26], who observed that $S G E$ scales with a measured residence time, until long residence times are approached and a plateau region is expected. However, if their data from Figure 2.3 are re-plotted on a linear rather than a logarithmic scale (Figure 4.8), it appears that the $S G E$ begins to decrease for acetylene and propylene at longer residence times rather than reach a plateau region. Sivathanu [36] also observed this trend with propane for a $5 \mathrm{~mm}$ diameter burner but did not include the data in his thesis, as he assumed the residence time scaling laws change at low values of $R i$ (i.e. large velocities). This was shown in Figure 2.5 where at $F r>1(R i<1)$ the residence time decreased with an increase in $F r$. However, since industrial flaring can occur at $R i<1$ [8], this regime is important and needs to be investigated. 


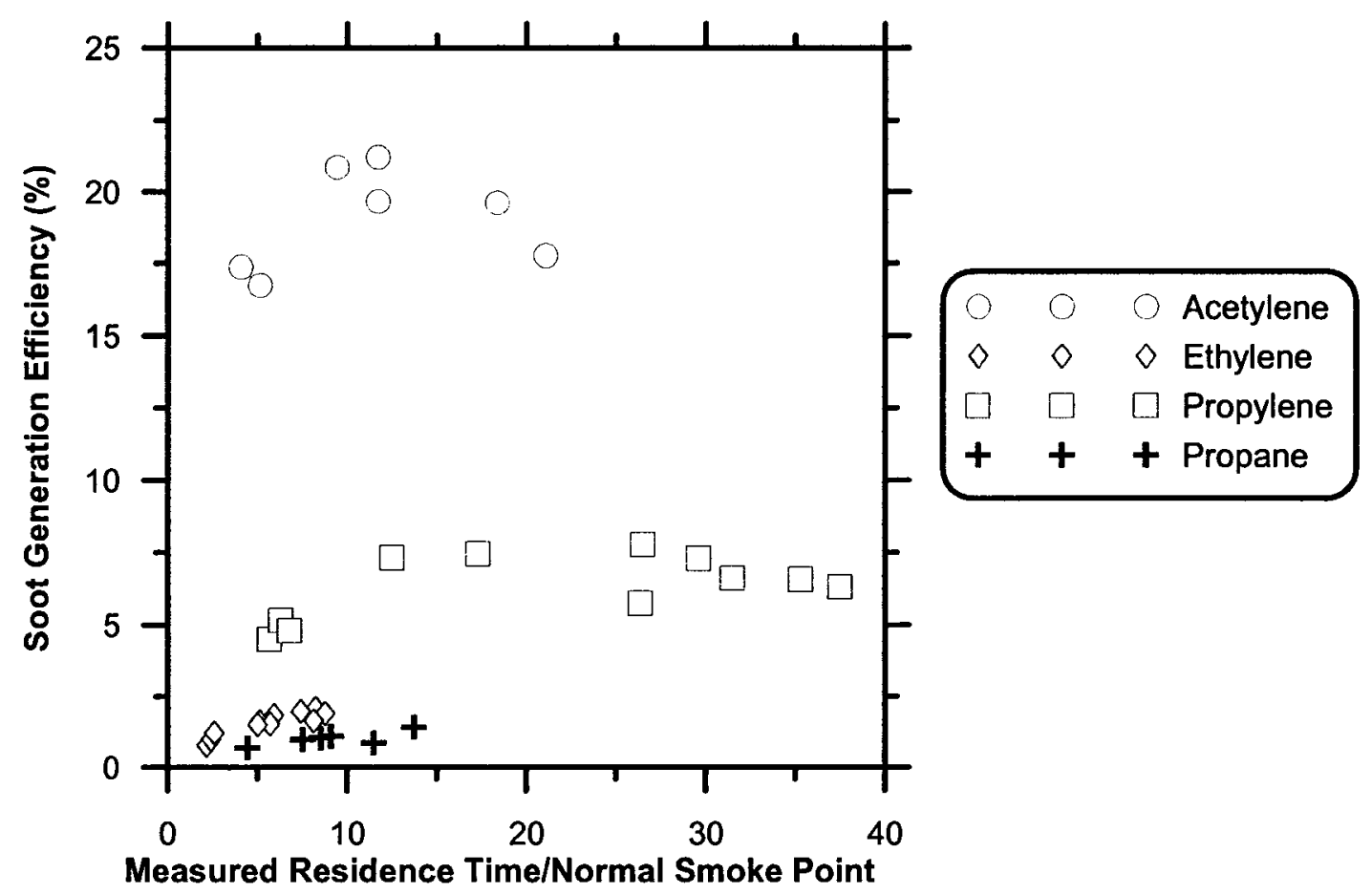

Figure 4.8: Soot generation efficiency data from Sivathanu [36] plotted on linear axes

A direct comparison between the data from Sivathanu and Faeth [26] and the present experiments could not be made, since the current experimental setup does not have the equipment to measure residence time using their method. However, as discussed above, it was clear that there was a difference between the $S G E$ measured by Sivathanu and Faeth [26] and the present data (Figure 4.7a). There are several potential sources that could be causing these discrepancies. The measurement of a soot volume fraction by optical methods (i.e. laser-extinction or LII) requires information about soot properties, such as the absorption coefficient and the density of soot. As discussed in Section 3.7, there is no common value in the literature for either of these properties. Therefore, discrepancies in these values when calculating the soot volume fraction could lead to significant differences in the absolute value of the results even if the actual amount of soot from the flame is the same. Also, the burners used in the present experiments are 
different than those of Sivathanu and Faeth [26] and Becker and Liang [27]; therefore, flow conditions (i.e. turbulence intensity) could vary between the burners and also be affecting the amount of soot produced. Furthermore, neither Sivathanu and Faeth [26] nor Becker and Liang [27] discuss the potential affects of dilution conditions on the soot concentration.

\subsection{Scaling of Soot Emissions}

In the soot emission experiments, there were only three controlled variables: the fuel velocity, the burner exit diameter, and the fuel. Therefore, for any given fuel, only the velocity and burner exit diameter are changing. The Froude number is a simple nondimensional parameter which incorporates both the velocity and exit diameter (Section 2.3) which could be expected to correlate soot yield results. However, for all three fuel types, as plotted in Figure 4.9a-c, the data do not appear to correlate well with Froude number. Moreover, the different trends in the current data set with Froude number are sufficiently inconsistent such that there does not appear to be any physical explanation for the results. These observations led to a reexamination of the full experimental methodology and performance of additional experiments as outlined in Chapter 5. 


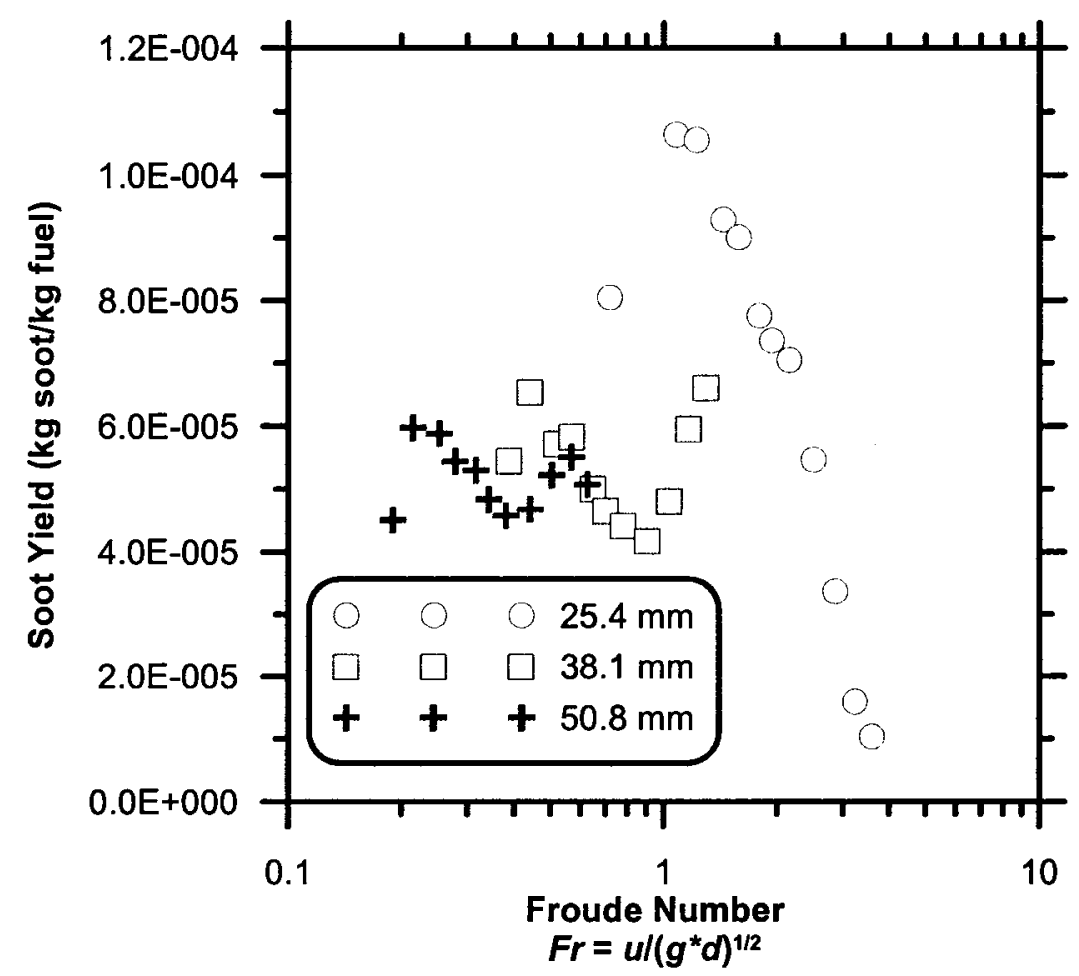

a) Methane

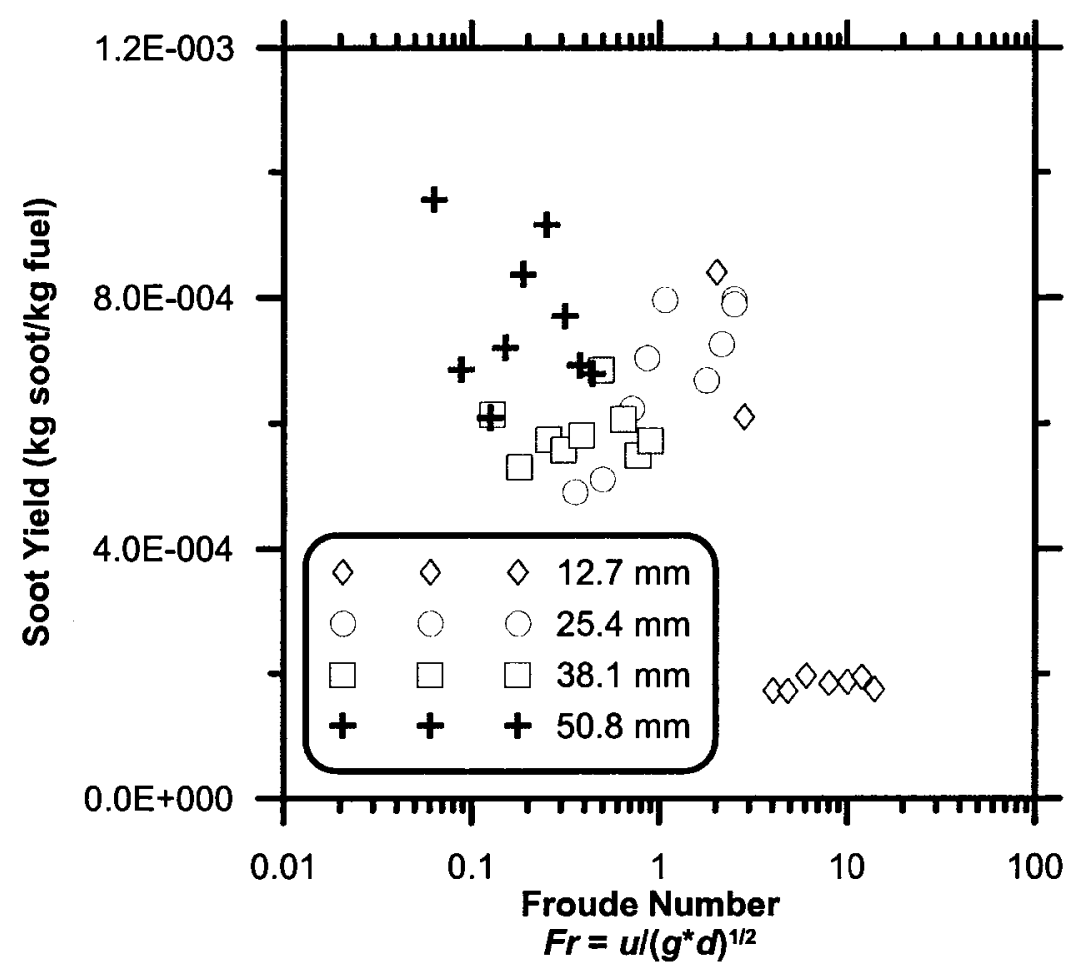

b) Ethane

Figure 4.9: Soot yield as a function of Froude number for the different fuels and burner exit diameters 


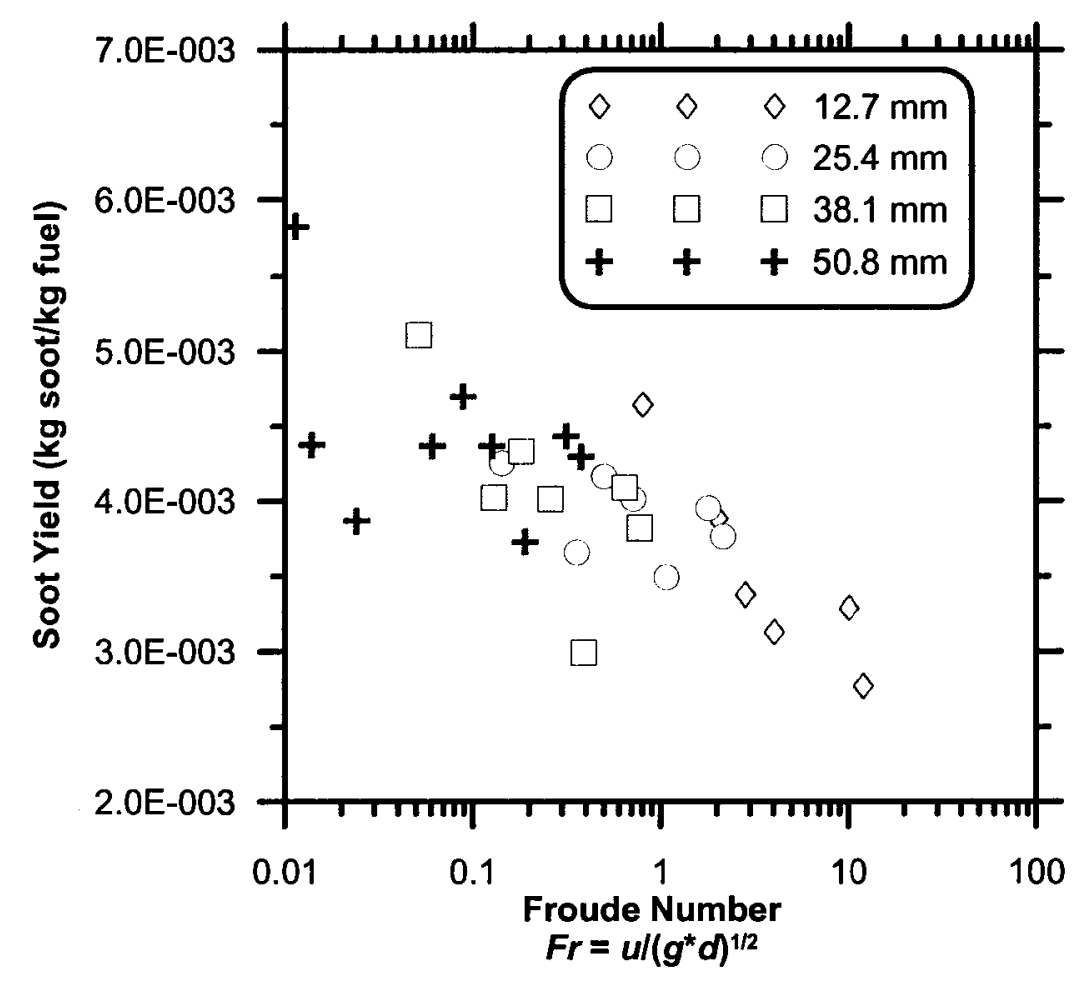

c) Propane

Figure 4.9: Soot yield as a function of Froude number for the different fuels and burner exit diameters 


\section{Chapter 5: $\quad$ Analysis and Discussion}

\subsection{Effects of Dilution Ratio and Exhaust Flow Rate}

One of the main assumptions made in these experiments was that the total mass of soot was constant when the dilution ratio and exhaust gas temperature were changing. From the literature (see Section 3.2) it has been shown that the sampling conditions can affect the size distribution of the soot; however, the total mass of soot should not change. Moreover, in parametric experiments to examine sampling sensitivities for PM measurement, Chang et al. [23] suggest that for dilution ratios above 20, measurements should be relatively independent of sampling conditions. Kittelson et al. [38] showed that the particles in the accumulation mode $\left(D_{p}>50 \mathrm{~nm}\right)$ are not affected by changes in the dilution conditions but the nuclei mode $\left(D_{p}=7-30 \mathrm{~nm}\right)$ are strongly affected by dilution conditions; however, they only make up $1 \%$ of the total mass of particles. Nevertheless, if the dilution ratio or temperature is affecting the total mass of soot in the sampling system, then this would indeed cause errors in the results.

Several experiments were performed to assess the effect of changing dilution ratio and exhaust gas temperature on the soot yield for propane and methane flames in the current setup. Figures 5.1a,b shows repeated measurements of soot yield for the same burner conditions and varied dilution ratio in the exhaust duct. Figure 5.2a,b shows results from the same experiments plotted against measured temperature in the exhaust duct. 


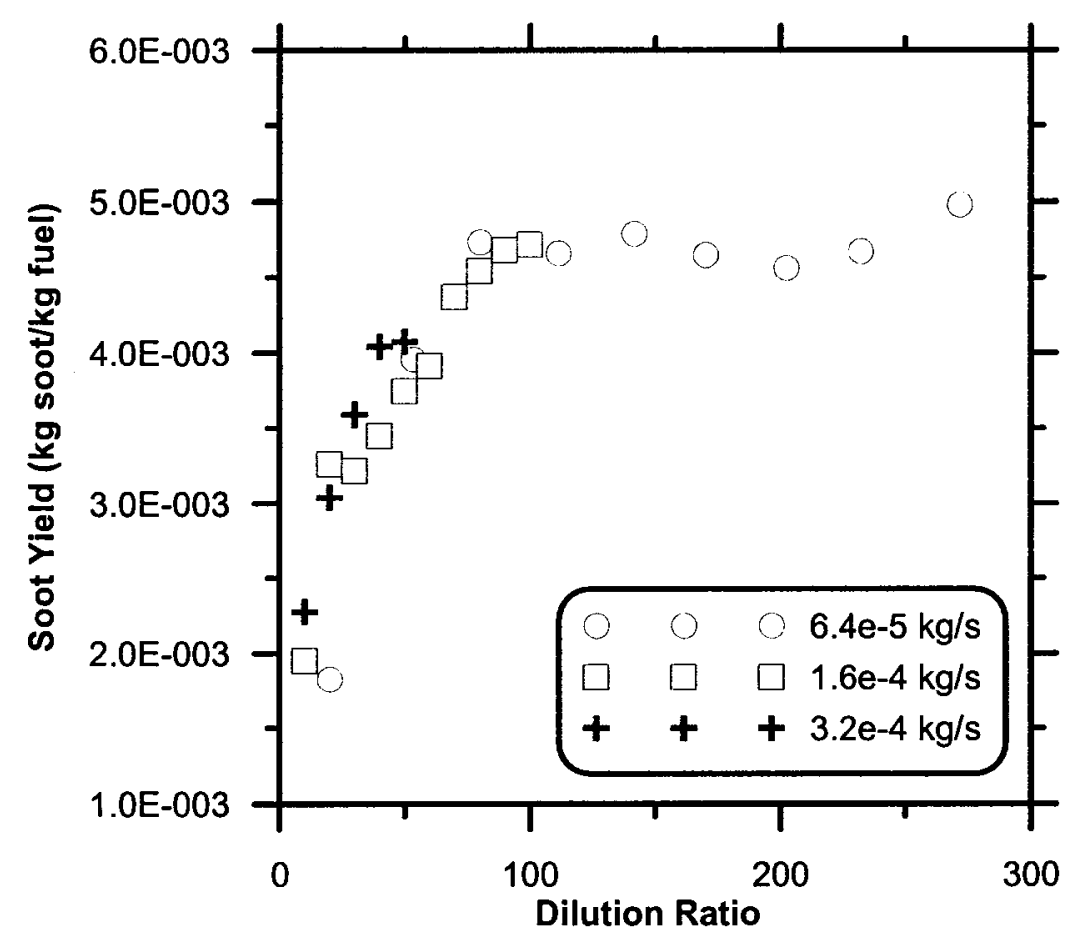

a) Dilution ratio with propane

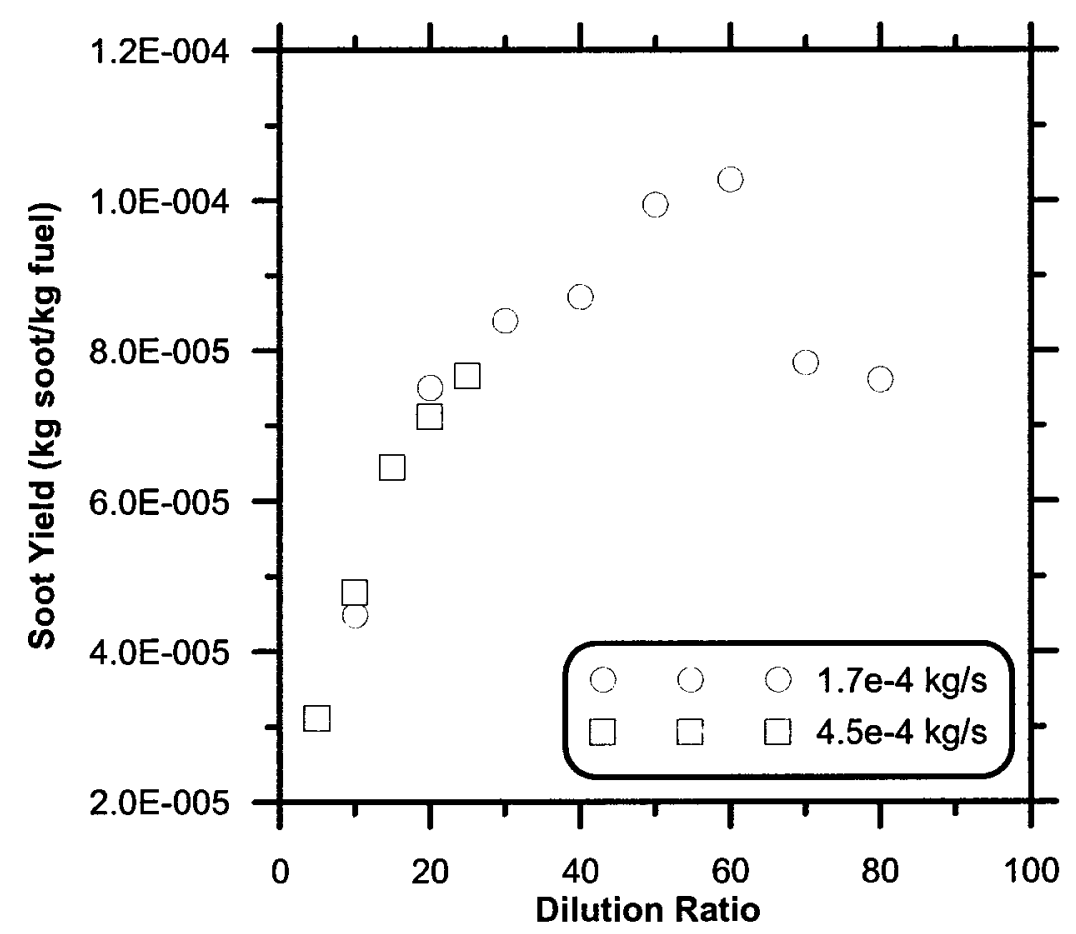

b) Dilution ratio with methane

Figure 5.1: Effect of varied dilution ratio on measured soot yield of a) propane and b) methane flames at different fuel flow rates 


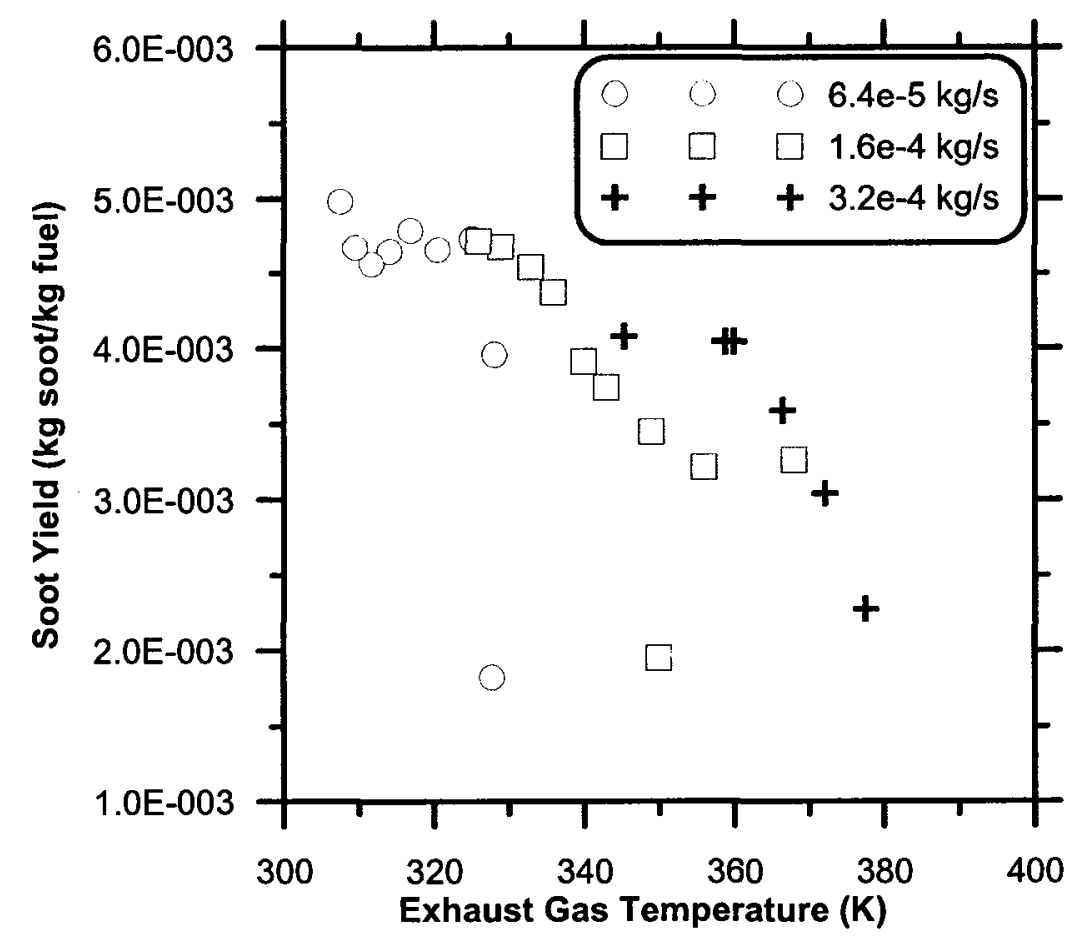

a) Exhaust gas temperature with propane

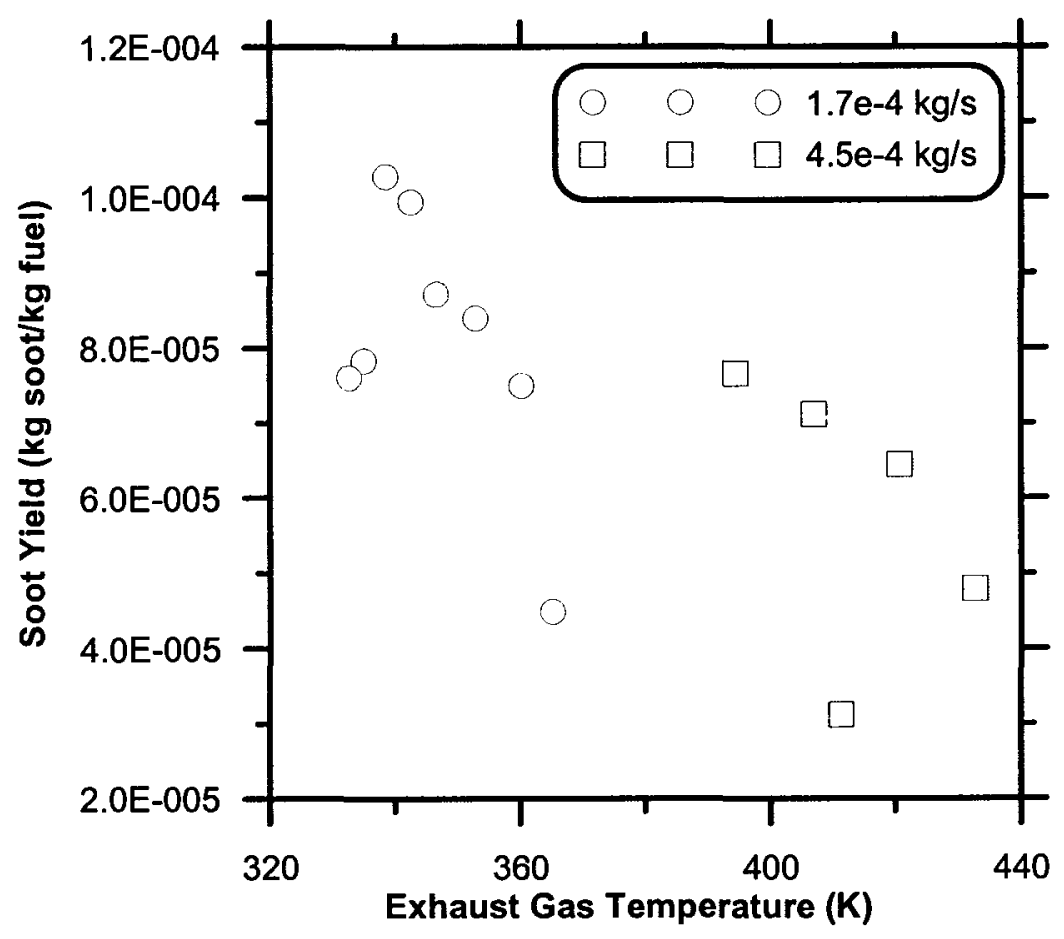

b) Exhaust gas temperature with methane

Figure 5.2: Effect of exhaust gas temperature on measured soot yield for a) propane and b) methane flames at different fuel flow rates 
The data shown in Figures 5.1a,b are quite unsettling since they show that the soot yield does not remain constant at different dilution ratios as initially assumed. Since the dilution ratio varied for different tests, this could be one of the main causes of the uncorrelated results shown in Chapter 4. Figures 5.2a,b show that the exhaust gas temperature may also be affecting the soot yield; however, the dilution ratio affects the exhaust gas temperature so it is more likely that the data in Figure 5.2 are just variations of those in Figure 5.1. Sampling losses could also be causing the change in soot yield; however, the estimates shown in Section 3.7.4 can not account for the $60 \%$ loss in soot observed in Figures 5.1a,b from a high flow rate to a low flow rate.

\subsubsection{Flow Rate Measurement Bias}

The calculation of soot yield is highly dependent upon an accurate measurement of the exhaust gas volumetric flow rate $\left(Q_{d u c t}\right)$ and the exhaust gas temperature $\left(T_{\text {duct }}\right)$. Two major assumptions were made for the measurement of these parameters: the averagingpitot tube requires an axisymmetric velocity profile to give an accurate measurement, and the measurement of temperature at a single point assumed uniform temperature throughout the duct. A horizontal and vertical traverse with a pitot-static tube was completed to check the validity of these assumptions. A thermocouple was also attached to the pitot-static tube and traversed to obtain a temperature profile. As can be seen in Figure 5.3a, the velocity profile is not symmetric in the vertical direction, especially at higher flow rates. The horizontal velocity profile (Figure 5.2b) appears to be symmetric. Since the velocity profile becomes less axisymmetric as the flow rate increases, the averaging-pitot tube could be producing larger measurement errors at these high flow rates. If this were the case, then the results shown in Figure 5.1a could be due to a measurement error and the soot yield may not actually be changing when varying dilution ratio. Since $Q_{d u c t}$ and $D R$ may be in error, the fan speed (FS) was used as the parameter to set the flow rate in the duct for the traversing pitot tube measurements to allow for repeatable conditions. The fan speed is set by sending a $0-5 \mathrm{~V}$ signal from the computer 
to the fan controller, which sets the fan motor speed. The fan speed is shown as a percentage of the operating span, for example, $\mathrm{FS}=100 \%$ refers to the maximum fan speed.

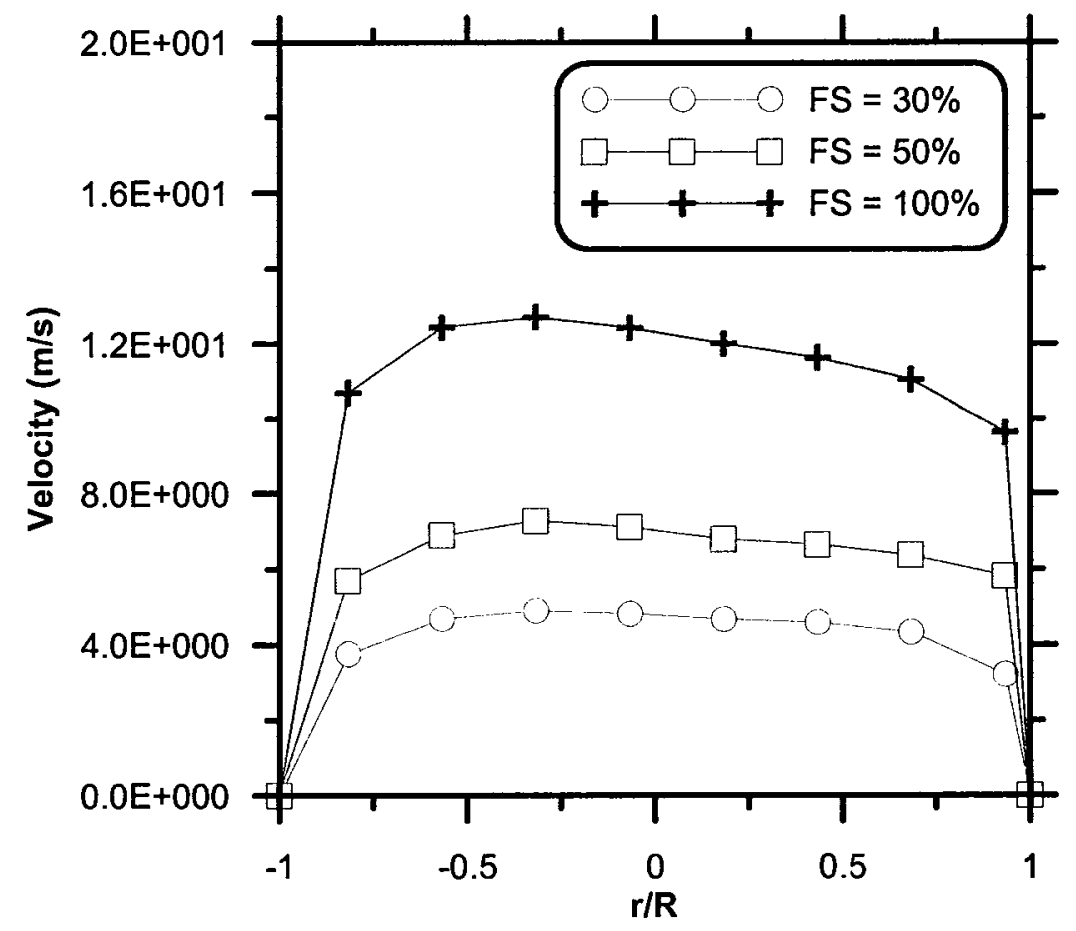

a) Vertical velocity profile in exhaust duct at different fan speeds

Figure 5.3: a) Vertical and b) horizontal velocity profiles obtained with a traversing pitotstatic tube in the sampling duct (flame burning ethane fuel at $1.1 \mathrm{e}-4 \mathrm{~kg} / \mathrm{s}$ ) 


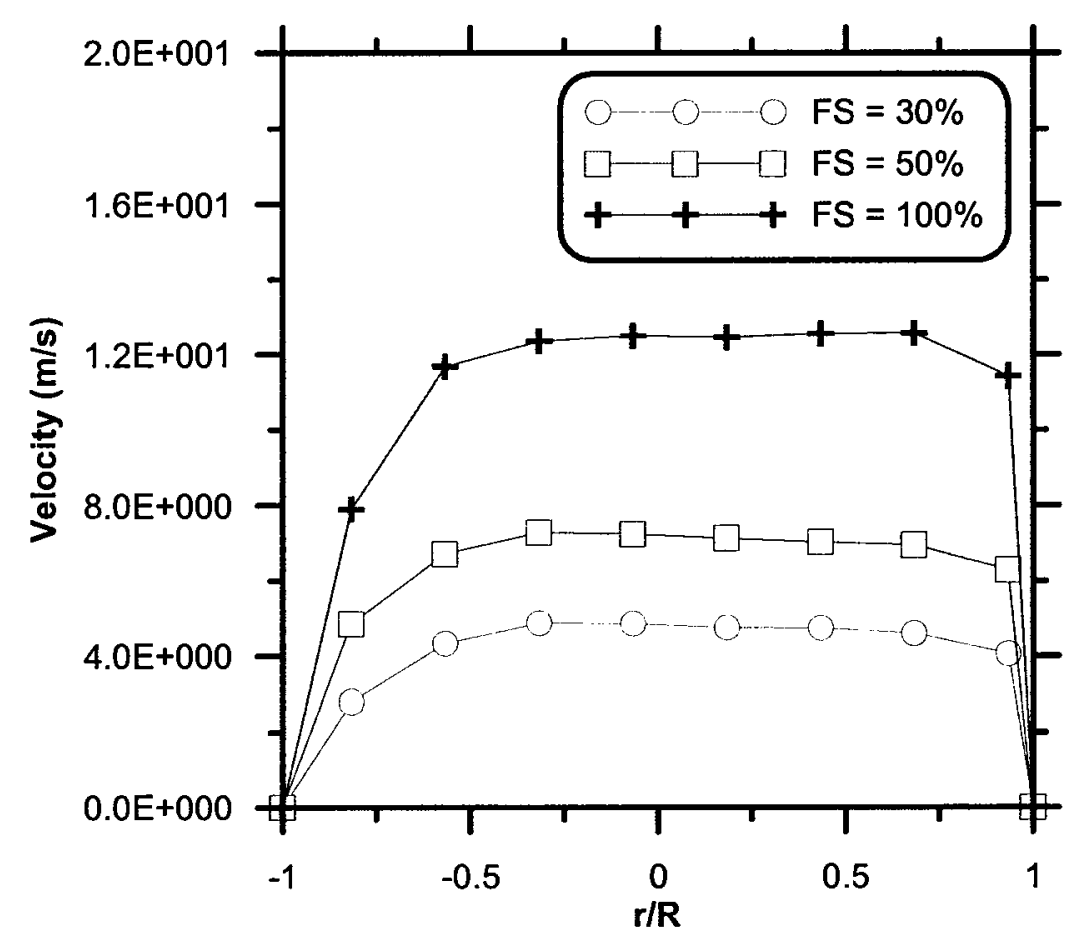

b) Horizontal velocity profile in exhaust duct for different fan speeds

Figure 5.3: a) Vertical and b) horizontal velocity profiles obtained with a traversing pitotstatic tube in the sampling duct (flame burning ethane fuel at $1.1 \mathrm{e}-4 \mathrm{~kg} / \mathrm{s}$ )

The measured temperature profiles in Figures 5.4a,b appear to be fairly constant throughout the duct. At the lowest flow rate, the temperature profile shows a slight decreasing trend as it approaches the duct wall: however, this variation is approximately $\pm 3 \mathrm{~K}$ from the centerline value. This is a small variation considering the uncertainty of the thermocouple itself is $\pm 2.2 \mathrm{~K}$. The apparent discontinuity of $\sim 2.5 \mathrm{~K}$ in the horizontal temperature profile is also attributable to measurement uncertainty. It should be noted that part of the duct insulation needed to be removed when conducting the traversing tests which could be causing a larger temperature gradients near the walls than would have been present during the actual soot emission tests when the insulation was undisturbed. Thus, the assumption of a uniform duct temperature is valid. 


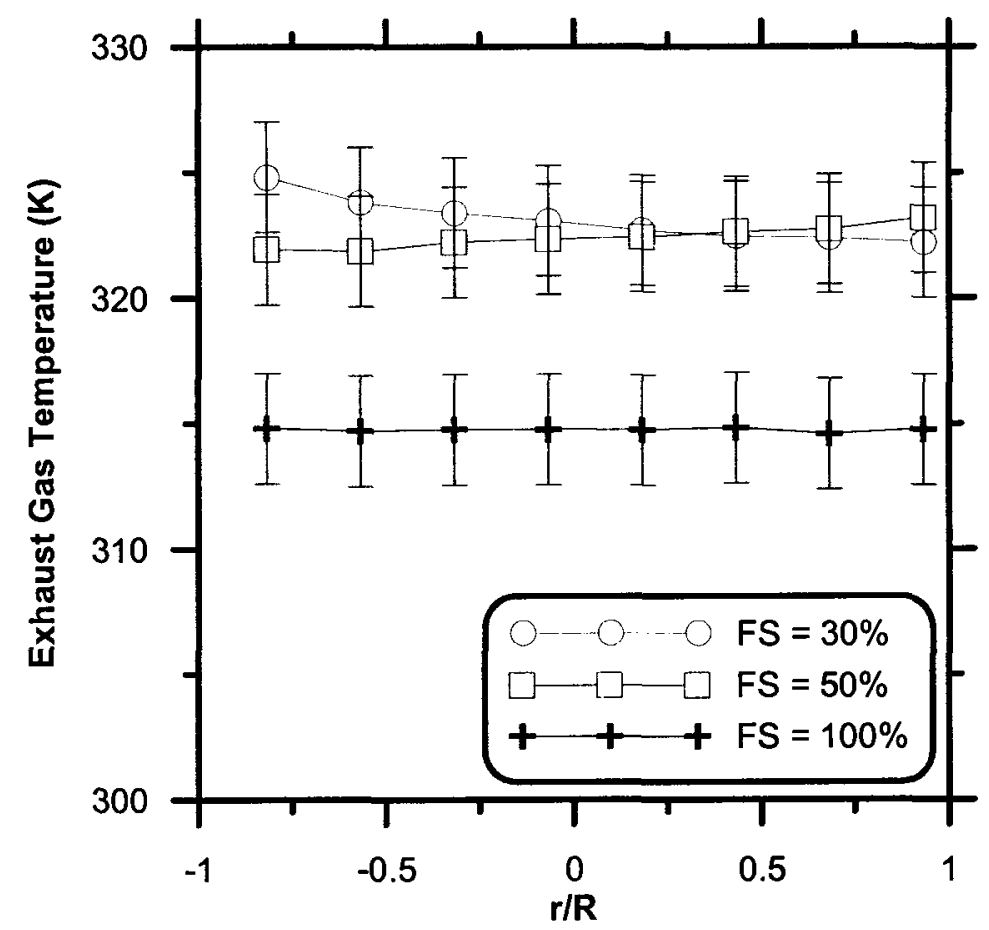

a) Vertical traverse

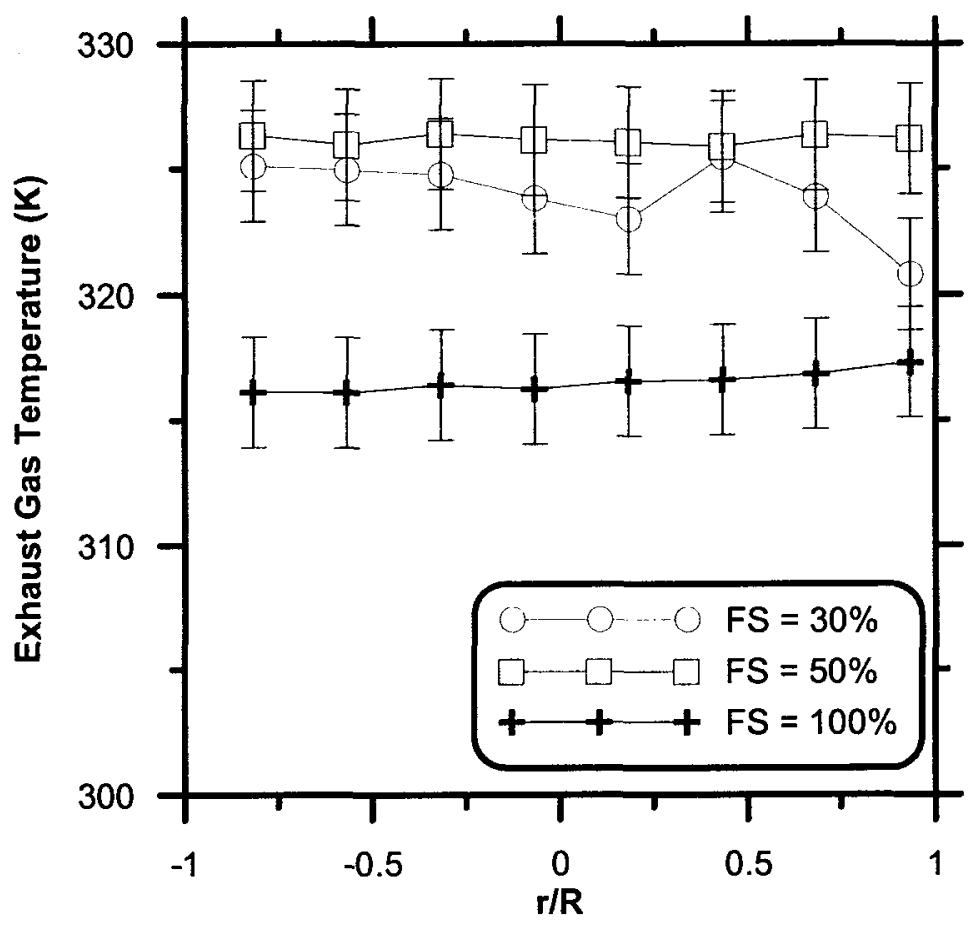

b) Horizontal traverse

Figure 5.4: a) Vertical and b) horizontal temperature profiles obtained with a thermocouple in the sampling duct (flame burning ethane fuel at $1.1 \mathrm{e}-4 \mathrm{~kg} / \mathrm{s}$ ) 
Figure 5.5 shows a direct comparison of measurements of $Q_{d u c t}$ using the traversing pitot tube and the averaging pitot tube. Although the averaging pitot tube overestimates $Q_{d u c t}$, the correlation between the two measurements is linear and close-fitting. This suggests that the effect of dilution ratio on soot yield is not a measurement error. There is a slight difference between the flow rate correlations for methane and ethane. However, this difference is most likely caused by the temperature difference between the two conditions $(\sim 50 \mathrm{~K})$ as discussed below in Section 5.4.

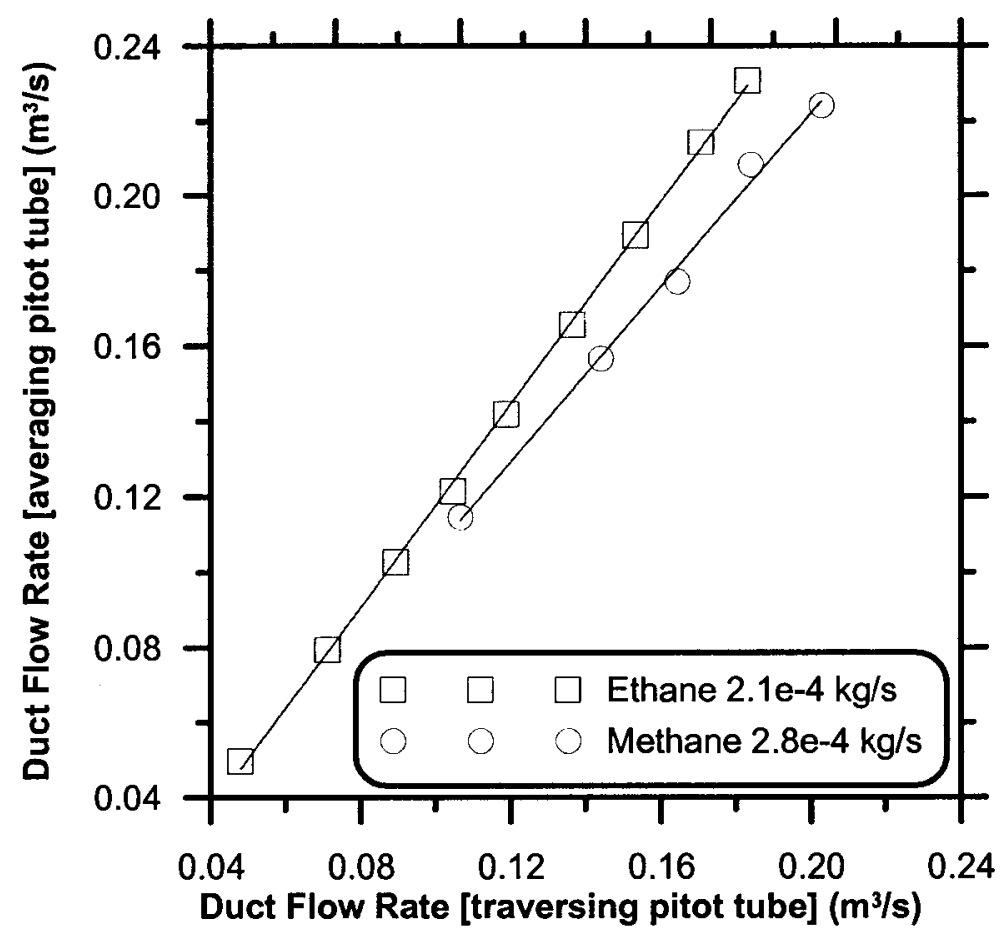

Ethane Linear Fit

$$
\begin{aligned}
& Q_{\text {duct laveraging pitot] }}=1.345^{*} Q_{\text {duct [raversing pitot] }}-0.0169 \\
& R^{2}=0.999 \\
& \text { Methane Linear Fit } \\
& Q_{\text {duct laveraging pitot] }}=1.161 * Q_{\text {duct [traversing pitot] }}-0.0107 \\
& R^{2}=0.995
\end{aligned}
$$

Figure 5.5: Comparison of duct volumetric flow rate measurement using an averaging pitotstatic tube and a traversing pitot-static tube 


\subsubsection{Duct Flow Rate Correction}

From the analysis above, it is apparent that asymmetry in the duct flow may have introduced bias into the flow measurements for the averaging pitot tube. Two correction factors will be implemented so that the soot emission trends can properly be analyzed; one for the bias in the averaging pitot tube measurements and the other to try to account for the effect of dilution ratio on soot yield.

For the duct flow rate correction, Figure 5.5 showed there is a correlation between the averaging pitot tube measurements and the traversing pitot tube. However, the correlations are slightly different for the methane and ethane conditions. Since this is most likely due to a temperature effect, a preferred correction for the averaging pitot tube could be based on the duct temperature. Figure 5.6 shows the ratio of the two duct flow rate measurements as a function of exhaust duct temperature. The figure shows a fairly good correlation between the two parameters; therefore, it will be used to correct the duct flow rate measurements of the soot emission tests. All results shown in the remaining sections will have the flow rate correction applied to them. 


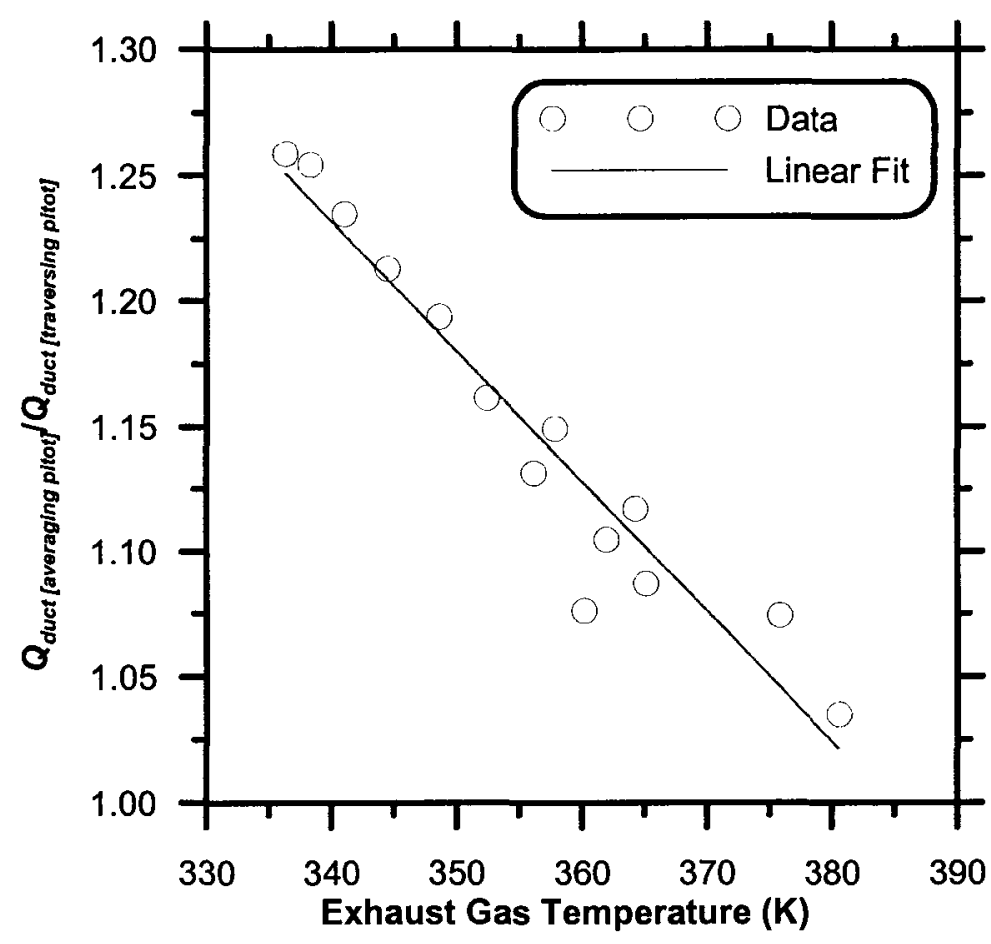

Linear Fit

$Q_{\text {duct [averaging pitotf }} / Q_{\text {duct fraversing pitot] }}=-0.00519^{*} T_{\text {duct }}+2.997$ $R^{2}=0.928$

Figure 5.6: Ratio of averaging pitot tube and traversing pitot tube duct flow rate measurements as a function of exhaust gas temperature

\subsection{Normalization of Dilution Ratio}

To further verify that the trends shown in Figures 5.1 and 5.2 were genuine and were unrelated to any bias error in the measurement of $Q_{\text {duct }}$, an additional series of tests were conducted in which soot yield was measured as a function of dilution ratio and duct flow rate was measured with the traversing pitot tubes. From Figure 5.7, it appears that the soot yield does actually vary with dilution ratio and this effect was not caused by a flow rate measurement error. Since the dilution ratio was not constant for the soot emission tests this effect is a main contributor to the peculiar trends observed in Chapter 4. 


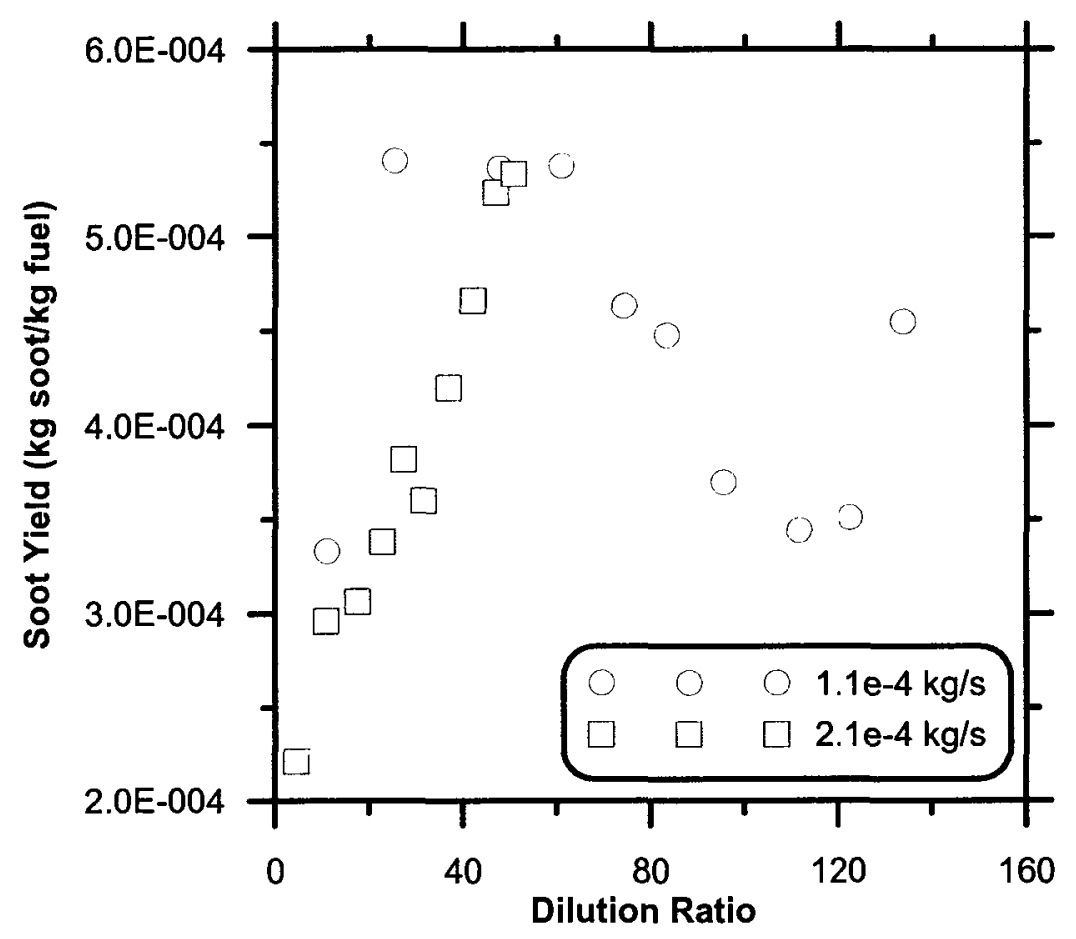

Figure 5.7: Effect of dilution ratio on soot yield using a traversing pitot-static tube for the exhaust gas flow rate measurements (ethane fuel using $38.1 \mathrm{~mm}$ burner at two different fuel mass flow rates)

Figure 5.8 shows a summary of all the dilution ratio tests discussed in this section, where tests in which the averaging pitot tube was used have been corrected for measurement bias according to the results of Figure 5.6 above. In each series of tests, the dilution ratios were increased until the capacity limit of the exhaust fan system was reached. In all tests, there is a similar increasing trend in measured soot yield as the dilution ratio is increased from very low values to about 50 . Above $D R \approx 50$, the ethane and methane data show a curious decreasing trend while the propane data reach an essentially steady limit. However, at very high dilution ratios, the sensitivity of the measurement system also becomes an issue as measured soot volume fractions are very low.

Figures 5.9a,b shows an ensemble plot of all the soot emission tests presented in Chapter 4 in which the exhaust gas temperature has been plotted against dilution ratio. The graphs show that the majority of tests conducted had conditions where $20<D R<50$. 
Chang et al. [23] and Kittelson et al. [38] both suggest that the particle size distribution and concentration should remain constant once the dilution ratio is increased above 20 for natural gas emissions [23] and 200 for diesel emissions [38]. Therefore, a useful approach for accounting for the changes in soot yield with dilution ratio is to normalize the data to a dilution ratio where these effects no longer occur. Despite the contradicting results from the methane and ethane tests after $D R \approx 50$, the propane data do show a plateau region where soot yield becomes relatively constant. Since most of the soot emission tests have a $D R<50$ the peculiar trends of methane and ethane after $D R \approx 50$ are not of concern. In this case, a correction factor can be developed by fitting a line to soot yield data that encompasses the dilution ratio range experienced during the soot emission tests (i.e. $20<D R<50$ ).

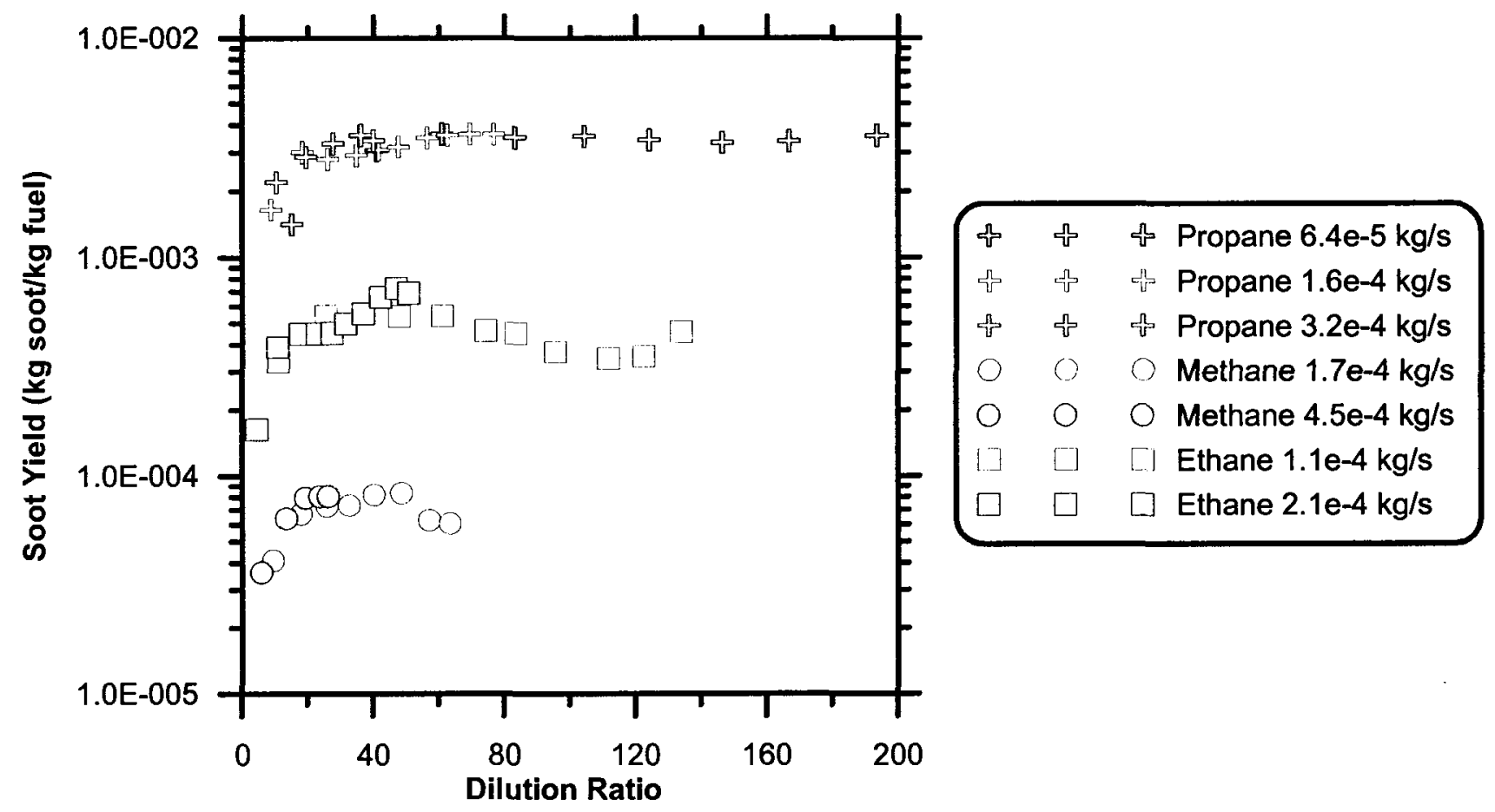

Figure 5.8: Summary of dilution ratio effect on soot yield for methane, ethane, and propane at different fuel flow rates 


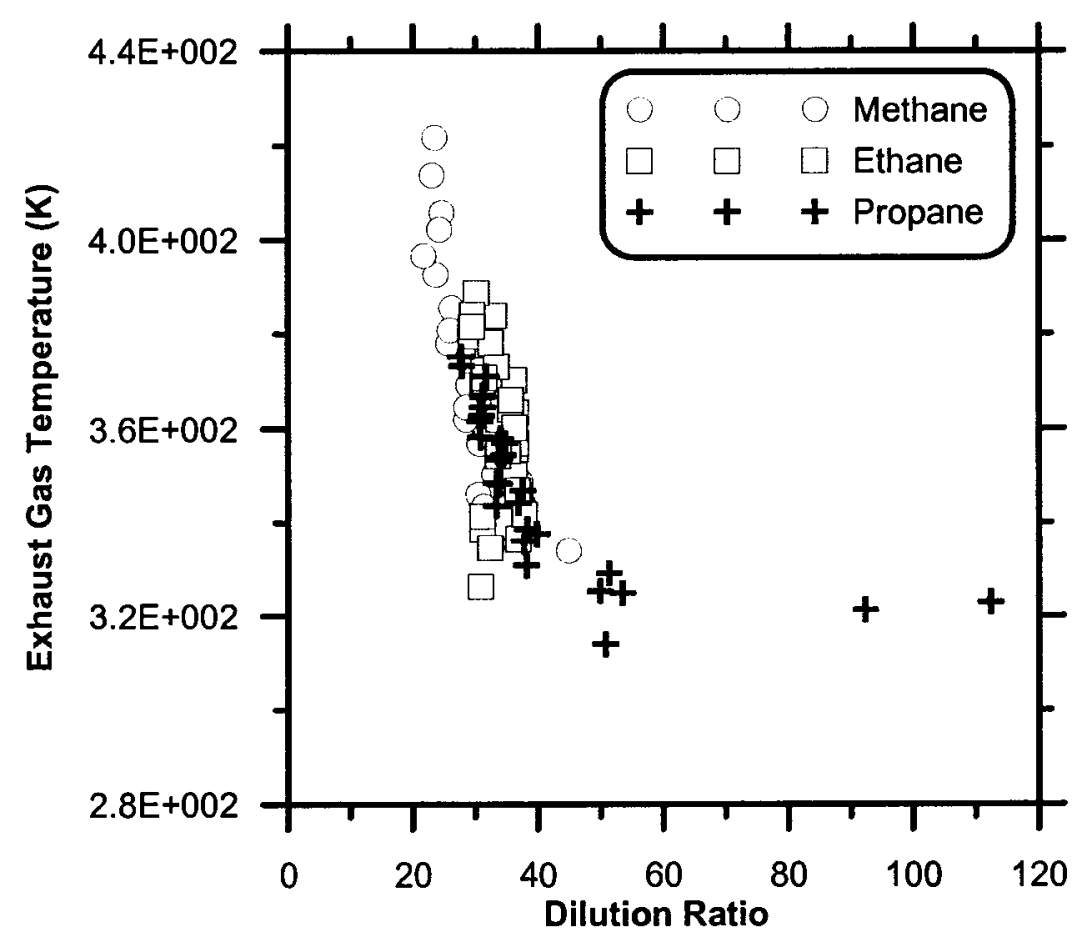

a) Pure fuels

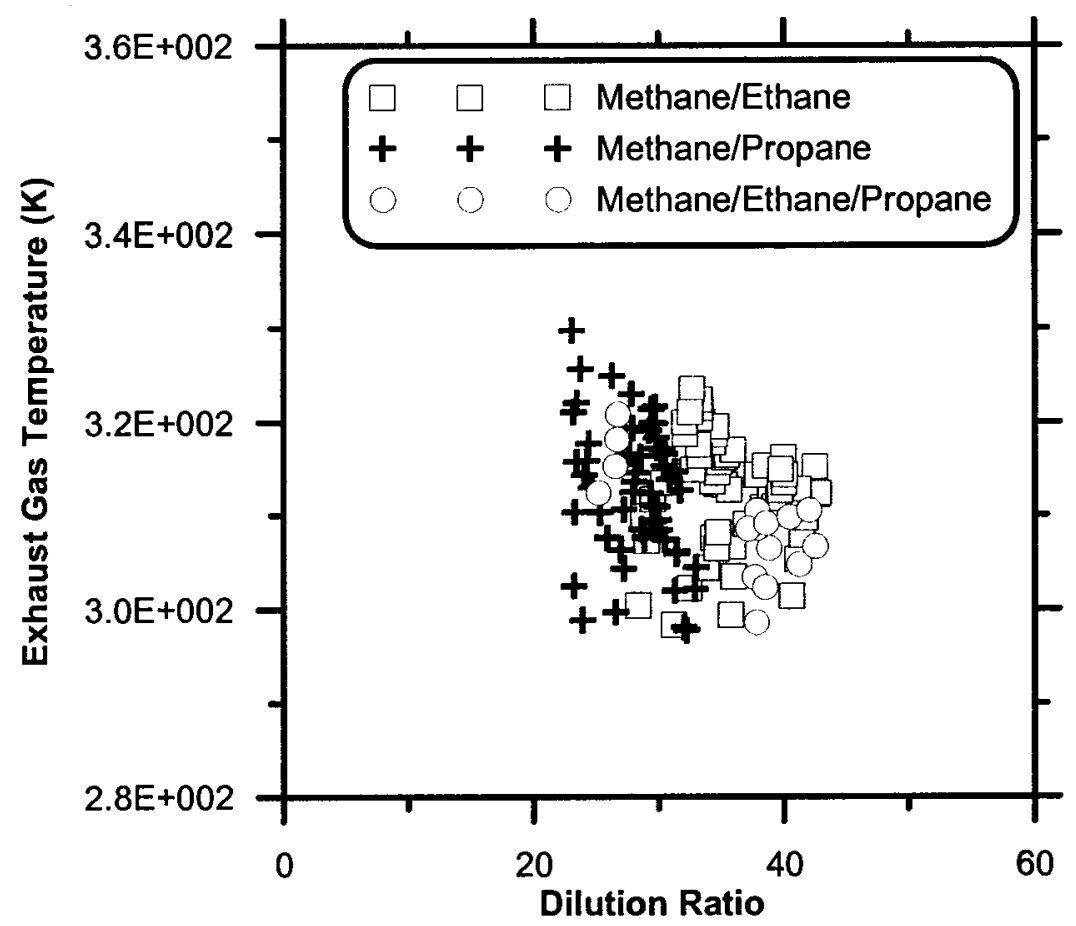

b) Fuel mixtures

Figure 5.9: Dilution ratio and exhaust gas temperature for all soot emission tests performed 
Figure 5.10 shows that a linear fit approximates the observed trends in measured soot yield with dilution ratio reasonably well for each fuel in the range of $20<D R<50$. These fits can then be used to standardize the soot yield data to a common dilution ratio to allow for a better analysis. Based on the results shown in Figures 5.8 and 5.9, a dilution ratio of 50 is selected as the standard condition for soot yield measurements. This is the condition at which soot yield appears to approach constant value with increased dilution ratio.

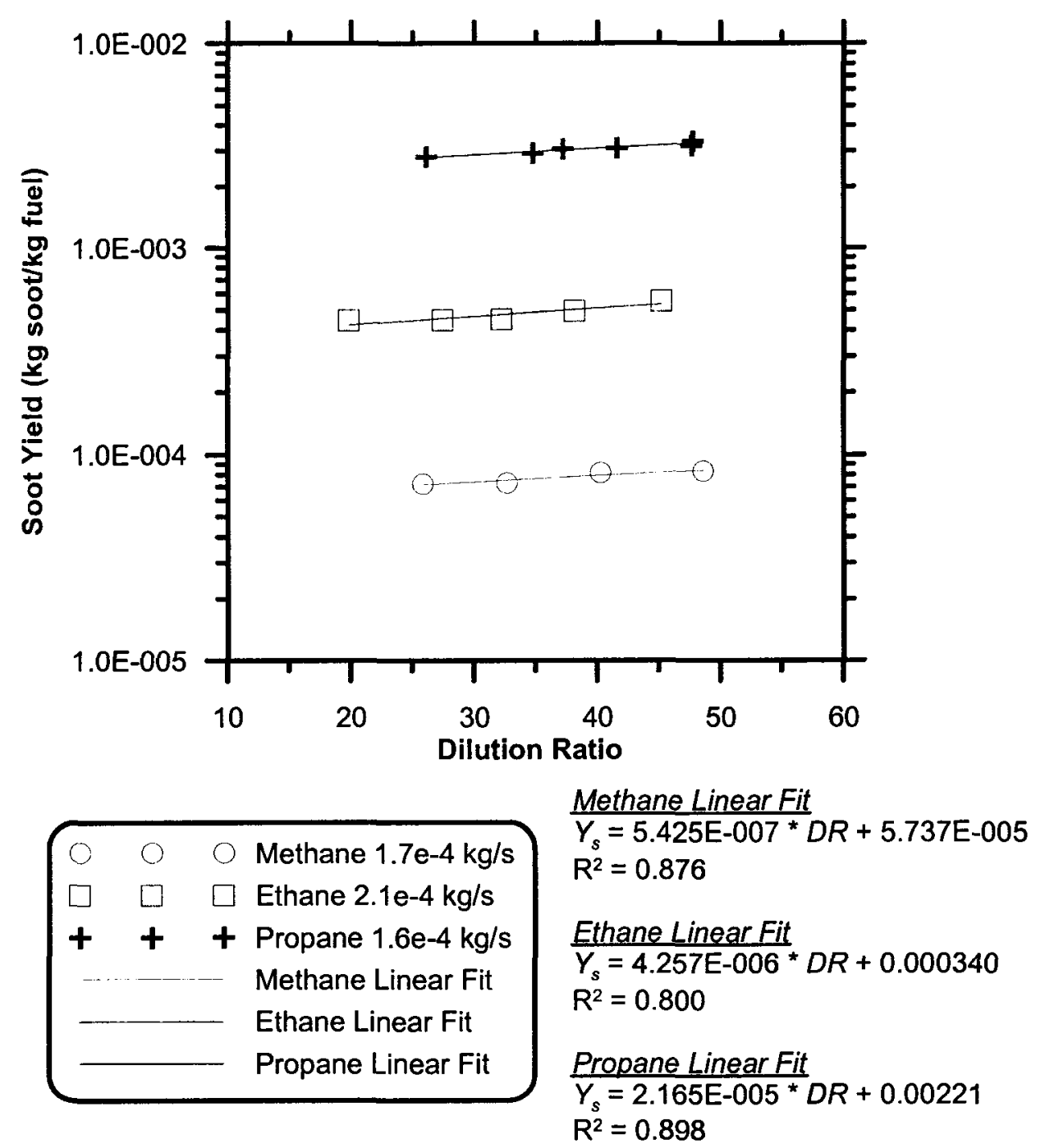

Figure 5.10: Soot yield as a function of dilution ratio in the range $20<D R<50$ for methane, ethane, and propane

The dilution ratio correction is applied to the measured soot yield data as follows, 


$$
Y_{s_{-} \text {corrected }}=Y_{s_{-} \text {meassured }} \cdot \frac{Y_{s}\left(D R_{50}\right)}{Y_{s}\left(D R_{\text {measured }}\right)}
$$

where, $Y_{s_{-} \text {corrected }}$ is the soot yield corrected to a dilution ratio of 50

$Y_{s_{-} \text {measured }}$ is the measured soot yield from the soot emission tests

$Y_{s}\left(D R_{50}\right)$ is the soot yield given from the linear fit at a dilution ratio of 50

$Y_{s}\left(D R_{\text {measured }}\right)$ is the soot yield given from the linear fit at the measured dilution ratio

To obtain an estimate of the uncertainty introduced by applying this correction factor to the data, Eq. (5.1) is applied to the variable dilution ratio test data from Figure 5.8. In this manner, measured data from $20 \leq \mathrm{DR}<50$ ( $\left.Y_{s_{-} \text {measured }}\right)$ can be standardized to the chosen reference dilution ratio of $50\left(Y_{S_{-} \text {corrected }}\right)$ and directly compared with the measured data at $D R=50$ given by the linear fit equation $\left(Y_{s}\left(D R_{50}\right)\right)$. Thus, if the correction were

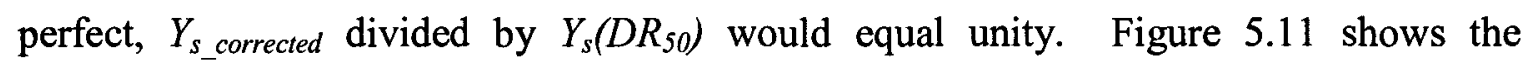
fractional difference between these two values for the different fuels. A numeric estimate of the uncertainty is then determined by taking the standard deviation of the ratio $Y_{s_{-} \text {corrected }} Y_{s}\left(D R_{\text {corrected }}\right)$ from a value of 1 instead of the mean. Applying this method to the data shown in Figure 5.11 gives an uncertainty of approximately $10 \%$ for propane and methane and $8.4 \%$ for ethane. These values will be used in all further plots to observe the uncertainty introduced by the correction factor. 


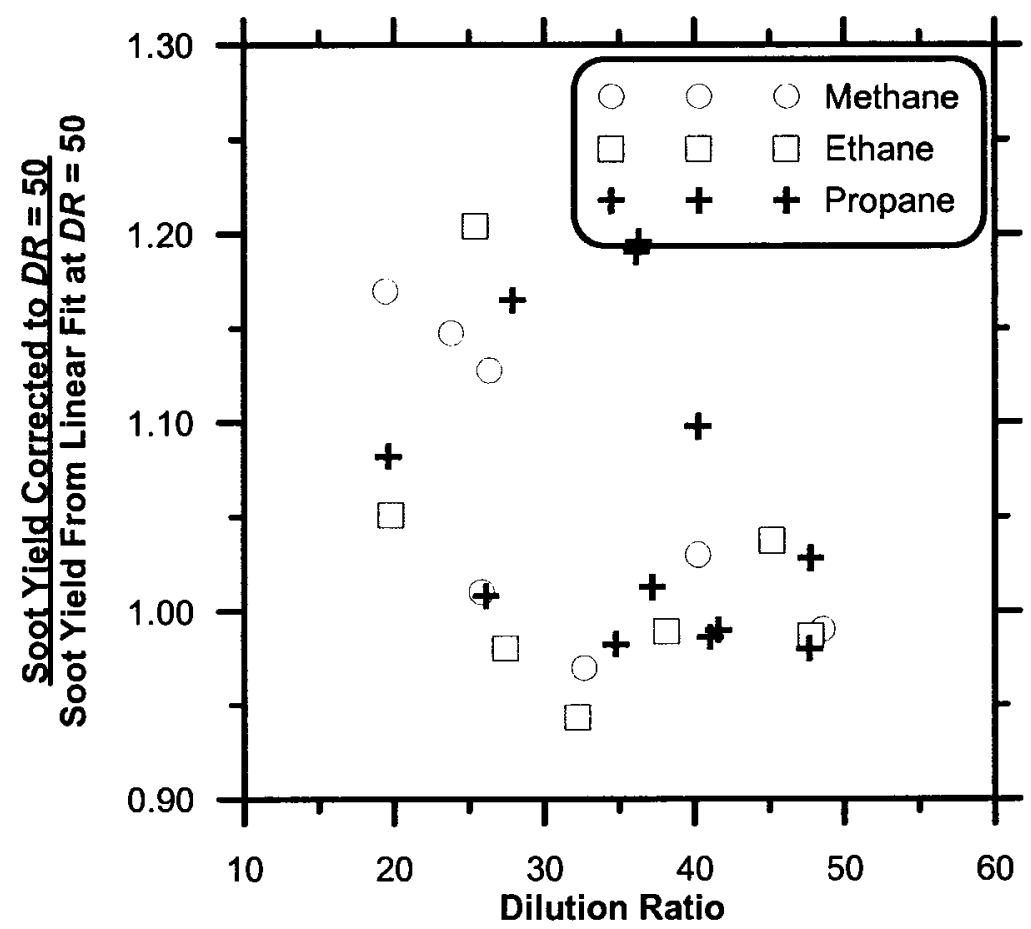

Figure 5.11: Estimate of the soot yield uncertainty introduced from dilution ratio correction factor

\subsection{A Revised Look at Simple Scaling Relations for Soot Emissions from Pure Fuels}

The results in Chapter 4 can now be reanalyzed correcting for flow rate measurement bias and normalizing to a standard dilution ratio. Figures 5.12a-c show the soot generation efficiency as a function of the characteristic residence time. It appears this still is not a suitable choice as a scaling parameter since no clear trends can be observed. 


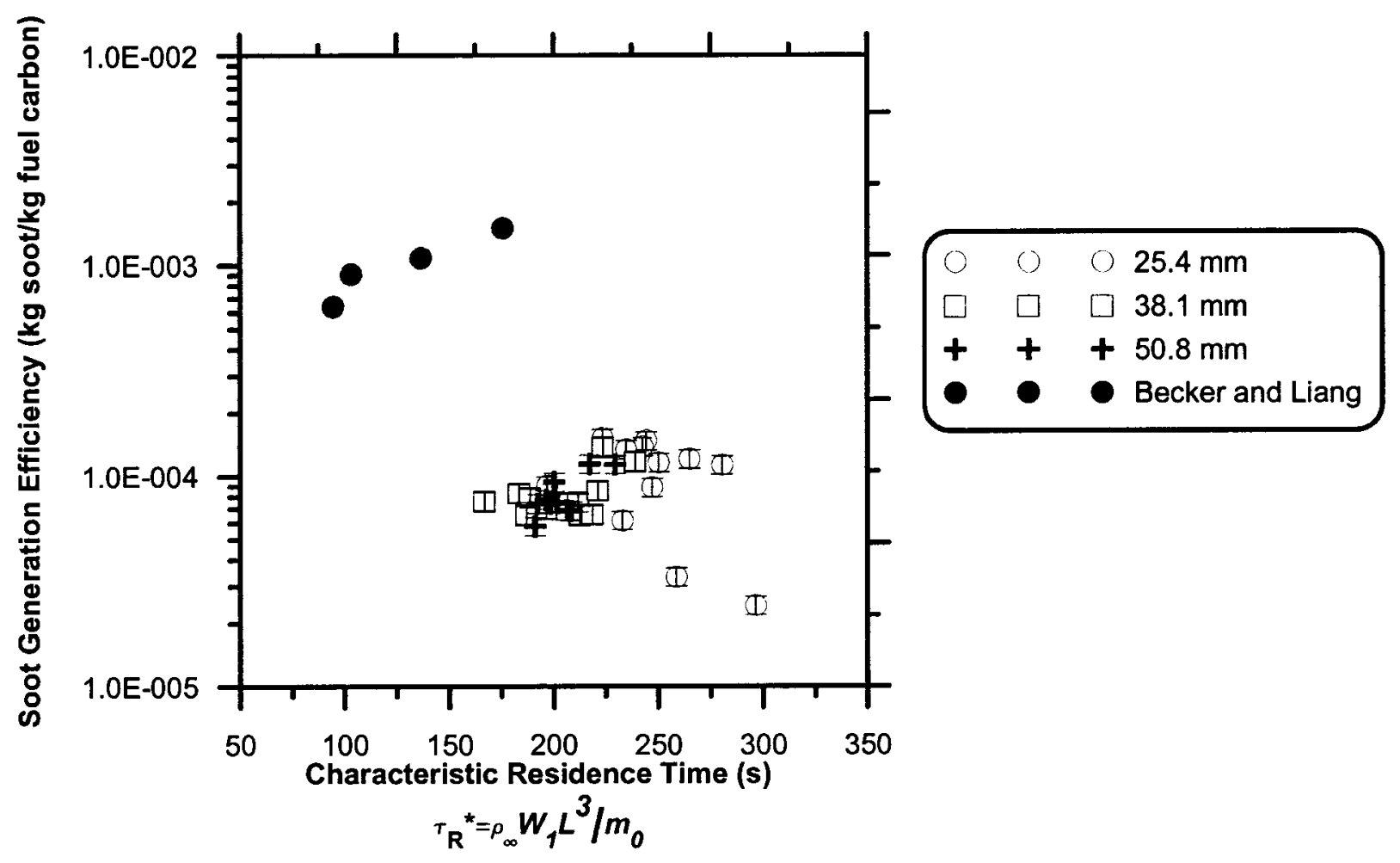

a) Methane

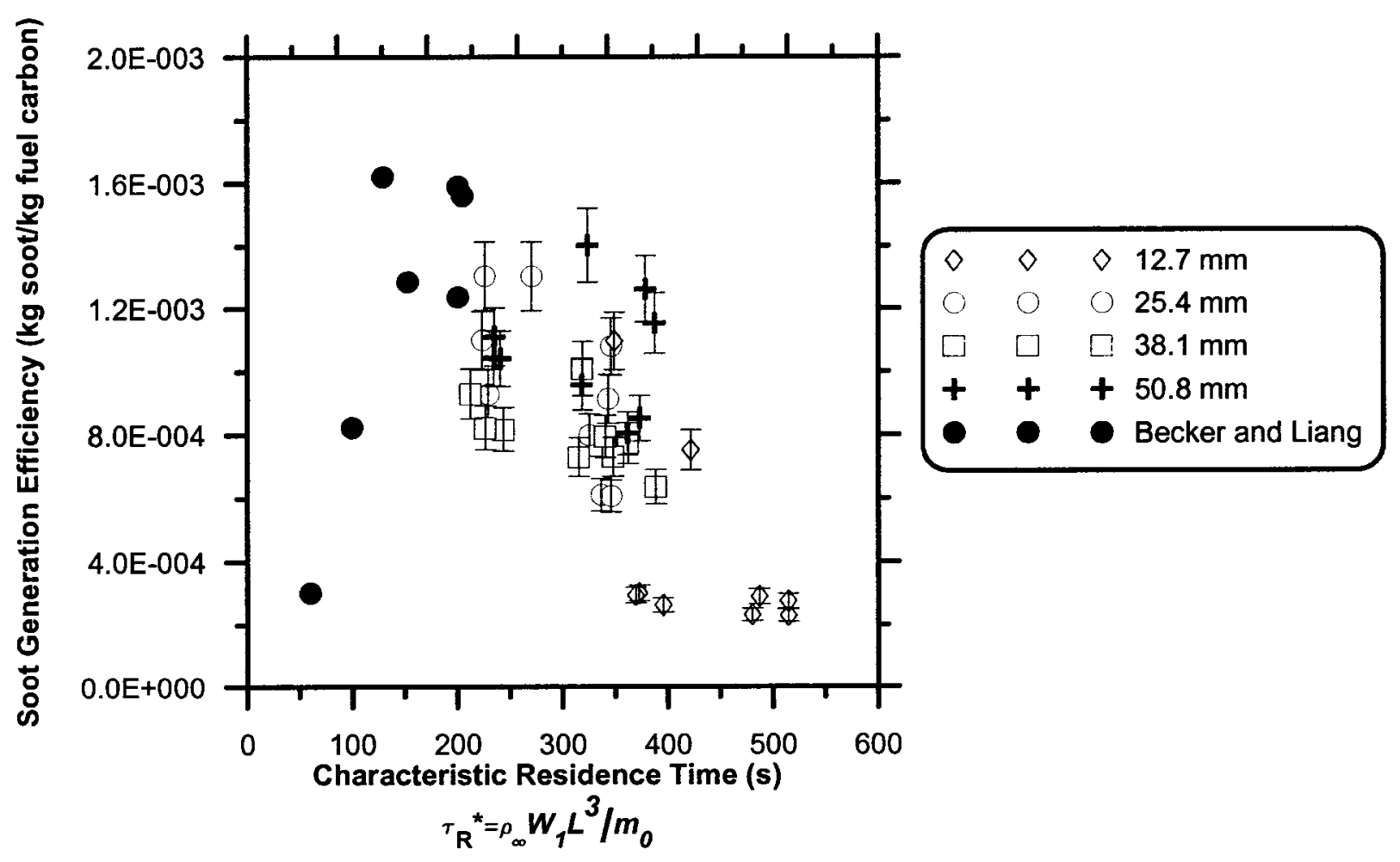

b) Ethane 


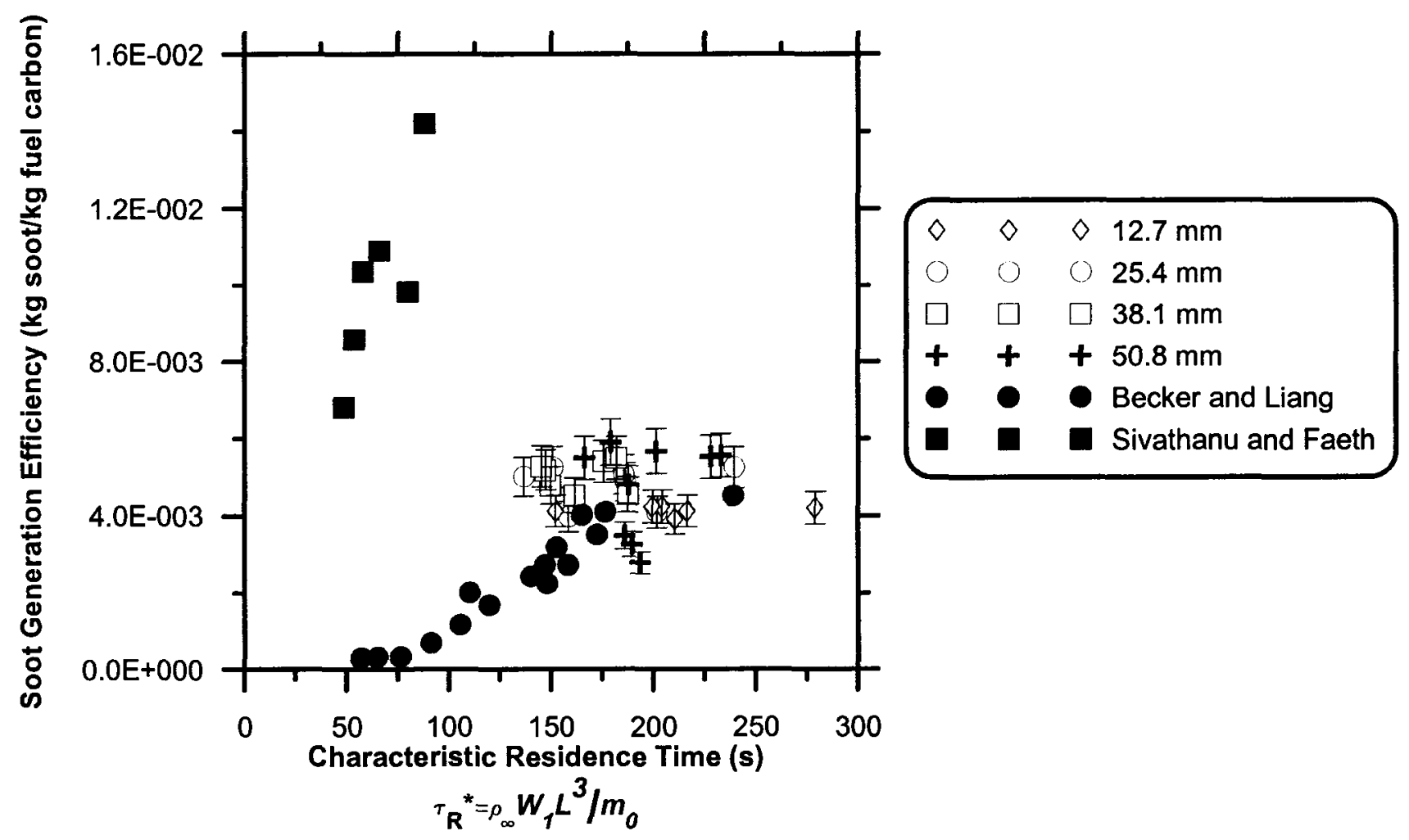

c) Propane

Figure 5.12: Soot yield as a function of characteristic residence time compared with Sivathanu and Faeth [26] and Becker and Liang [27] for a) methane, b) ethane, and c) propane fuels

Figures 5.13a-c show updated plots of using $F r$ as a scaling parameter. There is a clear separation in soot yield between the different burner exit diameters. The following discussion will be based on the propane data because its high sooting propensity allowed the largest span of $F r$ to be covered. The soot yield for the $50.8 \mathrm{~mm}$ burner with propane initially decreases as $F r$ increases. The data point with the lowest $F r$ corresponds to a very small flow rate where the flame was possibly in a laminar regime. This was visually observed in the video images where the flame was mostly laminar with a slight flicker. The initial decrease in soot yield is expected because of an increase in turbulent mixing. As $F r$ increases from 0.02 , there is an increasing trend in soot yield which begins to level-off at $F r>0.1$. The $25.4 \mathrm{~mm}$ data exhibits a similar trend to the $50.8 \mathrm{~mm}$ data, whereas the $38.1 \mathrm{~mm}$ shows no clear trends. The smallest diameter burner is mostly in 
the region where $F r>1$ which, by definition, is where the momentum forces become greater than buoyant forces. In this regime, the soot yield appears to be relatively constant. Similar trends were observed in methane and ethane, except for the $12.7 \mathrm{~mm}$ burner with methane which continues to decrease with increasing $F r$.

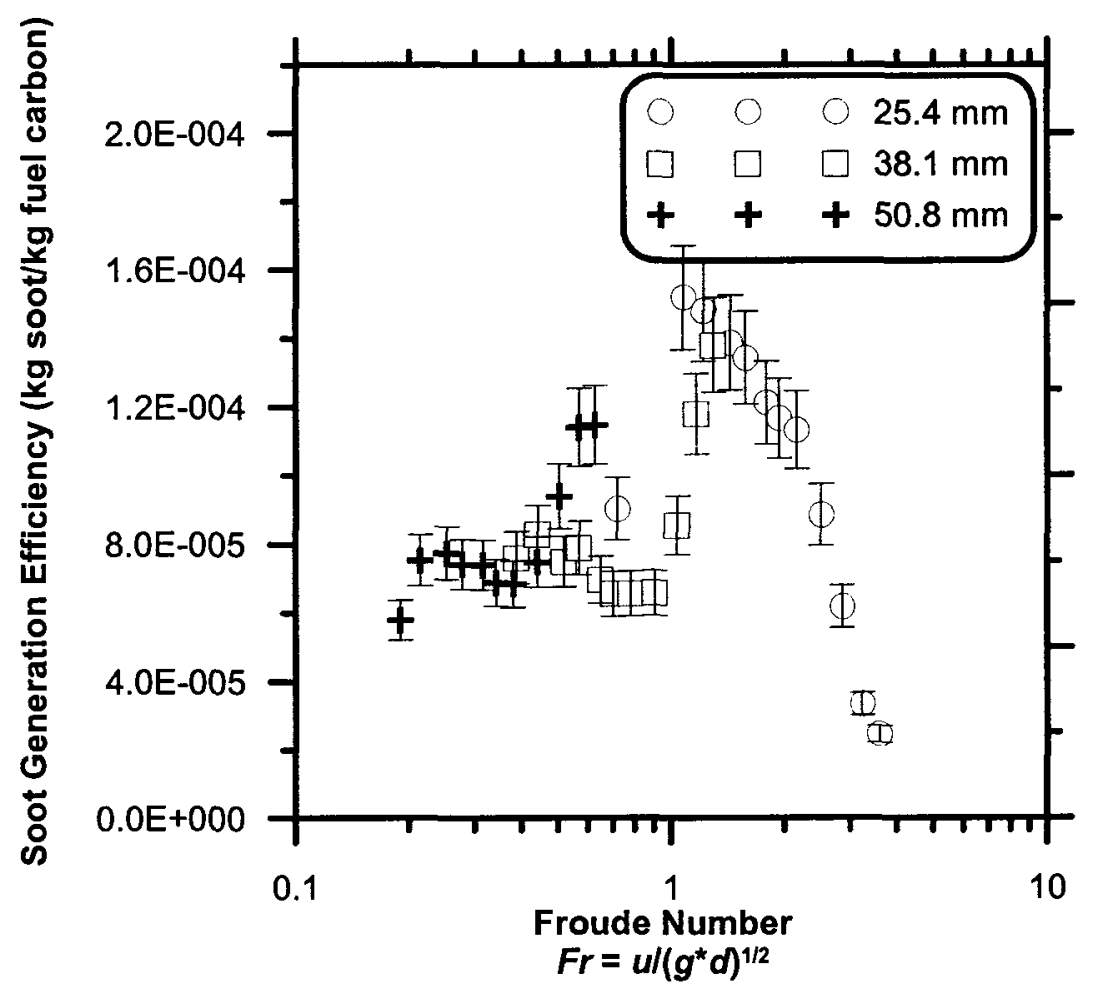

a) Methane

Figure 5.13: Soot yield as a function of Froude number for a) methane, b) ethane, and c) propane fuels 


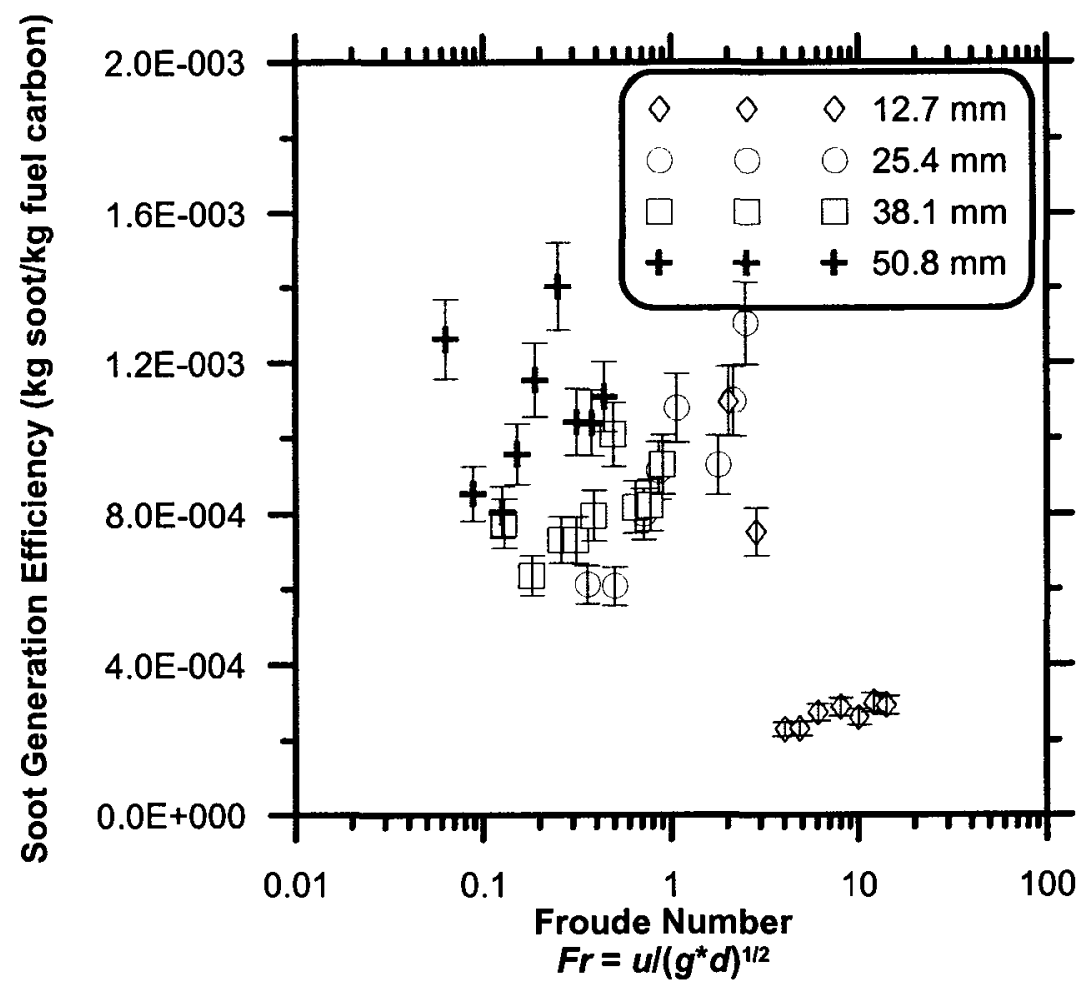

b) Ethane

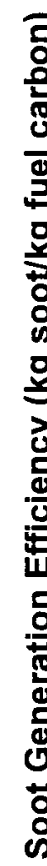

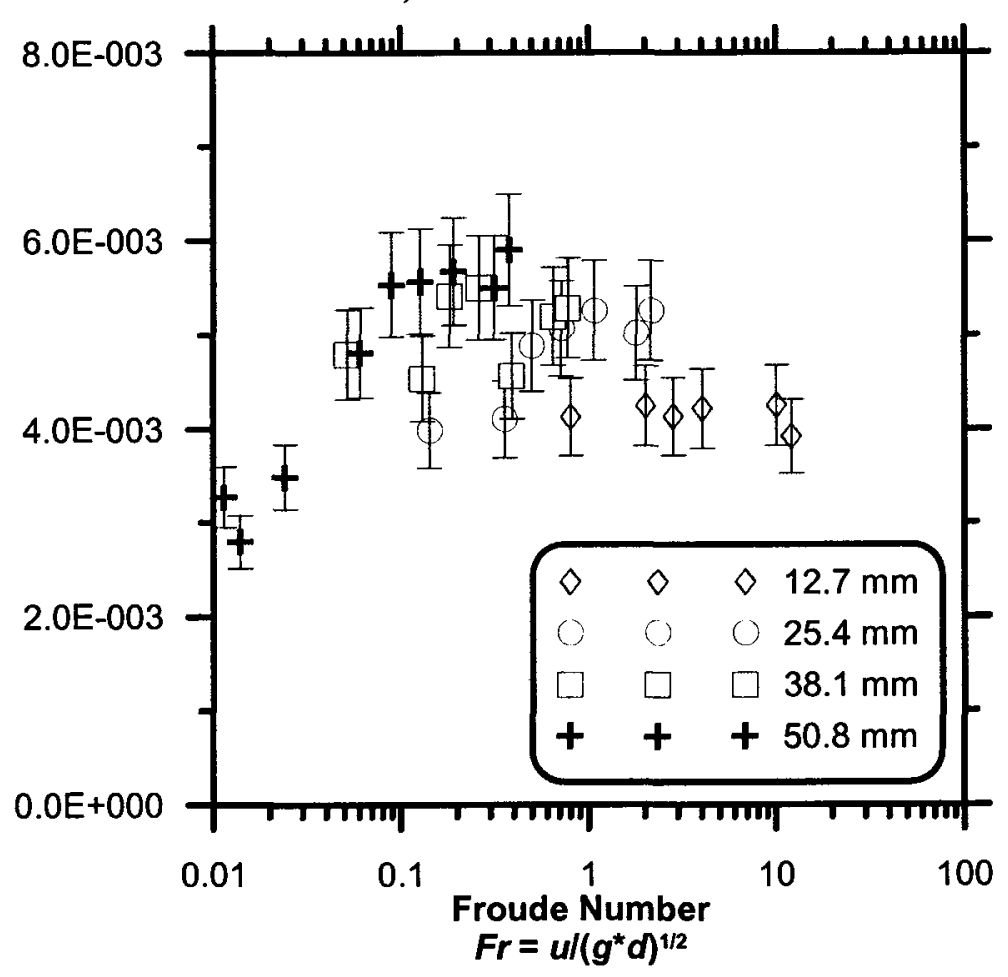

c) Propane

Figure 5.13: Soot yield as a function of Froude number for a) methane, b) ethane, and c) propane fuels 
The Froude number does not seem suitable for scaling the soot emissions data since there is still a considerable effect from the burner exit diameter and there are separate increasing and decreasing regimes seen in the data. These different regimes could be due to the competing parameters which affect soot formation and oxidation, such as, the residence time, mixing rate, and flame temperature (as detailed in Section 2.0). Therefore, a more physically based scaling parameter should include a measure of each of these effects to capture the physical processes occurring in the flame.

\subsubsection{Flame Geometry}

One approach to modeling the effects of residence time and mixing rate is to relate them to quantifiable geometric features of the flame such as flame length, maximum flame width, flame perimeter, and flame area. For example, the flame perimeter could be linked to the mixing rate since greater interaction with turbulent eddies should increase the perimeter of the flame. Similarly, flame length is linked to residence time. Flame width and area, two other readily calculated parameters from flame image data, are related to residence time and acceleration through the flame.

By processing collected digital images of the visible flame, these four geometric parameters can be calculated and plotted as shown in Figure 5.14a-d. Since normalized flame length $(L / d)$ is believed to be a function of $F r$ [21], it is convenient to plot this and each of the other geometrc measures normalized with the burner exit diameter and shown as a function of $F r$. 


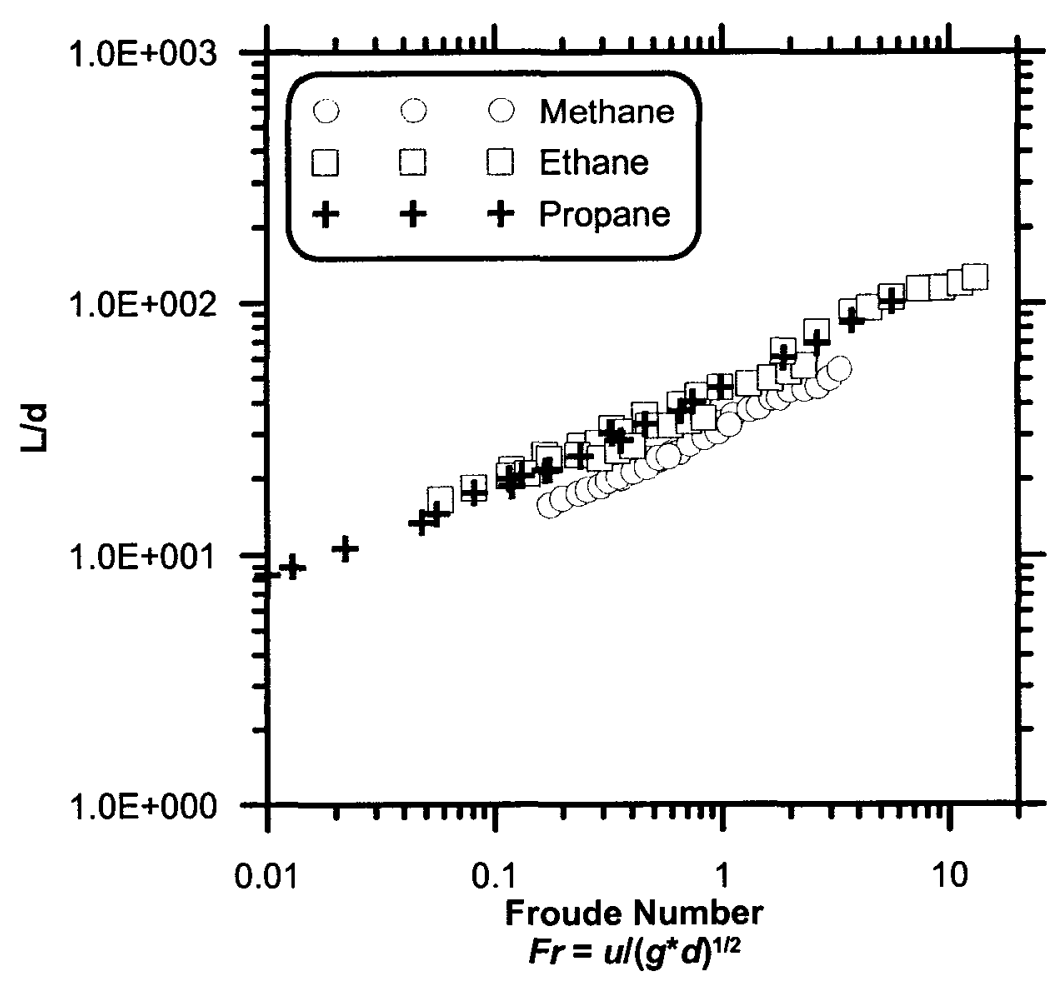

a) Normalized flame length

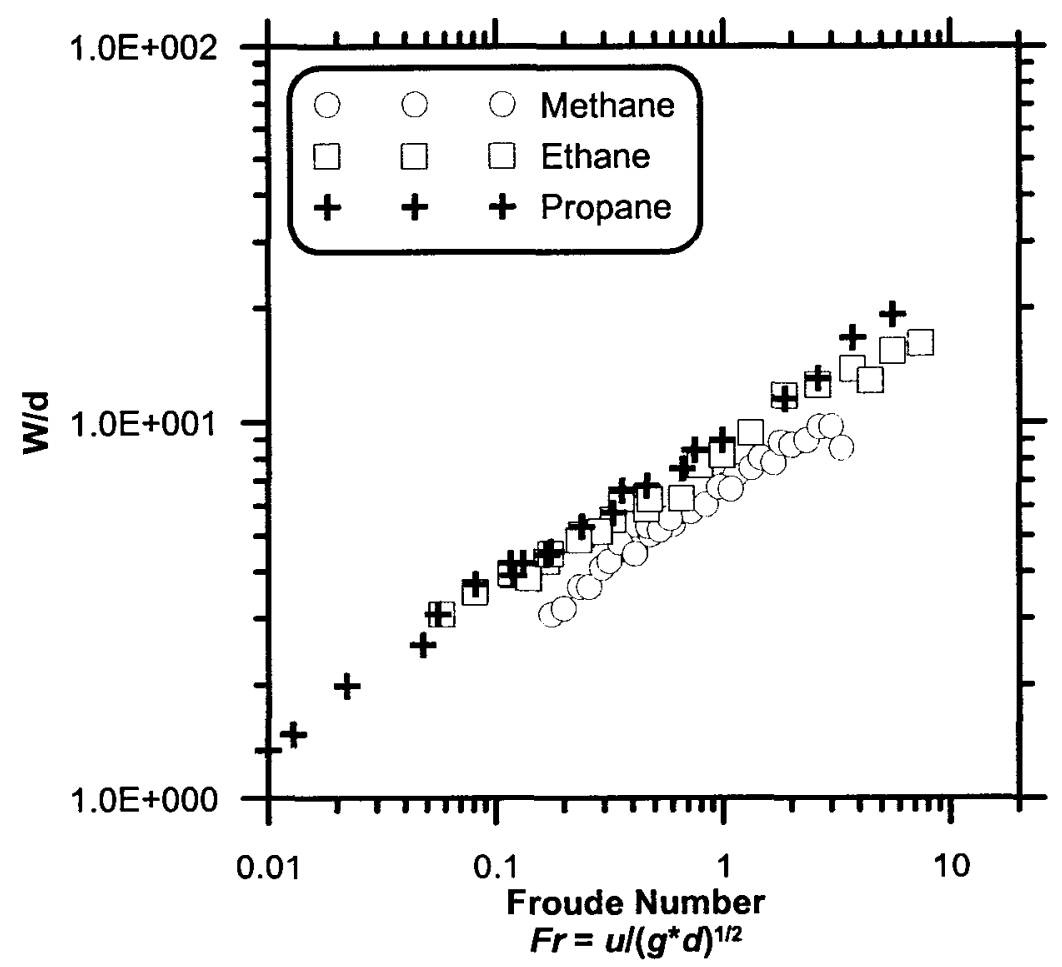

b) Normalized flame width

Figure 5.14: Normalized flame geometry parameters as a function of $F r$ for methane, ethane, and propane 


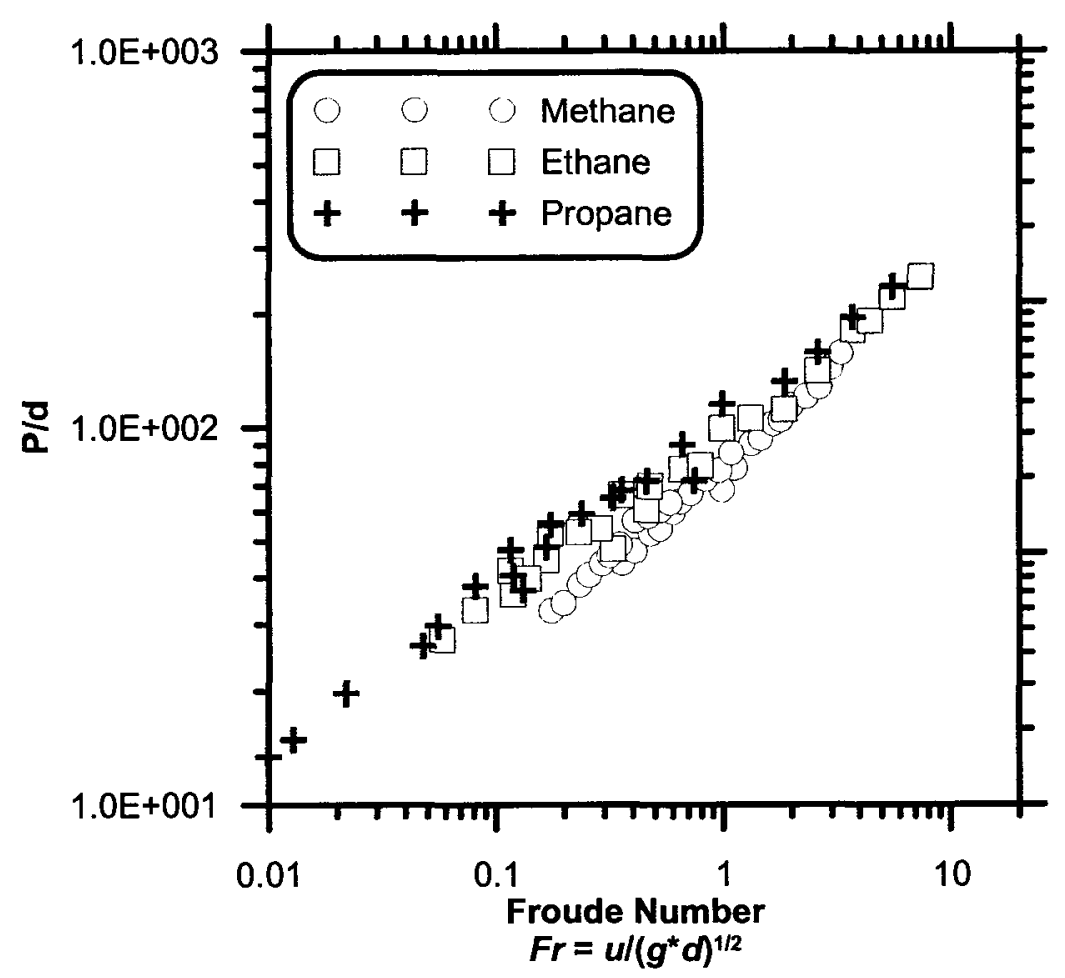

c) Normalized flame perimeter

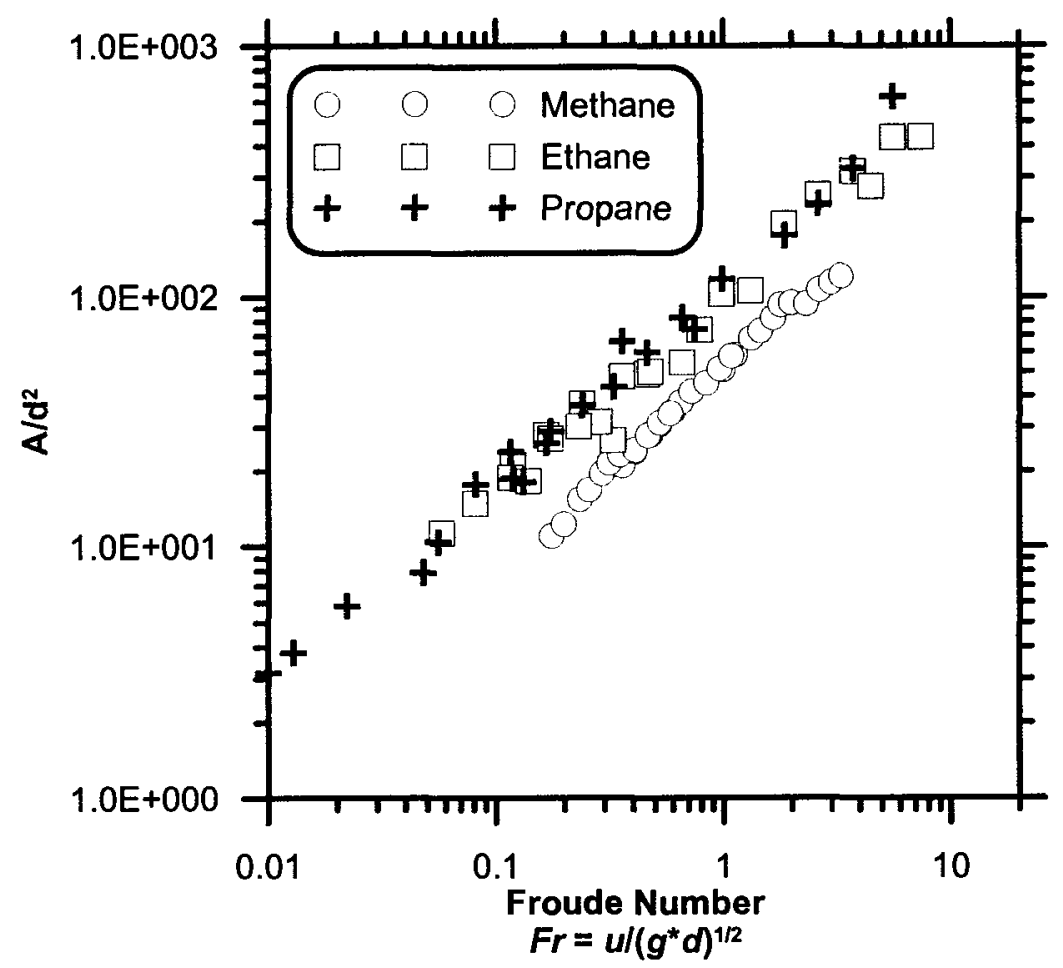

d) Normalized flame area

Figure 5.14: Normalized flame geometry parameters as a function of $\mathrm{Fr}$ for methane, ethane, and propane 
Figure 5.14a-d, show that each of the flame geometry parameters increase monotonically with Fr. Therefore, no further insight into the complicated increasing and decreasing trends of soot yield with $F r$ can be gained by observing these parameters.

\subsection{Physical Modeling of Soot Formation in Turbulent Flames}

Assuming that the correction factor is actually minimizing the effect of dilution ratio on soot yield, then it has been shown that neither the characteristic residence time nor the Froude number are suitable scaling parameters. However, as discussed above, this may be a rather simplistic view to assume that these simple parameters fully capture the effects of the numerous factors that affect soot formation and oxidation, such as, residence time, flame temperature, and mixing. In the following discussion, each of these physical effects will be examined separately in an attempt to incorporate them into a more meaningful scaling parameter.

\subsubsection{Residence Time}

As shown in the results of Sivathanu and Faeth [26], an increase in residence time will increase the soot yield up to a certain point. In Section 2.3, it was shown that at lower $\mathrm{Fr}$ the measured residence time increases but then begins to decrease at higher Fr. Hence, it was believed that the residence time scaling laws change at large Fr numbers. To study these two regimes further, an attempt was made to measure the residence time from the video images taken for the flames but the frame speed was too low to obtain an accurate measure. However, since the residence time is considered to be the time a particle takes

to travel from the burner exit to the flame tip, then an estimate for the residence time is given as,

$$
\tau_{R_{-} a=0}=\frac{L}{u}
$$


Eq. (5.2) will give an estimated residence time that assumes no acceleration occurs in the flame, which is equivalent to a non-buoyant (i.e. momentum) controlled flame. If a constant acceleration is assumed then the estimate of the residence time is,

$$
\begin{aligned}
\tau_{R_{-} a>0}=\frac{-u+\sqrt{u^{2}+2 a L}}{a} \\
a=\left(\frac{T_{f}-T_{\infty}}{T_{\infty}}\right) g
\end{aligned}
$$

where, $a$ is the effective acceleration [58]

$T_{f}$ and $T_{\infty}$ are the adiabatic flame and ambient temperatures, respectively

Eq. (5.3) is derived from simple kinematics of an accelerating particle with an initial velocity $(u)$ traveling a distance equal to the flame length. Figure 5.14 compares the residence time assuming no acceleration with the accelerating residence time. If the flame is momentum controlled (i.e. not accelerating), then $\tau_{R_{-} a>0}$ should be equal to $\tau_{R_{-} a=0}$. However, Figure 5.14 clearly shows that they are not equal and that the flames are still in a buoyancy controlled regime. The decreasing effect that Sivathanu and Faeth [26] observed may be due to the fact that they were not physically measuring residence time but the time for all luminosity to disappear in the flame, which is actually a measure of the time for the soot temperature to decrease below its luminous level. 


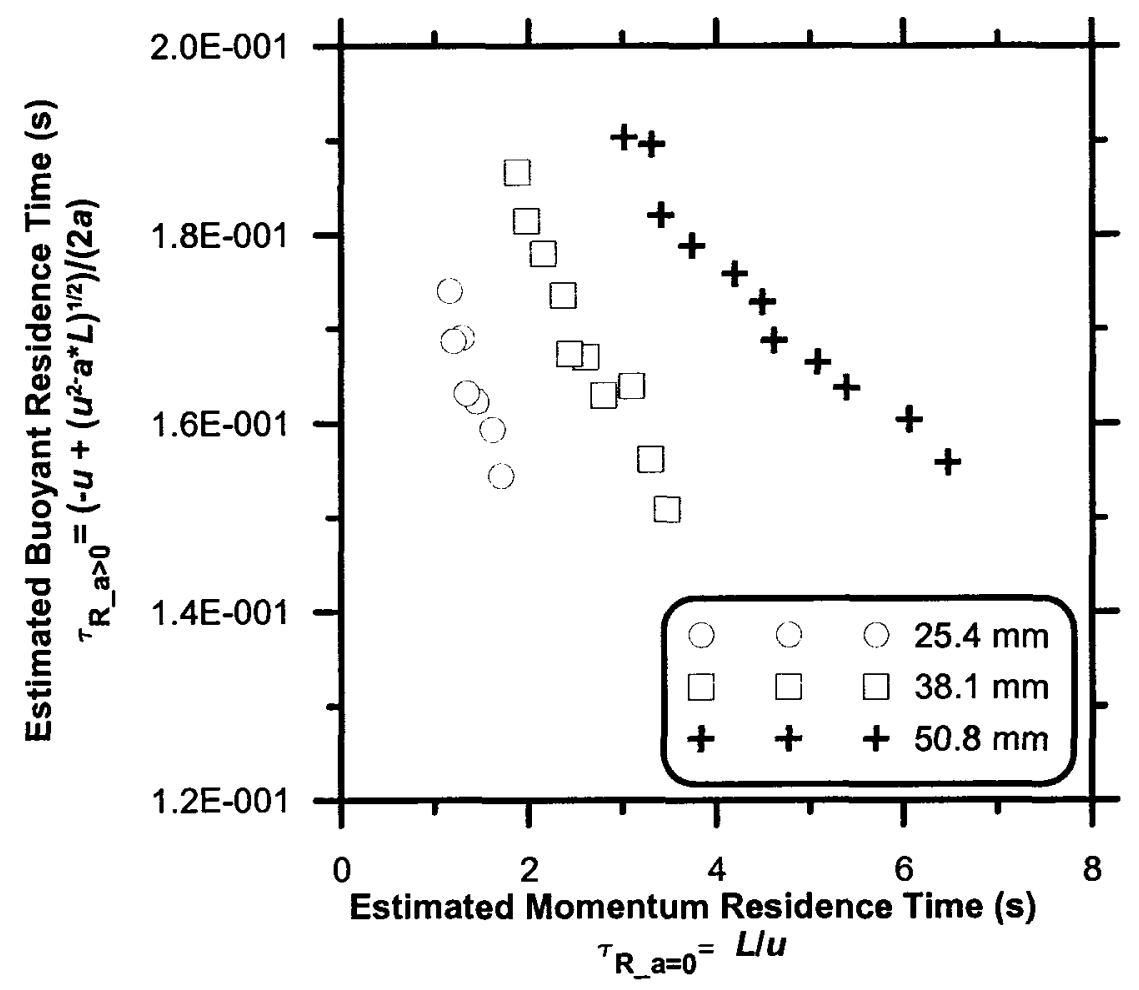

Figure 5.15: Comparison of estimated residence times assuming a particle with and without acceleration (methane fuel)

Although this shows that the flames are still buoyancy controlled it gives no insight into why the smallest burner exit diameters for a given fuel tended not to follow the soot yield trend exhibited by the other burners. However, as shown in Section 4.5, for the smallest diameter burner all points were in a region where $F r>1$ which may indicate the flames could be in a transition period where they are approaching a momentum controlled regime.

\subsubsection{Temperature Effects}

As discussed in Section 2.1, the flame temperature will affect both the soot formation and oxidation rates. Zimberg et al. [59] give a reaction rate for soot formation and oxidation, as given by Eq. (5.5) and (5.6) below. Lee [60] and Kent and Wagner [61] provide similar relations although they employ different exponents for the temperature component in the oxidation reactions, 


$$
\begin{array}{lll}
\text { Formation: } & \boldsymbol{k}_{\text {sf }} \propto \exp \left(-\frac{1}{T}\right) & \text { (Zimberg) (5.5) } \\
\text { Oxidation: } & k_{\text {sox }} \propto T^{0.5} \exp \left(-\frac{1}{T}\right) & \text { (Zimberg) (5.6) } \\
& k_{\text {sox }} \propto T^{-0.5} \exp \left(-\frac{1}{T}\right) & \text { (Lee) } \\
& k_{\text {sox }} \propto \exp \left(-\frac{1}{T}\right) & \text { (Kent) }
\end{array}
$$

where, $k_{s f}$ and $k_{s o x}$ are the reaction rates for soot formation and oxidation, respectively $T$ is the temperature

Since there is no clear choice in deciding the appropriate soot oxidation rate equation, Zimberg et al. [59] will be used as it is the most recent. The temperature needs to be related to some other known parameters since no temperature measurements were made during these experiments. From the data given in Becker and Yamazaki [62] for turbulent diffusion propane flames, the peak mean temperature at the centerline of the flame is a function of the $\mathrm{Fr}^{1 / 7}$ (Figure 5.16). 


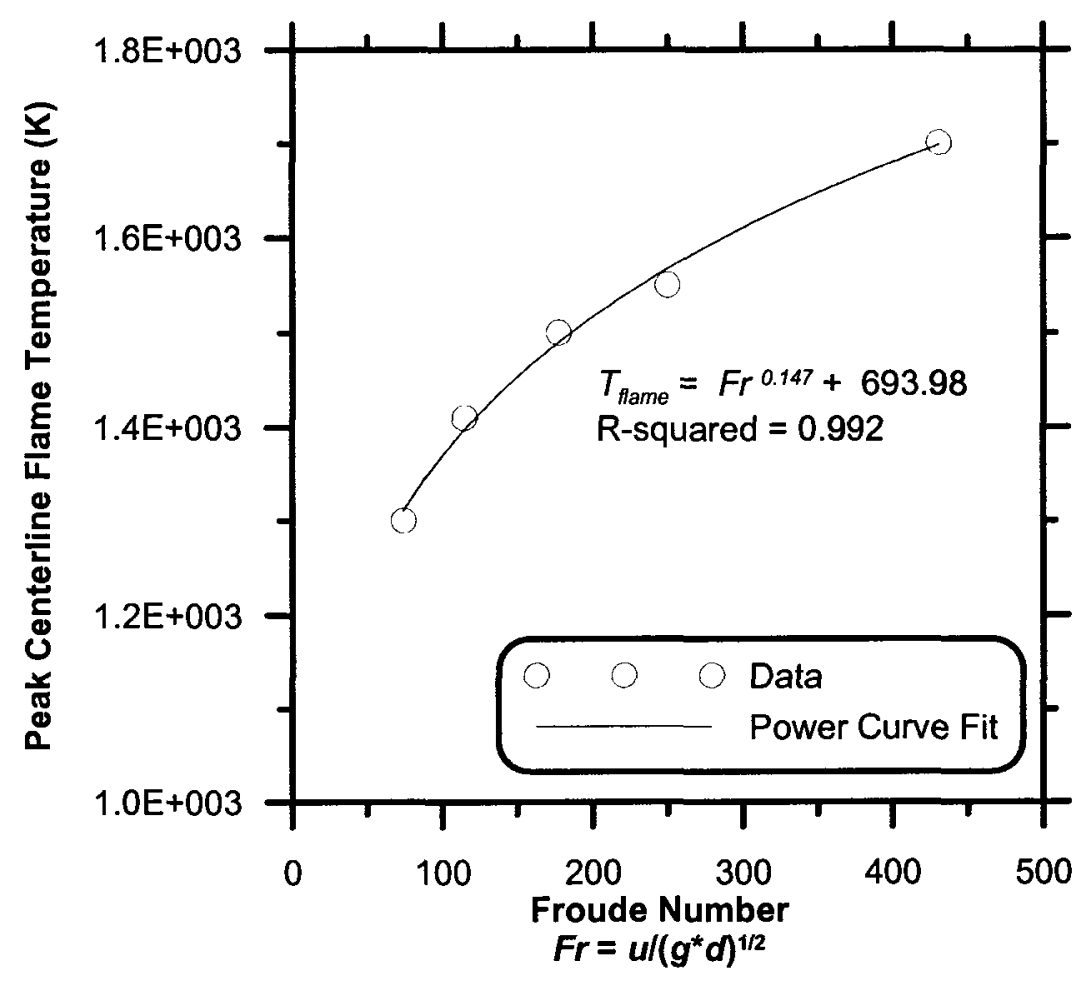

Figure 5.16: Peak mean centerline temperature for propane turbulent diffusion flames [62]

\subsubsection{Mixing Effects}

Kent and Bastin [25] show that the oxidation rate is dependent on the mixing rate.

Delichatsios [58] predicted that the entrainment rate (i.e. mixing rate) of air $\left(\dot{\boldsymbol{m}}_{e n t}\right)$ into a buoyant turbulent diffusion flame is,

$$
\dot{\boldsymbol{m}}_{e n t} \propto Z^{5 / 2}
$$

where, $Z$ is the height above the burner exit

However, as a global entrainment rate for the flame is desired rather than a local entrainment rate, the flame length could be used as a measure of the mixing rate. 
Now that parameters have been found to link the residence time, mixing rate, and temperature to the soot formation and oxidation rates, a new scaling parameter $(N S P)$ can be sought such that,

$$
N S P=f\left(\tau_{R}\right)+f\left(k_{s f o}\right)+f\left(\dot{m}_{e n t_{-} f}\right)-f\left(k_{s o x}\right)-f\left(\dot{m}_{\text {ent_o }}\right)
$$

where, $f()$ denotes a function

A physically based, semi-empirical functional relationship can be created by substituting in the relationships shown above for the functions in Eq. (5.8),

$$
\boldsymbol{N S P}=\alpha\left(\frac{\boldsymbol{L}}{\boldsymbol{u}}\right)^{E 1}+\beta\left[\exp \left(-\frac{1}{\boldsymbol{F r}^{1 / 7}}\right)\right]^{E 2}+\chi\left(\boldsymbol{L}^{5 / 2}\right)^{E 3}-\delta\left[\left(\boldsymbol{F} \boldsymbol{r}^{1 / 7}\right)^{1 / 2} \exp \left(-\frac{1}{\boldsymbol{F r}^{1 / 7}}\right)\right]^{E 4}-\varepsilon\left(\boldsymbol{L}^{5 / 2}\right)^{E 5}
$$

where, $\alpha, \beta, \chi, \delta, \varepsilon, E 1, E 2, E 3, E 4, E 5$ are curve fitting constants

It is interesting to note that each function in Eq. (5.9) uses $F r$ or the flame length which is a function of Fr. As shown in Section 5.3 and 5.4, Fr was deemed to be an unsuitable parameter for scaling soot yield; however, Eq. (5.9) allows Fr to account for both increasing and decreasing trends and therefore may still be a suitable parameter.

Figures 5.16a-c show an attempt at using Eq. (5.9) to scale the soot yield using the new scaling parameter. The coefficients used are given in Table 5.1. 


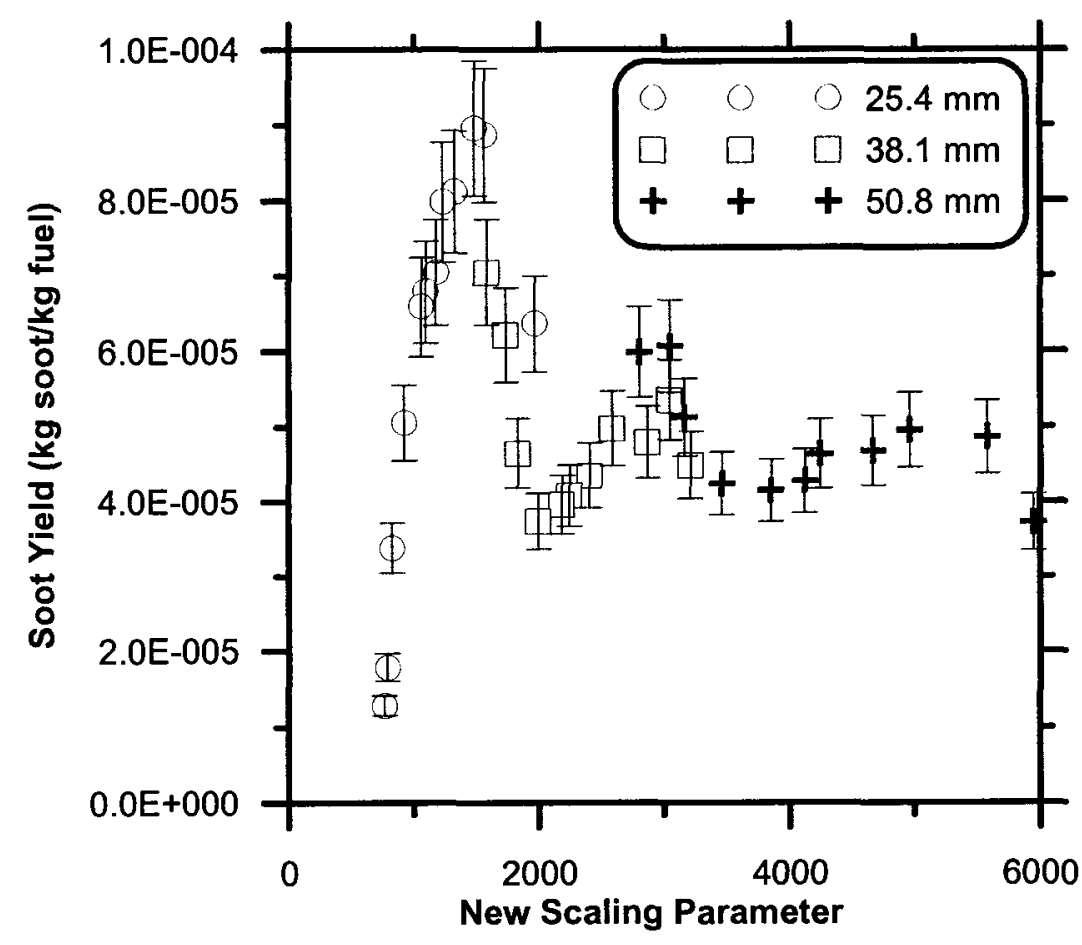

a) Methane

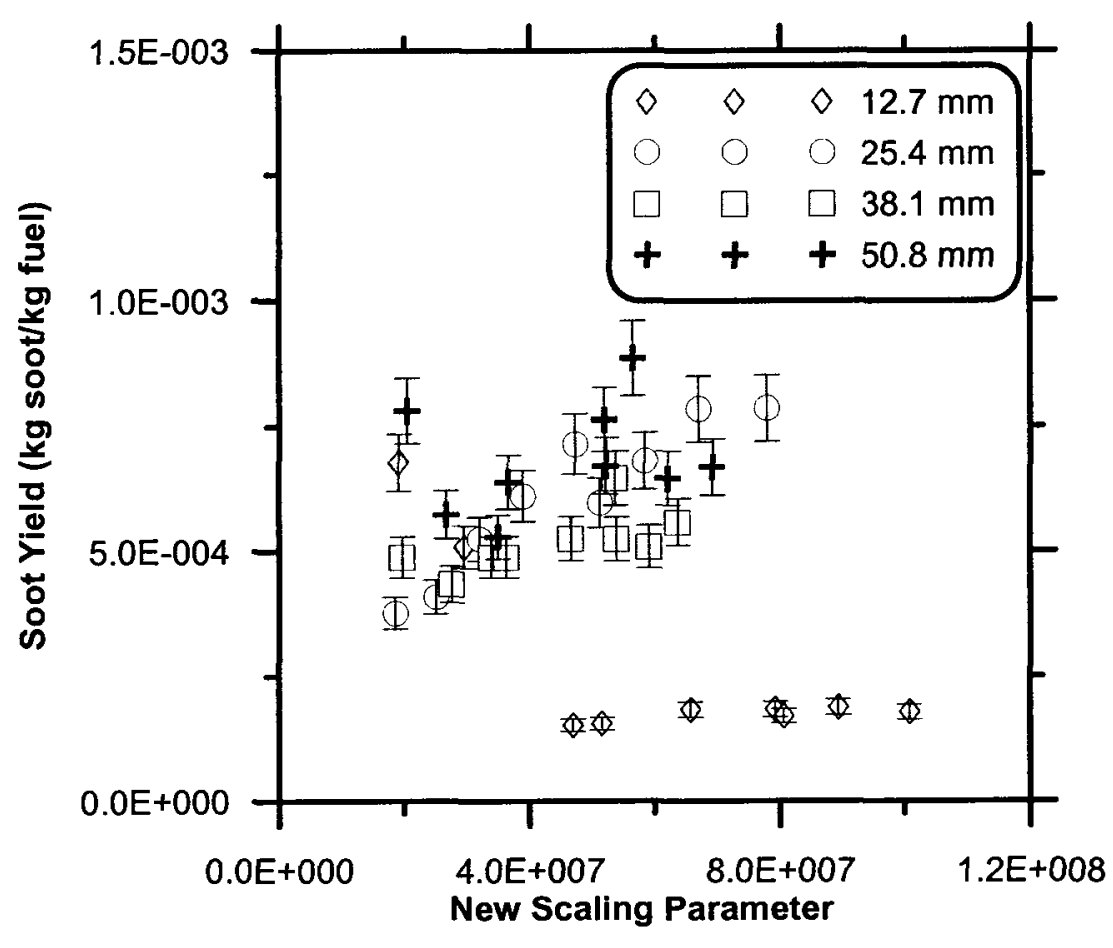

b) Ethane

Figure 5.17: New scaling parameter for soot yield from a) methane, b) ethane, and c) propane 


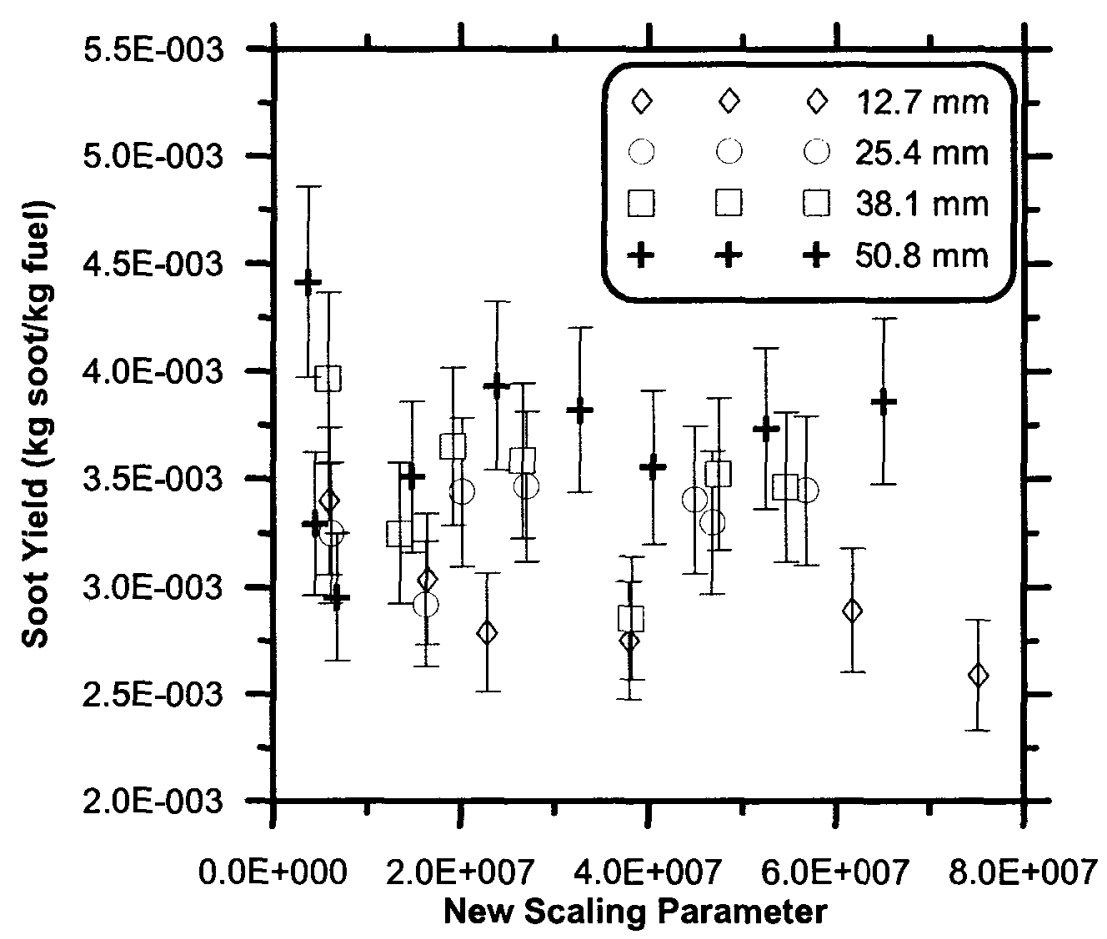

c) Propane

Figure 5.17: New scaling parameter for soot yield from a) methane, b) ethane, and c) propane

Table 5.1: Coefficients for Eq. (5.9)

\begin{tabular}{cccc}
\hline Coefficient & Methane & $\begin{array}{l}\text { Value } \\
\text { Ethane }\end{array}$ & Propane \\
\hline$\alpha$ & 1 & 1 & 1 \\
$\beta$ & 1 & 1 & 1 \\
$\chi$ & 1 & 2 & 2 \\
$\delta$ & 1 & 1 & 1 \\
$\varepsilon$ & 1 & 1 & 1 \\
$E 1$ & 1 & 1 & 1 \\
$E 2$ & 1 & 1 & 1 \\
$E 3$ & 1 & 1 & 1 \\
$E 4$ & 1 & 1 & 1 \\
$E 5$ & 1 & 1 & 1 \\
\hline
\end{tabular}

The new scaling parameter is shown in Figures 5.16a-c to have had limited success. The $25.4 \mathrm{~mm}$ and $38.1 \mathrm{~mm}$ burner for methane appear to show a continuing trend; however, 
the $50.8 \mathrm{~mm}$ burner shows a disconnect from the $38.1 \mathrm{~mm}$ burner. The ethane and propane data show the different burner diameters do not collapse to a single curve. Although the coefficients were altered to try and obtain the best visual trends, because of the large number of coefficients, this process would be better suited to a computer model perhaps using a genetic algorithm approach.

This section has shown that either the correction factors applied to the data are incorrect or the method of determining the soot emission from global flame parameters similar to Becker and Liang [27] is unsuitable. Although the method from Sivathanu and Faeth [26] of measuring a residence time appeared promising, their data set did not cover a large enough regime and the technique used for the actual residence time measurement may not have been appropriate. Therefore, it is proposed that the actual residence time of the soot be measured via some other technique, such as Laser Doppler Velocimetry (LDV) which should be able to provide greater insight into the effect residence time has on soot emissions. It may also be appropriate to measure the local flame temperatures within the flame as this is another parameter that can greatly affect the rate of soot emissions.

\subsection{Fuel Mixture Results}

Fuel mixtures of methane/propane, methane/ethane, and methane/ethane/propane were assessed. To allow a uniform basis of comparison the method from Trottier et al. [33] is used, where the soot generation efficiency is shown as a function of the percentage of one of the fuels in the mixture. Each mixture test was run at a constant volumetric flow rate as fuel mixture compositions are commonly expressed on a volumetric basis rather than mass.

In the above sections, each fuel required its own correction factor to minimize the dilution ratio effect on soot yield, those corrections cannot be applied to the fuel mixtures. Fortunately, each data set for the fuel mixture had a narrow band of dilution 
ratio with a maximum variation of 10 , but most only varied by approximately 5 . Therefore, error bars will be attached to the data which represent the possible change in soot yield that could be experienced from the change in dilution ratio from point to point. For methane/ethane and the tertiary fuel mixture, the error bars are $8 \%$ whereas, for the methane/propane mixture, the error bars are $16 \%$. These values were selected as being the largest expected change in soot yield with a given change in dilution ratio as taken from the results shown in the previous section.

\subsubsection{Methane / Propane Mixtures}

The soot generation efficiency was measured from a methane/propane fuel mixture running at a constant volumetric flow rate. Figures 5.17a,b show that the methane/propane mixtures generally have a linear trend with an increasing percentage of propane; however, at approximately $70 \%$ propane, the data points begin to deviate from the trend and the soot yield increases less quickly. The error bars show that this deviation could simply be a product of the dilution ratio error. Trottier et al. [33] observed no synergistic effect (i.e. they observed a linear trend) for their methane/propane mixtures. 


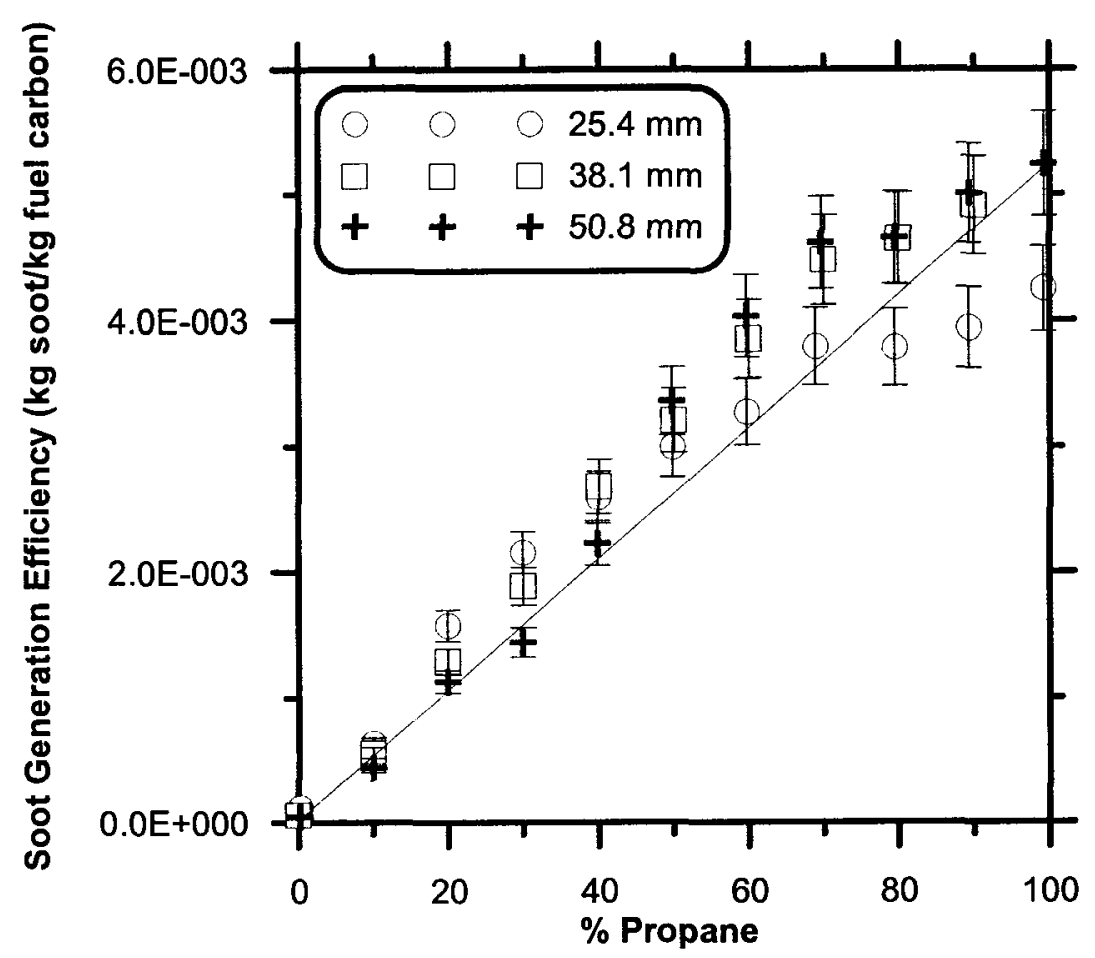

a) 15 SLPM

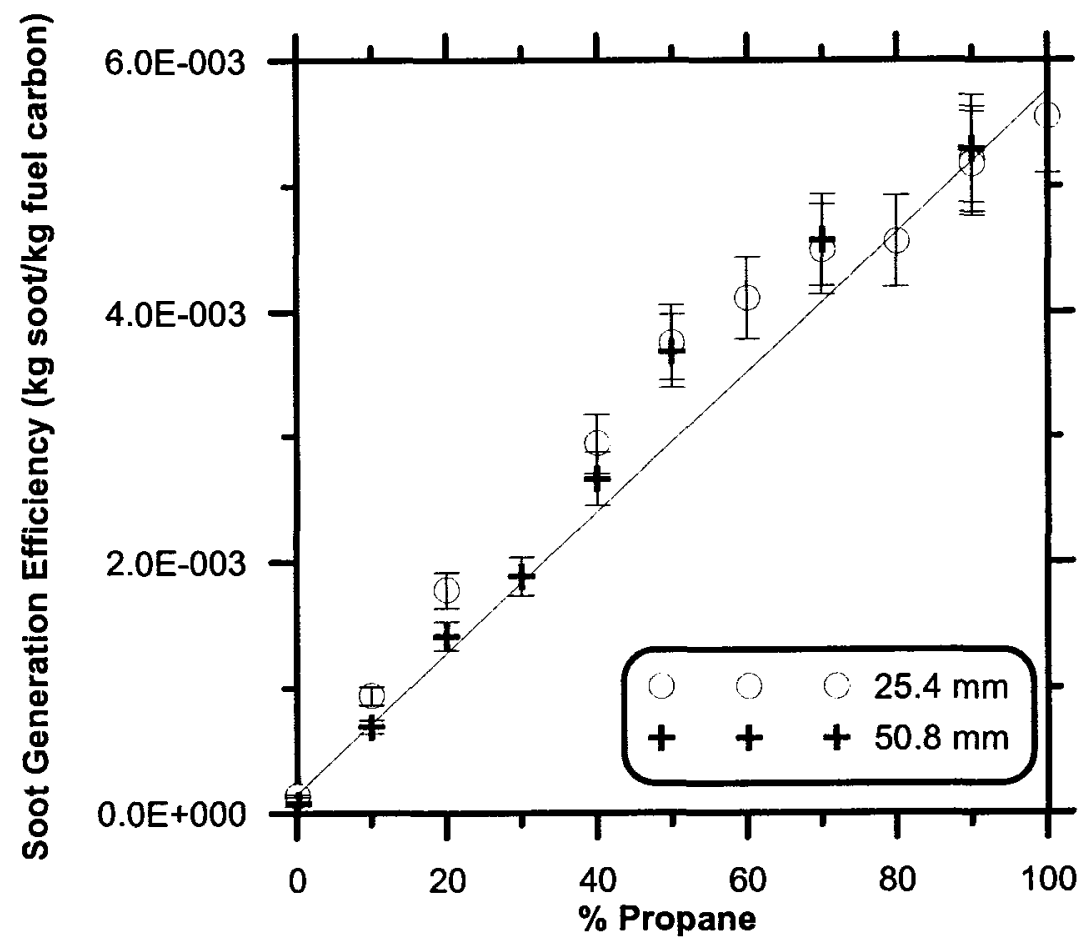

b) 20 SLPM

Figure 5.18: Soot generation efficiency from methane/propane fuel mixture 


\subsubsection{Methane / Ethane Mixtures}

Figure 5.18 shows soot generation efficiency as measured for methane/ethane mixtures running at constant flow rates. The $25.4 \mathrm{~mm}$ and $38.1 \mathrm{~mm}$ burner for the mixture running at 15 SLPM exhibit similar synergistic trends to Trottier et al. [33] where SGE increases far above what would be expected for a linear mixing effect from approximately $0-50 \%$ ethane before becoming relatively constant. The $50.8 \mathrm{~mm}$ burner shows much less of a synergistic effect and soot yield does not reach a plateau value in this case. This difference could potentially be due to the change in turbulence characteristics which could greatly alter the parameters that affect the synergistic soot chemical kinetics, such as, the mixing rate and flame temperature. At the increased flow rate of 20 SLPM, the synergistic effect becomes greater for the $25.4 \mathrm{~mm}$ burner, whereas the $38.1 \mathrm{~mm}$ and 50.1 $\mathrm{mm}$ burner appear to show approximately the same trends as in the 15 SLPM.

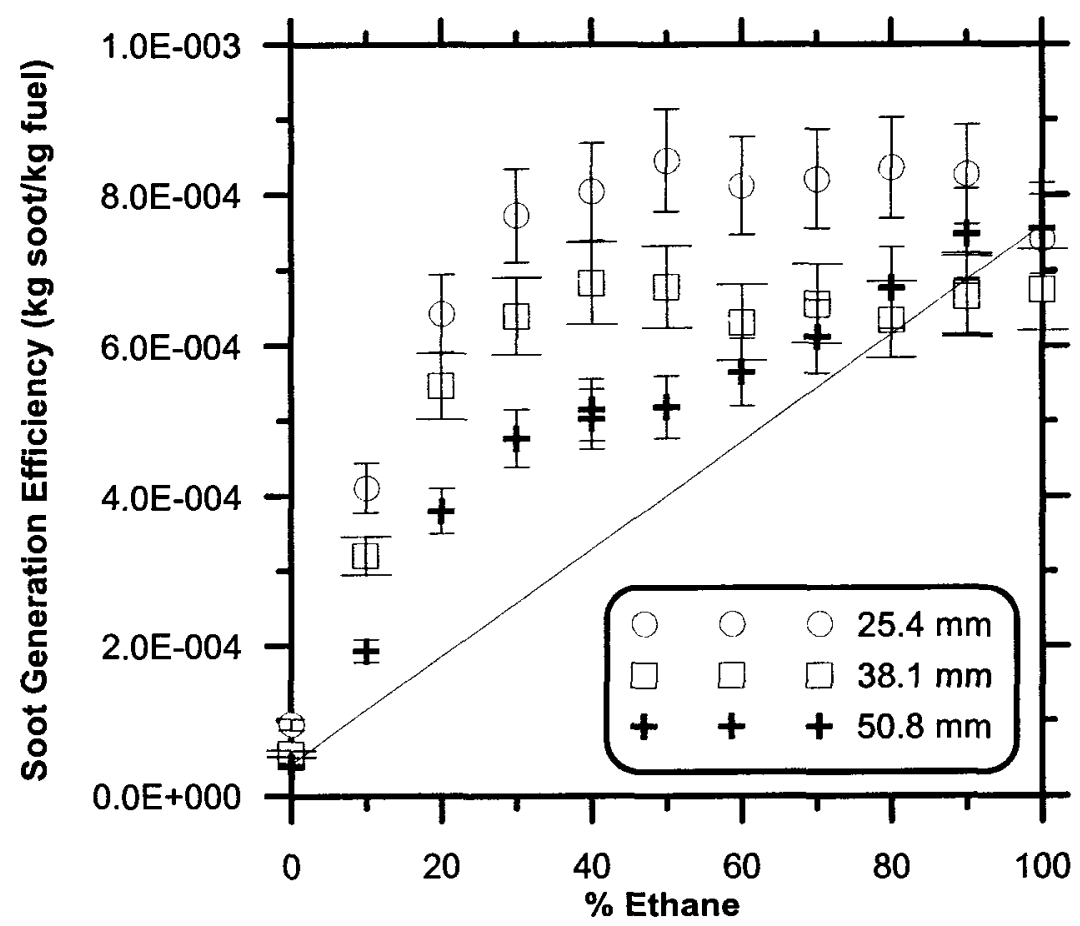

a) 15 SLPM

Figure 5.19: Soot generation efficiency from methane/ethane fuel mixture 


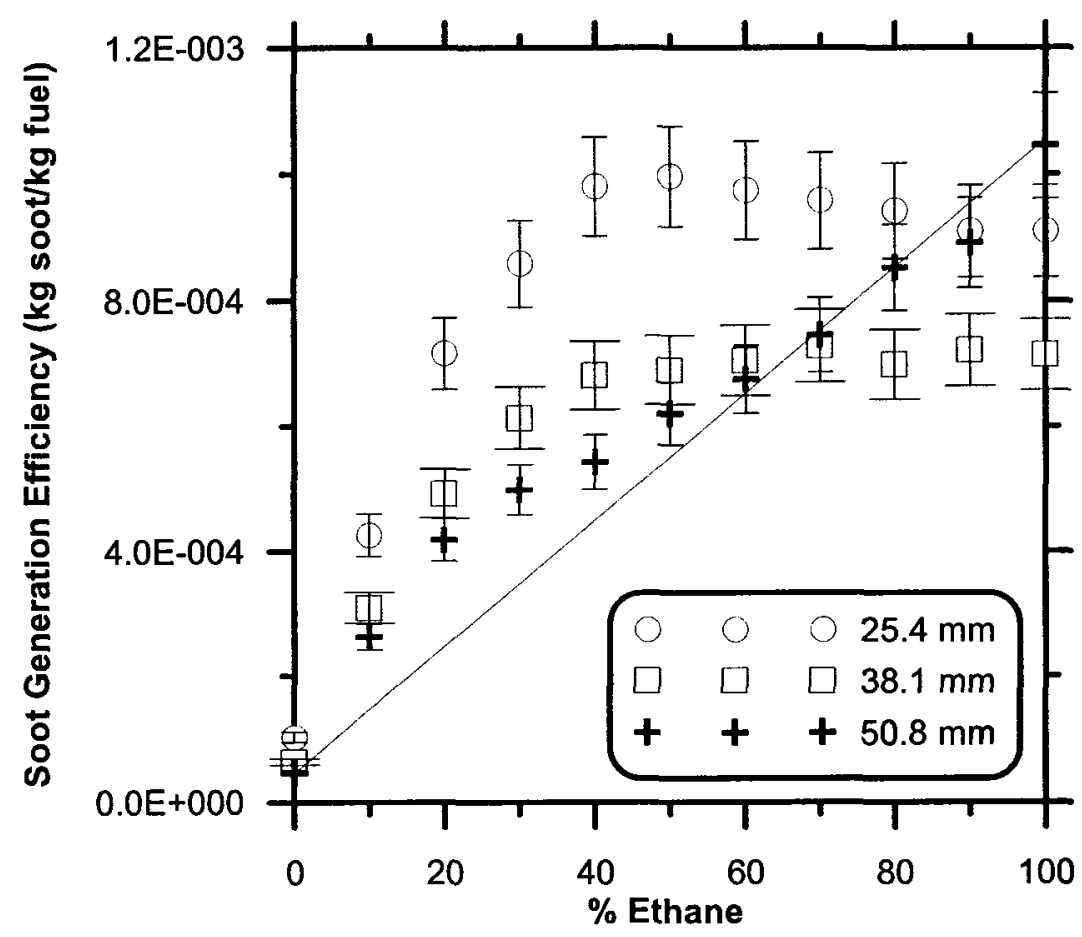

b) 20 SLPM

Figure 5.19: Soot generation efficiency from methane/ethane fuel mixture

\subsubsection{Methane/Ethane/Propane Mixtures}

Soot generation efficiencies were also measured for tertiary fuel mixture of methane/ ethane/propane at a constant flow rate of 15 SLPM (Figure 5.19). Corresponding to the range of basic compositions typically seen in solution gas flares, the mixture ranged from $70-100 \%$ methane with ethane and propane making up the difference in equal amounts (i.e. $70 \%$ methane, $15 \%$ ethane, $15 \%$ propane) [8]. The $S G E$ for all burners appears to decrease linearly in this range when the percent of methane is increased with the $38.1 \mathrm{~mm}$ and $50.8 \mathrm{~mm}$ following the same line. 


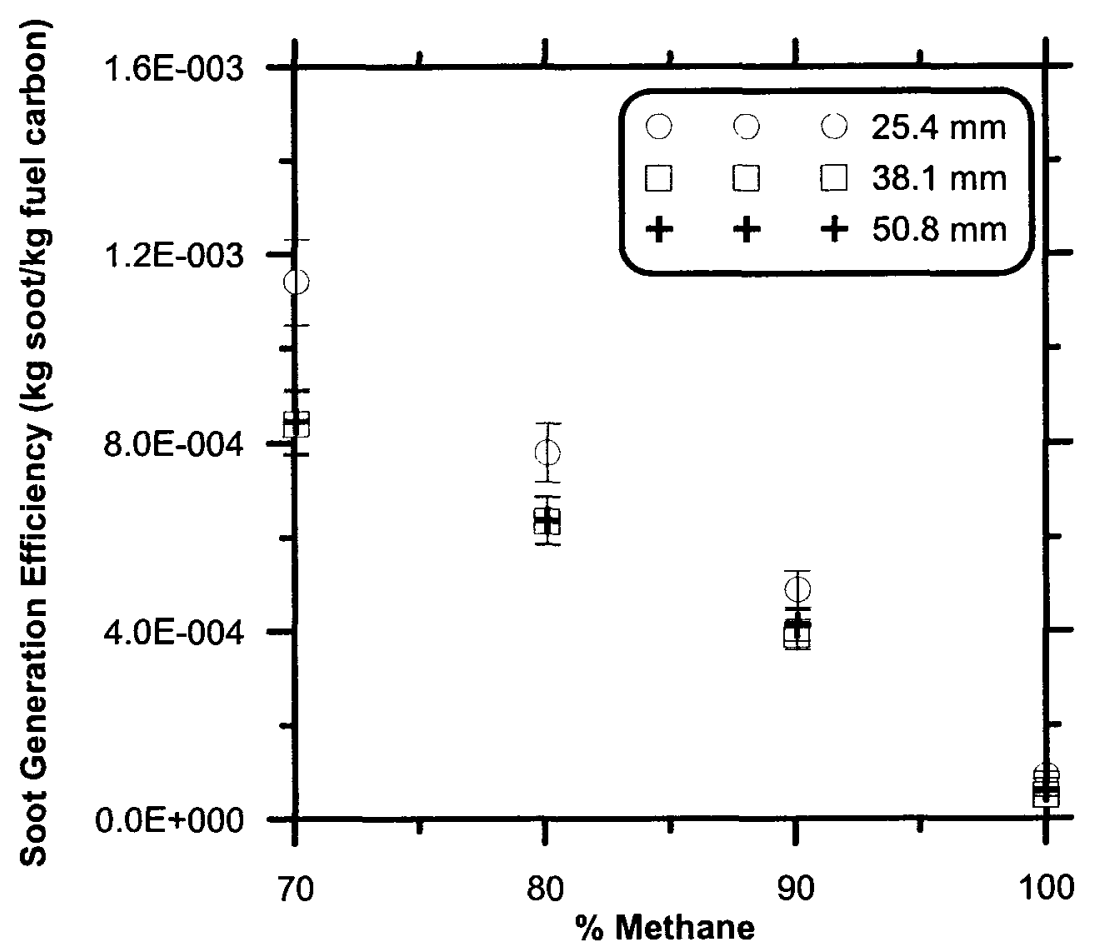

Figure 5.20: Soot generation efficiency of methane/ethane/propane fuel mixture running at a flow rate of 15 SLPM

Figure 5.20a,b brings together all of the fuel mixture data for a $25.4 \mathrm{~mm}$ and $50.8 \mathrm{~mm}$ burner at 15 SLPM. A scaling parameter for fuel mixtures would be a useful tool to predict soot emissions from mixtures. The smoke point is a parameter that has been used by other authors $[9,26]$ to normalize the soot emissions produced from different fuels. From Figure 5.20, it can be seen that there is a vertical shift between each mixture curve. Therefore, the smoke point will be incorporated into the soot generation efficiency in an attempt to collapse the data into a single curve. An average smoke point mass flow rate will be used instead of the mass of carbon fuel to normalize the $S G E$.

$$
S G E_{s p}=\frac{\dot{m}_{s o o t}}{\frac{\dot{m}_{C H_{4}}}{\dot{m}_{s p_{-} C H_{4}}}+\frac{\dot{m}_{C_{2} H_{6}}}{\dot{m}_{s p_{-} C_{2} H_{6}}}+\frac{\dot{m}_{C_{3} H_{8}}}{\dot{m}_{s p_{-} C_{3} H_{8}}}}
$$




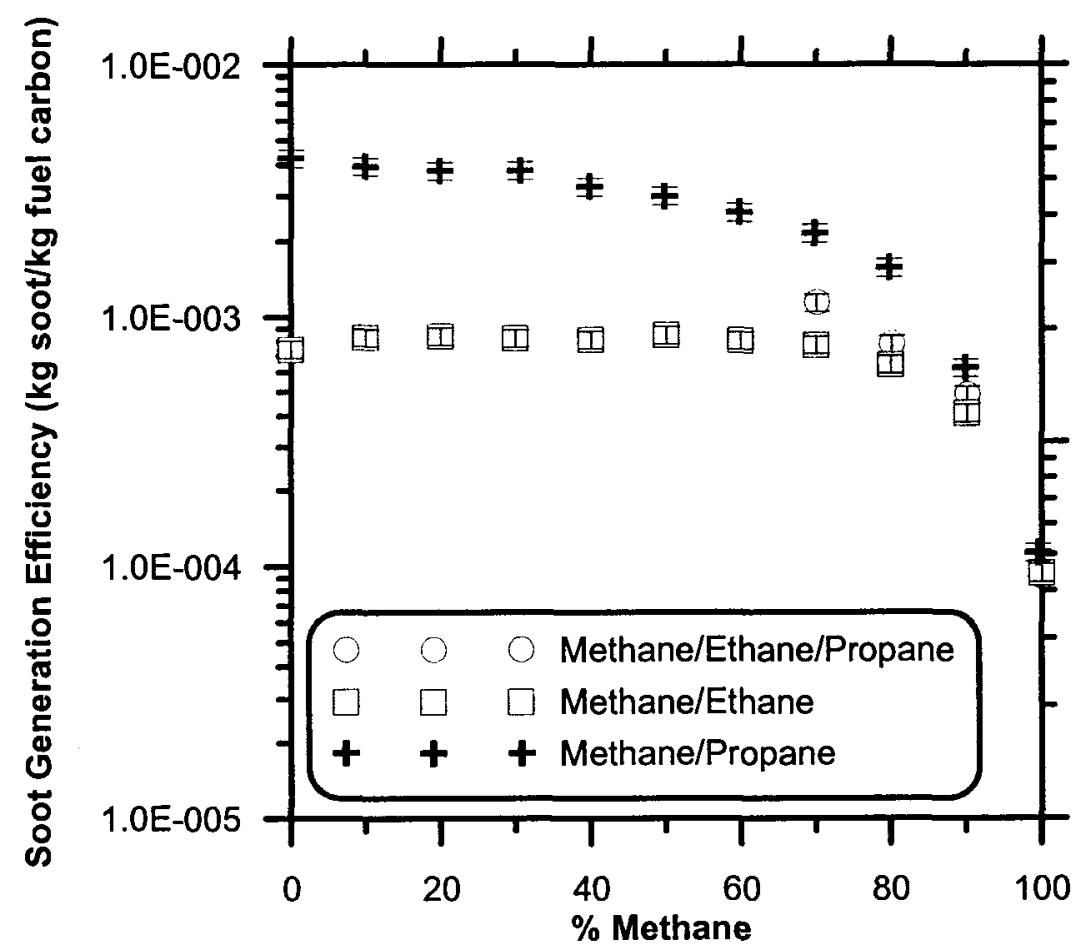

a) Mixtures using $25.4 \mathrm{~mm}$ burner

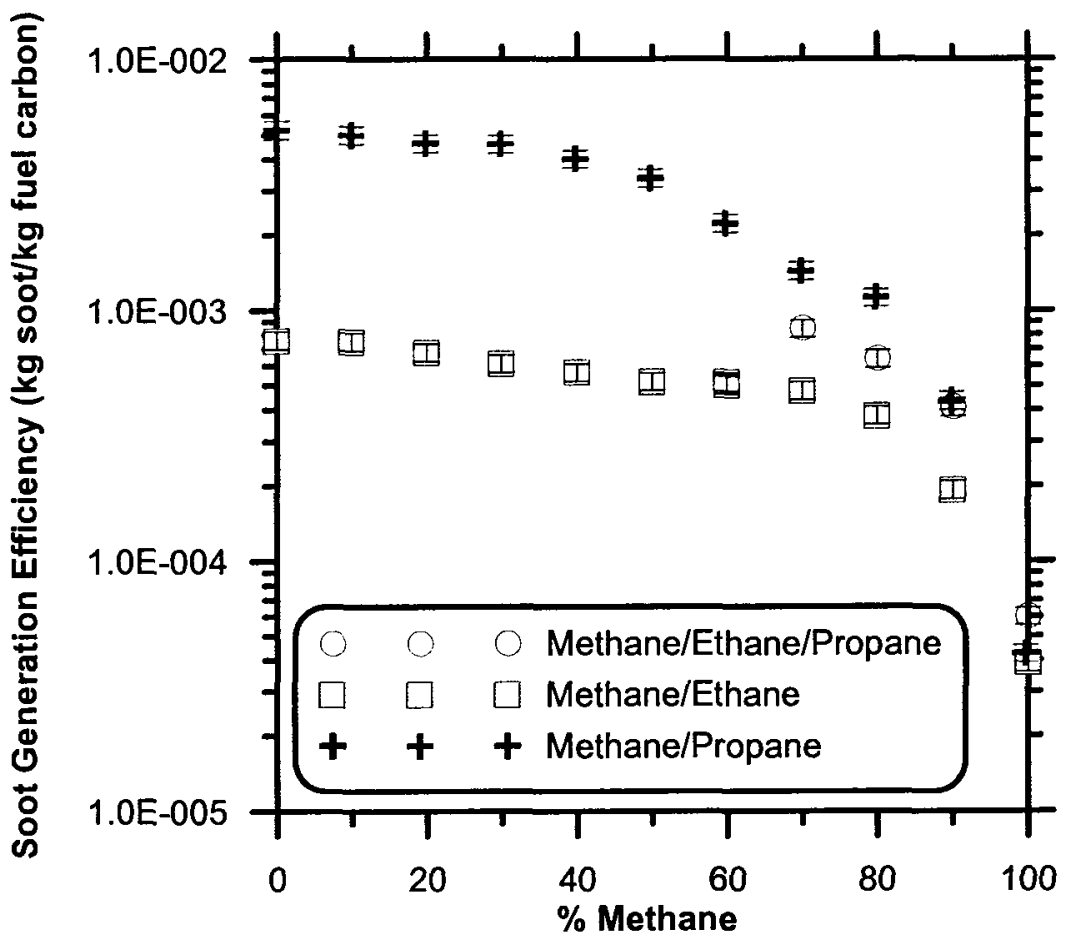

b) Mixtures using $50.8 \mathrm{~mm}$ burner

Figure 5.21: Soot generation for all fuel mixture data at a flow rate of 15 SLPM with a) 25.4 mm burner and b) $50.8 \mathrm{~mm}$ burner 
The laminar smoke point mass flow rates $\left(\dot{\boldsymbol{m}}_{s p}\right)$ have been estimated from the theoretical heat release smoke points given in Orloff et al. [63] and are shown in Table 5.2. Methane does not have a laminar smoke point as it transitions to turbulent flow before sooting begins. However, Orloff et al. [63] estimated a smoke point to fit the correlations in their work.

Table 5.2: Laminar smoke points for methane, ethane, and propane [63]

\begin{tabular}{lc}
\hline \multicolumn{1}{c}{ Fuel } & $\begin{array}{c}\text { Laminar Smoke Point } \\
(\mathbf{k g} / \mathbf{s})\end{array}$ \\
\hline Methane $\left(\mathrm{CH}_{4}\right)$ & $8.63 \mathrm{e}-6$ \\
Ethane $\left(\mathrm{C}_{2} \mathrm{H}_{6}\right)$ & $1.06 \mathrm{e}-5$ \\
Propane $\left(\mathrm{C}_{3} \mathrm{H}_{8}\right)$ & $6.79 \mathrm{e}-6$ \\
\hline
\end{tabular}

The results from using the smoke point soot generation efficiency $\left(S G E_{s p}\right)$ are shown in Figures $5.21 \mathrm{a}, \mathrm{b}$. The $\mathrm{SGE}_{\mathrm{sp}}$ seems to work reasonably well, especially for the tertiary fuel mixture and methane/propane, which appear to collapse onto a single curve whereas the methane/ethane mixture begins to deviate at higher fuel mass flow rates. This could suggest that the normalized soot generation efficiency may work well for fuels which do not exhibit a synergistic effect. 


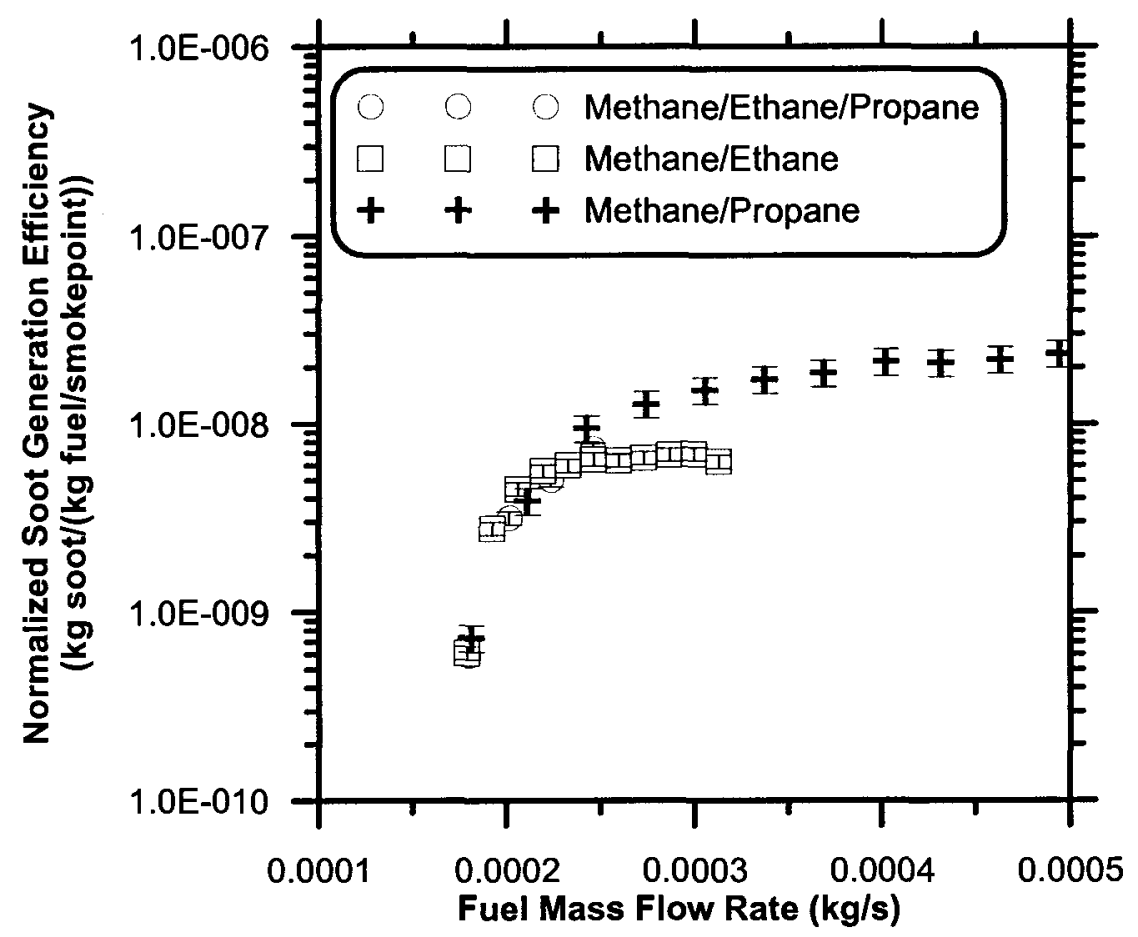

a) Mixture using $25.4 \mathrm{~mm}$ burner

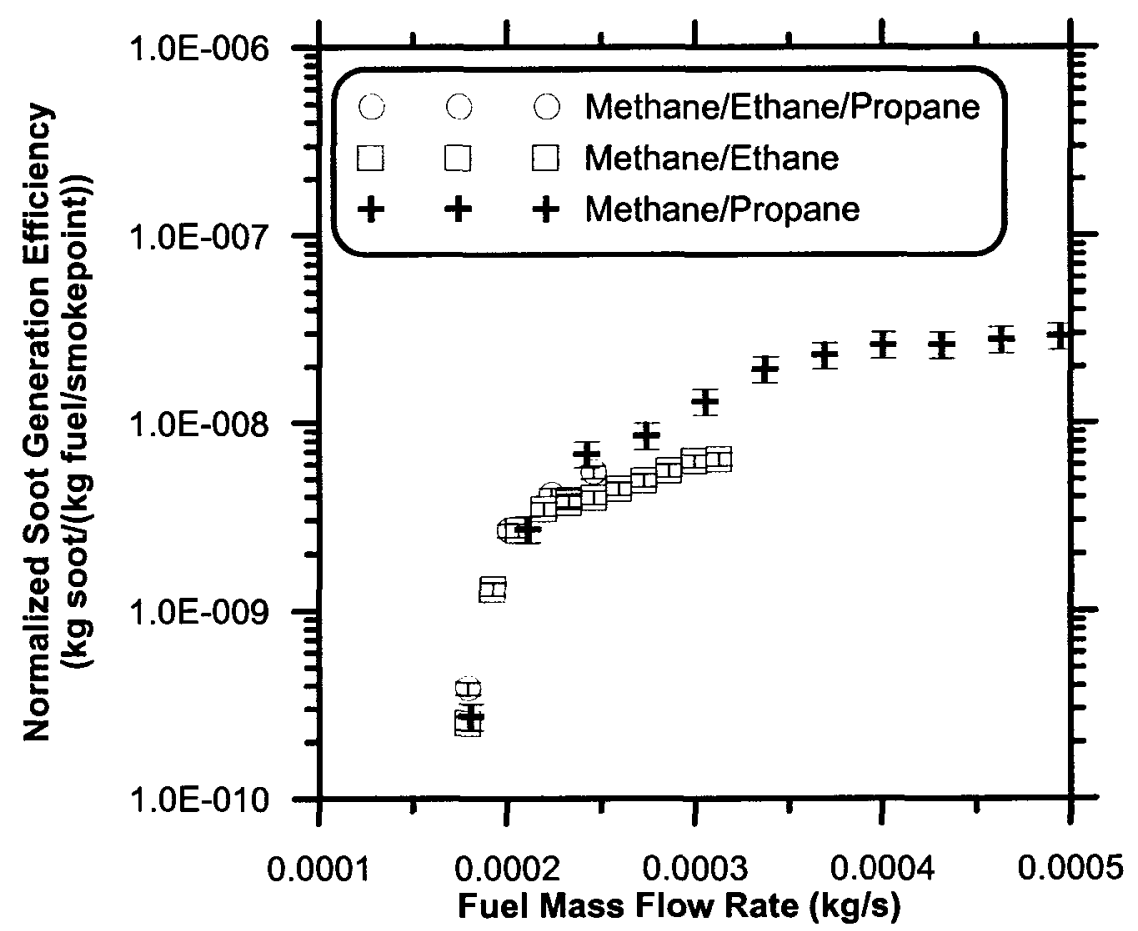

b) Mixture using $\mathbf{5 0 . 8} \mathrm{mm}$ burner

Figure 5.22: Normalized soot generation efficiency for all fuel mixtures at 15 SLPM with a) $25.4 \mathrm{~mm}$ burner and b) $50.8 \mathrm{~mm}$ burner 


\section{Chapter 6: Conclusion and Future Work}

Soot emissions from turbulent diffusion flames burning simple alkane fuels have been studied. A turbulent diffusion burner and sampling system were used in conjunction with an LII instrument to measure soot yield for a wide range of conditions including four different burner exit diameters, a large span of flow rates, and three fuel mixtures. A sampling protocol was developed in order to achieve accurate measurements through using high-accuracy equipment and using a statistically based approach to obtain appropriate sampling times. Although it was found that the sampling conditions influenced soot yield, a correction protocol was implemented to minimize the effects to allow a proper analysis of the results.

From the experiments, it was found that the soot yield was no greater than $0.09,0.9$, and $4.5 \mathrm{~g}$ per $\mathrm{kg}$ fuel for methane, ethane, and propane, respectively. The results were compared with the published literature and it was found that there were discrepancies among the existing data as well as with the current results. However, the flow conditions of Becker and Liang [27] differed significantly from those used in the present experiments, and therefore a proper comparison could not be made. Several experiments were run to match the conditions of Sivathanu and Faeth [26]; however, there was still a variation in the measured soot yield. The differences in soot yield are mainly attributed to the different burner apparatus and soot measurement equipment used. Although Sivathanu and Faeth [26] and Becker and Liang [27] both proposed parameters to scale soot emissions, neither author spanned a large enough range of flow conditions to prove 
the universality of their scaling parameters. When their data were combined on the same graph along with the current results, it was demonstrated that these scaling parameters were insufficient to effectively correlate the data.

This thesis has shown that the process of soot formation and oxidation from a buoyant turbulent diffusion flame is too complex to be examined on a global level. The residence time, mixing rate, and flame temperature all have competing affects on soot formation and oxidation and this was observed in the results. However, global parameters such as the fuel exit velocity and burner exit diameter were not enough to give a scaling relationship of the soot emissions. The results from the fuel mixtures exhibited synergistic effects that have also been shown to exist in laminar diffusion flames [33]. However, the magnitude of these synergistic effects was less significant when the largest diameter burner was used. A soot generation efficiency parameter which used the laminar smoke point for fuels seemed to correlate the fuel mixture data fairly well for mixtures which did not exhibit a synergistic effect.

It is recommended that further work be completed to develop a thorough understanding of the parameters which influence soot released from buoyant turbulent diffusion flames. An accurate measure of soot residence time should be carried out using a technique such as Laser Doppler Velocimetry (LDV). A temperature map throughout the flame could provide additional insight as well. Finally, more experiments using a larger span of flow conditions with different burner diameters should be conducted in order to help establish a more universal scaling parameter. 


\section{References}

[1] Bockhorn, H., Soot Formation in Combustion - Mechanisms and Models, Springer Series in Chemical Physics 59, Germany, (1994).

[2] Gülder, O.L., "Soot Particulate Formation and Characterization in Combustion," Transactions of the CSME 23, No. 1B, pp. 225-240 (1999).

[3] Arden, C., et al., "Lung Cancer, Cardiopulmonary Mortality, and Long-Term Exposure to Fine Particulate Air Pollution," Journal of the American Medical Association 287, 1132-1141 (2002).

[4] Hansen, J., et al., "Global Warming in the Twenty-First Century: An Alternative Scenario," Proceedings of the National Academy of Sciences 97, No. 18, pp. 98759880 (2000).

[5] Environment Canada, (http://www.ec.gc.ca/pdb/cac/cac_home_e.cfm), accessed August 8, 2007.

[6] The World Bank, (http://web.worldbank.org), accessed March 21, 2007.

[7] Alberta Energy and Utilities Board, Upstream Petroleum Industry Flaring and Venting Report: Industry Performance for Year Ending December 31, 2006, ST60B2007, Calgary, Alberta, June 2007.

[8] Johnson, M.R., Spangelo, J.L., Kostiuk, L.W., "A Characterization of Solution Gas Flaring in Alberta," Journal of the Air \& Waste Management Association 51, pp. 1167-1177 (2001).

[9] Schug, K.P., Manheimer-Timnat, Y., Yaccarion, P., Glassman, I., "Sooting Behaviour of Gaseous Hydrocarbon Diffusion Flames and the Influence of Additives," Combustion Science and Technology 22, pp. 235-250 (1980).

[10] Brzustowski, T.A., "Flaring in the Energy Industry," Progress in Energy and Combustion Science 2, pp. 129-141 (1976).

[11] Pohl J.H., Lee J., Payne R., Tichenor B.A., "Combustion Efficiency of Flares," Combustion Science and Technology 50, pp. 217-231.

[12] Kostiuk L.W., Johnson, M.R., Thomas, G., University of Alberta Flare Research Project - Final Report November 1996 - September 2004, (http://www.mece.ualberta.ca/groups/combustion/flare /papers/Final\%20Report2004.pdf), accessed July 29, 2007.

[13] Johnson, M.R., Wilson, D.J., and Kostiuk, L.W., "A Fuel Stripping Mechanism for Wake-Stabilized Jet Diffusion Flames in a Crossflow," Combustion Science and Technology 169, pp. 155-174 (2002).

[14] Johnson, M.R., and Kostiuk, L.W., "A Parametric Model for the Efficiency of Flares in a Crosswind," Proceedings of the Combustion Institute 29, pp. 1943-1950 (2002).

[15] Ellzey J.L., Berbee J.G., Tay Z.F., Foster D.E., "Total Soot Yield from a Propane Diffusion Flame in Cross-Flow," Combustion Science and Technology 71, pp. 41-52 (1990).

[16] Prybysh, R., The Production of Toxic Emissions from Reacting Diffusion Jet Flames in a Crossflow, M.A.Sc. Thesis, University of Alberta, Edmonton, Alberta, Canada (2002). 
[17] The Centre for Disease Control and Prevention, Particulates not Otherwise Regulated, Total 0500, (http://www.cdc.gov/niosh/nmam/pdfs/0500.pdf), accessed August 8, 2007.

[18] Snelling, D.R., Thomson, K.A., Smallwood, G.J., Gülder, O.L., "Twodimensional Imaging of Soot Volume Fraction in Laminar Diffusion Flames," Applied Optics 38, No.12, pp. 2478-2485 (1999).

[19] Smallwood, G.J., Bachalo, W.D., Sankar, S.V., Particulate Measurement Methods, Optical Metrology for Fluids, Combustion, and Solids, Ed. C. Mercer, Kluwer Academic Publishers, U.S.A. (2003).

[20] Hottel, H.C. and Hawthorne, W.R., "Diffusion in Laminar Diffusion Flames," Third Symposium on Combustion and Flame and Explosion Phenomenon, pp. 254266 (1949).

[21] Delichatsios, M.A., "Transition from Momentum to Buoyancy-Controlled Turbulent Jet Diffusion Flames and Flame Height Relationships," Combustion and Flame 92, pp. 349-364 (1993).

[22] Abdul-Khalek, I.S., Kittelson, D., Brear, F., "The Influence of Dilution Conditions on Diesel Exhaust Particle Size Distribution," SAE Technical Paper Series 1999-01-1142 (1999).

[23] Chang, M.C., Chow, J.C., Watson, J.G., Hopke, P.K., Yi, S.M., England, G.C., "Measurement of Ultrafine Particle Size Distributions from Coal-, Oil-, and GasFired Stationary Combustion Sources," Journal of the Air \& Waste Management Association 54, pp. 1494-1505 (2004).

[24] Glassman I., Combustion - $2^{\text {nd }}$ Edition, Academic Press, U.S.A. (1987).

[25] Kent, J.H., and Bastin, S.J., "Parametric Effects on Sooting in Turbulent Acetylene Diffusion Flames," Combustion and Flame 56, pp. 29-42 (1984).

[26] Sivathanu, Y.R., and Faeth, G.M., "Soot Volume Fractions in the Overfire Region of Turbulent Diffusion Flames," Combustion and Flame 81, pp. 133-149 (1990).

[27] Becker, H.A., and Liang, D., "Total Emission of Soot and Thermal Radiation by Free Turbulent Diffusion Flames," Combustion and Flame 44, pp. 305-318 (1982).

[28] Coppalle A. and D. Joyeux, "Temperature and Soot Volume Fraction in Turbulent Diffusion Flames: Measurements of Mean and Fluctuating Values," Combustion and Flame 96, pp. 275-285 (1994).

[29] Nishida, O. and Mukohara, S., "Characterisitics of Soot Formation and Decomposition in Turbulent Diffusion Flames," Combustion and Flame 47, pp.269279 (1982).

[30] Gülder, O.L., and Snelling, D.R., "Influence of Nitrogen Dilution and Flame Temperature on Soot Formation in Diffusion Flames," Combustion and Flame 92, pp. 115-124 (1993).

[31] Glassman I. and Yaccarino P., "The Temperature Effect in Sooting Diffusion Flames," Eighteenth Symposium (International) on Combustion, pp. 1175-1183 (1981).

[32] Thomson, K.A., Gülder, O.L., Weckman, E.J., Fraser, R.A., Smallwood, G.J., Snelling, D.R., "Soot Concentration and Temperature Measurements in Co-Annular, Nonpremixed $\mathrm{CH}_{4} /$ air laminar flames at pressures up to $4 \mathrm{MPa}$," Combustion and Flame 140, pp.222-232 (2005). 
[33] Trottier, S., Guo, H., Smallwood, G.J., Johnson, M.R., "Measurement and modeling of the sooting propensity of binary fuel mixtures," Proceedings of the Combustion Institute 31, pp. 611-619 (2007).

[34] Frenklach, M., Yuan, T., Ramachandra, M.K., "Soot Formation in Binary Hydrocarbon Mixtures," Energy and Fuels 2, pp. $462-480$ (1988).

[35] Hwang, J.Y., Lee, W., Kang, H.G., Chung, S.H., "Synergistic Effect of EthylenePropane Mixture on Soot Formation in Laminar Diffusion Flames," Combustion and Flame 114, pp. 370-380 (1998).

[36] Sivathanu, Y.R., Soot and Radiation Properties of Buoyant Turbulent Diffusion Flames, Ph.D. Thesis, University of Michigan, U.S.A. (1990).

[37] Tsai, C.J., Lin J.S., Aggarwal, S.G., Chen, D.R., "Thermophoretic Deposition of Particles in Laminar and Turbulent Tube Flows," Aerosol Science and Technology 38 , pp. 131-139 (2004).

[38] Kittelson, D.B., Watts, W.F., Johnson, J.P., "On-Road and Laboratory Evaluation of Combustion Aerosols - Part 1: Summary of Diesel Engine Results," Journal of Aerosol Science 37, pp. 913-930 (2006).

[39] Snelling, D.R., Smallwood, G.J., Liu, F., Gülder, O.L., Bachalo, W.D., "A Calibration-Independent Laser-Induced Incandescence Technique for Soot Measurement by Detecting Absolute Light Intensity," Applied Optics 44, No. 31, pp. 6773-6785 (Nov. 2005).

[40] Becker, H.A. and Liang, D.,"Visible Length of Vertical Free Turbulent Diffusion Flames," Combustion and Flame 32, pp. 115-137 (1978).

[41] Heskestad, G., "Turbulent Jet Diffusion Flames - Consolidation of Flame Height Data," Combustion and Flame 118, pp. 51-66 (1999).

[42] Kalghatgi, G.T., "The Visible Shape and Size of a Turbulent Hydrocarbon Jet Diffusion Flame in a Cross-wind," Combustion and Flame 52, pp. 91-106 (1983).

[43] Kalghatgi, G.T., "Lift-off Heights and Visible Lengths of Vertical Turbulent Jet Diffusion Flames in Still Air," Combustion Science and Technology 41, pp. 17-29 (1984).

[44] Kostiuk, L.W., Majeski, A.J., Johnson, M.R., Wilson, D.J., "Scaling of WakeStabilized Jet Diffusion Flames in a Traverse Air Stream," Proceedings of the Combustion Institute 28, pp. 553-559 (2000).

[45] Brockmann J.E., Sampling and Transport of Aerosols, Aerosol Measurement 2nd Edition, Ed. Baron, P., and Willeke, K., John Wiley and Sons, U.S.A. (2001).

[46] Hurley, C.D., "Measurements of Particulates from an Engine Combustor," AEROTRACE Proc. International Colloquium, Impact of Aircraft Emissions upon the Atmosphere, Paris, October 15-18 (1996).

[47] Newman, J.S., and Steciak, J., "Characterization of Particulates from Diffusion Flames," Combustion and Flame 67, pp. 55-64 (1987).

[48] Dobbins, R.A., Mulholland, G.W., Bryner, N.P., "Comparison of a Fractal Smoke Optics Model with Light Extinction Measurements," Atmospheric Environment 28, No. 5, pp. 889-897 (1994).

[49] Choi, M.Y., and Jensen, K.A., "Comparisons of the Soot Volume Fraction Using Gravimetric and Light Extinction Techniques," Combustion and Flame 102, pp. 161169 (1995). 
[50] Wu, J.S., Krishnan, S.S., Faeth, G.M., "Refractive Indicies at Visible Wavelengths of Soot Emitted from Buoyant Turbulent Diffusion Flames," Transactions of the ASME 119, pp. 230-237 (May 1997).

[51] Krishnan, S.S., Lin, K.C., Faeth, G.M., "Optical Properties in the Visible of Overfire Soot in Large Buoyant Turbulent Diffusion Flames," Journal of Heat Transfer 122, pp. 517-524 (August 2000).

[52] Krishnan, S.S., Lin, K.C., Faeth, G.M., "Extinction and Scattering Properties of Soot Emitted from Buoyant Turbulent Diffusion Flames," Journal of Heat Transfer 123, pp. 331-339 (April 2001).

[53] Krishnan, S.S., - private communication via email (Jan. 23, 2007)

[54] Koylu, U.O., and Faeth, G.M., "Spectral Extinction Coefficients of Soot Aggregates from Turbulent Diffusion Flames," Journal of Heat Transfer 118, pp. 415-421 (May 1996).

[55] Bruce, C.W., Stromberg, T.F., Gurton, K.P., Mozer, J.B., "Trans-spectral Absorption and Scattering of Electromagnetic Radiation by Diesel Soot," Applied Optics 30, No. 12, pp. 1537-1546 (April 1991).

[56] Schnaiter, M., Horvath, H., Mohler, O., Naumann, K.H., Saathoof, H., Schock, O.W., "UV-VIS-NIR Spectral Optical Properties of Soot and Soot-Containing Aerosols," Aerosol Science 34, pp.1421-1444 (2003).

[57] Snelling, D.R., Liu, F., Smallwood, G.J., Gülder, O.L., "Determination of the Soot Absorption Function and Thermal Accomodation Coefficient Using LowFluence LII in a Laminar Coflow Ethylene Diffusion Flame," Combustion and Flame 136, pp. 180-190 (2004).

[58] Delichatsios, M.A., "Air Entrainment into Buoyant Jet Flames and Pool Fires,“ Combustion and Flame 70, pp.33-46 (1987).

[59] Zimberg, M.J., Frankel, S.H., Gore, J.P., Sivathanu, Y.R., "A Study of Coupled Turbulent Mixing, Soot Chemistry, and Radiation Effects Using the Linear Eddy Model," Combustion and Flame 113, pp.454-469 (1998).

[60] Lee, K.B., Thring, M.W., Beer, J.M., "On the Rate of Combustion of Soot in a Laminar Soot Flame," Combustion and Flame 6, pp.137-145 (1962).

[61] Kent, J.H., and Wagner, H., "Why Do Diffusion Flames Emit Smoke," Combustion Science and Technology 41, pp.245-269 (1984).

[62] Becker, H.A., and Yamazaki, S., "Entrainment, Momentum Flux and Temperature in Vertical Free Turbulent Diffusion Flames," Combustion and Flame 33, pp.123-149 (1978).

[63] Orloff, L., Ris, J., Delichatsios, "Radiation from Buoyant Turbulent Diffusion Flames," Combustion Science and Technology 84, pp.177-186 (1992).

[64] White, F.M., Fluid Mechanics $-4^{\text {th }}$ Edition, McGraw-Hill, U.S.A. (1999).

[65] Hinze, J.O., Turbulence, McGraw-Hill, U.S.A. (1959).

[66] Deschamps, B., Etude Spatiale et Temporelle de la Structure Dynamique et Scalaire des Flammes Turbulentes Premelangees de Methane-Air, Ph.D. Thesis, L'Universite D'Orleans, France (1990).

[67] Wong, R., Sautet, J.C., Snelling, D.R., Smallwood, G.J., and Gülder, O.L., "2-D Profiles of the Flame Front in Turbulent Premixed Flames Using Laser Induced Fluorescence and Laser Mie Scattering," Combustion Institute - Canadian Section Spring Technical Meeting, Laval, Quebec, Canada (1993). 
[68] Argarwal, J.K. and Sem, G.J., "Generating Submicron Monodisperse Aerosols for Instrument Calibration," TSI Quarterly 4, No.2, May-June, pp.3-8 (1978).

[69] TSI, Series 3080 Electrostatic Classifiers Manual, Revision F, March 2005.

[70] Michelsen, H.A., "Understanding and Predicting the Temporal Response of Laser Induced Incandescence from Carbonaceous Particles," Journal of Chemical Physics 118 , pp. $7012-7045$ (2003). 


\section{Appendix A: Characterizing Burner Turbulence}

As discussed in section 1.1.1, a representative solution gas flare has a $0.10 \mathrm{~m}$ inner diameter at the exit and is approximately $10 \mathrm{~m}$ high. Assuming methane as the fuel and an exit velocity of $6 \mathrm{~m} / \mathrm{s}$, the Reynolds number $(R e)$ would be approximately 40000 . If the fuel is assumed to be propane, this would give a $R e=150000$. The estimated entrance length for a turbulent flow can be approximated by [63],

$$
\frac{L_{e}}{d} \approx 4.4 \mathrm{Re}^{1 / 6}
$$

For the $R e$ values given above, this would correspond to entrance lengths of approximately $26 d$ for methane and $32 d$ for propane. Since the $L / d$ for an average industrial flare is 100 , the flow from a flare can be characterized as fully developed turbulent pipe flow.

Hinze [64] estimated that the turbulence intensity $\left(u^{\prime} / \bar{u}\right)$ for fully developed flow in a smooth pipe should be less than $10 \%$. In most of the conditions run with the lab-scale flare, $R e$ is usually much less than 2300 which is the transition point from laminar to turbulent pipe flow. Therefore, turbulence generating grids (Figure A.1) are used to achieve the same turbulence intensity that would occur in fully developed pipe flow. 


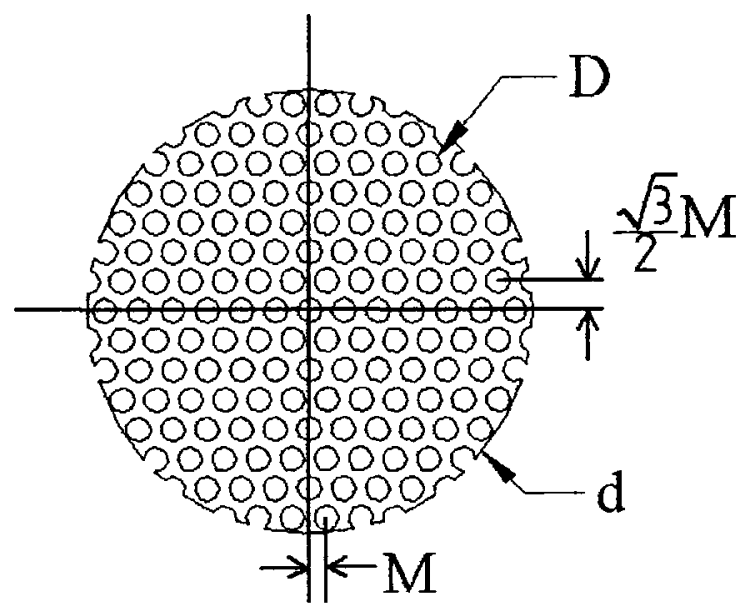

Figure A.1: Turbulence grid schematic

The grids were based on the design of Deschamps [65] who found the blockage ratio $(\sigma)$ to be the important parameter in determining the level of turbulence intensity. The blockage ratio is defined as,

$$
\begin{gathered}
\sigma=(\text { blocked surface area }) /(\text { total surface area) } \\
\sigma=1-\frac{\pi}{2 \sqrt{3}}\left(\frac{D}{M}\right)^{2} \quad(\text { A.2) }
\end{gathered}
$$

Table A.1 gives a list of the grids that were created and used in the hotwire anemometer tests. These grids were selected from Deschamps [65] since they produced a turbulence intensity in the $5-8 \%$ range. The grids in Table A.1 were then tested with a hotwire anemometer and only the grids which could produce a turbulence intensity similar to fully developed turbulent pipe flow were selected to be used in the soot emission experiments. 
Table A.1: Turbulence grid specifications

\begin{tabular}{ccccc}
\hline Grid & $\begin{array}{c}\boldsymbol{d} \\
(\mathbf{m m})\end{array}$ & $\begin{array}{c}\boldsymbol{D} \\
(\mathbf{m m})\end{array}$ & $\begin{array}{c}\boldsymbol{M} \\
(\mathbf{m m})\end{array}$ & $\boldsymbol{\sigma}$ \\
\hline 1 & 12.7 & 1.5 & 2.0 & 0.490 \\
2 & 12.7 & 2.5 & 3.4 & 0.510 \\
3 & 12.7 & 3.3 & 4.6 & 0.533 \\
4 & 25.4 & 1.5 & 2.0 & 0.490 \\
5 & 25.4 & 2.5 & 3.4 & 0.510 \\
6 & 25.4 & 3.3 & 4.6 & 0.533 \\
7 & 38.1 & 1.5 & 2.0 & 0.490 \\
8 & 38.1 & 2.5 & 3.4 & 0.510 \\
9 & 38.1 & 3.3 & 4.6 & 0.533 \\
10 & 50.8 & 1.5 & 2.0 & 0.490 \\
11 & 50.8 & 2.5 & 3.4 & 0.510 \\
12 & 50.8 & 3.3 & 4.6 & 0.533 \\
\hline
\end{tabular}

\section{A.1 Hotwire Results}

The AN-1005 constant temperature anemometer from A.A. Lab Systems was used for the hotwire experiments. The system is capable of capturing data at a sample rate of 800 $\mathrm{kHz}$ at a 16 bit resolution. The hotwire was connected to a computer via a USB2 port, which allowed the data analysis to be conducted in LabVIEW.

The grids were placed at three to five diameters upstream of the burner exit nozzle as recommended by Wong et al. [66]. Each grid was tested in the appropriate size burner at the three upstream locations and at three different flow rates which spanned the range expected to be used in the soot emission experiments. The hotwire probe was positioned in the centre of the burner and less than $3 \mathrm{~mm}$ above the burner exit. The hotwire collected 20000 samples at a sampling rate of $20 \mathrm{kHz}$ to avoid aliasing. Air was used as the working fluid. 
A calibration was conducted on the hotwire system before running a set of experiments. A burner with no grid was used along with an accurately calibrated mass flow controller ( $<1.0 \%$ full-scale error). Typically, a set of eight to ten data points were collected by running through the entire range of flow rates. King's Law, shown below, was used to fit a curve to the data.

$$
E_{\text {T.o.B. }}^{2}=A+B \cdot \boldsymbol{u}^{n}(\mathrm{~A} .3)
$$

where, $E_{\text {T.о.в. }}$ is the top-of-bridge voltage

$u$ is the fluid velocity

$A, B$, and $n$ are numerical coefficients

The coefficients were solved for using the Levenberg-Marquardt algorithm available in LabVIEW. The turbulent length scale $\left(l_{t}\right)$ was found by using the autocorrelation function.

The results of the selected grids are shown in Table A.2 and the turbulence intensity profiles are shown in Figure A.2. Grids 1 and 8 were placed outside the three to five diameter range to produce an acceptable level of turbulence intensity. A 13 point traverse was conducted across the diameter of the burner exit for the selected grids to ensure a uniform turbulence profile existed. 
Table A.2: Turbulence intensity results from turbulence generating grid

\begin{tabular}{cccccc}
\hline Grid & $\begin{array}{c}\boldsymbol{d} \\
(\mathbf{m m})\end{array}$ & $\begin{array}{c}\text { Location } \\
\text { (in diameters) }\end{array}$ & $\boldsymbol{R} \boldsymbol{e}$ & $\begin{array}{c}\boldsymbol{u}^{\prime} / \overline{\boldsymbol{u}} \\
(\%)\end{array}$ & $\begin{array}{c}\boldsymbol{l}_{\boldsymbol{t}} \\
(\mathrm{mm})\end{array}$ \\
\hline 1 & 12.7 & 10 & 834 & 3.2 & 6.4 \\
& & & 4646 & 6.1 & 6.0 \\
& & & 8578 & 5.2 & 6.5 \\
\hline 4 & 25.4 & 5 & 417 & 1.4 & 12.1 \\
& & & 2323 & 4.8 & 1.7 \\
& & & 4289 & 5.4 & 3.5 \\
\hline 8 & 38.1 & 2 & 278 & 3.7 & 0.1 \\
& & & 1549 & 5.4 & 1.0 \\
& & & 2859 & 5.8 & - \\
\hline 10 & 50.8 & 5 & 208 & 2.0 & 0.1 \\
& & & 1162 & 5.3 & 0.8 \\
& & & 2145 & 3.1 & 0.3 \\
\hline
\end{tabular}

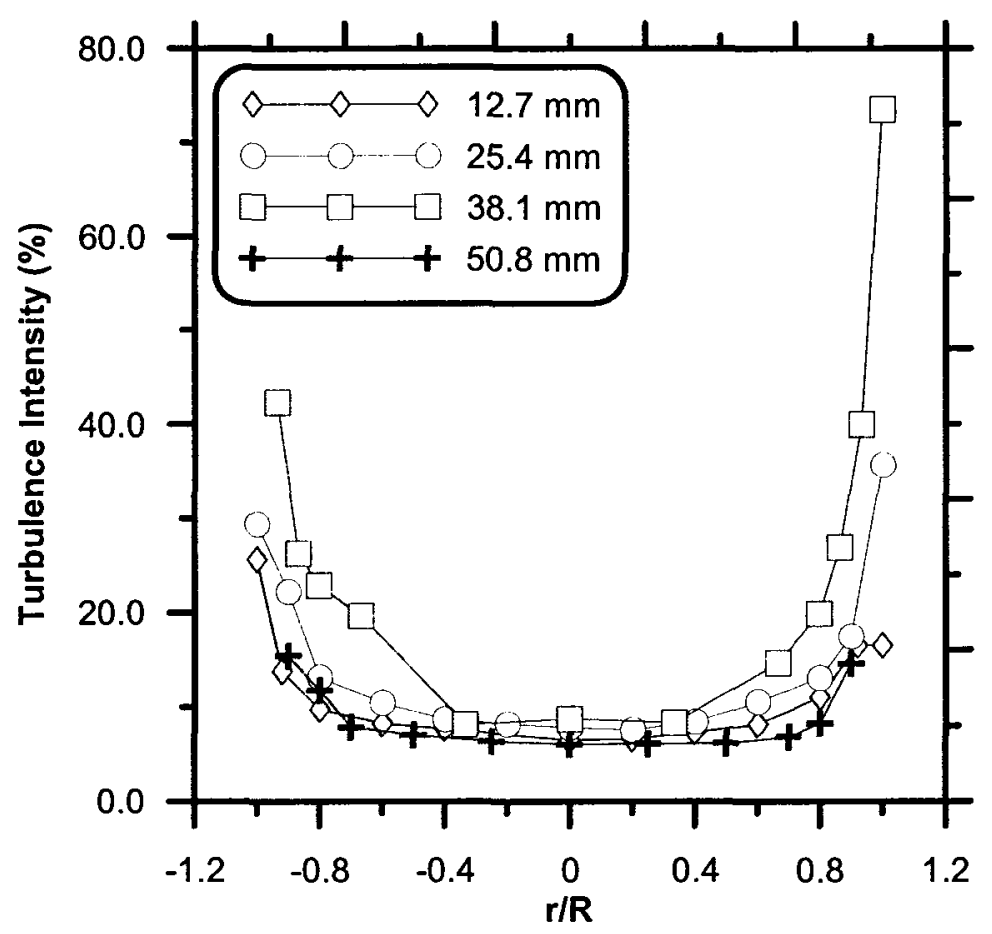

Figure A.2: Turbulence intensity profiles for the four burner diameters using the grids listed in Table A.2 at the largest $R e$ value 


\section{Appendix B: Scanning Mobility Particle Sizer (SMPS)}

\section{B.1 Description}

The SMPS is used to determine the number concentration and electric mobility diameter of the soot particles. The electric mobility $\left(Z_{p}\right)$ of a particle is inversely proportional to its size $\left(d_{\mathrm{p}}\right)$ and proportional to the number of charges $(n)$ it carries and is commonly used as a characteristic length scale of particles [67].

$$
Z_{p}=\frac{n e C}{3 \pi \mu d_{p}}
$$

where, $e$ is the elementary unit of charge

$C$ is the Cunningham slip correction

$\mu$ is the gas viscosity

The particles enter an aerosol neutralizer (Figure B.1) which applies an electrical charge to the particles. The differential mobility analyzer (DMA) contains two concentric metallic cylinders. The charged particles travel through the annulus between the two cylinders. The inner cylinder has an electrical charge applied to it, which causes the particles to follow a curved path. Depending on the charge of the inner cylinder, only a certain size of particle will be able to pass through the outlet. The particles that are allowed to pass through the DMA then enter a condensation particle counter (CPC). The CPC enlarges the particles by condensing vapour onto them so they can be detected with 
an optical system. Size distribution and number concentration of the soot particles are found by varying the charge of the DMA. However, as shown in Eq. B.1, a larger particle with half the number of charges will have the same mobility as a particle with half the diameter. This has the potential to cause errors in the reported size distribution.

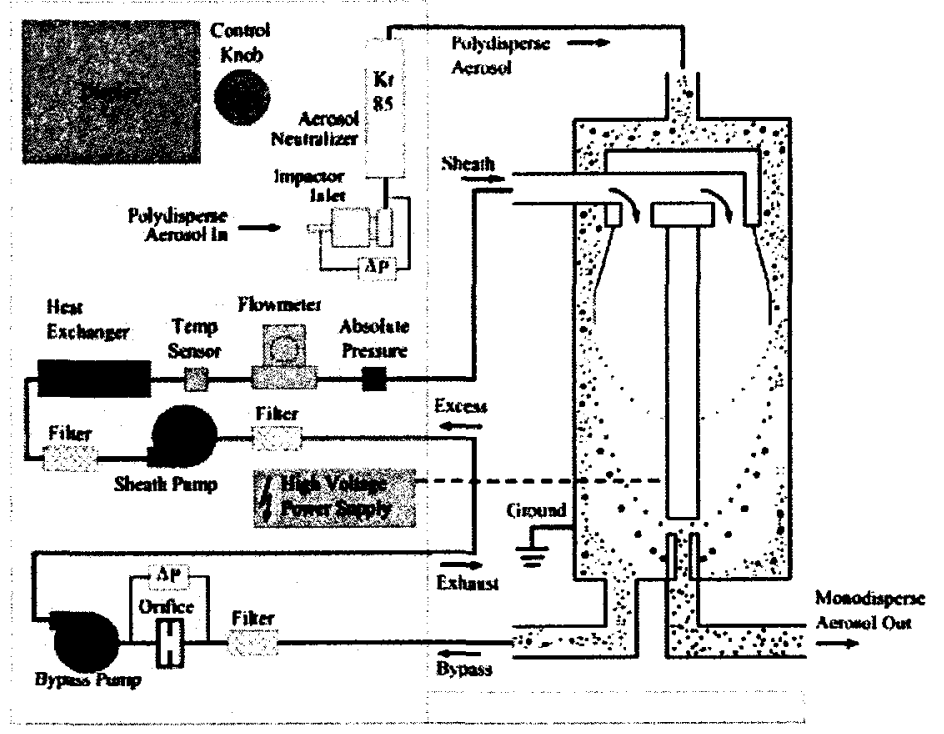

Figure B.1: DMA schematic [68]

\section{B.2 SMPS Results}

The SMPS was used to analyze samples from methane and propane flames with different burner diameters and fuel flow rates. Due to dilution of the exhaust gas, the soot concentrations were below the detectable limit of the SMPS at the normal sampling point in the experimental setup. Therefore, a probe was placed above the flame $(\sim 0.25$ $0.50 \mathrm{~m}$ ) to sample the exhaust gas in order to obtain a measurable quantity of soot. Figures B.2a,b show the particulate size distributions for the methane and propane flames. It should be noted that the number concentrations in these figures do not 
accurately represent the quantity of soot produced from the given flame as the probe was moved from test to test. These results were obtained merely to give an idea of the size distribution expected from methane and propane flames at different conditions.

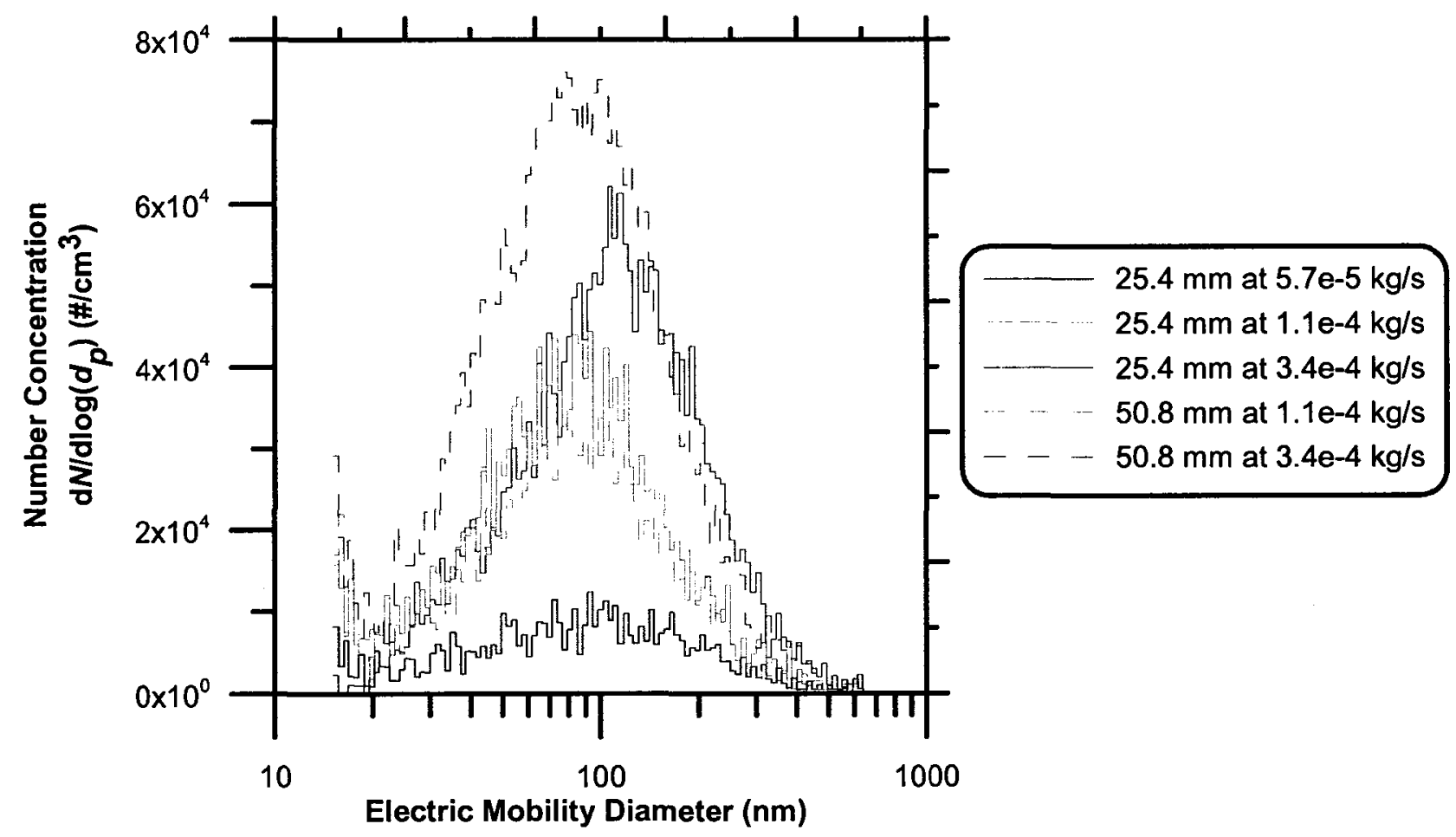

a) Methane

Figure B.2: Particle size distribution results from SMPS for methane and propane flames with different burner diameters and fuel flow rates 


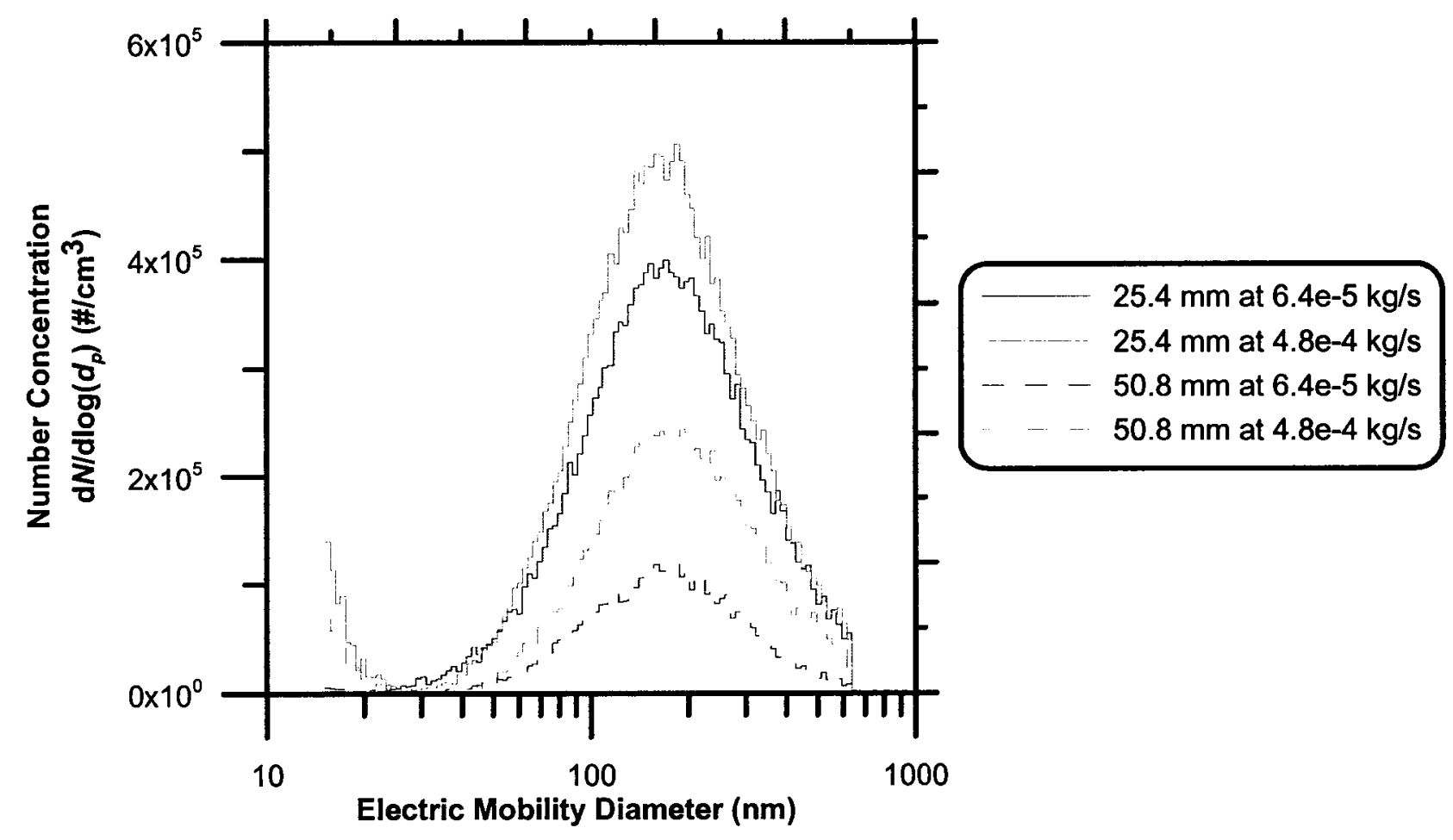

b) Propane

Figure B.2: Particle size distribution results from SMPS for methane and propane flames with different burner diameters and fuel flow rates

The size distributions shown in Figures B.2a,b generally show the same "bell" curve on the logarithmic scale. Also, the size distribution does not appear to change when different burner diameters or fuel flow rates are used. The SMPS was currently setup only to measure particle sizes from $15 \mathrm{~nm}-673 \mathrm{~nm}$; however, it does appear that most of the particles fall into this size range. Below $20 \mathrm{~nm}$, the curve begins to increase, which is consistent with the results of Kittelson et al. [1] who also showed this bimodal distribution with particulate matter from diesel fuel. As noted above, the SMPS gives an electric mobility diameter which means that a given soot particle only has the same 
electric mobility as a spherical particle with a given diameter. However, if it can be assumed that the actual soot particle diameter is on the same order of magnitude as the electric mobility diameter, then this suggests that despite the flow conditions, particulates from methane and propane flames all fall within the $\mathrm{PM}_{2.5}$ classification. As discussed in Chapter $1, \mathrm{PM}_{2.5}$ is an important categorization for regulatory limits and particles in this regime are linked to health risks. 


\section{Appendix C: Sampling Loss Calculations}

This appendix attempts to estimate the soot sampling losses expected to occur in the sampling system. The equations given in this section have all been obtained from Brockmann [44].

\section{C.1 Inlet Efficiency of Sampling Probe}

The inlet efficiency $\left(\eta_{\text {inlet }}\right)$ is composed of an aspiration efficiency ( $\left.\eta_{\text {asp }}\right)$ and a transmission efficiency ( $\left.\eta_{\text {trans }}\right)$,

$$
\eta_{\text {inlet }}=\eta_{\text {asp }} \eta_{\text {trans }}
$$

The aspiration efficiency is a measure of the concentration of particles that enter the sampling probe compared to the concentration in the free stream. The transmission losses occur at the sampling probe entrance due to gravitational settling or inertial effects where the particles may impact the wall.

For isoaxial sampling, which refers to the sampling probe being aligned with the direction of the free stream gas flow, Zhang and Liu [44], give the following correlation for the aspiration efficiency, 


$$
\begin{aligned}
& \eta_{a s p}=1+\frac{\left[\frac{U_{o}}{U}-1\right]}{\left[1+\frac{0.418}{S t k}\right]} \quad \frac{U_{o}}{U}>1 \\
& S t k=\frac{\tau \cdot U_{o}}{d} \\
& \tau=\frac{\rho_{p} d_{p} C_{c}}{18 \mu}
\end{aligned}
$$

where, $U_{o}$ is the free stream gas velocity

$U$ is the sampling probe gas velocity

Stk is the Stokes number

$\tau$ is the particle relaxation time

$d$ is the sampling probe diameter

$\rho_{p}$ is the particle density

$d_{p}$ is the particle diameter

$C_{c}$ is the slip correlation factor

$\mu$ is the free stream gas viscosity

For the experimental conditions used in the soot emission tests, the velocity ratio is approximately between $2.2<U_{o} / U<11$. The sampling probe inner diameter is $7.7 \mathrm{~mm}$ and the free stream gas is assumed to have the same properties as air at $80^{\circ} \mathrm{C}$ so that the gas viscosity is $2.05 \mathrm{e}-5 \mathrm{~N} \cdot \mathrm{s} / \mathrm{m}^{2}$. The soot particle density is $1893 \mathrm{~kg} / \mathrm{m}^{3}$ and the expected range of soot particle diameter is $0.1 \mu \mathrm{m}<d_{p}<1.0 \mu \mathrm{m}$. The slip correlation factors for 
$0.1 \mu \mathrm{m}$ and $1.0 \mu \mathrm{m}$ particle diameters are 2.866 and 1.152 , respectively. For the range of parameters used, the aspiration efficiency is calculated to be 1.00 .

As mentioned above, the transmission efficiency is dependent on a gravitational-settling transmission efficiency ( $\left.\eta_{\text {trans,grav }}\right)$ and a inertial transmission efficiency ( $\left.\eta_{\text {trans,inert }}\right)$. Okazaki et al. [44] performed experiments to create a correlation for $\eta_{\text {trans,grav, }}$

$$
\begin{aligned}
& \eta_{\text {trans }, \text { grav }}=\exp \left(-4.7 K^{0.75}\right) \\
& K=Z^{1 / 2} S t k^{1 / 2} R e^{-1 / 4} \\
& Z=\frac{L}{d} \frac{V_{t s}}{U} \\
& V_{t s}=\frac{\rho_{p} d_{p}^{2} g C_{c}}{18 \mu}
\end{aligned}
$$

where, $Z$ is the gravitational deposition length

$R e$ is the Reynolds number

$L$ is the inlet region length

$V_{t s}$ is the terminal settling velocity

$g$ is the gravitational constant

The inlet region length is assumed to be $0.05 \mathrm{~m}$ as this is the length from the sampling probe inlet to the start of a $90^{\circ}$ bend. However, as the inlet region length decreases, the transmission efficiency increases. The "worst-case" scenario for gravitational-settling 
losses occurs with a particle size of $0.1 \mu \mathrm{m}$ and the highest free stream flow rate which yield $\eta_{\text {trans, grav }}=0.98$

Hangal and Willeke [44] have assumed that for sub-isokinetic sampling $\left(U_{o} / U>1\right)$ there are no inertial transmission losses so $\eta_{\text {trans,inert }}=1.00$.

Taking into account all of the efficiency terms outlined above, the inlet efficiency of the sampling probe is calculated to be no worse than $\eta_{\text {inlet }}=0.98$.

\section{C.2 Transport Efficiency through Sampling Duct and Sample Lines}

There are numerous components that contribute to the transport efficiency ( $\left.\eta_{\text {transort }}\right)$, such as gravitational-settling losses, diffusional losses, turbulent inertial deposition, inertial deposition in a bend, and thermophoresis. Similar to the inlet efficiency, the transport efficiency is calculated by multiplying together the individual efficiencies,

$$
\eta_{\text {transport }}=\eta_{\text {tube, grav }} \eta_{\text {tube,diff }} \eta_{\text {tube, inert }} \eta_{\text {tube,bend }}
$$

Gravitational-settling losses will only occur in the main sampling duct and the sampling probe inlet (as described above). The sampling line from the duct to the LII is vertical and gravitational settling is not important. For the sampling duct, Schwendiman et al. [44] have given a correlation for turbulent flow in a horizontal tube, 


$$
\eta_{t u b e, g r a v}=\exp \left[-\frac{d L_{d} V_{t s}}{Q}\right]
$$

where, $L_{d}$ is the duct length $(4 \mathrm{~m})$

$Q$ is the duct gas volumetric flow rate

Even in the "worst-case" scenario for gravitational settling with a low flow rate and small particle diameter $\eta_{t u b e, g r a v}=1.00$.

For diffusional losses, the duct wall can act as a sink for the soot particles which will diffuse from high particle concentrations to low particle concentrations. These losses can occur in both the turbulent flow of the sampling duct and laminar flow of the sampling line. The general equation for the transport efficiency with diffusive particle loss is,

$$
\begin{aligned}
& \eta_{\text {tube }, \text { iff }}=\exp (-\xi S \boldsymbol{h}) \\
& \xi=\frac{\pi D L_{d}}{Q}
\end{aligned}
$$

$$
\begin{array}{ll}
\text { Laminar Flow (Holmann [44]): } & \boldsymbol{S h}=3.66+\frac{0.2672}{\xi+0.10079 \xi^{1 / 3}} \\
\text { Turbulent Flow (Friedlander [44]): } & \boldsymbol{S h}=0.0118 \boldsymbol{R} \boldsymbol{e}^{7 / 8} \boldsymbol{S} \boldsymbol{c}^{1 / 3} \\
S \boldsymbol{c} & =\frac{v_{g}}{D}
\end{array}
$$

where, $S h$ is the Sherwood number 
$D$ is the particle diffusion coefficient

$S c$ is the Schmidt number

$v$ is the kinematic viscosity of the duct gas

The particle diffusion coefficients for $0.1 \mu \mathrm{m}$ and $1 \mu \mathrm{m}$ particle diameters are $6.80 \mathrm{e}-$ $10 \mathrm{~m}^{2} / \mathrm{s}$ and $2.70 \mathrm{e}-11 \mathrm{~m}^{2} / \mathrm{s}$, respectively. The calculated transport efficiency for both the laminar and turbulent case is $\eta_{\text {tube, diff }}=1.00$.

It has been shown in experiments that particle deposition is enhanced in turbulent flows [44]. This mechanism could cause losses in the main sampling duct where the flow is turbulent. The transport efficiency for turbulent inertial deposition is,

$$
\begin{aligned}
& \eta_{\text {tube, } \text { inert }}=\exp \left[-\frac{\pi d L_{d} V_{t}}{Q}\right] \\
& V_{t}=\frac{V_{+} U}{5.03 \operatorname{Re}^{1 / 8}} \\
& V_{+}=6 e-4 \tau_{+}^{2}+2 e-8 \operatorname{Re} \\
& \tau_{+}=0.0395 \text { Stk } \operatorname{Re}^{3 / 4}
\end{aligned}
$$

where, $V_{t}$ is the turbulent inertial deposition velocity

$V_{+}$is the dimensionless deposition velocity

$\tau_{+}$is the dimensionless particle relaxation time 
The losses via turbulent inertial deposition increase with particle diameter and duct volumetric flow rate and are estimated to be $\eta_{t u b e, d i f f}=0.99$.

Pui et al. [44] proposed a simple correlation for particles undergoing inertial deposition in a bend.

$$
\eta_{\text {tube }, \text { bend }}=\left[1+\left[\frac{S t k}{0.171}\right]^{0.452 \frac{S t k}{0.171}+2.242}\right]^{-\frac{2}{\pi} \varphi}
$$

where, $\varphi$ is the angle of the bend in radians $\left(90^{\circ}=1.57\right)$.

The estimated losses through this mechanism are $\eta_{\text {tube, bend }}=0.99$.

Thermophoresis is a phenomenon where hot soot particles are attracted to cool surfaces (i.e. sampling duct wall). The thermophoretic losses are estimated in a similar manner as the losses from turbulent inertial deposition, except that a thermophoretic velocity is used,

$$
\eta_{\text {tube,th }}=\exp \left[-\frac{\pi d L_{d} V_{t h}}{Q}\right]
$$




$$
V_{t h}=\frac{2\left(\frac{k_{g}}{k_{p}}\right) k_{g} \nabla T}{5 P\left[1+2 \frac{k_{g}}{k_{p}}\right]}
$$

where, $k_{g}$ is the thermal conductivity of the gas

$k_{p}$ is the thermal conductivity of the soot particles

$\nabla T$ is the temperature gradient in the gas

$P$ is the pressure in the duct

The thermal conductivity of graphite $(4.01 \mathrm{~W} / \mathrm{m} \cdot \mathrm{K}$ [69]) is used as an estimate for the soot particles. The critical parameter that controls thermophoresis is the temperature gradient. A worst-case estimate of the gradient would be assuming that the duct walls are at ambient temperature. The exhaust gas temperature is expected to be no greater than $423 \mathrm{~K}$; therefore, an estimate for the maximum possible temperature gradient is 1706 $\mathrm{K} / \mathrm{m}$. Using this temperature gradient, the thermophoretic losses are estimated to be approximately $\eta_{\text {tube,th }}=0.95$. However, because the duct walls are insulated, the temperature gradient is expected to be much lower. The temperature profiles shown in section 5.1.1 show the duct wall temperature most likely varies from the exhaust gas temperature by no more than $10 \mathrm{~K}$. This results in the thermophoretic losses to be $\eta_{\text {tube,th }}$ $=1.00$. 


\section{C.3 Total Sampling Losses}

Combining the various modes of losses in the sampling system results in an estimated transport efficiency of $\eta_{\text {tube,diff }}=0.98$.

The total losses in the system is the combination of inlet losses and transport losses,

$$
\eta_{\text {sample }}=\eta_{\text {inlet }} \eta_{\text {transport }} \quad \text { (C.22) }
$$

From the above calculations, it is estimated that the worst-case total sampling efficiency is $\eta_{\text {sample }}=0.97$. 


\section{Appendix D: Experimental Test Conditions}

The test conditions for the experiments are outlined in this appendix.

Table D.1: Methane test conditions

\begin{tabular}{|c|c|c|c|c|c|}
\hline $\begin{array}{c}\text { Burner Exit } \\
\text { Diameter } \\
(\mathrm{mm})\end{array}$ & $\begin{array}{c}\text { Fuel Mass Flow } \\
\text { Rate } \\
(\mathrm{kg} / \mathrm{s})\end{array}$ & $\begin{array}{c}\text { Burner Exit } \\
\text { Velocity } \\
(\mathrm{m} / \mathrm{s})\end{array}$ & $\begin{array}{c}\text { Fuel } \\
\text { Density } \\
\left(\mathrm{kg} / \mathrm{m}^{3}\right)\end{array}$ & $\begin{array}{c}\text { Reynolds } \\
\text { Number }\end{array}$ & $\begin{array}{c}\text { Froude } \\
\text { Number }\end{array}$ \\
\hline 25.4 & $1.20 \mathrm{E}-04$ & 0.358 & 0.659 & 584 & 0.717 \\
\hline 25.4 & $1.79 \mathrm{E}-04$ & 0.537 & 0.659 & 875 & 1.076 \\
\hline 25.4 & $2.03 \mathrm{E}-04$ & 0.609 & 0.659 & 992 & 1.220 \\
\hline 25.4 & $2.39 \mathrm{E}-04$ & 0.717 & 0.658 & 1166 & 1.436 \\
\hline 25.4 & $2.63 \mathrm{E}-04$ & 0.788 & 0.658 & 1283 & 1.579 \\
\hline 25.4 & $2.99 \mathrm{E}-04$ & 0.896 & 0.658 & 1458 & 1.795 \\
\hline 25.4 & $3.22 \mathrm{E}-04$ & 0.968 & 0.657 & 1574 & 1.939 \\
\hline 25.4 & $3.59 \mathrm{E}-04$ & 1.077 & 0.657 & 1750 & 2.157 \\
\hline 25.4 & $4.18 \mathrm{E}-04$ & 1.250 & 0.659 & 2040 & 2.505 \\
\hline 25.4 & $4.78 \mathrm{E}-04$ & 1.430 & 0.659 & 2331 & 2.864 \\
\hline 25.4 & $5.37 \mathrm{E}-04$ & 1.615 & 0.656 & 2622 & 3.236 \\
\hline 25.4 & $5.97 \mathrm{E}-04$ & 1.796 & 0.656 & 2913 & 3.598 \\
\hline 38.1 & $1.79 \mathrm{E}-04$ & 0.238 & 0.662 & 584 & 0.389 \\
\hline 38.1 & $2.03 \mathrm{E}-04$ & 0.270 & 0.660 & 661 & 0.442 \\
\hline 38.1 & 2.39E-04 & 0.318 & 0.660 & 778 & 0.520 \\
\hline 38.1 & $2.63 \mathrm{E}-04$ & 0.349 & 0.660 & 855 & 0.571 \\
\hline 38.1 & $2.99 \mathrm{E}-04$ & 0.397 & 0.659 & 972 & 0.650 \\
\hline 38.1 & $3.23 \mathrm{E}-04$ & 0.429 & 0.659 & 1050 & 0.702 \\
\hline 38.1 & $3.58 \mathrm{E}-04$ & 0.477 & 0.659 & 1167 & 0.781 \\
\hline 38.1 & $4.18 \mathrm{E}-04$ & 0.555 & 0.661 & 1360 & 0.907 \\
\hline 38.1 & $4.78 \mathrm{E}-04$ & 0.634 & 0.660 & 1554 & 1.038 \\
\hline 38.1 & $5.37 \mathrm{E}-04$ & 0.714 & 0.660 & 1748 & 1.168 \\
\hline 38.1 & $5.97 \mathrm{E}-04$ & 0.794 & 0.660 & 1942 & 1.298 \\
\hline 50.8 & $1.79 \mathrm{E}-04$ & 0.134 & 0.659 & 438 & 0.190 \\
\hline 50.8 & $2.03 \mathrm{E}-04$ & 0.152 & 0.660 & 496 & 0.215 \\
\hline 50.8 & $2.39 \mathrm{E}-04$ & 0.179 & 0.660 & 583 & 0.253 \\
\hline 50.8 & $2.63 \mathrm{E}-04$ & 0.197 & 0.659 & 641 & 0.279 \\
\hline 50.8 & $2.99 \mathrm{E}-04$ & 0.224 & 0.659 & 729 & 0.317 \\
\hline 50.8 & $3.23 \mathrm{E}-04$ & 0.242 & 0.659 & 787 & 0.342 \\
\hline 50.8 & $3.58 \mathrm{E}-04$ & 0.269 & 0.658 & 875 & 0.381 \\
\hline 50.8 & $4.18 \mathrm{E}-04$ & 0.311 & 0.662 & 1020 & 0.441 \\
\hline 50.8 & 4.77E-04 & 0.355 & 0.662 & 1163 & 0.503 \\
\hline 50.8 & $5.37 \mathrm{E}-04$ & 0.402 & 0.660 & 1311 & 0.569 \\
\hline 50.8 & $5.92 \mathrm{E}-04$ & 0.442 & 0.660 & 1444 & 0.627 \\
\hline
\end{tabular}


Table D.2: Ethane test condtions

\begin{tabular}{|c|c|c|c|c|c|}
\hline $\begin{array}{c}\text { Burner Exit } \\
\text { Diameter } \\
(\mathrm{mm})\end{array}$ & $\begin{array}{c}\text { Fuel Mass Flow } \\
\text { Rate } \\
(\mathrm{kg} / \mathrm{s})\end{array}$ & $\begin{array}{c}\text { Burner Exit } \\
\text { Velocity } \\
(\mathrm{m} / \mathrm{s})\end{array}$ & $\begin{array}{c}\text { Fuel } \\
\text { Density } \\
\left(\mathrm{kg} / \mathrm{m}^{3}\right) \\
\end{array}$ & $\begin{array}{c}\text { Reynolds } \\
\text { Number }\end{array}$ & $\begin{array}{c}\text { Froude } \\
\text { Number }\end{array}$ \\
\hline 12.7 & $1.12 \mathrm{E}-04$ & 0.716 & 1.236 & 1322 & 2.028 \\
\hline 12.7 & $1.57 \mathrm{E}-04$ & 1.002 & 1.236 & 1849 & 2.838 \\
\hline 12.7 & $2.24 \mathrm{E}-04$ & 1.431 & 1.236 & 2642 & 4.053 \\
\hline 12.7 & $2.69 \mathrm{E}-04$ & 1.717 & 1.235 & 3169 & 4.864 \\
\hline 12.7 & $3.36 \mathrm{E}-04$ & 2.145 & 1.235 & 3959 & 6.077 \\
\hline 12.7 & 4.44E-04 & 2.837 & 1.235 & 5234 & 8.037 \\
\hline 12.7 & $5.58 \mathrm{E}-04$ & 3.565 & 1.235 & 2915 & 10.099 \\
\hline 12.7 & $6.70 \mathrm{E}-04$ & 4.281 & 1.235 & 3500 & 12.129 \\
\hline 12.7 & $7.81 \mathrm{E}-04$ & 4.991 & 1.235 & 4079 & 14.141 \\
\hline 25.4 & $1.12 \mathrm{E}-04$ & 0.178 & 1.240 & 661 & 0.357 \\
\hline 25.4 & $1.57 \mathrm{E}-04$ & 0.250 & 1.239 & 925 & 0.500 \\
\hline 25.4 & $2.24 \mathrm{E}-04$ & 0.357 & 1.237 & 1321 & 0.716 \\
\hline 25.4 & $2.69 \mathrm{E}-04$ & 0.429 & 1.236 & 1584 & 0.859 \\
\hline 25.4 & $3.36 \mathrm{E}-04$ & 0.536 & 1.235 & 1979 & 1.074 \\
\hline 25.4 & $5.58 \mathrm{E}-04$ & 0.892 & 1.235 & 1457 & 1.787 \\
\hline 25.4 & $6.70 \mathrm{E}-04$ & 1.071 & 1.235 & 1750 & 2.146 \\
\hline 25.4 & $7.81 \mathrm{E}-04$ & 1.248 & 1.235 & 2039 & 2.501 \\
\hline 25.4 & $7.82 \mathrm{E}-04$ & 1.250 & 1.235 & 2039 & 2.503 \\
\hline 38.1 & $1.12 \mathrm{E}-04$ & 0.079 & 1.239 & 440 & 0.130 \\
\hline 38.1 & $1.57 \mathrm{E}-04$ & 0.111 & 1.239 & 617 & 0.182 \\
\hline 38.1 & $2.24 \mathrm{E}-04$ & 0.159 & 1.238 & 881 & 0.259 \\
\hline 38.1 & $2.69 \mathrm{E}-04$ & 0.190 & 1.238 & 1056 & 0.311 \\
\hline 38.1 & $3.36 \mathrm{E}-04$ & 0.238 & 1.237 & 1320 & 0.389 \\
\hline 38.1 & $4.25 \mathrm{E}-04$ & 0.301 & 1.237 & 1670 & 0.493 \\
\hline 38.1 & $5.58 \mathrm{E}-04$ & 0.396 & 1.237 & 972 & 0.648 \\
\hline 38.1 & $6.71 \mathrm{E}-04$ & 0.476 & 1.237 & 1166 & 0.778 \\
\hline 38.1 & 7.82E-04 & 0.555 & 1.237 & 1360 & 0.907 \\
\hline 50.8 & $1.12 \mathrm{E}-04$ & 0.045 & 1.237 & 330 & 0.063 \\
\hline 50.8 & $1.57 \mathrm{E}-04$ & 0.062 & 1.238 & 462 & 0.089 \\
\hline 50.8 & $2.24 \mathrm{E}-04$ & 0.089 & 1.238 & 660 & 0.126 \\
\hline 50.8 & $2.69 \mathrm{E}-04$ & 0.107 & 1.238 & 792 & 0.152 \\
\hline 50.8 & $3.36 \mathrm{E}-04$ & 0.134 & 1.238 & 990 & 0.190 \\
\hline 50.8 & $4.45 \mathrm{E}-04$ & 0.177 & 1.237 & 1312 & 0.251 \\
\hline 50.8 & $5.58 \mathrm{E}-04$ & 0.222 & 1.237 & 729 & 0.315 \\
\hline 50.8 & $6.70 \mathrm{E}-04$ & 0.267 & 1.237 & 875 & 0.379 \\
\hline 50.8 & $7.81 \mathrm{E}-04$ & 0.312 & 1.237 & 1020 & 0.441 \\
\hline
\end{tabular}


Table D.3: Propane test conditions

\begin{tabular}{|c|c|c|c|c|c|}
\hline $\begin{array}{c}\text { Burner Exit } \\
\text { Diameter } \\
(\mathrm{mm})\end{array}$ & $\begin{array}{c}\text { Fuel Mass Flow } \\
\text { Rate } \\
(\mathrm{kg} / \mathrm{s}) \\
\end{array}$ & $\begin{array}{c}\text { Burner Exit } \\
\text { Velocity } \\
(\mathrm{m} / \mathrm{s})\end{array}$ & $\begin{array}{c}\text { Fuel } \\
\text { Density } \\
\left(\mathrm{kg} / \mathrm{m}^{3}\right)\end{array}$ & $\begin{array}{c}\text { Reynolds } \\
\text { Number }\end{array}$ & $\begin{array}{c}\text { Froude } \\
\text { Number }\end{array}$ \\
\hline 12.7 & $6.56 \mathrm{E}-05$ & 0.284 & 1.824 & 871 & 0.804 \\
\hline 12.7 & $1.64 \mathrm{E}-04$ & 0.713 & 1.821 & 2184 & 2.019 \\
\hline 12.7 & $2.30 \mathrm{E}-04$ & 0.999 & 1.817 & 3055 & 2.830 \\
\hline 12.7 & $3.28 \mathrm{E}-04$ & 1.426 & 1.818 & 4362 & 4.039 \\
\hline 12.7 & 8.23E-04 & 3.573 & 1.818 & 2917 & 10.122 \\
\hline 12.7 & 9.87E-04 & 4.286 & 1.818 & 3499 & 12.144 \\
\hline 25.4 & $6.56 \mathrm{E}-05$ & 0.071 & 1.818 & 435 & 0.143 \\
\hline 25.4 & $1.64 \mathrm{E}-04$ & 0.179 & 1.818 & 1092 & 0.358 \\
\hline 25.4 & 2.30E-04 & 0.250 & 1.817 & 1527 & 0.500 \\
\hline 25.4 & $3.28 \mathrm{E}-04$ & 0.357 & 1.815 & 2180 & 0.715 \\
\hline 25.4 & $4.92 \mathrm{E}-04$ & 0.536 & 1.813 & 3268 & 1.073 \\
\hline 25.4 & $8.21 \mathrm{E}-04$ & 0.894 & 1.813 & 1458 & 1.791 \\
\hline 25.4 & $9.85 \mathrm{E}-04$ & 1.073 & 1.813 & 1749 & 2.149 \\
\hline 38.1 & $6.56 \mathrm{E}-05$ & 0.032 & 1.811 & 290 & 0.052 \\
\hline 38.1 & 1.64E-04 & 0.080 & 1.808 & 728 & 0.130 \\
\hline 38.1 & 2.30E-04 & 0.112 & 1.807 & 1018 & 0.183 \\
\hline 38.1 & $3.28 \mathrm{E}-04$ & 0.159 & 1.806 & 1454 & 0.261 \\
\hline 38.1 & 4.92E-04 & 0.240 & 1.802 & 2179 & 0.392 \\
\hline 38.1 & 8.14E-04 & 0.396 & 1.802 & 972 & 0.648 \\
\hline 38.1 & $9.78 \mathrm{E}-04$ & 0.476 & 1.802 & 1166 & 0.778 \\
\hline 50.8 & $2.94 \mathrm{E}-05$ & 0.008 & 1.806 & 98 & 0.011 \\
\hline 50.8 & $3.59 \mathrm{E}-05$ & 0.010 & 1.807 & 119 & 0.014 \\
\hline 50.8 & $6.24 \mathrm{E}-05$ & 0.017 & 1.807 & 207 & 0.024 \\
\hline 50.8 & $1.58 \mathrm{E}-04$ & 0.043 & 1.806 & 524 & 0.061 \\
\hline 50.8 & $2.30 \mathrm{E}-04$ & 0.063 & 1.805 & 764 & 0.089 \\
\hline 50.8 & $3.28 \mathrm{E}-04$ & 0.090 & 1.806 & 1090 & 0.127 \\
\hline 50.8 & $4.92 \mathrm{E}-04$ & 0.134 & 1.806 & 1634 & 0.191 \\
\hline 50.8 & 8.13E-04 & 0.222 & 1.806 & 729 & 0.315 \\
\hline 50.8 & 9.77E-04 & 0.267 & 1.806 & 875 & 0.378 \\
\hline
\end{tabular}

